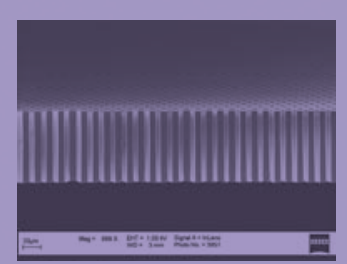

The world is on the verge of an energy crisis with fossil fuels depleting day by day. The poliution caused by burning of fuels by a population of around 6 bilion people is posing an environmental hazard to our planet earth. Will the world come to an end by the time all the non-renewable energy stocks a

Of course not! Humankind has cleared a lot of survival tests before reaching this point in time and shall smartly find out new ways to evolve through these hard times too. As a solution to the world energy and environmental crisis, scientists with foresight have been developing hydrogen based clean power generators: The Fuel Cells. Fuel cells are electrochemical devices which convert chemical energy to electrical energy without a combustion process. There are various kinds of fue cells of which proton conducting polymer electrolyte membrane type are the most successful ones for portable power applications. Another class of fuel cells with solid acid electrolyte has been recentily developed and has many extra advantages. Realizing a periect membrane electrode assembiy with a new kind of electrolyte is always a big chalienge, which is precisely what this thesis deals with. This thesis aims at encapsulating the water soluble solid acid electrolyte between two dense micromachined hydrogen diffusive palladium assembly. Will such a configuration be successful? What tre the hurdles one could face on the way to realization? To know more, read on with my thesis...
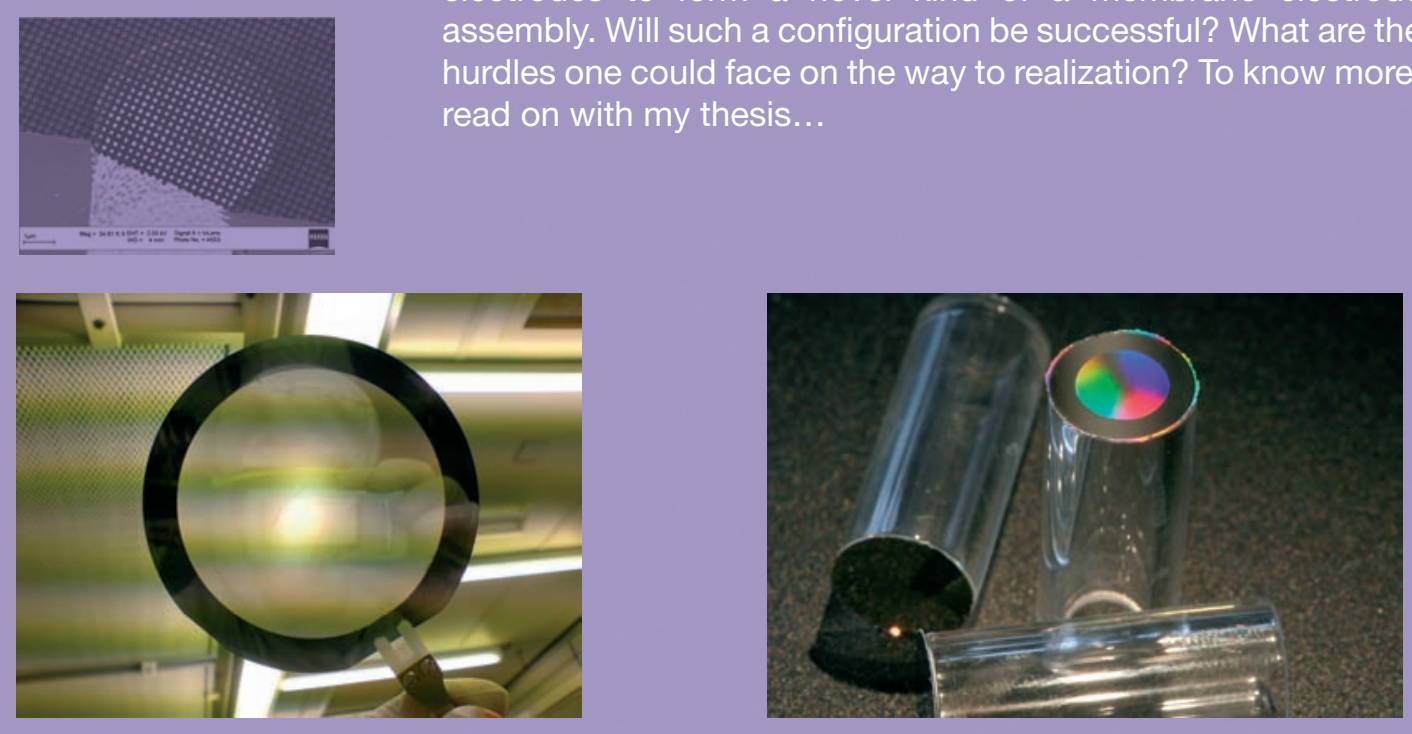

Micromachined Dense Palladium Electrodes for Thin-film Solid Acid Fuel Cells

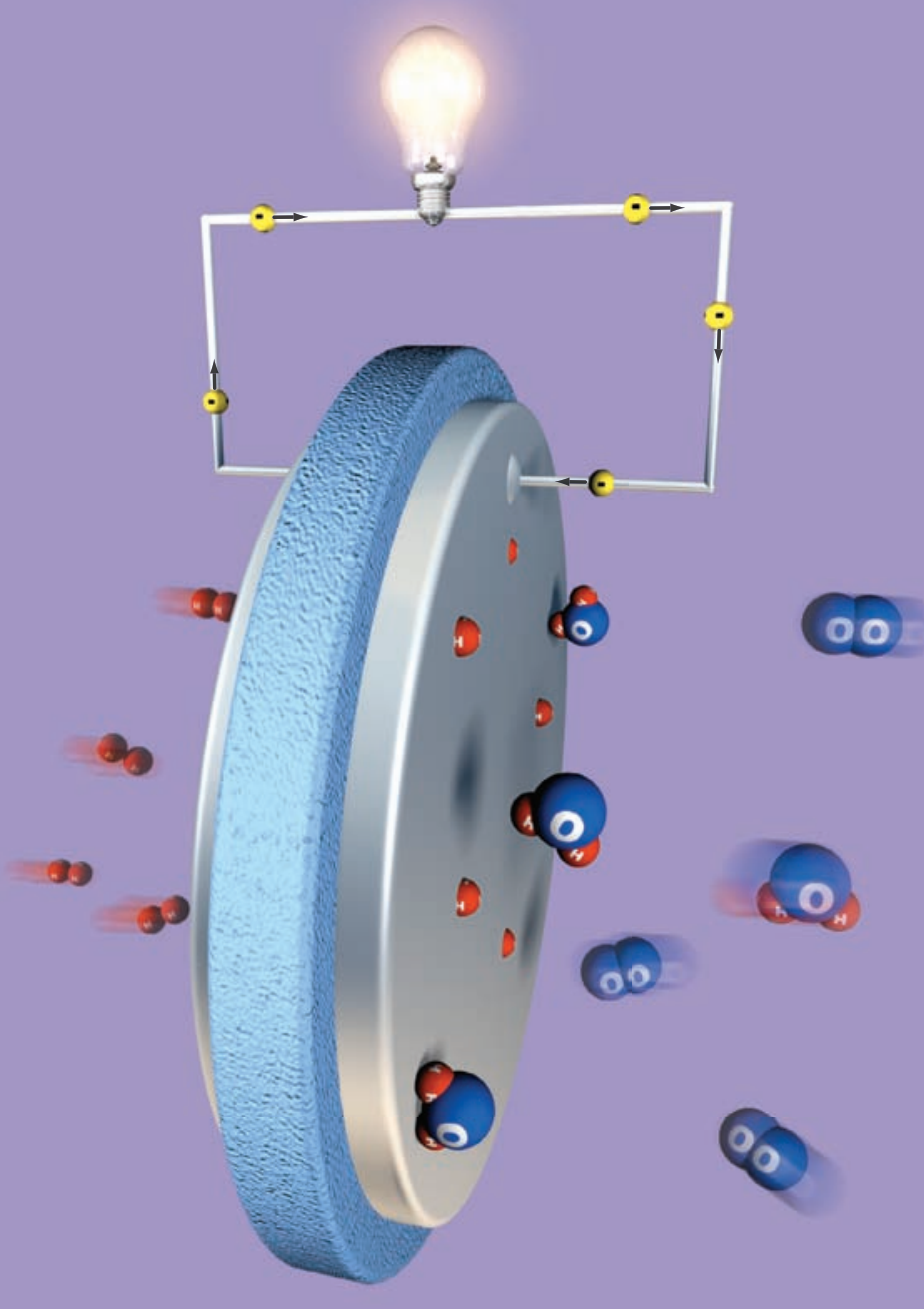

Invitation

It is my pleasure to invite you to the public defense of my doctoral dissertation

on $10^{\text {th }}$ December (Thursday) at 13:15h

in room SP2 of the Spiegel building at the University of Twente.

Prior to the defense, I will give a short introduction to my thesis at 13:00h.

The promotion ceremony shall immediately be followed by a reception at the Vestingbar in the Bastille building of the University.

In the evening I cordially invite you to a party at 20:00h in the Vestingbar.

Sandeep Unnikrishnan Toekomststraat 73-33 7521 CM Enschede

Paranimfen: Jitender Kumar j.k.chinthaginjala@utwente.n Marcus Louwerse 


\section{Micromachined Dense Palladium Electrodes for Thin-film Solid Acid Fuel Cells}

Sandeep Unnikrishnan 
The research described in this thesis was carried out at the Transducers Science and Technology Group of the MESA+ Institute of Nanotechnology at the University of Twente, Enschede, the Netherlands. This project was financially supported by the Dutch Technology Foundation STW (project number: TPC 6611).

Graduation committee:

\section{Chairman}

Prof. dr. ir. A.J. Mouthaan University of Twente

Secretary

Prof. dr. ir. A.J. Mouthaan

University of Twente

Promotor

Prof. dr. M.C. Elwenspoek University of Twente

Assistent promotor

Dr. ir. H.V. Jansen

University of Twente

Members

Prof. dr. ir. J. C. Schouten

Technical University of Eindhoven

Prof. dr.-Ing. Peter Woias

IMTEK, University of Freiburg

Prof. dr. J. G. E. Gardeniers

University of Twente

Dr. H. J. M. Bouwmeester

University of Twente

Dr. G. J. M. Janssen

ECN, Petten

Sandeep Unnikrishnan

Micromachined dense palladium electrodes for thin-film solid acid fuel cells

Ph.D. Thesis, University of Twente, Enschede, the Netherlands

ISBN: 978-90-365-2949-5

Cover design by: Stefan Schlautmann

Copyright (C) 2009 by Sandeep Unnikrishnan, Enschede, the Netherlands All rights reserved. 


\title{
MICROMACHINED DENSE PALLADIUM ELECTRODES FOR THIN-FILM SOLID ACID FUEL CELLS
}

\author{
DISSERTATION
}

to obtain

the degree of doctor at the University of Twente, on the authority of the rector magnificus, prof. dr. H. Brinksma, on account of the decision of the graduation committee, to be publicly defended on Thursday, 10 December 2009 at 13:15 hrs.

by

Sandeep Unnikrishnan

born on 22 March 1979

in Chennai, India 
This dissertation has been approved by,

Promotor: $\quad$ Prof. dr. M.C. Elwenspoek

Assistant promotor : Dr. ir. H.V. Jansen 
To my Parents and Jalaja 



\section{Contents}

Chapter 1: General Introduction $\quad 1$

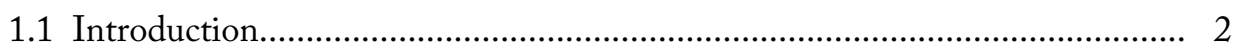

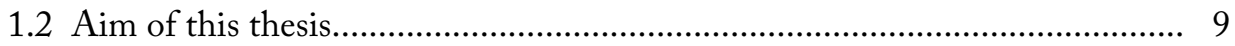

1.3 Thesis outline

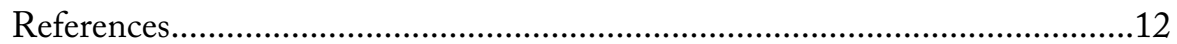

Chapter 2: The Gas Diffusive Support $\quad 15$

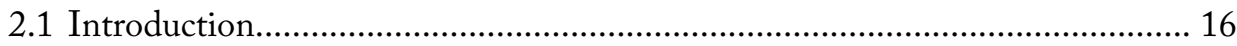

2.2 Microsieve Gas Diffusive Support............................................................ 18

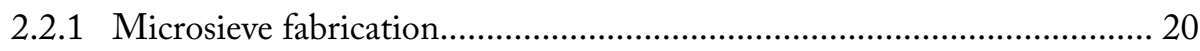

2.2.1.1 Deep Reactive Ion Etching............................................................... 22

2.2.1.2 Plasma based wafer-back etching...................................................... 26

2.2.2 Microsieve characterization........................................................... 28

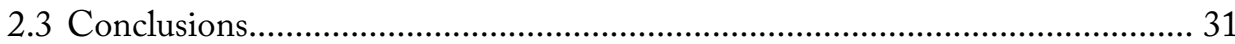

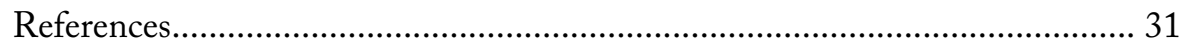

Chapter 3: The Palladium Electrode $\quad 33$

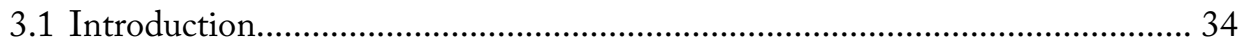

3.2 Theory of hydrogen permeation through palladium........................................ 35

3.2.1 Bulk diffusion of atomic hydrogen through palladium........................... 37

3.2.2 Surface desorption of molecular hydrogen from the palladium surface... 39

3.3 Palladium electrode membrane fabrication....................................................... 42

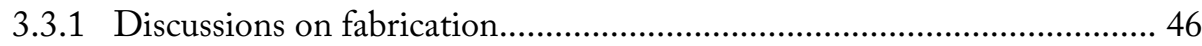

3.4 Palladium electrode membrane characterization........................................... 52

3.4.1 Gas permeation set-up................................................................ 53

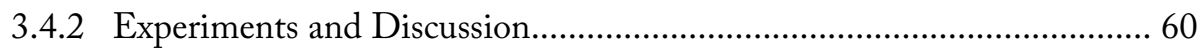

3.4.2.1 Hydrogen permeability dependence on pressure and temperature..... 60

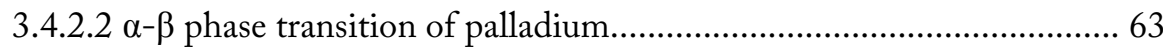

3.4.2.3 Influence of external mass transfer..................................................... 71

3.4.2.4 Stability and durability test............................................................... 74 
3.4.2.5 Rate limiting step determination and comparison with theory.......... 75

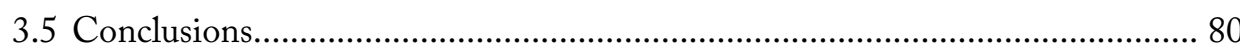

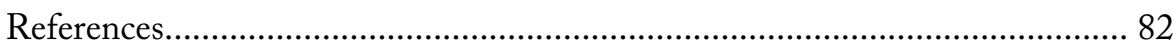

Chapter 4: The Membrane Electrode Assembly 85

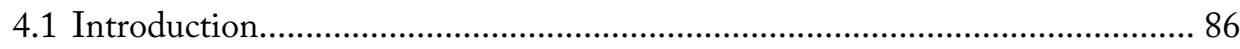

4.2 The Electrolyte: Solid Acid........................................................................ 91

4.2.1 Solid acid preparation and characterization............................................. 92

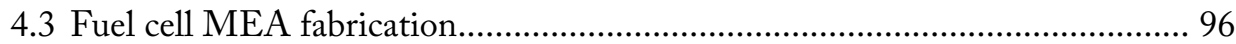

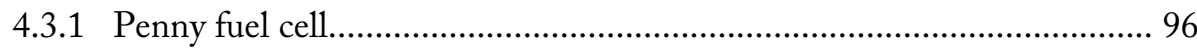

4.3.2 Thin-film electrolytic layer......................................................................102

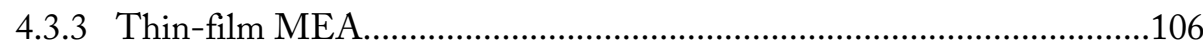

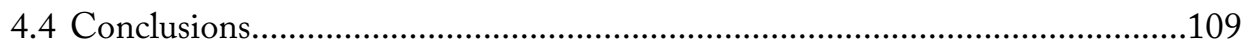

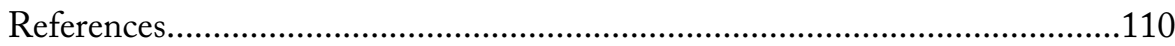

Chapter 5: Membrane Packaging 113

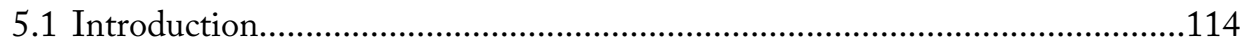

5.2 Fabrication technique.......................................................................115

5.2.1 MEMS-on-tube: main concept.......................................................115

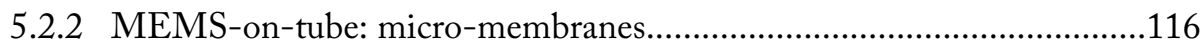

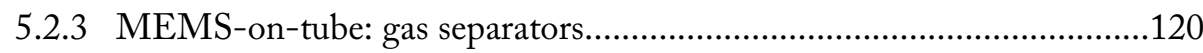

5.2.4 MEMS-on-tube: micro-valves.........................................................122

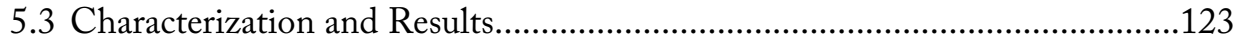

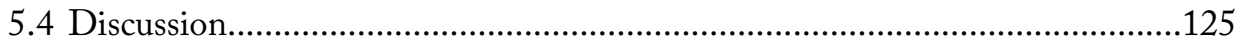

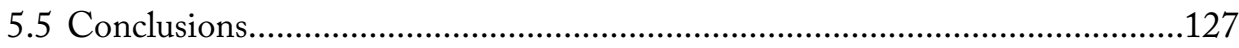

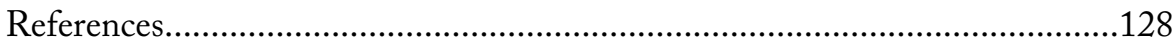

Chapter 6: The Nanosieve $\quad 131$

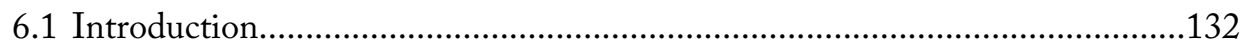

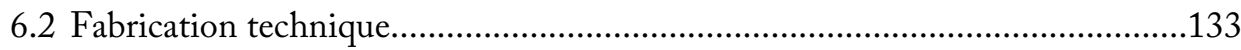

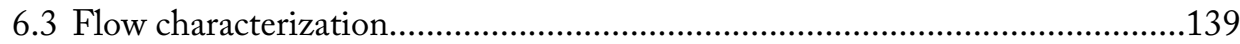

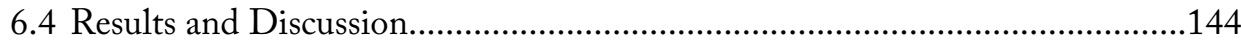

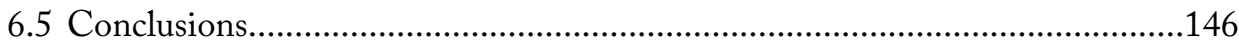


References.

Chapter 7: Conclusions and Future scope

7.1 Conclusions: What has been done until now?

.150

7.2 Future scope: What more needs to be done to achieve the final goal? 152

References .154

\section{Appendix}

A. Fabrication process for the microsieve supported palladium membrane. 155

B. Permeated hydrogen flux conversion calculations. 165

\section{Publications \& Patents}

\section{Summary}

Samenvatting

Acknowledgements

Biography 



\section{General Introduction}

This chapter gives a brief introduction on fuel cells and in specific about a relative newcomer: the solid acid fuel cell. After highlighting the challenges involved in fabricating an efficient and durable membrane electrode assembly (MEA) with solid acid electrolyte, a novel approach of encapsulating the latter between two dense bydrogen diffusive palladium electrodes is shown. This has the advantage of shifting the cathode half-cell reaction to a place where the water evolution will not harm the solid-acid, which typically dissolves in water. The choice of palladium as the electrode material and advantages of using microfabrication techniques to obtain thinfilm membranes are explained. After giving a detailed description of the aim of this thesis, finally a thesis outline is presented. 


\subsection{Introduction}

In order to have a sustainable high quality of life we should have a clean, safe, reliable and secure source of energy supply. To ensure a competitive economic environment, the energy systems must meet some common needs at affordable prices viz. to lessen the effects of climate change, reduce toxic pollutants and planning for the security of diminishing oil reserves. Our aim must be towards an emission-free future based on sustainable energy. Hydrogen based energy generation represents one of the most promising ways to achieve this. Hydrogen is not a primary energy source like coal and gas, but it is being used as the major energy carrier since many decades and is popular among futurists and some policy makers. Due to the recent intensive focus on climate change and green energy, much effort is being made on production of hydrogen using renewable sources of energy like sun, wind etc. To be able to ensure a completely green future, it is not only important to produce hydrogen in a green way, but also to consume it in an emission-free manner. One of the effective and pollutionfree methods for efficient usage of hydrogen is by means of fuel cells [1]. The invention of fuel cells as an electrical energy conversion system is attributed to Sir William Grove, however, the principle was discovered by Christian Friedrich Schönbein in the $19^{\text {th }}$ century [2]. Till the mid $20^{\text {th }}$ century, there was not much advancement in the fuel cell sector, because of the abundance of primary energy sources like oil and coal. One of the major factors that have influenced the development of fuel cells in the past few decades is the increasing concern about the environmental consequences of fossil fuel usage. Fuel cells are power generators that electrochemically convert the energy stored in hydrogen to useful electricity, without polluting the environment. Typically, in a fuel cell hydrogen is supplied at the anode and oxygen (or air) is supplied at the cathode. Based on the material type of its electrolyte (which is an electronic insulator), either the hydrogen ions (i.e. protons) migrate to the cathode side or the anions migrate to the anode side, driving the usable electrons via the external circuit. Table 1.1 shows the various types of commonly used fuel cells [3]. The fuel cell types with liquid electrolytes are getting less popular due to maintenance problems caused by leakage and corrosion $[4,5,6]$.

In the group of solid electrolytes, solid-oxides operate at very high temperatures and find applications in large scale installations for power generation, but are not suitable 
for small scale portable systems. Polymer electrolyte membranes (PEMs), on the other hand have attained high popularity in the recent years due to the following reasons:

- operational temperature being close to room temperature

- mass-producibility of polymer electrolyte making them commercially viable

- usability in miniature power supply systems

- capability of forming micron-thick defect free electrolyte sheets having less proton transfer resistance

There has been a large amount of studies done on PEMFC producing an ocean of literature on them $[7,8,9,10,11]$.

Table 1.1. Classification of fuel cells $[3,12]$

\begin{tabular}{|c|l|l|c|}
\hline $\begin{array}{c}\text { Type of } \\
\text { fuel cell }\end{array}$ & Electrolyte & $\begin{array}{c}\text { Operational } \\
\text { Temp. in }{ }^{\circ} \mathrm{C}\end{array}$ & $\begin{array}{c}\text { Charge carrier } \\
\text { in Electrolyte }\end{array}$ \\
\hline AFC & Potassium hydroxide - Liquid & $<100$ & $\mathrm{OH}^{-}$ \\
\hline PAFC & Phosphoric acid - Liquid & $160-220$ & $\mathrm{H}^{+}$ \\
\hline MCFC & $\begin{array}{l}\text { Compounds of salt carbonates (mixture of } \\
\text { lithium and potassium carbonates) - Liquid }\end{array}$ & $600-800$ & $\mathrm{CO}_{3}^{2-}$ \\
\hline SOFC & $\begin{array}{l}\text { Solid oxide ceramic compound (e.g. Yittria } \\
\text { stabilized zirconia) - Solid }\end{array}$ & $800-1000$ & $\mathrm{O}^{2-}$ \\
\hline PEMFC & $\begin{array}{l}\text { Polymer Electrolyte Membrane (Nafion } \\
\text { Gore }\end{array}$ & $60-120$ & $\mathrm{H}^{+}$ \\
\hline \hline SAFC Solid & Solid acid compounds - Solid & $130-250$ & $\mathrm{H}^{+}$ \\
\hline
\end{tabular}

PEMFCs are proton conducting fuel cells, a 2D illustration of their working principle is depicted in figure 1.1 showing the essential components of its membrane electrode assembly (MEA). The overall fuel cell reaction in the MEA of a proton conducting fuel cell can be split into two half-cell electrochemical reactions occurring at each of the electrodes.

Anode half-cell reaction (Oxidation): $\mathrm{H}_{2} \rightarrow 2 \mathrm{H}^{+}+2 \mathrm{e}^{-}$

Cathode half-cell reaction (Reduction): $2 \mathrm{H}^{+}+2 \mathrm{e}^{-}+1 / 2 \mathrm{O}_{2} \rightarrow \mathrm{H}_{2} \mathrm{O}$

Thus, the overall reaction is: $\mathrm{H}_{2}+1 / 2 \mathrm{O}_{2} \rightarrow \mathrm{H}_{2} \mathrm{O}+$ energy 


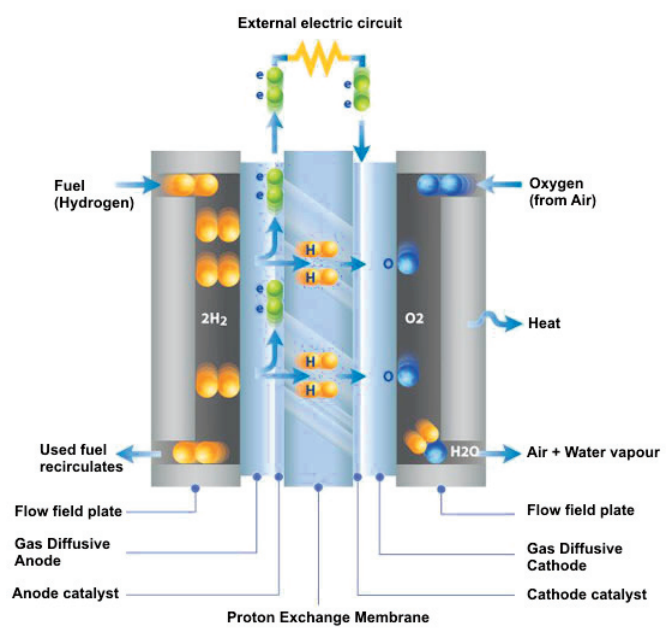

Figure 1.1. A 2D illustration of the membrane electrode assembly (MEA) of a PEMFC, showing its working principle (image courtesy of Ballard Power Systems, www.ballard.com).

The Gibbs' free energy change for the formation of water from hydrogen and oxygen is the driving force behind the fuel cell. When hydrogen and oxygen chemically react to form water, this exothermic reaction produces heat. Using the fuel cell, a part of this energy can be extracted as usable electrical power. Depending on how much of it can be converted into electrical energy, the conversion efficiency of a fuel cell is determined.

The proton conducting mechanism in a PEMFC is described as a vehicle mechanism involving "piggy-back" transport in which the protons are carried by water molecules from the anode to the cathode of the fuel cell [12] (see figure 1.2a). Due to this reason the PEMFC needs constant humidification for efficient functioning. Since water is the carrier for the protons, the maximum working temperature of the fuel cell has to be limited close to $100{ }^{\circ} \mathrm{C}$ (the boiling point of water). Such a temperature limitation gives rise to the disadvantage that the catalysts used in a PEMFC (e.g. platinum particles) could get easily poisoned by gaseous impurities like $\mathrm{CO}$ and $\mathrm{H}_{2} \mathrm{~S}$ that are present in small quantities in the fuel stream [13,14]. A slightly higher temperature $\left(150^{\circ} \mathrm{C}-250^{\circ} \mathrm{C}\right)$ of operation not only avoids catalyst poisoning but also enables waste heat extraction. 
A solid acid based electrolyte operating in the aforementioned intermediate temperature regime was reported by Haile et al. [15]. Solid acids are salts with acid like properties also having temperature regulated superprotonic conductivity [16]. Solid acids, or acid salts, are a class of compounds with unique properties arising from the incorporation of "acid" protons into a crystalline structure: e.g., $1 / 2 \mathrm{Cs}_{2} \mathrm{SO}_{4}+1 / 2$ $\mathrm{H}_{2} \mathrm{SO}_{4} \rightarrow \mathrm{CsHSO}_{4}$. The solid acid electrolytes have numerous advantages as compared to the polymer electrolytes. Issues faced by PEMFCs like continuous humidification requirement and poisoning of catalyst due to low operational temperatures, do not concern solid acid fuel cells which operate anhydrously at relatively higher temperature [15]. Solid acids exhibit a small protonic conduction at room temperature. When they are heated, they come to a certain stage where they 'all of a sudden' undergo a phase transformation to attain superprotonic conductivity. The solid acids exhibit a Grotthus mechanism of proton transport [17,18] (illustrated in figure 1.2b). Most solid acids with superprotonic phase transitions have monoclinic symmetry in their room temperature phase [18]. Above the phase transition temperature, the symmetry of the compounds increases and to accommodate the higher symmetry, the oxygen atoms become disordered. The partial occupancy of the oxygen sites gives a nearly liquid-like nature to the protons as the previously static hydrogen bonded system becomes highly dynamic [19]. This fast reorientation of the tetrahedra in conjunction with proton translations leads to the jump in conductivity across the phase transition and the "superprotonic conduction" many solid acids exhibit in their high temperature phases.

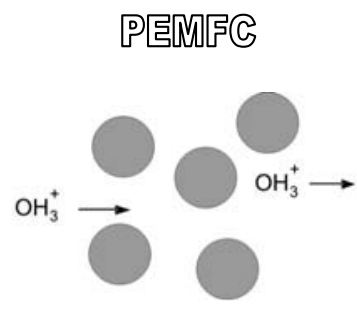

(a)

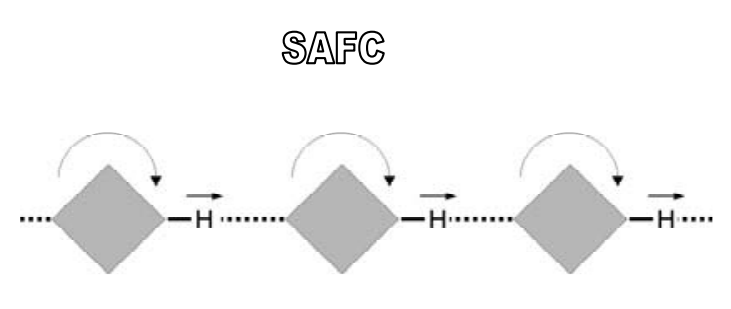

(b)

Figure 1.2. Mechanisms of proton transport [12] a) vehicle mechanism b) Grotthus mechanism 
Table 1.2. Desired properties and functionalities of a MEA and its components

\begin{tabular}{|c|c|}
\hline MEA & $\begin{array}{l}\text { 1) Good thermal and chemical stability } \\
\text { 2) Mechanical integrity } \\
\text { 3) Corrosion free and insoluble in the reactants or in the products }\end{array}$ \\
\hline \multirow{2}{*}{ Membrane (Electrolyte) } & $\begin{array}{l}\text { Functionalities } \\
\text { 1) To separate fuel and oxidant } \\
\text { 2) Ion conduction/transfer } \\
\text { 3) To act as a non-conductor for electrons }\end{array}$ \\
\hline & $\begin{array}{l}\text { Desired characteristics or properties } \\
\text { 1) High ion conductivity } \\
\text { 2) Nil electron conductivity } \\
\text { 3) Impermeable to gaseous and liquid }\end{array}$ \\
\hline \multirow[b]{2}{*}{ Electrode } & $\begin{array}{l}\text { Functionalities } \\
\text { 1) To conduct electrons to and from the reaction sites } \\
\text { 2) To act as a catalyst (in case of dual functionality electrodes) }\end{array}$ \\
\hline & $\begin{array}{l}\text { Desired characteristics or properties } \\
\text { 1) High electrical conductivity } \\
\text { 2) Porous } \\
\text { 3) Corrosion resistant }\end{array}$ \\
\hline \multirow{2}{*}{ Catalyst } & $\begin{array}{l}\text { Functionalities } \\
\text { 1) Catalyzing the oxidation reaction at anode } \\
\text { 2) Catalyzing the reduction reaction at cathode }\end{array}$ \\
\hline & $\begin{array}{l}\text { Desired characteristics or properties } \\
\text { 1) High and non-degrading catalytic activity } \\
\text { 2) Large surface area of contact with the reactants }\end{array}$ \\
\hline
\end{tabular}

In this project, special interest is given to investigate methods of making a micromachined fuel cell. The desired characteristics and functionalities of the various components of a micromachined membrane electrode assembly (MEA), shown in figure 1.1, are listed in table 1.2. The objective of making a micromachined MEA is to primarily reduce its thickness with the intention of reducing the electrolyte impedance (or ohmic losses). Micromachining also helps in shrinking the overall size of the fuel cell thus making it embeddable in portable applications. There have been many reports in literature about micromachined fuel cells using polymer electrolytes [20,21,22], a few examples of which are shown in figure 1.3. Micromachined fuel cells using other 
kinds of electrolytes are rare due to the limitation that either the electrolyte is in liquid form or the working temperature is too high.

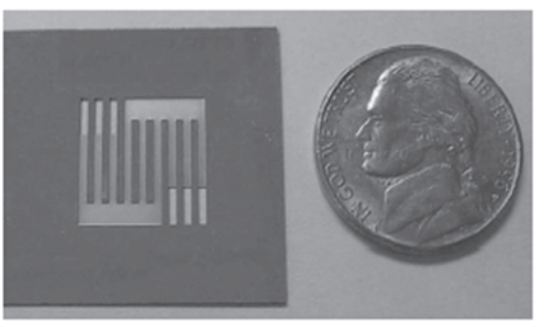

(a)

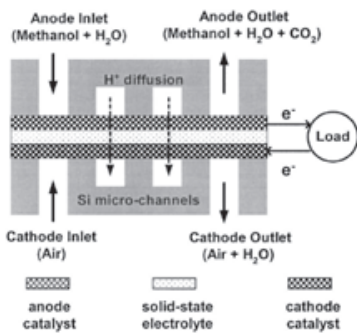

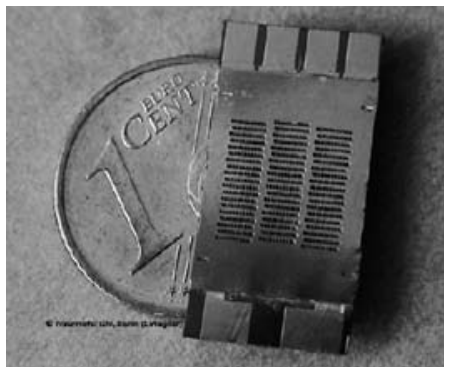

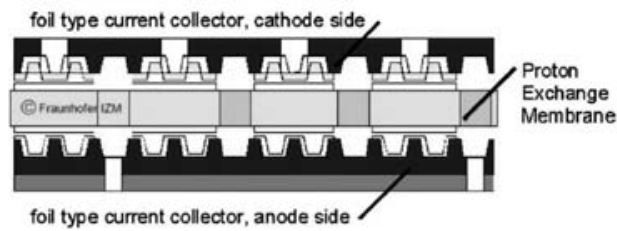

(b)
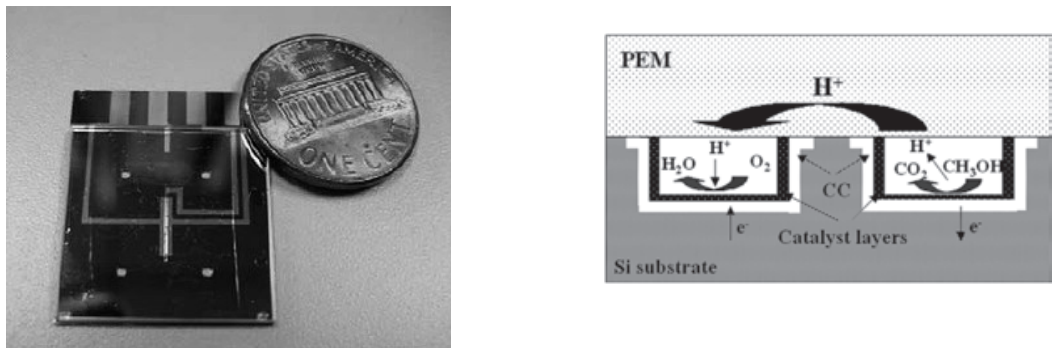

(c)

Figure 1.3. Various micromachined polymer electrolyte based fuel cells and their cross sectional illustrations a) a direct methanol fuel cell giving a power of $47.2 \mathrm{~mW} / \mathrm{cm}^{2}$ at $60{ }^{\circ} \mathrm{C}$ [20] b) a hydrogen based PEMFC giving a power of $80 \mathrm{~mW} / \mathrm{cm}^{2}$ at ambient conditions [21] c) a direct methanol fuel cell with a Pt-Ru anode [22].

Our research is attempted in the direction of making a novel microfabricated Solid Acid Fuel Cell ( $\mu \mathrm{SAFC)}$, which uses a proton conducting acidic salt as the electrolyte [12]. The biggest challenge when working with solid acid electrolytes is that they are 
water soluble [15]. This can render problems during start-up and shut-down of the fuel cell, because water could condense. In this work, we investigate a new method to overcome this limitation by the usage of dense hydrogen diffusive electrodes (HDEs) based on palladium to encapsulate the electrolyte (see figure 1.4b). Unlike the conventional fuel cell systems, where porous electrodes are used for diffusing hydrogen and oxygen till the electrolyte-electrode interfaces (figure 1.4a), in a dense electrode fuel cell the palladium electrodes selectively diffuses only hydrogen through them. These HDEs sandwich the solid acid electrolyte, thus protecting it from any contact with water.

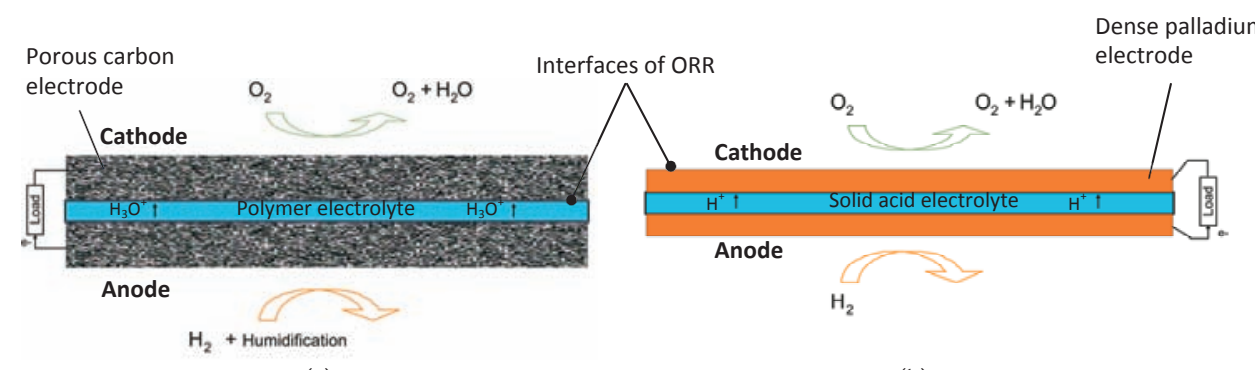

(a)

(b)

Figure 1.4. 2D cross sectional illustration of the MEA sandwich of a) conventional PEM fuel cell with porous electrodes b) the proposed solid acid fuel cell with dense hydrogen diffusive electrodes. The interfaces at which the Oxygen Reduction Reaction (ORR) takes place are also shown.

In this new approach, the driving force for hydrogen diffusion is still the electrochemical potential of the Water Formation Reaction or Oxygen Reduction Reaction (ORR) on the cathode side. The main operational difference with respect to a conventional fuel cell is that in a dense electrode fuel cell the ORR shifts to the cathode-oxygen interface (shown in figure 1.4b) from the usual cathode-electrolyteoxygen interface (shown in figure 1.4a). This offers a tremendous advantage in the case of the solid acid fuel cell, since now the electrolyte will be protected from liquid water in all instances. The choice of palladium for the dense electrode is based on the fact that it has high selective permeability for hydrogen and it can absorb up to several hundred times its volume of hydrogen [23]. Although metals such as niobium, vanadium, and tantalum show better solubility and diffusivity for hydrogen than palladium [24], the latter is still the dominant material for this purpose. This is 
because palladium does not have the refractory surface oxide film that the aforementioned metals possess (which limits the hydrogen transport). Another advantage of using palladium is that it is from the noble metal family, thus noncorrosive when in contact with the acidic electrolyte. Moreover, palladium has also the capability of catalyzing the electrochemical reactions in a fuel cell [25]. Micromachining techniques are chosen to fabricate the palladium electrodes due to their capability of controlling thickness and material structure down to nanometer scale. Only with such a precise control can one eliminate the occurrence of pin-holes in the membrane that could result in leaks. As mentioned before, the thinner the components of the MEA are, the lower the ohmic losses of the fuel cell will be. However, thin electrode membranes are mechanically weak. To ensure their mechanical integrity, they need to be supported on robust gas diffusive supports (GDS), which enhances the robustness of the MEA.

\subsection{Aim of this thesis}

The overall aim of the project is to fabricate a micromachined solid acid fuel cell ( $\mu \mathrm{SAFC}$ ), which has a membrane electrode assembly (MEA) consisting of a thin-film solid acid electrolyte encapsulated between two dense palladium electrode membranes and supported by a GDS. In this thesis microfabrication techniques to realize freehanging dense palladium membranes are investigated, as well as insights on their suitability as hydrogen diffusive palladium electrodes for the $\mu$ SAFC are quested.

Although, there are many advantages of using a dense electrode fuel cell configuration for the solid acid encapsulation, there are also certain challenges to be overcome in this design. The temperature range in which the solid acids like $\mathrm{CsHSO}_{4}$ exhibit superprotonic conductivity is from $140{ }^{\circ} \mathrm{C}-200{ }^{\circ} \mathrm{C}$, after which they start to decompose [15]. Ideally, as shown by Haile [15], they can be operated in the range $150{ }^{\circ} \mathrm{C}-160{ }^{\circ} \mathrm{C}$ (i.e. $423 \mathrm{~K}-433 \mathrm{~K}$ ). If our dense electrodes based fuel cell concept has to work successfully, then the palladium electrode membranes need to show adequate hydrogen permeability at this temperature, ensuring that they do not act as the bottle-neck. The application of palladium as a dense hydrogen diffusive electrode (HDE) is quite novel, and needs much investigation, especially at lower temperatures 
( $<473$ K). Previous research presented by H. D. Tong at the Transducer Science \& Technology group of the University of Twente, the Netherlands, has shown a hydrogen permeability of $5 \cdot 10^{-5} \mathrm{~mol} \mathrm{H}_{2} / \mathrm{cm}^{2}$.s for a $1 \mu \mathrm{m}$ thick palladium based membrane operating at $723 \mathrm{~K}$ [26]. Extrapolated to $423 \mathrm{~K}$ using other experimental data from Tong [26], the flux could be approximately $0.5 \cdot 10^{-5} \mathrm{~mol} \mathrm{H}_{2} / \mathrm{cm}^{2}$.s, which is equivalent to a current density of $1 \mathrm{~A} / \mathrm{cm}^{2}$. Such a current density would be sufficient for efficient functioning of the $\mu \mathrm{SAFC}$ (and is commercially attractive). The investigations in this thesis are focused on confirming whether we can indeed achieve this current density for lower temperatures $(<473 \mathrm{~K})$ without causing palladium embrittlement, which is an issue while working with palladium in presence of hydrogen. The embrittlement, which is a consequence of $\alpha$ to $\beta$ palladium hydride phase transition, is thoroughly studied and ways to elude this problem are investigated in this work.

During the execution of this thesis work, initial efforts were made to develop a micromachined gas diffusive support (GDS), which would provide robustness for the MEA of the proposed $\mu$ SAFC. A microporous and a nanoporous GDS were developed for suitably supporting various thicknesses of the palladium membrane. Next, a new packaging cum interfacing technique (MEMS-on-tube assembly) was developed, which enabled the gas transport characterization of the GDS. Subsequent experiments were focused on microfabricating a dense palladium electrode membrane on the GDS using a thin-film transfer technique. This was followed by detailed characterization of the palladium electrode membrane to study its selective hydrogen permeability in the operational temperature window of the $\mu$ SAFC. Finally, methods of integrating the electrodes with the electrolyte to form the MEA were investigated.

\subsection{Thesis outline}

The contents of this thesis are structured in a manner that focuses on the step-bystep construction of the $\mu \mathrm{SAFC}$, of which development of the MEA is given prime importance. As the title suggests, this thesis focuses on applying microfabrication techniques for the realization of the dense thin-film palladium electrode membranes for the $\mu \mathrm{SAFC}$. In the next chapter (Chap. 2), the design, fabrication and 
characterization of the micromachined GDS for supporting the hydrogen diffusive dense palladium membranes of the micro solid acid fuel cell is described. Various plasma-etching experiments undertaken to arrive at an optimized process recipe for the fabrication of a silicon microsieve type GDS are discussed.

In Chapter 3, the microfabrication of the dense palladium electrode membranes and their characterization with regard to selective hydrogen permeability is presented. The first part of the chapter describes a novel method, the thin-film transfer technique, to integrate the micromembrane atop the silicon GDS. Subsequently, the focus shifts to studying the hydride phase change of the palladium membranes, which is dependent on the hydrogen pressure as well as temperature. This enables us to understand this phase transformation on the operational window of the $\mu$ SAFC.

Chapter 4 explains the solid acid electrolyte as well as its properties and proceeds towards describing the initial experiments performed for electrolyte characterization independent of the palladium electrode. This topic will be discussed in more detail in the thesis of project partner W. Zhou of the Inorganic Membranes group; only the details needed for this thesis are provided in this chapter. Also, the various methods of integrating the dense palladium electrode and the thin-film electrolyte are depicted here.

Reported in Chapter 5 is a novel packaging technique for micro membranes in order to do fault free characterization and interfacing of the micro world to the macro world. The method focuses on hermetic sealing of the microfabricated membranes on standard glass tubes as substrates, which directly translates into 'plug-n-play' devices. Such packaging enables the membrane-on-tube assembly to be encapsulated within standard Swagelok ${ }^{\circledR}$ connectors, which can easily be connected to fluidic equipments.

Chapter 6 describes a nanosieve that can be applied as a nano-GDS, which is an alternative for the micro-GDS (described in chapter 2), while working with extremely thin $(<100 \mathrm{~nm})$ palladium electrode membranes. Presented in this chapter is the fabrication technique for realizing such a nano-perforated sieve and a detailed gas flow study through it.

Finally, Chapter 7 provides a general conclusion of this thesis and recommendations for future research. 


\section{References}

[1] Hydrogen Energy and Fuel Cells: A vision of our future, Final report of the high level group, European Commission, 2005

[2] U. Bossel, The birth of the Fuel Cell; European Fuel Cell. Forum: Oberrohrdorf, 2000

[3] L. Carrette, K. A. Friedrich and U. Stimming, Fuel Cells, 2001, 1 (1), pp. 5-39

[4] S. Freni, S. Cavallaro, M. Aquino, D. Ravida, N. Giordano, International Journal of Hydrogen Energy, 1994, 19 (4), pp. 337-341

[5] K. Tomantschger, R. Findlay, M. Hanson, K. Kordesch, S. Srinivasan, Journal of Power Sources, 1992, 39 (1), pp. 21-41

[6] K. Mitsuda and T. Murahashi, Journal of Applied Electrochemistry, 1993, 23, pp. 19-25

[7] T. Schultz, S. Zhou and K. Sundmacher, Chemical Engineering Technology, 2001, 24 (12), pp.1223-1233

[8] Q. Li, R. He, J. Jensen and N. J. Bjerrum, Chemistry of Materials, 2003, 15, pp.4896-4915

[9] K. Scott and A.K. Shukla, Reviews in Environmental Science E Bio/Technology, 2004, 3, pp.273-280

[10] T. Fuller, H. Gasteiger, S. Cleghorn, V. Ramani, T. Zhao, T. Nguyen, A. Haug, C. Bock, C. Lamy, K. Ota (Eds.), ECS Transactions, 2007, 11 (1)

[11] Handbook of fuel cells: Fundamentals technology and applications, W. Vielstich, A. Lamm, H. A. Gasteiger (Eds.); John Wiley and Sons Publication, 2003

[12] D. A. Boysen, Superprotonic Solid Acids: Structure, Properties, and Applications, PhD Thesis, California Institute of Technology, Pasadena, California, 2004

[13] J. J. Baschuk and X. Li, International Journal of Energy Research, 2001, 25, pp.695-713

[14] R. Mohtadi, W.-k. Lee, S. Cowan, J. W. Van Zee, and Mahesh Murthy, Electrochemical and Solid-State Letters, 2003, 6 (12) A272-A274

[15] S. M. Haile, D. A. Boysen, C. R. I. Chisholm and R. B. Merle, Nature, 2001, 410 (19), pp.910-913

[16] A. I. Baranov, L. A. Shuvalov, N. M. Shchagina, JETP Letters, 1982, 36, pp.459-462

[17] K. -D. Kreuer, Chemistry of Materials, 1996, 8, pp.610-641

[18] C. R. I. Chisholm, Superprotonic Phase Transitions in Solid Acids: Parameters affecting the presence and stability of superprotonic transitions in the MHnXO4 family of compounds (X=S, Se, $P$, $A s ; M=L i, N a, K, N H 4, R b, C s)$, PhD Thesis, California Institute of Technology, Pasadena, California, 2002

[19] R. Blinc, J. Dolinsek, G. Lahajnar, I. Zupancic, L. A. Shuvalov and A. I. Baranov, Physica Status Solidi B, 1984, 123, pp.83-87

[20] T. J. Yen, N. Fang, and X. Zhang, Applied Physics Letters, 2003, 83 (19), pp.4056-58 
Chapter 1: General Introduction

[21] R. Hahn, S. Wagner, A. Schmitz, H. Reichl, Journal of Power Sources, 2004, 131, pp.73-78

[22] S. Motokawa, M. Mohamedi, T. Momma, S. Shoji, T. Osaka, Electrochemistry Communications, 2004, 6, pp.562-565

[23] T. Graham, Proceedings of the Royal Society of London, 1868 - 1869, 17, pp. 212-220

[24] J.W. Phair and R. Donelson, Industrial and Engineering Chemistry Research, 2006, 45 (16), pp. 5657-74

[25] X. Wang, N. N. Kariuki, S. Niyogi, M. C. Smith and D. J. Myers, T. Hofmann, Y. Zhang, M. Bär and C. Heske, ECS Transactions, 2008, 16 (2), pp.109-119

[26] H. D. Tong, Microfabricated Palladium-based Membranes for Hydrogen Separation, $\mathrm{PhD}$ Thesis, University of Twente, Enschede, The Netherlands, 2004; ISBN: 90-365-2058-4 



\section{The Gas Diffusive Support}

This chapter explains the design, fabrication and characterization of a gas diffusive support (GDS) for dense electrodes of a micro solid acid fuel cell ( $\mu S A F C)$. After discussing the differences in functionality and property of the GDS of the $\mu S A F C$ as compared to the gas diffusive electrode (GDE) of a PEMFC, a detailed description of the micromachining process is given. The GDS comprises a sieve structure with an uniform array of well defined cylindrical pores, created by deep reactive ion etching, for diffusing the fuel and oxidant gases onto the dense palladium electrodes. Finally, the characterization of the GDS is presented, which includes the morphology, strength and gas flow behavior.

Parts of this chapter have been included in a publication in J. Micromechanics and Microengineering, 2009,19 (3) 033001 


\subsection{Introduction}

A Gas Diffusive Support (GDS) is a vital component in the Membrane Electrode Assembly (MEA) of a fuel cell. The GDS, in the conventional design of the fuel cell, can have multiple functions: it might serve as an electrode, as a gas diffusive enclosure for the electrolyte and as a porous mechanical support [1]. Conventionally, the GDS is referred to as Gas Diffusive Electrode (GDE) because of its main functionality being that of an electrode. Usually, porous carbon or graphite sheets (paper or cloth) are used to make GDEs for proton-conducting PEM fuel cells [2]. Figure 2.1 shows an illustration of a conventional MEA consisting of polymer electrolyte sandwiched between two catalyst-coated GDEs. Catalysts are placed at the electrode-electrolyte interfaces, where the anode and cathode half-cell reactions take place.

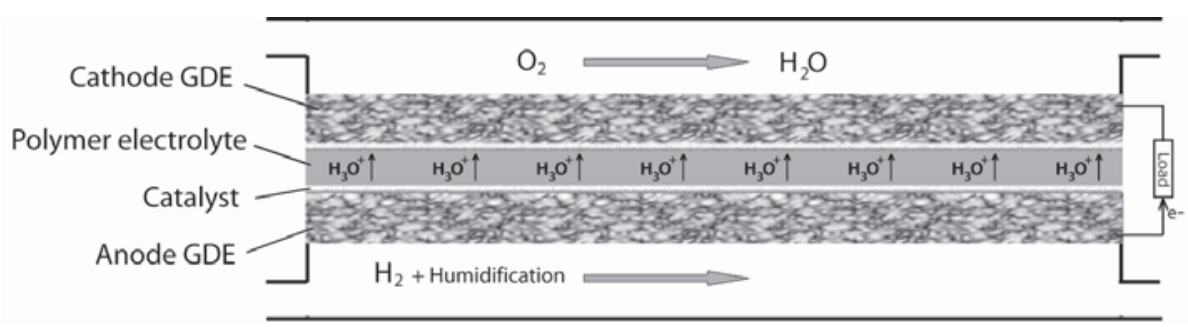

Figure 2.1: Cross sectional illustration of a humidified PEMFC with a conventional GDE, showing the protons being transported by water molecules via a vehicle mechanism [3].

One of the main problems faced by the cathode GDE in a PEM fuel cell is water clogging $[4,5]$. The polymer electrolyte (e.g. Nafion ${ }^{\circledR}$ ) needs constant humidification since its proton conducting mechanism is based on water molecules as carrier of protons (in the form of $\mathrm{H}_{3} \mathrm{O}^{+}$) [3]. But this conflicts with the functionality of the GDE, whose gas diffusive efficiency decreases with the increase of water presence in it. Since PEM fuel cells usually operate below $100{ }^{\circ} \mathrm{C}$, the condensation of water produced at the cathode-electrolyte interface due to oxygen-reduction-reaction (ORR) is high. This liquid water not only blocks the pores of the cathode GDE, but also reduces the electrochemical activity of the catalyst particles (e.g. platinum) present at the interface [4]. The pores of the GDE are flooded with even more water when high currents are drawn from the fuel cell, due to super-saturation of water vapour. The 
problem of water clogging worsens when the vehicle mechanism of proton conduction in the polymer membrane (depicted in fig.2.1) transports water to the cathode from the anode via electro-osmotic drag [6].

During the design of the micro Solid Acid Fuel Cell ( $\mu \mathrm{SAFC}$ ), the water clogging issue has to be kept in mind. In the proposed $\mu \mathrm{SAFC}$, the GDE is split into two parts: a dense hydrogen diffusive electrode (HDE) using palladium and a gas diffusive support (GDS). Figure 2.2 shows an illustration of the MEA of the $\mu$ SAFC. Whereas, the function of the dense palladium electrodes is to conduct electrons, conduct $\mathrm{H}$ atoms and to isolate the electrolyte from water (as explained in chapter 1), the GDS mechanically supports the fuel cell MEA and is transparent to gases at the same time.

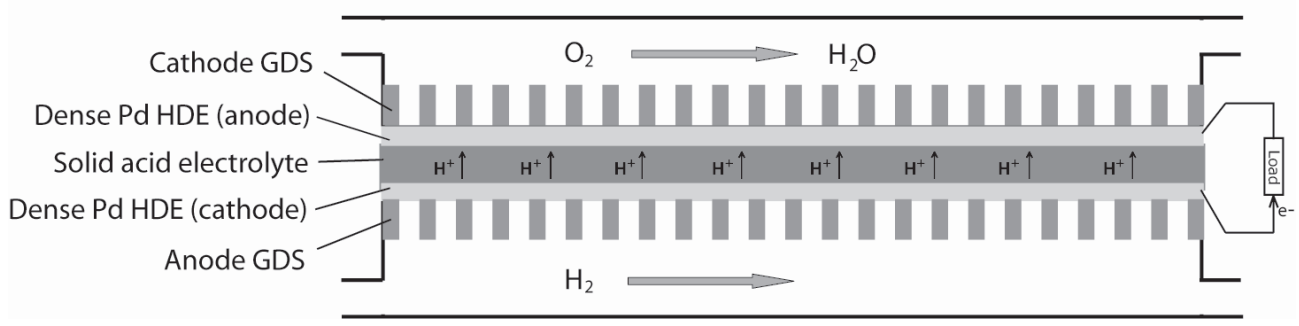

Figure 2.2: Cross sectional illustration of non-humidified MEA of the $\mu$ SAFC's with the new GDS supporting the dense palladium electrodes.

The issue of water clogging is less in the GDS of the $\mu$ SAFC due to the following reasons.

1) The proton transport mechanism being anhydrous [7], there would not be any osmotic drag of water molecules.

2) The operational temperature of the SAFC exceeds $140{ }^{\circ} \mathrm{C}$, thus the water formed at the cathode is in the form of vapour.

However, even in the case of the $\mu \mathrm{SAFC}$, if the GDS is a randomly pored structure with a wide pore size distribution and with many dead-end and tortuous pores, water clogging could still happen due to condensation [8]. To avoid this scenario, the GDS is designed to have a sufficiently large uniform array of straight pores with a low pressure drop. So, we add an additional advantage: 3) The pores of the GDS are 
adequately large enough (at the same time not compromising on its strength) to enable easy gas diffusion to the electrodes, and also for the easy removal of water vapour from the cathode. Using micromachining it is possible to create perforated membrane sieves with precise control over its geometrical structure $[9,10,11]$. The design of the GDS is based on this microsieve concept, which ensures a low pressure drop and combined with sufficient strength. Described in the following sections of this chapter are the details of the GDS fabrication and characterization.

\subsection{Microsieve Gas Diffusive Support: Fabrication and Characterization}

Since the intention is to microfabricate a fuel cell, cleanroom compatible materials like silicon, silicon dioxide or silicon nitride etc. are to be used for GDS fabrication. The GDS needs to be of a rigid material, since the electrodes supported by it as well as the electrolyte have to be crack free. The methods described in references 9-11 involving thin perforated silicon nitride microsieves, although a break-through in membrane technology, have certain limitations. Firstly, this microsieve is too thin $(\sim 1$ $\mu \mathrm{m})$ to span wafer-scale without another robust support underneath the sieve. Secondly, any thin-film membrane to be supported on such a sieve has to be deposited on the patterned side of the wafer having the sacrificial layer [12], which is a problem for further processing of the fuel cell. Moreover, since its fabrication involves wetetching of the silicon support, it is slow and crystal orientation dependent process and this could affect the membrane's quality since the wet-etching of silicon is done after the membrane is deposited. The abovementioned drawbacks can be (partially) avoided by changing the design of the sieve for better strength and by modifying the fabrication scheme to make is compatible for fuel cell processing. We choose to make a microsieve thick enough to span a silicon wafer $(\varnothing 100 \mathrm{~mm})$ and porous enough to have a low pressure drop. The new technique involves the use of Deep Reactive Ion Etching (DRIE) to get cylindrical pores through the silicon wafer and thus forming the GDS membrane. Silicon is chosen, due to its good mechanical strength, stiffness and controlled etchability $[13,14]$. For the design and fabrication process of the GDS, it is important to consider the subsequent step of electrode fabrication as well. The palladium electrode will be supported on the sieve's flat side (as presented in chapter 
3), which needs to be atomically smooth (i.e. roughness $s_{\mathrm{rms}}<3 \mathrm{~nm}$ for bonding purposes) to avoid any defects in the thin-film palladium electrode layer. Depending on the thickness of the palladium electrode to be supported (typically between 1000 $\mathrm{nm}$ and $100 \mathrm{~nm}$ ), the pore sizes of the gas diffusive sieve have to be tuned from micrometers down to nanometers.

Figure 2.3 shows an illustration of the microsieve GDS supporting a dense electrode membrane. The pores in the microsieve are cylindrical perforations through silicon substrate created by photolithography and etching technique. The usage of the microsieve as the GDS has the advantage that there are no dead-end or tortuous pores.

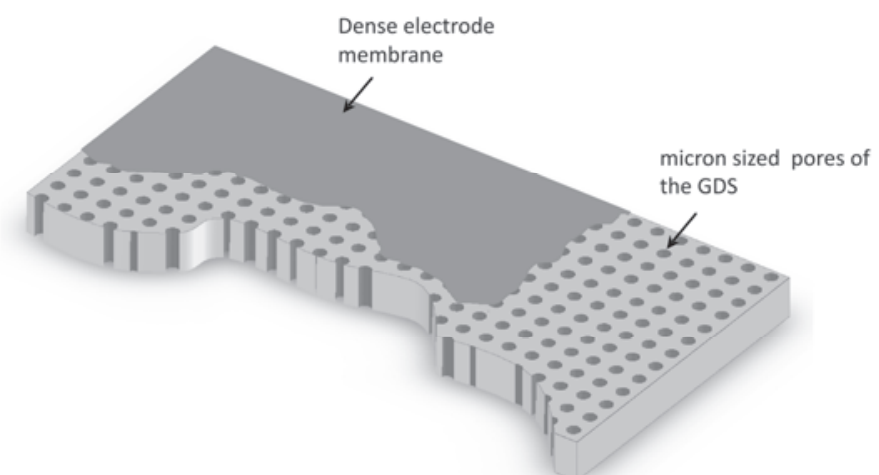

Figure 2.3: Illustration of a microsieve supported electrode membrane

As described in chapter 3, the initial thickness of the palladium electrodes is chosen to be $1 \mu \mathrm{m}$. For a palladium membrane of this thickness, to withstand a transmembrane pressure of at least 5 bar, its span diameter should not exceed $10 \mu \mathrm{m}$ (as calculated from equation $2.1[15])$.

$$
P_{\text {max. }}=6.4 \frac{t \sigma_{\text {yield }}^{3 / 2}}{d E^{1 / 2}}
$$

where, $\sigma_{\text {yield }}$ is the yield stress of palladium $\left[\mathrm{N} / \mathrm{m}^{2}\right], E$ is the Young's modulus $\left[\mathrm{N} / \mathrm{m}^{2}\right], t$ is the thickness of the membrane $[\mathrm{m}]$ and $d$ is its characteristic width [m]. Based on this calculation, and considering a fabrication safety factor, the pores of the microsieve are designed to be $\varnothing 5 \mu \mathrm{m}$ with an inter-pore distance of $12.5 \mu \mathrm{m}$. The 
resultant porosity of the sieve (shown in fig.2.4) is about $12 \%$. The porosity of the sieve can still be increased (without affecting the pore size) by just reducing the interpore distance. To start with, the thickness of the microsieve is chosen to be $\sim 100 \mu \mathrm{m}$, so that the wafer can be handled with ease during and after micromachining.

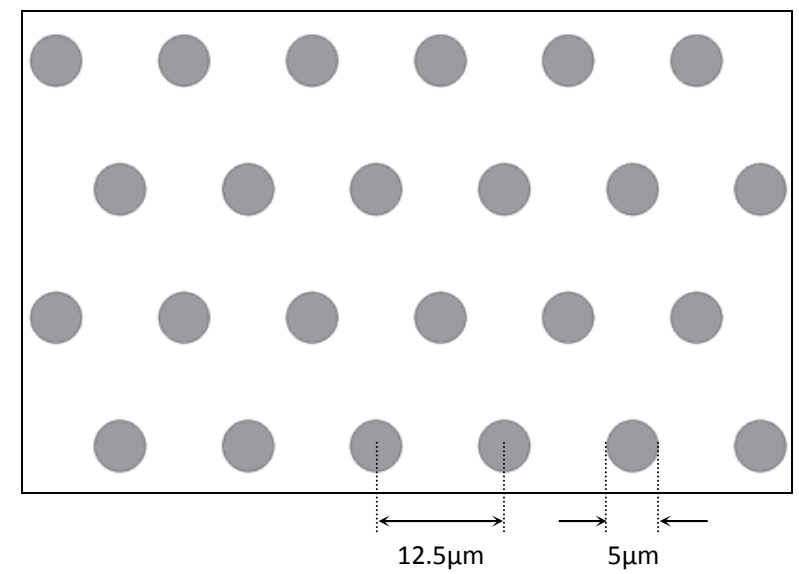

Figure 2.4: Microsieve mask design with hexagonally packed microholes pattern

\subsubsection{Microsieve fabrication}

The fabrication process is a single mask process. Dual side plasma etching is the key technique used for micromachining the silicon microsieve. Figure 2.5 illustrates the the fabrication process. The process starts with the dry oxidation of a silicon wafer to grow $200 \mathrm{~nm}$ of silicon dioxide (fig.2.5-a). Then a resist layer is applied and the wafer is patterned with the microsieve mask. A microsieve mask pattern (with hexagonally packed holes) containing $\varnothing 5 \mu \mathrm{m}$ pore size (as shown in fig.2.4) is used. After photolithography, the resist is post baked at $120{ }^{\circ} \mathrm{C}$ for $30 \mathrm{~min}$ and then transferred into the oxide layer using buffered-HF etching (fig.2.5-b). Subsequently, the pattern is etched $90 \mu \mathrm{m}$ deep into the silicon wafer (see fig.2.5-c) by a Deep Reactive Ion Etching (DRIE) process employing sulfur hexafluoride $\left(\mathrm{SF}_{6}\right)$ gas (explained in detail in section 2.2.1.1). Then, the resist is stripped off the wafer and the wafer is dry oxidized for 10 minutes at $1100{ }^{\circ} \mathrm{C}$ in order to burn off the fluorocarbon residue deposited during the plasma etching step, rendering also a $50 \mathrm{~nm}$ thick layer of silicon 
dioxide (fig.2.5-d). The oxide on the back side (non-pore side) is removed in buffered$\mathrm{HF}$, while oxide at the micropores side is protected with a BHF resistant masking foil. Subsequently, the foil is removed and the back side of the wafer is etched with an isotropic plasma etching process (fig. $2.5-\mathrm{g}$ ). This back-etch process is time controlled and is stopped when the oxidized micropores are reached. The oxide in the micropores, due to its selectivity to $\mathrm{SF}_{6}$ gas, acts as an etch-stop layer and prevents the fluorine radicals from attacking the pore walls, thus maintaining helium wafer backside cooling (which is required for good etch results). This back-etch stop layer is removed by dipping the wafer in $50 \% \mathrm{HF}$, resulting in a $90 \mu \mathrm{m}$ thick microsieve membrane (fig.2.5-h). During the whole process flow, care is taken to avoid damage of the smooth silicon surface, which is crucial for the integration of the palladium electrode.

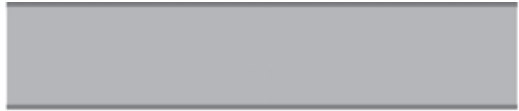

a) Growth of 200nm oxide on silicon wafer

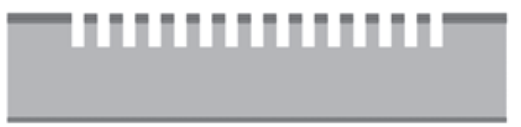

c) Plasma etching of $90 \mu \mathrm{m}$ deep micropores

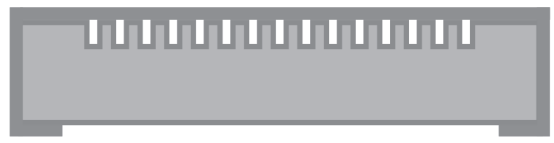

e) Protecting the holes side using a HF resistant foil

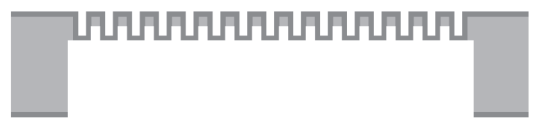

g) Wafer through plasma back etching

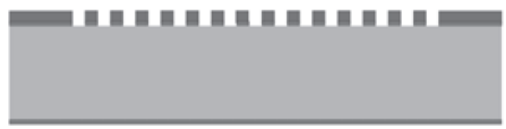

b) Photolithography and oxide etching of microsieve pattern

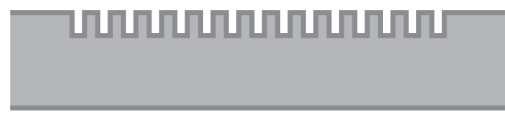

d) Resist strip and dry oxidation at $1100^{\circ} \mathrm{C}$

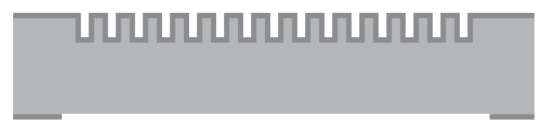

f) Buffered-HF etch of the oxide and removal of foil

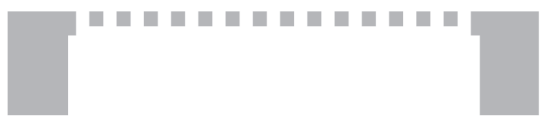

h) Stripping oxide stop-layer in $50 \% \mathrm{HF}$

Figure 2.5: $2 \mathrm{D}$ fabrication process outline for microsieve 


\subsubsection{Deep Reactive Ion Etching}

The Deep Reactive Ion Etching (DRIE) process used to etch the (micro) holes or pores of the sieve is a dry etching technique employing plasma ionized radicals. DRIE is usually used to create deep, steep sided features in wafers, with aspect ratios (etch depth/feature width) beyond 10:1. Due to their high etch rates, normally halogenbased plasmas (e.g. $\mathrm{SF}_{6}$ plasma $[16,17]$ ) are used for the DRIE of silicon, forming volatile etch products (e.g. $\mathrm{SiF}_{4}$ ). While etching silicon using fluorine based plasma, an inhibiting layer (e.g. the $\mathrm{SiO}_{\mathrm{x}} \mathrm{F}_{\mathrm{y}}$ layer) is needed to achieve directionality (i.e. anisotropic etch-profile), for which an inhibitor gas (e.g. $\mathrm{O}_{2}, \mathrm{CHF}_{3}$ ) is introduced into the plasma. The inhibitor gas forms a layer that prevents the plasma radicals from attacking silicon. During directional etching, this layer protects the side walls of the structure from etching, whereas the bottom of the structure etches further, aided by the directional ion bombardment due to an applied electric field between the plasma and the wafer (i.e. dc bias). Insertion of inhibitor gases can be done in two ways. In one technique the inhibitor-usually oxygen-is added at the same time the etch gas $\left(\mathrm{SF}_{6}\right)$ enters, and often the wafer is cryogenically cooled to strengthen the inhibitor $[18,19]$. This form of etching is called mixed-mode DRIE (e.g. $\mathrm{SF}_{6}+\mathrm{O}_{2}$ ). Alternatively, the inhibitor can be introduced sequentially (time-multiplexed) from the etch gas and typically strong polymer-building fluorocarbon gases are used to make room temperature processing possible [20,21]. This form of etching, which is also sometimes referred to as the "Bosch" method, is termed pulsed-mode DRIE (e.g. $\mathrm{SF}_{6} / \mathrm{CHF}_{3}$ or $\left.\mathrm{SF}_{6} / \mathrm{O}_{2}\right)$. This time-multiplexed method will be used in our etching process (fig.2.5-c), because of its better etch profile control when compared to mixedmode DRIE processes [22]. The DRIE system used in this project is the Adixen AMS100 SE DRIE system from Alcatel.

The main process parameters for pulsed-mode DRIE are ICP power (for plasma generation), etch gas flow rate, inhibitor gas flow rate, exhaust throttle valve position (indirectly chamber pressure), CCP power (to create an electric field between plasma and the wafer for directional ion bombardment), wafer holder distance from plasma source (SH-position), wafer chuck temperature, and loading of the masked pattern (which is the amount of unmasked area exposed to the plasma). All these parameters have different effects on the etch-speed and etch-profile. A detailed explanation on the 
effects of each parameter on the DRIE process is provided in our publication [22], a summary of which is given below. If we vary only one parameter at a time, then the following effects are observed.

i) When the ICP power is increased, the etch-speed increases, since there is more power to radicalize the etch gas molecules in the plasma. This increase saturates at a level depending on the flow rate of the etch gas.

ii) An increase in etch gas flux increases the etch-speed (because of availability of more radicals for etching) till a maximum is reached, which relates to a certain ICP power, and then decreases. However, this could have an adverse effect on the anisotropic etch-profile if the inhibitor gas flow is not adjusted.

iii) An increase in inhibitor gas flow decreases the etch-speed, but results in better etch-profile anisotropy due to better side-wall passivation. However, above an optimal limit this causes etching retardation due to positively tapered profile formation.

iv) When the chamber pressure (which is proportional to the residence time of the gas species inside the chamber) is increased by closing the exhaust throttle valve, the etch-speed initially increases till a maximum and then decreases. The initial etch-speed increase is due to the longer time the gas species spend in the plasma. The subsequent decrease in etch-speed is due to the probable recombination of the radicals back to stable species. An increased chamber pressure will have a bad effect on the etch-profile due to the increase in non-directional (lateral) etching.

v) An increase in $\mathrm{CCP}$ power increases the directional etch-speed (not lateral) due to more ion bombardment perpendicular to the wafer surface. However, this reduces the etch resistance (or selectivity) of the masking material. This could also increase the wafer temperature, if metallic masks are used.

vi) When the distance between the silicon wafer and the plasma source is decreased, the etch-speed increases since getting closer to the high density zone increases the probability of radicals arriving at the wafer surface.

vii) With decreasing wafer temperature, the inhibitor layer formation is stronger thus resulting in a better anisotropic etch-profile. A reduction in wafer 
temperature also increases the etch resistance (selectivity) of the masking material.

viii) An increase in wafer loading decreases the etch-speed since the concentration of etch radicals depletes. This also increases the wafer temperature, which affects the etching as explained in (vii).

The different effects the above mentioned parameters can have on the etch-profile anisotropy (e.g. bowing, bottling, tapering etc.) and methods to avoid these problems have been well documented by Jansen [23,24]. By tuning all the aforementioned parameters via detailed etching experiments depicted in [22], a conclusive recipe is obtained (see table 2.1), which is used as the base recipe for etching of the microsieve mask pattern.

Table 2.1: Etch recipe that is used as the base for the microsieve etching experiments [22]

\begin{tabular}{|l|l|}
\hline Parameter & Value \\
\hline $\mathrm{SF}_{6}$ flow (etch gas) & $400 \mathrm{sccm}$ \\
\hline $\mathrm{CHF}_{3}$ flow (inhibitor gas) & $200 \mathrm{sccm}$ \\
\hline $\mathrm{SF}_{6}$ pulsing time & $4 \mathrm{sec}$ \\
\hline $\mathrm{CHF}_{3}$ pulsing time & $0.5 \mathrm{sec}$ \\
\hline $\mathrm{ICP}$ power & $2500 \mathrm{~W}$ \\
\hline $\mathrm{CCP}_{\mathrm{LF}}$ power & $50 \mathrm{~W}(10 \mathrm{~ms} \mathrm{ON}, 90 \mathrm{~ms} \mathrm{OFF})$ \\
\hline Substrate distance from source $(\mathrm{SH})$ & $110 \mathrm{~mm}$ \\
\hline Throttle valve position & $15 \%($ i.e. chamber pressure $=10 \mathrm{~Pa})$ \\
\hline Helium wafer backside cooling pressure & $10 \mathrm{mbar}$ \\
\hline Wafer chuck temperature & $0{ }^{\circ} \mathrm{C}$ \\
\hline
\end{tabular}

The base recipe is slightly customized for suiting the microsieve mask, since its silicon loading and the mask design are different. The results of various experiments done are listed in table 2.2. The masking material used on the wafer during etching is a $1.7 \mu \mathrm{m}$ thick photo resist layer (Olin907-17). After masking the wafer using the photoresist, it is baked at $120{ }^{\circ} \mathrm{C}$ for 30 minutes to strengthen the mask. The experiments are started with the recipe shown in table 2.1. As the micropores need to be etched around $\sim 100 \mu \mathrm{m}$ deep, the selectivity of the mask needs to be good. So, to reduce the mask erosion rate, the CCP power is lowered to $20 \mathrm{~W}$ (\#1) instead of the 
$50 \mathrm{~W}$ shown in table 2.1. The etch-profile shows undercut due to insufficient side wall passivation. To reduce this undercut, the $\mathrm{CHF}_{3}$ pulse time is doubled from $1 / 2$ to 1 second (\#2). Indeed, the undercut decreases but roughness (black silicon) appears at the bottom of the hole. This effect is reduced by doubling the CCP duty cycle from 10 msec ON to $20 \mathrm{msec}$ ON (\#3). Indeed, the result is better, but the topside of the hole shows some bottling.

Table 2.2: Etch parameter tuning for etching of the microholes. One parameter at a time is varied during the tuning procedure. The shaded cells indicate the parameter changed during each of the experiments.

\begin{tabular}{|c|c|c|c|c|c|c|c|c|c|}
\hline Exp.\# & 1 & 2 & 3 & 4 & 5 & 6 & 7 & 8 & 9 \\
\hline $\mathrm{T}\left[{ }^{\circ} \mathrm{C}\right]$ & 0 & 0 & 0 & -40 & -40 & -80 & -80 & -120 & -120 \\
\hline $\mathrm{CCP}_{\mathrm{LF}}[\mathrm{W}]$ & 20 & 20 & 20 & 20 & 20 & 20 & 20 & 20 & 20 \\
\hline $\begin{array}{l}\text { CCP On- } \\
\text { Off [ms] }\end{array}$ & $10-90$ & $10-90$ & $20-80$ & $20-80$ & $20-80$ & $20-80$ & $20-80$ & $20-80$ & $20-80$ \\
\hline $\begin{array}{l}\mathrm{CHF}_{3} \text { pulse } \\
\text { time [sec] }\end{array}$ & $1 / 2$ & 1 & 1 & 1 & 1 & 1 & 1 & 1 & $1 / 2$ \\
\hline $\begin{array}{l}\text { Etch time } \\
{[\mathrm{min}]}\end{array}$ & 3 & 3 & 3 & 3 & 15 & 15 & 20 & 20 & 15 \\
\hline $\begin{array}{l}\text { Etch profile } \\
\text { of a micro } \\
\text { hole }\end{array}$ & & & & & & & & & \\
\hline
\end{tabular}


This bottling is reduced by lowering the wafer temperature from $0{ }^{\circ} \mathrm{C}$ to $-40{ }^{\circ} \mathrm{C}$ (\#4). When increasing the etch depth time from 3 to 15 minutes, the profile again starts to show undercut and bottling (\#5). Also, a reduction in the etch rate is observed, which is due to RIE lag problem that becomes substantial for high aspect ratio structures [25]. To limit the effects of undercut and bottling, the temperature is further lowered from $-40{ }^{\circ} \mathrm{C}$ to $-80{ }^{\circ} \mathrm{C}$ to improve the inhibitor stength (\#6). Again undercut shows up when increasing the etch depth by increasing the etch time (\#7). To avoid the undercut, the temperature is further lowered to $-120{ }^{\circ} \mathrm{C}$ (\#8). Since the profile starts to get positively tapered, the $\mathrm{CHF}_{3}$ pulse time is reset to the original $1 / 2$ second to optimize the etch rate and profile (\#9). Due to the lower amount of inhibition in this final experiment, the etch depth has reached around $95 \mu \mathrm{m}$ in 15 minutes of etching. The final optimized microsieve etching recipe is shown in table 2.3.

Table 2.3: Etch recipe that is used for the microsieve etching

\begin{tabular}{|l|l|}
\hline Parameter & Value \\
\hline $\mathrm{SF}_{6}$ flow (etch gas) & $400 \mathrm{sccm}$ \\
\hline $\mathrm{CHF}_{3}$ flow (inhibitor gas) & $200 \mathrm{sccm}$ \\
\hline $\mathrm{SF}_{6}$ pulsing time & $4 \mathrm{sec}$ \\
\hline $\mathrm{CHF}_{3}$ pulsing time & $0.5 \mathrm{sec}$ \\
\hline $\mathrm{ICP}_{\text {power }}$ & $2500 \mathrm{~W}$ \\
\hline $\mathrm{CCP}_{\mathrm{LF}}$ power & $20 \mathrm{~W}(20 \mathrm{~ms} \mathrm{ON}, 80 \mathrm{~ms} \mathrm{OFF})$ \\
\hline Substrate distance from source $(\mathrm{SH})$ & $110 \mathrm{~mm}$ \\
\hline Throttle valve position & $15 \%($ i.e. chamber pressure $=10 \mathrm{~Pa})$ \\
\hline Helium wafer backside cooling pressure & $10 \mathrm{mbar}$ \\
\hline Wafer chuck temperature & $-120^{\circ} \mathrm{C}$ \\
\hline
\end{tabular}

\subsubsection{Plasma based wafer-back etching}

The isotropic wafer-back etch process (fig.2.5-g) involves the usage of a pure $\mathrm{SF}_{6}$ based continuous plasma to spontaneously etch silicon. The etch recipe used is shown in table 2.4. The etch-speed of this recipe is $\sim 8 \mu \mathrm{m} / \mathrm{min}$ for an unmasked silicon wafer of $\varnothing 100 \mathrm{~mm}$. This process showed non-uniform etching, possibly due to the local depletion of etch-radicals by the etching silicon surface. This depletion was stronger at 
the wafer center than at the wafer edge (the so-called Edge effect or Bull's-eye [26]). The problem due to non-uniform etching is that the microsieve membrane finally becomes thinner close to the edge than at the center of the wafer, which makes it very fragile (as illustrated in figure 2.6a). Another cause of non-uniformity is the resputtered deposition of wafer clamp-ring material on the wafer circumference, which acts as an irregular mask in the proximity of the clamp ring.

Table 2.4: Etch process parameters for wafer-back etching

\begin{tabular}{|l|l|}
\hline Parameter & Value \\
\hline $\mathrm{SF}_{6}$ flow (etch gas) & $400 \mathrm{sccm}$ \\
\hline $\mathrm{ICP}$ power & $2500 \mathrm{~W}$ \\
\hline $\mathrm{CCP}_{\mathrm{LF}}$ power & $0 \mathrm{~W}$ \\
\hline Substrate distance from source $(\mathrm{SH})$ & $110 \mathrm{~mm}$ \\
\hline Throttle valve position & $15 \%$ \\
\hline Helium wafer backside cooling pressure & $10 \mathrm{mbar}$ \\
\hline Wafer chuck temperature & $10^{\circ} \mathrm{C}$ \\
\hline
\end{tabular}

As a solution to these problems, a $9 \mathrm{~mm}$ wide laser-cut silicon sacrificial ring was used (immobilized on the wafer using Fomblin oil, which was later removed by cleaning in iso-propanol) that 'consumed' the extra etch-radicals at the wafer edge and also protected the wafer circumference from resputtered deposition (see figure 2.6b).
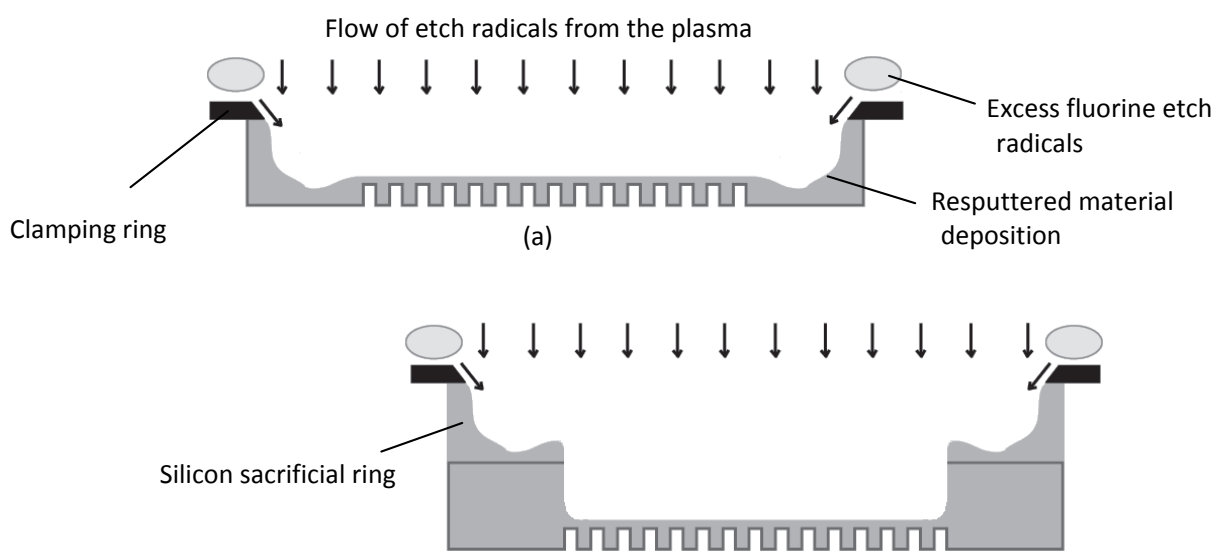

(b)

Figure 2.6: a) Non-uniform back etching problem b) Sacrificial silicon ring as a solution 
Depending on its thickness, the ring can be re-used multiple times. The usage of such a sacrificial ring mask also offered an additional advantage: the microsieve wafer after etching had a residual non-etched ring around it, which made it easier to handle.

The DRIE process developed to etch the microholes (table 2.3) exhibited good anisotropy and uniformity across the wafer. The thickness of the final microsieve membrane was defined by the depth of the micropores. Figure 2.7 shows a $90 \mu \mathrm{m}$ thick microsieve membrane released by plasma back etching. The microsieve was controllably etched to have well defined, uniform pore depths and diameters, thus enabling us to have good strength and well defined porosity.
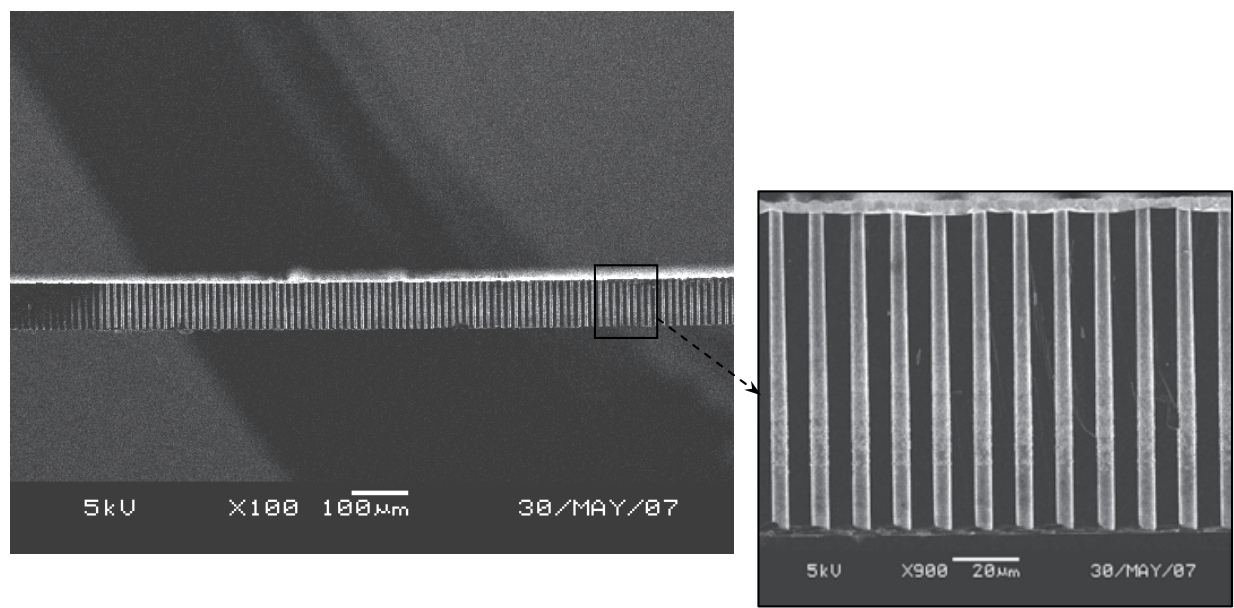

Figure 2.7: SEM picture of the cross-section of a $90 \mu \mathrm{m}$ thick silicon microsieve with $\varnothing 5 \mu \mathrm{m}$ holes

\subsubsection{Microsieve characterization}

In order to test the gas flow through the microsieve, a piece of $3 \mathrm{~mm}$ diameter is assembled onto a glass tube (see fig.2.8). This technique of membrane-on-tube assembly [27] is elaborated in chapter 5 of this thesis. The tube-assembled sieve is mounted in a compressed air flow set-up (shown in fig.2.9) and its flux and pressure drop are characterized. 


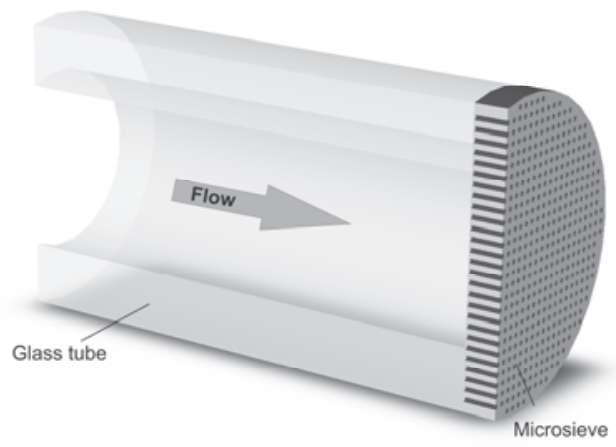

Figure 2.8: Illustration of a glass tube assembled silicon microsieve for flow testing

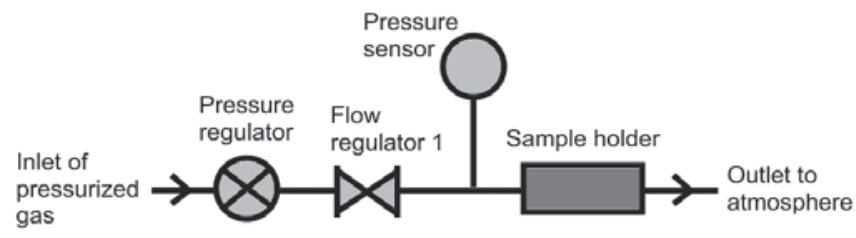

Figure 2.9: Schematic of the air flow set-up used for flow testing of the microsieve

The theoretical pressure drop for air flow through the microsieve can be determined using the following formula (assuming viscous transport behavior),

$$
\Delta P=\frac{8 Q \eta l}{p A r^{2}}
$$

where, $Q$ is the air flux $\left[\mathrm{m}^{3} / \mathrm{s}\right], \eta$ is the viscosity of air [Pa.s], $l$ is the thickness of the microsieve membrane $[\mathrm{m}], p$ is the porosity of the microsieve [-], $A$ is the area of the microsieve sample $\left[\mathrm{m}^{2}\right]$ and $r$ is the radius of one micropore $[\mathrm{m}]$.

The flow measurements showed a pressure drop of $0.086 \pm 0.005$ bar for an air flux of $2.0 \times 10^{6} 1 / \mathrm{m}^{2} . \mathrm{hr}$ through the microsieve. The calculated value for the pressure drop (using eq. 2.2) across the sieve for the same flow is 0.098 bar. This difference may be that although $\varnothing 5 \mu \mathrm{m}$ is the size of micropores on the mask pattern, they widen (as observed by HRSEM) because of lateral etching during the DRIE process. 
The strength of the microsieve is verified using water pressurizing equipment. For this, $3 \mathrm{~mm}$ internal diameter glass assembled samples (figure 2.8) are used. Tests done by pressurizing the water from the inside of the glass tube revealed a burst strength of $\sim 7$ bar for the $90 \mu \mathrm{m}$ thick microsieve. To check the conformity of the measurement with the theory, the radial stress in the membrane at its bonded circumference (where it is the maximum) is determined. Since the deflection of the membrane is at least an order of magnitude smaller than its thickness and the membrane radius is 17 times larger than its thickness, the theoretical estimations are based on thin plate theory [28]. The load to stress relationship for a dense circular membrane with clamped edges is given by the following equation.

$$
\sigma_{r(\max )}=\frac{3}{4} \frac{q a^{2}}{t^{2}}
$$

Where, $\sigma_{r(\max )}\left[\mathrm{N} / \mathrm{m}^{2}\right]$ is the maximum radial stress at the membrane edge, $q[\mathrm{~Pa}]$ is the uniform load over the membrane, $t[\mathrm{~m}]$ is the membrane thickness and $a[\mathrm{~m}]$ its radius. For a perforated membrane, the load bearing strength reduces by its void fraction (i.e. porosity), as approximated by Van Rijn [15]. For a load of 7 bar, the maximum radial stress in the microsieve is calculated to be $0.19 \mathrm{GPa}$. This value is in the same order of magnitude as $0.47 \mathrm{GPa}$, which is the yield strength of a processed silicon wafer (in millimeter scale) as measured by Namazu [29]. The reason for the difference in the stress values of the microsieve membrane could be due to various factors, including etching induced defects in the membrane and thermally induced stresses.

Although a GDS with large pores is suitable for supporting palladium membranes with a thickness in the micron-range, when it comes to thinner membranes $(<100$ $\mathrm{nm}$ ), poresizes in nanometers are required for sufficient mechanical strength. In chapter 6 , the fabrication and characterization of a nanosieve suitable to be used as a fuel cell nano-GDS is explained. 


\subsection{Conclusions}

A Gas Diffusive Support (GDS) for the dense electrodes of the solid acid fuel cell has been successfully fabricated and characterized. The GDS is a $90 \mu \mathrm{m}$ silicon microsieve having straight cylindrical through pores of around $\varnothing 5 \mu \mathrm{m}$, which show low pressure drop as well as good strength. To reduce the pressure drop of the supporting sieve, an increment in its porosity is essential, without affecting its pore size. A customized recipe based on deep reactive ion etching (DRIE) has been developed to anisotropically etch the micropores. The smoothness of the sieve surface is maintained so as to enable successful assembly of the dense electrode onto it. Two of such sieve supported electrodes can be used to sandwich the electrolyte in between them to form the Membrane Electrode Assembly (MEA) of the solid acid fuel cell.

\section{Acknowledgements}

Thanks to Dr. Henri Jansen for his help in understanding plasma based etching.

\section{References}

[1] V. A. Lysenko, Fibre Chemistry, 2008, 40 (3)

[2] W. Vielstich, H. A. Gasteiger, and A. Lamm (eds.), Handbook of Fuel Cells - Fundamentals, Technology, and Applications, Vol. 3, Fuel Cell Technology and Applications, Wiley, New York 2003.

[3] D. A. Boysen, Superprotonic Solid Acids: Structure, Properties, and Applications, PhD Thesis, California Institute of Technology, Pasadena, California, 2004

[4] U. Pasaogullari and C. Y. Wang, Journal of The Electrochemical Society, 2004, 151 (3) A399A406

[5] F. Y. Zhang, X. G. Yang and C. Y. Wang, Journal of The Electrochemical Society, 2006, 153 (2) A225-A232

[6] G. J. M. Janssen, Journal of The Electrochemical Society, 2001, 148 (12) A1313-A1323

[7] S. M. Haile, D. A. Boysen, C. R. I. Chisholm and R. B. Merle, Nature, 2001, 410 (19), pp.910-913

[8] T. Berning and N. Djilali, Journal of The Electrochemical Society, 2003, 150 (12) A1589-A1598

[9] C.J. M. Van Rijn and M. C. Elwenspoek, IEEE Micro Mechanical Systems, 1995, pp 83-7 
[10] S. Kuiper, C.J. M. Van Rijn, W. Nijdam and M .C. Elwenspoek, Journal of Membrane Science, 1998, 150, 1-8

[11] H. D. Tong, H. V. Jansen, V. J. Gadgil, C. G. Bostan, J. W. Berenschot, C. J. M. Van Rijn and M .C. Elwenspoek, Nanoletters, 2004, 4, pp.283-7

[12] H. D. Tong, F. C. Gielens, J. G. E. Gardeniers, H. V. Jansen, J. W. Berenschot, M. J. de Boer, J. H. de Boer, C. J. M. Van Rijn and M .C. Elwenspoek, Journal of Microelectromechanical Systems, 2005, 14, pp.1113-24

[13] K. E. Petersen, Proceedings of the IEEE, 1982, 70 (5), pp.420-457

[14] G. T. A. Kovacs, N. I. Maluf and K. E. Petersen, Proceedings of the IEEE, 1998, 86 (8), pp.1536-51

[15] C. J. M. Van Rijn, M. Wekken, W. Nijdam and M .C. Elwenspoek, Journal of Microelectromechanical Systems, 1997, 6 (1), pp.48-54

[16] H. Boyd, M.S. Tang, Solid State Technology 1979, 22 (4), p.133

[17] M. Chen, V.J. Minkiewicz, K. Lee, Journal of The Electrochemical Society, 1979, 126 (11), p.1946

[18] H. V. Jansen, M. J. de Boer, R. Legtenberg, M. C. Elwenspoek, Journal of Micromechanics and Microengineering, 1995, 5 (2), p.115

[19] T.D. Bestwick, G.S. Oehrlein, D. Angell, Applied Physics Letters, 1990, 57 (5), p.431

[20] F. Laermer, A. Urban, Microelectronic Engineering, 2003, 67-68, p.349

[21] T. Kure, H. Kawakami, S. Okudaira, S. Tachi, K. Tsujimoto, M. Kanetomo, Proceedings of The Electrochemical Society, 1989, 90 (1), p.175

[22] H. V. Jansen, M. J. De Boer, S. Unnikrishnan, M. C. Louwerse and M. C. Elwenspoek, Journal of Micromechanics and Microengineering 2009, 19, 033001

[23] H. V. Jansen, M. J. De Boer, H. Wensink, B. Kloeck and M. C. Elwenspoek, Microelectronics Journal, 2001, 32 (9), pp.769-777

[24] H. V. Jansen, M. J. De Boer and M. C. Elwenspoek, Proc. of IEEE MEMS, 1996, pp. 250-257

[25] H. V. Jansen, M. J. de Boer, R. Wiegerink, N. R. Tas, E. Smulders, C. Neagu, M. C. Elwenspoek, Microelectronic Engineering, 1997, 35 (1-4), p.45

[26] A. G. Nagy, Journal of the Electrochemical Society, 1984, 131, pp.1871-5

[27] S. Unnikrishnan, H. Jansen, E. Berenschot, B. Mogulkoc and M. Elwenspoek, Lab Chip, 2009, 9, pp.1966-1969

[28] S. Timoshenko and S. Woinowsky-Krieger, Theory of Plates and Shells, McGraw-Hill publication, 2nd Edition, 1959, pp.55-56

[29] T. Namazu, Y. Isono, and T. Tanaka, Journal of Microelectromechanical Systems, 2000, 9(4), pp.450-459 


\section{The Palladium Electrode}

This chapter describes a method for the microfabrication of dense palladium Hydrogen Diffusive Electrodes (HDEs) and its characterization via gas permeation techniques. The process of hydrogen permeation through palladium and the theoretical model for quantifying the permeation rate are given. The focus is to understand the influence of the palladium hydride phase change (causing membrane embrittlement), on its functionality and suitability as a dense electrode for the proposed $\mu S A F C$. At a hydrogen feed pressure of 1.5 bar and temperature of $150^{\circ} \mathrm{C}$, a $1 \mu \mathrm{m}$ thick sputter deposited palladium membrane is found to be composed of $\alpha$-phase palladium bydrides and the maximum measured hydrogen flux through it is about $8.8 \cdot 10^{-6} \mathrm{~mol} \mathrm{H} / \mathrm{cm}^{2} . s$, which resembles a current of $0.8 \mathrm{~A} / \mathrm{cm}^{2}$.

Part of this chapter has been published in J. Micromechanics and Microengineering, 2008, 18 (6) 064005. Part on palladium micromembrane characterization is being prepared for submission to J. Membrane Science. 


\subsection{Introduction}

Electrodes play an important role in defining how efficiently a fuel cell works. The various properties of a porous electrode in a conventional fuel cell are: good diffusivity for the fuel and oxidant gas streams, diffusivity for water formed at the cathodeelectrolyte interface, conductivity for electrons and optionally of the electro-catalyst to enhance the fuel cell reactions. Normally in fuel cells the functionalities of a Gas Diffusive Support (GDS) and the electrode are combined as Gas Diffusive Electrodes (GDEs), an example being carbon paper or carbon cloth commonly used in a PEMFC [1]. We cannot use such porous GDE's for our micro solid-acid fuel cell ( $\mu \mathrm{SAFC}$ ), since according to the unique construction of the $\mu \mathrm{SAFC}$ (shown in chapter 1 , figure 1.4), it is clear that the electrode should be dense, restricting liquid water penetration through it which would otherwise cause electrolyte dissolution. As already seen in chapter 2 (figure 2.2), the $\mu \mathrm{SAFC}$ has two such thin and dense electrodes supported on the GDSs. The dense electrodes must be hydrogen diffusive and for a better permeability of hydrogen, they must be very thin. Apart from good hydrogen diffusivity, the electrodes should possess good electronic conductivity, thus motivating our choice for metal membranes used in gas separation. Although metals like niobium, vanadium, and tantalum show better solubility and diffusivity of hydrogen than palladium, the latter is still the dominant material for this purpose. This is because palladium stays noble under most conditions and does not possess the refractory surface oxide film that the aforementioned metals possess [2]. Although palladium membranes are well known for their selective hydrogen permeability, they have been not yet studied to serve the purpose of a Hydrogen Diffusive Electrode (HDE) for a fuel cell. The general application of palladium membranes has been for hydrogen separation at high-temperatures $\left(>300{ }^{\circ} \mathrm{C}\right)[3,4,5]$. In this chapter we report the fabrication and characterization of micromachined palladium electrode membranes to understand its selective hydrogen permeability at temperatures ranging from $75{ }^{\circ} \mathrm{C}$ to $250^{\circ} \mathrm{C}$, within which most of the solid acid salts exhibit a superprotonic transition [6]. At these low temperatures, pure palladium is known to have the problem of grain deformation and embrittlement due to $\alpha$ to $\beta$ phase transformation in the presence of hydrogen. This transformation depends on the concentration of hydrogen in the palladium lattice at a given temperature [7]. Usually, to avoid this problem of phase 
transition from hydrogen-poor $\alpha$-phase to hydrogen-rich $\beta$-phase, palladium membranes are operated at temperatures above $300{ }^{\circ} \mathrm{C}$. However, since solid acids are super-protonically active only at lower temperatures, we are forced to operate palladium electrodes at these temperatures, which thus limits the allowed concentration of hydrogen in the fuel stream of the $\mu$ SAFC. The other possibility to suppress the phase transition is to use palladium alloys (e.g. $\mathrm{Pd}-\mathrm{Ag}$ or $\mathrm{Pd}-\mathrm{Cu}$ ) $[8,9]$. The problem with alloying is that over a period of time, the alloyed metal could diffuse towards the surface of the palladium electrode, which could affect the surface kinetics of the fuel cell reactions. Thus, in this chapter we show the results of investigations with pure polycrystalline palladium membranes, focusing on their usability as dense HDEs in the $\mu$ SAFC application and study the effects of their crystal phase changes in the presence of hydrogen.

\subsection{Theory of hydrogen permeation through palladium}

The hydrogen transport through palladium membranes occurs via a solutiondiffusion mechanism [10]. Several models are proposed for hydrogen permeation through palladium [11,12]. Ward and Dao [13]recently proposed a complete model for hydrogen permeation through palladium, which is well accepted and referred to by the membrane community. The peculiarity of this model is that it assumes a high surface coverage of hydrogen on palladium unlike the previously proposed models. Such an assumption is appropriate for modeling desorption limited permeation processes, which could be the case for our temperature window of operation. Based on their explanation, the permeation process involves several steps in series from the high partial pressure side (feed side) to the low partial pressure side (permeate side), as listed below. All these steps are also pictorially represented in figure 3.1.

1. External mass transfer of molecular hydrogen from the bulk of the gas phase to the vicinity of the gas layer adjacent to the metallic palladium surface on the high pressure side.

2. Reversible dissociative adsorption of hydrogen molecules onto the palladium surface on the high pressure surface. 
3. Reversible dissolution or transition of surface atomic hydrogen from the palladium surface into the bulk metallic layer of the palladium metal.

4. Diffusion of atomic hydrogen inside the metallic bulk palladium.

5. Reversible movement of atomic hydrogen or in other words transition from the bulk palladium metal to the palladium surface on the low partial pressure side.

6. Reversible recombinative desorption of hydrogen from the low pressure side of the palladium surface.

7. External mass transfer of molecular hydrogen from the vicinity of the metallic palladium surface into the gas bulk at the low pressure side of the palladium surface.

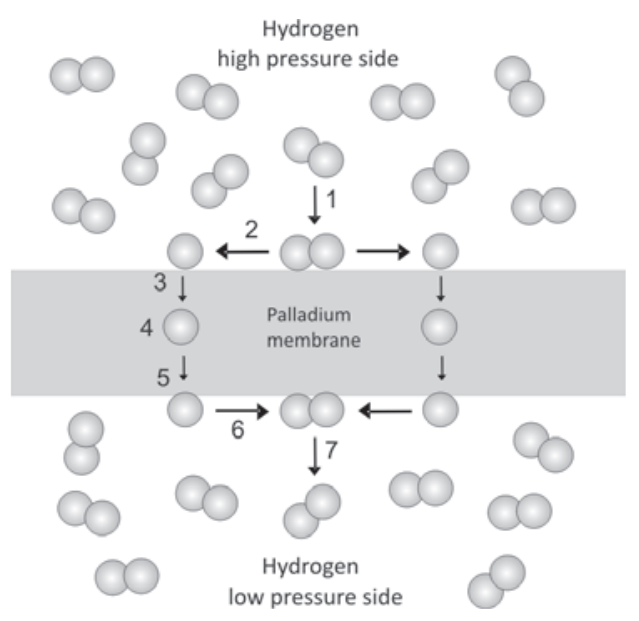

Figure 3.1: $2 \mathrm{D}$ illustration of the 7 steps involved in hydrogen permeation through palladium membrane

Each of these steps is characterized by an intrinsic forward and reverse rate. The overall observed rate of permeation may be limited by one step if it is much slower than the others, or may be governed by a combination of steps. According to conclusions of Ward \& Dao based on experimental data from literature [13], in case of pure hydrogen being used for permeation experiments, depending on the operational temperature, three major steps could become rate-limiting: 1) bulk diffusion of atomic hydrogen through the palladium membrane, 2) surface desorption of molecular hydrogen on the permeate side of the membrane, 3) external mass transfer of hydrogen 
to and from the membrane surface. By maintaining an adequate amount of hydrogen supply on the feed side and by ensuring an efficient removal of hydrogen from the permeate side, the effects of external mass transfer can be neglected. In the following sub-sections the theoretical formulation for bulk diffusion and surface desorption based on the Ward and Dao model [13] are presented. This model will be used as reference for comparing the characterization results of our micromachined palladium membrane.

\subsubsection{Bulk diffusion of atomic hydrogen through palladium}

In this section, only the diffusion of hydrogen through the lattice of the palladium grain will be discussed and not the inter-granular diffusion (i.e. via grain boundaries). In the following discussion, the assumption is that the palladium membrane is in an as-fabricated state without any phase change. Hydrogen is known to diffuse through the palladium lattice atomically. Hydrogen molecules $\left(\mathrm{H}_{2}\right)$ from the feed gas stream are catalytically dissociated into $\mathrm{H}$ atoms and absorbed into the palladium bulk. The $\mathrm{H}$ atoms pass easily through the polycrystalline matrix of the membrane by hopping from one crystal lattice site to another. The $\mathrm{H}$ atom prefers to occupy lattice sites where its potential energy is at a minimum. There are two types of such sites in the face centered cubic (f.c.c.) structure of the palladium crystal lattice: octahedral and tetrahedral sites [14]. The atomic diffusion of hydrogen through the bulk of palladium occurs by the hydrogen atoms jumping between the nearest neighboring octahedral sites while passing through the tetrahedral sites. The atomic hydrogen diffusion flux $[\mathrm{mol}$ $\mathrm{H} / \mathrm{cm}^{2} \mathrm{~s}$ ] through the bulk palladium can be expressed with the one-dimensional Fickian expression:

$$
J_{d i f f}=\frac{D N_{b}\left(X_{1}-X_{2}\right)}{\Delta z}
$$

where, $D$ is the diffusion coefficient $\left[\mathrm{cm}^{2} / \mathrm{s}\right], N_{b}$ is the bulk palladium atomic concentration $\left[\mathrm{mol} \mathrm{Pd} / \mathrm{cm}^{3}\right], \Delta z$ is the membrane thickness [cm], $X_{1}$ and $X_{2}$ are the bulk $\mathrm{H} / \mathrm{Pd}$ atomic ratios (or in other words - hydrogen concentration) adjacent to the 
feed and permeate sides respectively. The diffusion coefficient for hydrogen-inpalladium is expressed as:

$$
D=D_{0} \exp \left(\frac{-E_{\text {diff }}}{R T}\right)
$$

where, $E_{\text {diff }}$ is the activation energy for atomic diffusion $[\mathrm{J} / \mathrm{mol}], D_{0}$ is the preexponential factor $\left[\mathrm{cm}^{2} / \mathrm{s}\right], R$ is the universal gas constant $[\mathrm{J} / \mathrm{mol} . \mathrm{K}]$ and $T$ the operational temperature $[\mathrm{K}]$.

If bulk diffusion is the rate-limiting step of the permeation process, $X_{1}$ and $X_{2}$ can be related to the hydrogen partial pressures on the feed and the permeate streams $\left(P_{H 2, f e d}\right.$ and $\left.P_{H 2, \text { perm }}\right)$ by Sievert's law shown in equation 3.3.

$$
X=\frac{P_{H_{2}}^{0.5}}{K_{s}}
$$

where, $K_{\mathrm{s}}$ is the Sievert's constant $\left[\mathrm{Pa}^{0.5}\right]$, which is also referred to as the equilibrium constant for the following hydrogen dissolution reaction under conditions of $X$ « 1 .

$$
0.5 \mathrm{H}_{2} \text { (gas) } \longleftrightarrow \mathrm{H}(\text { abs. })
$$

The factor 0.5 reflects the dissociation of the gaseous hydrogen molecule into two hydrogen atoms in the palladium bulk during dissolution. For $X$ « 1 , the value of $K_{s}$ can be determined via the following relation [15]:

$$
K_{s}=K_{s 0} \exp \left(\frac{-\Delta \bar{G}_{H}^{0}}{R T}\right)=K_{s 0} \exp \left(\frac{-\Delta \bar{H}_{H}^{0}}{R T}+\frac{\Delta \bar{S}_{H}^{0}}{R}\right)
$$

where, $K_{s 0}$ is the pre-exponential factor having a value of $\sqrt{ } 101325\left[\mathrm{~Pa}^{0.5}\right], \Delta \bar{H}_{H}^{0}$ and $\Delta \bar{S}_{H}^{0}$ are the relative partial molar enthalpy and entropy of dissolution at infinite dilution. Using values reported by Holleck [15]: $\Delta \bar{H}_{H}^{0}=8373.6 \mathrm{~J} / \mathrm{mol}$ and $\Delta \bar{S}_{H}^{0}=$ 
$48.776 \mathrm{~J} / \mathrm{mol} \mathrm{K}$, for as-fabricated membranes at moderately elevated temperatures and for $X$ « 1 , equation 3.5 can be rewritten as:

$$
K_{s}=\sqrt{101325} \exp \left(\frac{-1007}{T}+5.866\right)
$$

Combining equations (3.1)-(3.6), we can express the diffusion flux as follows.

$$
\begin{aligned}
J_{\text {diff }}\left[\mathrm{molH} / \mathrm{cm}^{2} s\right] & =\frac{D N_{b}\left(\frac{P_{H_{2}, \text { feed }} 0.5-P_{H_{2}, \text { perm }} 0.5}{K_{s}}\right)}{\Delta z} \\
& \approx \frac{D_{0} \exp \left(\frac{-E_{\text {diff }}}{R T}\right) N_{b}\left(\frac{P_{H_{2}, \text { feed }}^{0.5}-P_{H_{2}, \text { perm }} 0.5}{111919.9 \exp \left(\frac{-1007}{T}\right)}\right)}{\Delta z}
\end{aligned}
$$

Doing separation at high temperatures will increase the hydrogen diffusivity, thus increases the hydrogen separation flux. However, a high temperature decreases hydrogen solubility [15], which thus flattens the temperature dependence of the hydrogen bulk diffusion. Therefore, hydrogen separation experiments through the palladium based membranes are generally performed in an optimum temperature window of $300{ }^{\circ} \mathrm{C}$ to $500{ }^{\circ} \mathrm{C}$.

\subsubsection{Surface desorption of molecular hydrogen from the palladium surface}

Hydrogen atoms, when reaching the permeate side of the palladium membrane undergoes recombinative desorption. With regard to desorption kinetics, the rate of this recombinative desorption $\left[\mathrm{mol} \mathrm{H} / \mathrm{cm}^{2} \mathrm{~s}\right]$ can be expressed as:

$$
J_{d}=2 k_{d}^{\prime \prime} N_{A A}
$$


where, $N_{\mathrm{AA}}$ is the concentration of nearest neighbor occupied site pairs on the surface. Within the quasi-chemical approximation, $N_{\mathrm{AA}}$ it is expressed as:

$$
N_{A A}=\frac{z N_{S} \theta}{2} F(\theta)
$$

where,

$$
F(\theta)=\left(1-\frac{2-2 \theta}{[1-4 \theta(1-\theta)(1-\exp (-w / k T))]^{0.5}+1}\right)
$$

here, $\theta$ is the fractional surface coverage of hydrogen, $z$ is the number of nearest neighbors on the surface, which is taken to be $4, N_{\mathrm{s}}$ is the surface $\mathrm{Pd}$ atom concentration $\left[\mathrm{mol} \mathrm{Pd} / \mathrm{cm}^{2}\right]$ and $w$ is the pairwise interaction energy $[\mathrm{J} / \mathrm{mol}]$.

And $k_{d}^{\prime \prime}$ is expressed as follows,

$$
k_{d}^{\prime \prime}=\frac{k_{d} N_{S}}{2}
$$

where, $k_{\mathrm{d}}$ is an activated rate constant, given by:

$$
k_{d}=k_{0} \exp \left(\frac{-2 E_{d}}{R T}\right)
$$

where, $E_{d}$ is the activation energy for atomic $\mathrm{H}$ desorption $[\mathrm{J} / \mathrm{mol} \mathrm{H}]$ and $k_{0}$ is the pre-exponential factor $\left[\mathrm{cm}^{2} / \mathrm{mol} \mathrm{H} \mathrm{s}\right]$. The factor 2 in the exponent accounts for the fact that two $\mathrm{H}$ atoms must be simultaneously desorbed forming one molecule of hydrogen. Using equations (3.8)-(3.12), the desorption flux can be expressed as follows,

$$
J_{d}\left[\mathrm{molH} / \mathrm{cm}^{2} s\right]=2\left(\frac{k_{0} \exp \left(\frac{-2 E_{d}}{R T}\right) \cdot N_{S}}{2}\right)\left(\frac{z N_{S} \theta}{2} F(\theta)\right)
$$

The theoretical rates of bulk diffusion and surface desorption are calculated for various temperatures using equations (3.7) and (3.13) and are plotted in figure 3.2. The parametric values used for the calculation (suggested by Ward \& Dao) are listed 
beside the figure. From figure 3.2, it can be seen that at lower temperatures the flux through the palladium membrane is limited by the surface kinetics of desorption. At higher temperatures, the permeation process gets into the diffusion limited regime as the surface reactions are well activated and thus faster than bulk diffusion. The thinner the membrane, higher the temperature required to get it into the diffusion limitation. Although, as will be shown in further sections of this chapter, it is possible to microfabricate dense palladium membranes down to hundreds of nanometers, we initially perform our experiments with a $1 \mu \mathrm{m}$ thick palladium electrode membrane to check its permeation rate limitation.

While using the Ward and Dao model [13] as a theoretical reference for our experimental results, it is important to remember that this model does not consider phase-transition effects of the palladium lattice, as all the equations are for operational temperatures high enough $\left(>200{ }^{\circ} \mathrm{C}\right)$ to avoid any palladium phase-change at $1 \mathrm{~atm}$ hydrogen pressure. This also means that these equations are for as-fabricated membranes which can be considered to be neither $\mathrm{Pd}-\mathrm{H} \alpha$ phase nor the $\mathrm{Pd}-\mathrm{H} \beta$ phase.

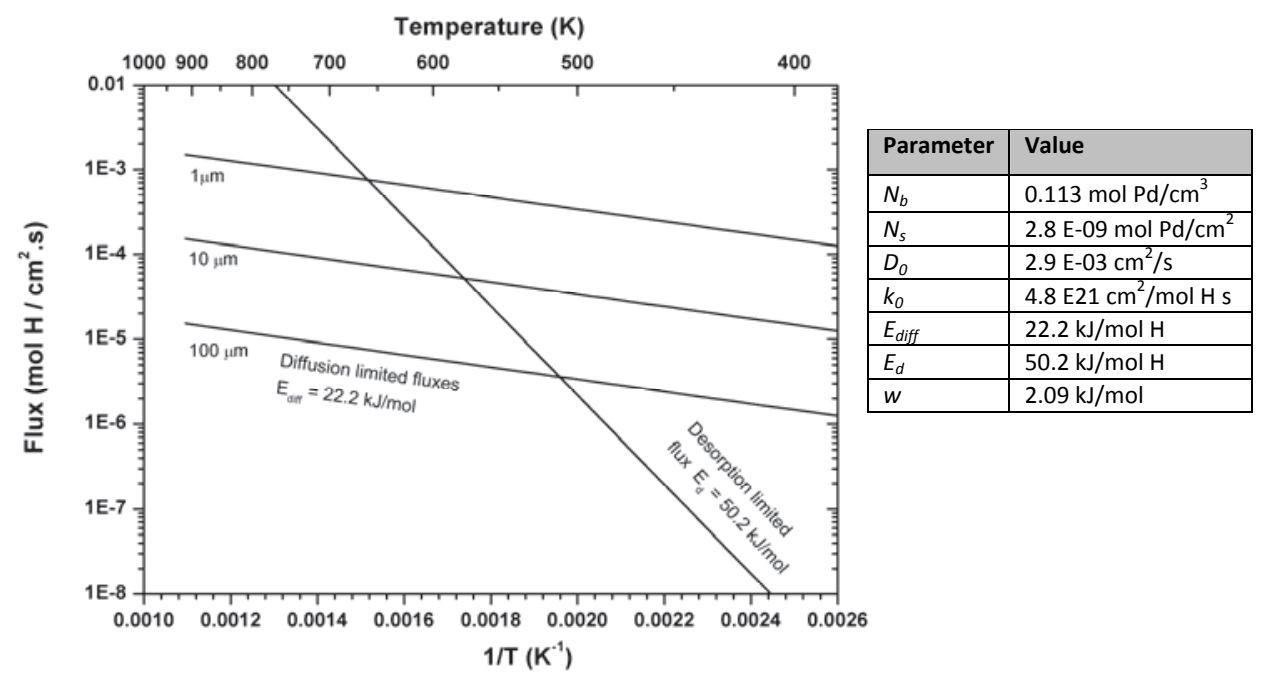

Figure 3.2: Illustration of estimation of hydrogen permeation through palladium membranes of different thicknesses at $\mathrm{P}_{\mathrm{H} 2, \text { feed }}=1 \mathrm{~atm}$ and $\mathrm{P}_{\mathrm{H} 2 \text {,perm }}=0 \mathrm{~atm}$, plotted using the model of Ward \& Dao [13] 


\subsection{Palladium electrode membrane fabrication}

To make a palladium membrane with micrometer thickness, there are different kinds of fabrication methodologies reported in the literature [16-22]. An idea about the suitability of different methodologies can be obtained from table 3.1, where the thickness, permeability and selectivity obtained for membranes fabricated using various techniques are listed. Due to availability and accuracy, we employ sputtering as technique to microfabricate our palladium membrane samples. The usage of microfabrication technology enables precise control over the membrane properties like thickness, material structure etc.

Table 3.1: A comparison of results obtained for palladium based membranes fabricated by different techniques

\begin{tabular}{|c|c|c|c|c|c|}
\hline Membrane & $\begin{array}{l}\text { Preparation } \\
\text { method }\end{array}$ & $\begin{array}{l}\text { Membrane } \\
\text { thickness } \\
{[\mu \mathrm{m}]}\end{array}$ & $\begin{array}{l}\mathrm{H}_{2} \text { flux } \\
{\left[\mathrm{mol} \mathrm{H}_{2} / \mathrm{m}^{2} . \mathrm{s}\right]}\end{array}$ & $\begin{array}{l}\text { Selectivity } \\
\left(\mathrm{H}_{2} / \mathrm{N}_{2} \text { or }\right. \\
\left.\mathrm{H}_{2} / \mathrm{He}\right)\end{array}$ & $\begin{array}{l}\text { Temp. of } \\
\text { operation } \\
{\left[{ }^{0} \mathrm{C}\right]}\end{array}$ \\
\hline $\mathrm{Pd}-\mathrm{Ag}[16]$ & $\begin{array}{l}\text { PVD } \\
\text { process } \\
\text { (Sputtering) }\end{array}$ & 0.5 & $3.6-4.2$ & $>1500$ & 450 \\
\hline $\mathrm{Pd} / \mathrm{Al}_{2} \mathrm{O}_{3}[17]$ & $\begin{array}{l}\text { Electroless } \\
\text { Plating. }\end{array}$ & 17 & 2.49 & $>1000$ & 500 \\
\hline $\begin{array}{l}\mathrm{Pd} / 23 \% \mathrm{Ag} \text { on } \\
\mathrm{Al}_{2} \mathrm{O}_{3}[18]\end{array}$ & $\begin{array}{l}\text { Electroless } \\
\text { Plating. }\end{array}$ & 5.8 & 4.7 & - & 400 \\
\hline $\begin{array}{l}\mathrm{Pd} / \text { Stainless } \\
\text { steel [19] }\end{array}$ & $\begin{array}{l}\text { Electroless } \\
\text { Plating. }\end{array}$ & - & 1.0 & 5000 & 350 \\
\hline $\mathrm{Pd} / \mathrm{Al}_{2} \mathrm{O}_{3}[20]$ & MOCVD & 3.5 & 0.9 & $\sim 1000$ & 300 \\
\hline $\mathrm{Pd} / \mathrm{Al}_{2} \mathrm{O}_{3}[21]$ & MOCVD & $0.5-1$ & $0.05-1.0$ & - & $350-450$ \\
\hline $\begin{array}{l}\mathrm{Pd} / \text { sol-gel } \\
\mathrm{Al}_{2} \mathrm{O}_{3}[22]\end{array}$ & MOCVD & $0.5-5$ & $0.1-0.2$ & $200-300$ & 300 \\
\hline
\end{tabular}

The thin-film palladium membrane will be supported on a silicon microsieve GDS for mechanical strength. In chapter 2, the process of fabricating the microsieve GDS has already been discussed. In this section we illustrate a new micromachining approach to make a wafer-scale defect free palladium membrane bonded to the GDS. 
A thin-film transfer technique is used here, involving the fabrication of the membrane independent of the GDS and the final integration of both. The silicon microsieve used in this fabrication process has a thickness of $90 \mu \mathrm{m}$, with $\varnothing 5 \mu \mathrm{m}$ pores and a design porosity of $27 \%$.

After the microsieve GDS is fabricated, it is fusion bonded to a silicon carrier wafer with a $50 \mathrm{~nm}$ thick thermal oxide film on it (fig.3.3b). The cleanliness and flatness of the bondable surface is crucial for this direct silicon fusion bonding procedure [23]. Prior to bonding, the microsieve wafer and the thin-film carrying sacrificial wafer are thoroughly cleaned in $100 \% \mathrm{HNO}_{3}$ for 10 mins followed by $69 \%$ fuming $\mathrm{HNO}_{3}$ (at $\left.90{ }^{\circ} \mathrm{C}\right)$ for 10 mins and finally in Piranha $\left(96 \% \mathrm{H}_{2} \mathrm{SO}_{4}+31 \% \mathrm{H}_{2} \mathrm{O}_{2}=3: 1\right.$ mixture at $100{ }^{\circ} \mathrm{C}$ ) for 30 mins to ensure a clean and hydrophilic bondable surface. After this thorough cleaning, the wafer surfaces are mated and checked using infrared imaging.

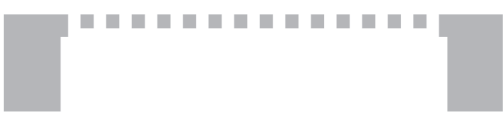

a) Cleaning of the silicon microsieve

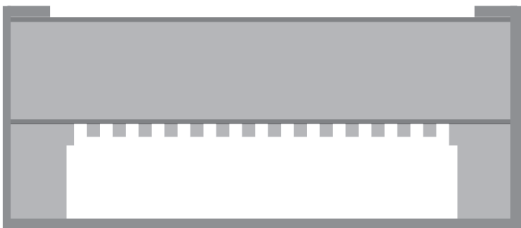

c) Foil protection for selective removal of oxide layer from the wafer using buffered-HF

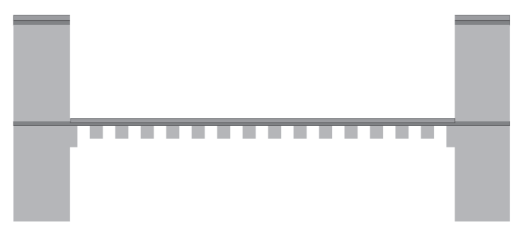

e) Sputter deposition of $1 \mu \mathrm{m}$ palladium layer

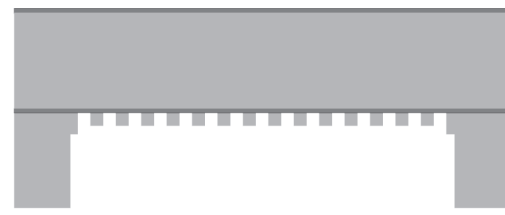

b) Fusion bonding of the sieve to a wafer with $50 \mathrm{~nm}$ thermal oxide layer by annealing at $1100^{\circ} \mathrm{C}$

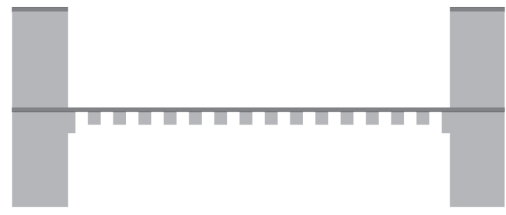

d) Plasma back-etching of the carrier wafer until the oxide layer

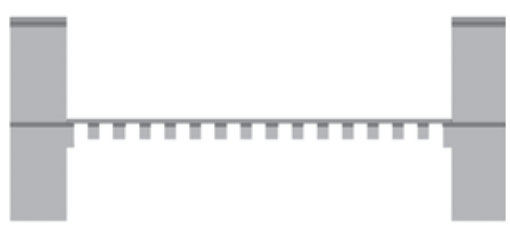

f) Release of the palladium membrane by the selective removal of $\mathrm{SiO}_{2}$ underneath it using $1 \% \mathrm{HF}$

Figure 3.3: Fabrication process flow for micromachined palladium membrane 
Once the mating is proper, the wafers are annealed at $1100{ }^{\circ} \mathrm{C}$ for 2 hours under nitrogen atmosphere to form the permanent bond. The infrared check is performed once more after the annealing step to inspect the quality of the bond. The next step in the fabrication process is to etch the oxide layer on the back side of the carrier wafer in buffered-HF, while the rest of the wafer stack is protected with a BHF resistant masking foil (fig.3.3c). Subsequently, the foil is removed and the wafer is back etched with an isotropic $\mathrm{SF}_{6}$ plasma etching process (fig.3.3d), resulting in a silicon dioxide nano-membrane supported on the $\varnothing 80 \mathrm{~mm}$ silicon microsieve (see figure 3.4). This back-etch process is time controlled and is stopped when the oxide layer is completely exposed. The details of the process parameters and the etch time can be found in appendix A. The spontaneous etch rate of a silicon wafer of $100 \mathrm{~mm}$ diameter using the back etching recipe (shown in chapter 2, table 2.4) is measured to be around 8 $\mu \mathrm{m} / \mathrm{min}$. The thermal oxide's high selectivity $(>1200)$ to silicon in $\mathrm{SF}_{6}$ plasma prevents its breakage during over etching.

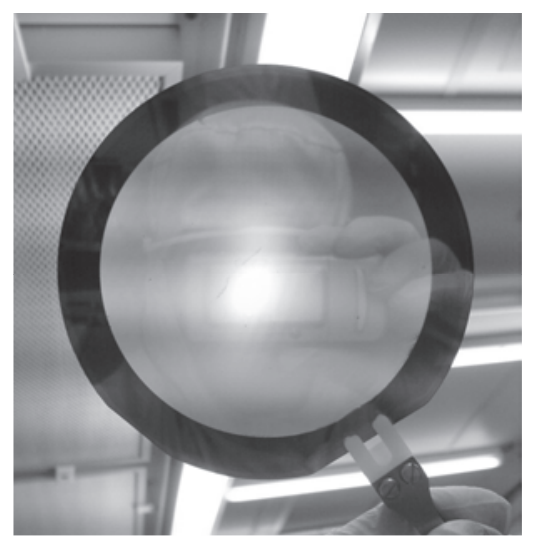

(a)

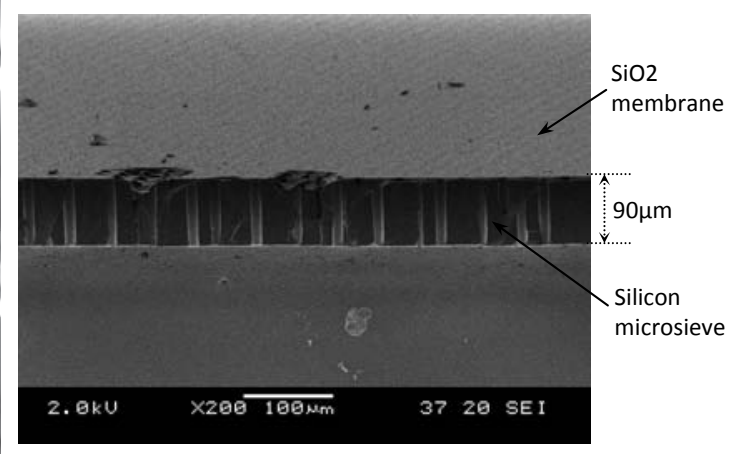

(b)

Figure 3.4: a) Wafer scale $50 \mathrm{~nm}$ oxide membrane supported on a microsieve having $\varnothing 5 \mu \mathrm{m}$ pores b) SEM photo showing the cross-section of a microsieve with the thin-film transferred oxide membrane on top

During the back-etching step a silicon sacrificial ring is used for etch uniformity as already explained in chapter 2, section 2.2.1.2. Subsequently, the wafer stack is thoroughly cleaned in $100 \% \mathrm{HNO}_{3}$ for 10 mins followed by $69 \%$ fuming $\mathrm{HNO}_{3}$ (at $90{ }^{\circ} \mathrm{C}$ ) for 10 mins. Next, a $1 \mu \mathrm{m}$ palladium layer is sputter deposited on the oxide 
nano-membrane (fig.3.3e) for which a $15 \mathrm{~nm}$ thick sputtered titanium adhesion layer is employed. To release the palladium membrane, the underlying oxide and titanium in every micropore of the microsieve GDS are sacrificially removed in HF solution from the back side (fig.3.3f). Figure 3.5 shows a detailed illustration of the palladium membrane release process. When the microsieve supporting the silicon dioxide, titanium and palladium layers is immersed in HF solution, the etchant enters from the backside of the micropores and starts to isotropically etch the oxide layer and then the titanium layer. Palladium is not attacked by the etchant and thus gets released as a free-hanging membrane.

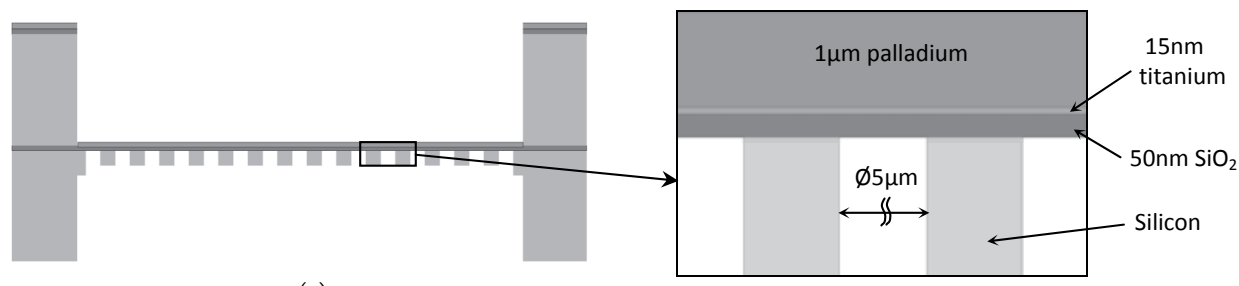

(a)

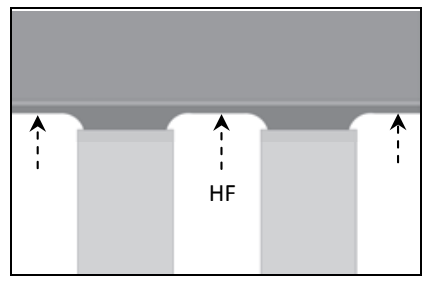

Figure 3.5: Illustration of palladium membrane release using hydrofluoric acid a) silicon microsieve supporting the oxide, titanium and the palladium layers $b$ ) isotropic etching of the oxide and titanium layers

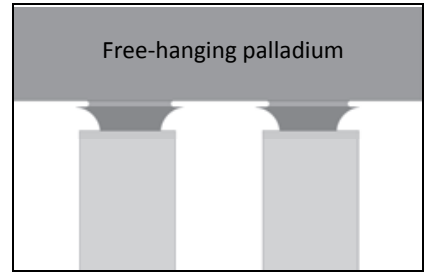

(b)

The size and shape of the final samples for characterization are adapted to the sample-holder of the gas permeation set-up. The final palladium membrane samples fabricated are discs of $19 \mathrm{~mm}$ outer diameter and $9 \mathrm{~mm}$ inner diameter as shown in figure 3.6. For the fabrication of these samples the bottom wafer mask design was 
modified to yield twelve individual membrane samples out of every processed wafer. The samples are cleaved out of the wafer aided by the micropores pattern around it. To ensure that vibrations during the cleaving process do not affect the palladium membrane, the cleaving process is performed under (deionised) water. The surface area of the palladium supported on the microsieve is $63.6 \mathrm{~mm}^{2}$. Multiplied with the porosity of the GDS, the effective open area of palladium available for permeation is $22.9 \mathrm{~mm}^{2}$. Although the porosity of the microsieve was designed to be $27 \%$, during microfabrication its porosity increased to $\sim 36 \%$ due to excess lateral etching via under cutting during plasma etching of the micropores.

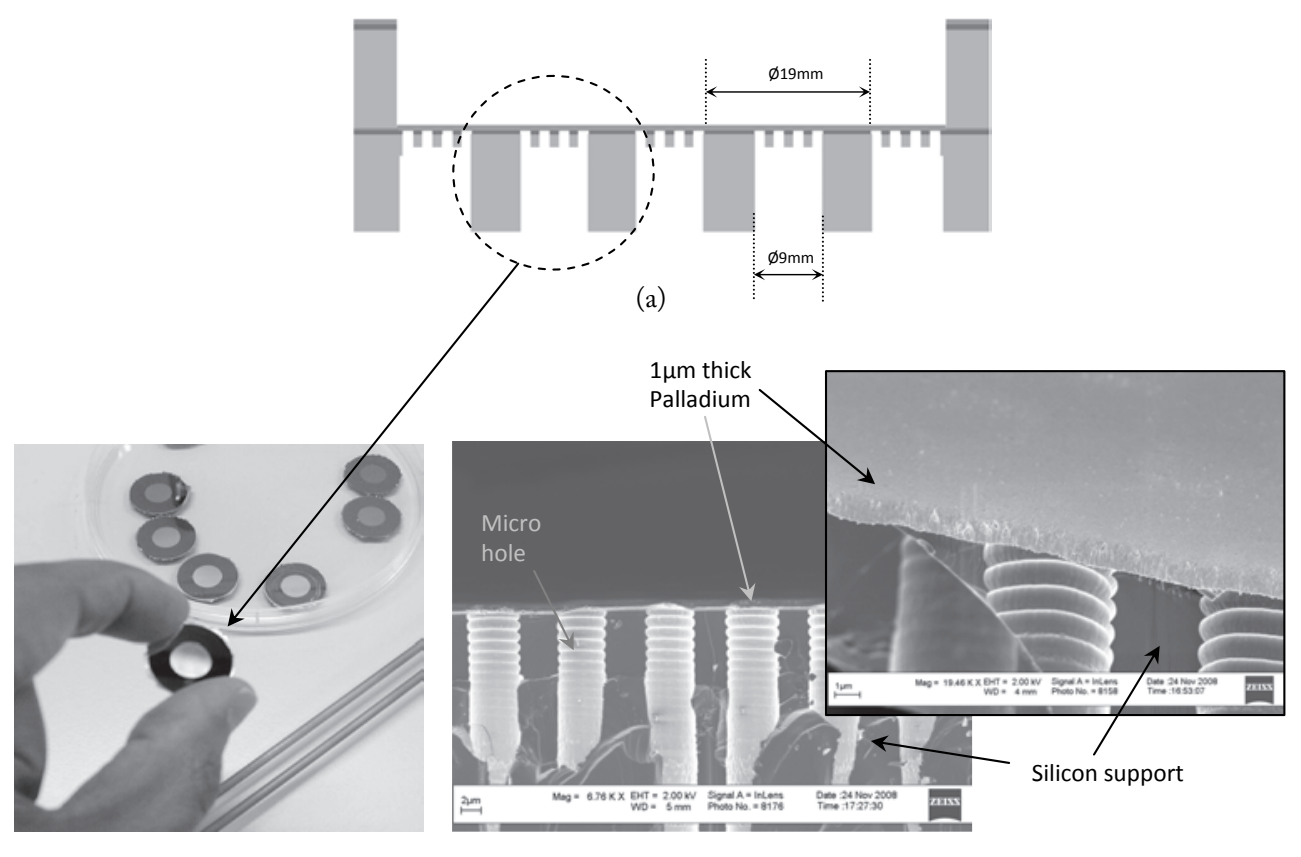

(b)

(c)

Figure 3.6: a) Cross-sectional disproportionate illustration of the modified wafer stack before cleavage of the samples b) Disc type palladium samples c) SEM picture of the sample cross-section

\subsubsection{Discussions on fabrication}

1) During mating of wafers for fusion bonding, there can be air or particle entrapment at the bond interface. In such cases, the mated surfaces have to be carefully 
detached by placing them in deionised water and then thoroughly cleaned again as explained before. Slight roughness of the wafer surface could also lead to air filled voids at the bond interface. Apart from reducing the effective bond area, the problem with the entrapped air pockets is that they expand during the subsequent annealing step, which could lead to bond failure. In most cases particles and roughness can be prevented, but entrapped gas is a more fundamental problem. The fusion bonding of the thin-film was chosen to be done after the creation of the etched through micropores, so that the problems due to entrapped gas during surface mating or annealing steps get eliminated.

2) Apart from protecting the bondable wafer surface from resputtered deposition, the $200 \mathrm{~nm}$ thick protective oxide layer on top of the microsieve (see chapter 2, figure 2.5a) also helped to maintain the wafer surface flat as explained next.

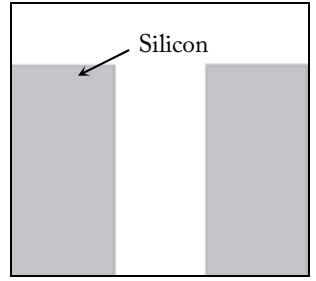

(a)

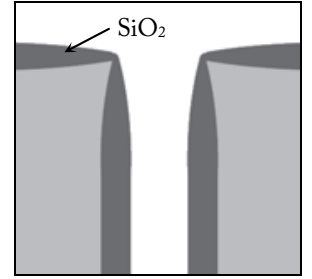

(b)

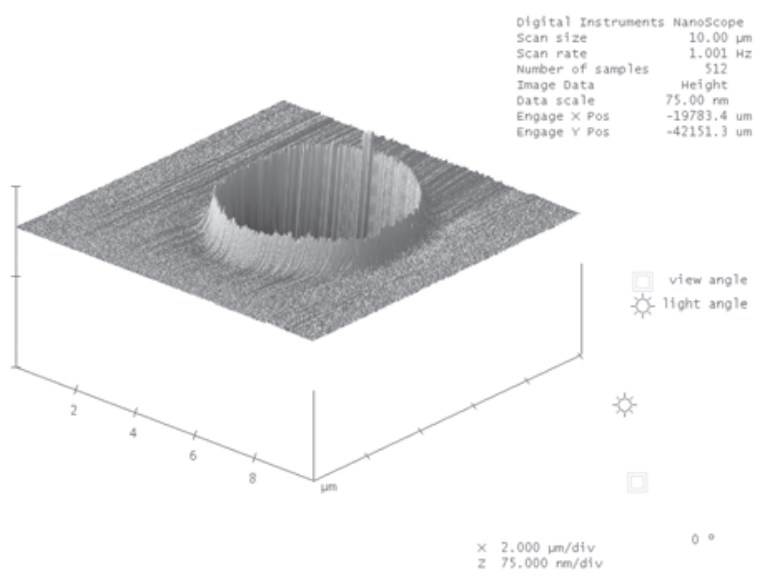

(c)

Figure 3.7: a) Cross section of a micropore in silicon b) non-uniform oxidation at the edges c) AFM image of a micropore with $23 \mathrm{~nm}$ protruding edge, measured after stripping a $300 \mathrm{~nm}$ thermal oxide grown at $1000{ }^{\circ} \mathrm{C}$ 
When thermal oxidation to create the back-etch stop layer (see chapter 2, figure $2.5 \mathrm{~d}$ ) is done without this protective oxide layer on top, the silicon at the edges of the micropore is less oxidized as compared to the plain surfaces. This is due to the stress at the silicon- $\mathrm{SiO}_{2}$ interface at the convex edges of the hole [24]. This effect worsens with longer oxidation times and lower oxidation temperatures $\left(<1050{ }^{\circ} \mathrm{C}\right)$ [25]. Figures 3.7a,b illustrate this phenomenon. After stripping the oxide, protrusions are seen at the wafer surface, which prevent correct bonding (fig. 3.7c).

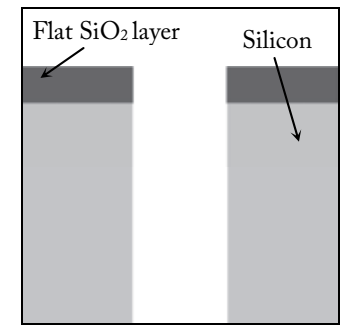

(a)

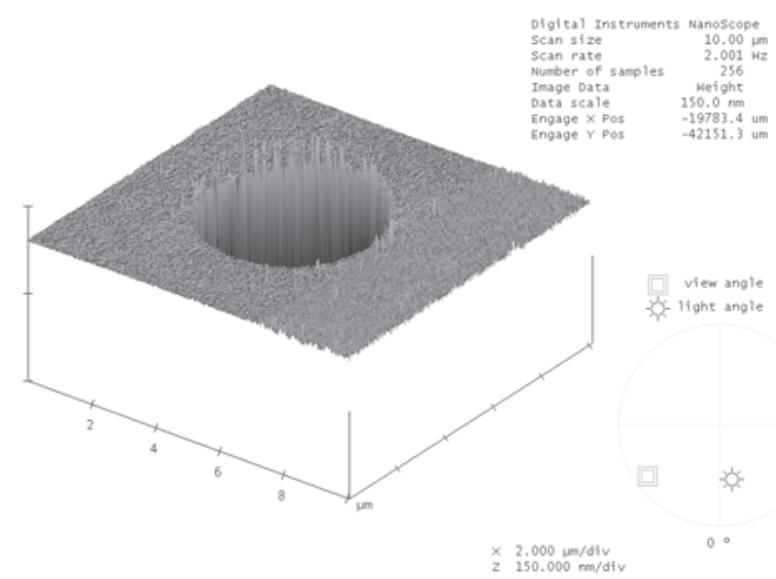

(c)

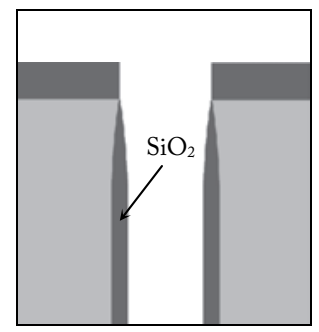

(b)

Figure 3.8: a) Cross section of a micropore with flat oxide layer on top b) surface flat during oxidation c) AFM image of a micropore measured after stripping the oxide layer grown at $1100{ }^{\circ} \mathrm{C}$

As shown in figure 3.8, by using a flat and thick protective oxide layer on top and by growing a thinner oxide back-etch stop layer at a higher temperature $\left(1100^{\circ} \mathrm{C}\right)$, the flatness of the bondable surface is retained. The flat protective layer retarded the 
oxidation on the top surface and also countered the stress at the micropore edges. And, at such high temperatures the viscosity of the oxide is lower, which allows reflow thereby relieving stress.

3) Using the fabrication process (shown in figure 3.3), palladium membranes of thickness from $1 \mu \mathrm{m}$ down to $150 \mathrm{~nm}$ were successfully fabricated. The thicker the membrane, the lesser would be the amount of defects or pinholes in them, but they would have the slight disadvantage of an increased influence of compressive stress. This stress is caused by the expanding grain lattices during the film growth during the deposition process [26]. The disadvantage of this intrinsic stress is that the palladium films show less adhesion to the microsieve GDS. This was verified using a scotch tape test, wherein a sticky tape is stuck on the deposited palladium film and peeled off. If the membrane peels along with the tape, then the adhesion is concluded to be bad. If sputtering is done at an elevated temperature, the intrinsic stress can be reduced.

During the fabrication of thinner palladium membranes, an interesting phenomenon was observed. The palladium membrane showed a subtle pattern of nano-bumps on its surface (shown in figure 3.9a). After analysis it was found that these nano-bumps are faithful copies of the nano-bumps on the silicon dioxide membrane (figure $3.9 \mathrm{~b}$ ) on which the palladium is deposited before releasing. This pattern on the silicon dioxide membrane is caused by the slight attack from the $\mathrm{SF}_{6}$ plasma used for silicon wafer back etching. Figure 3.9c shows the bottom surface of the palladium that had an interfacial contact with the silicon dioxide layer.

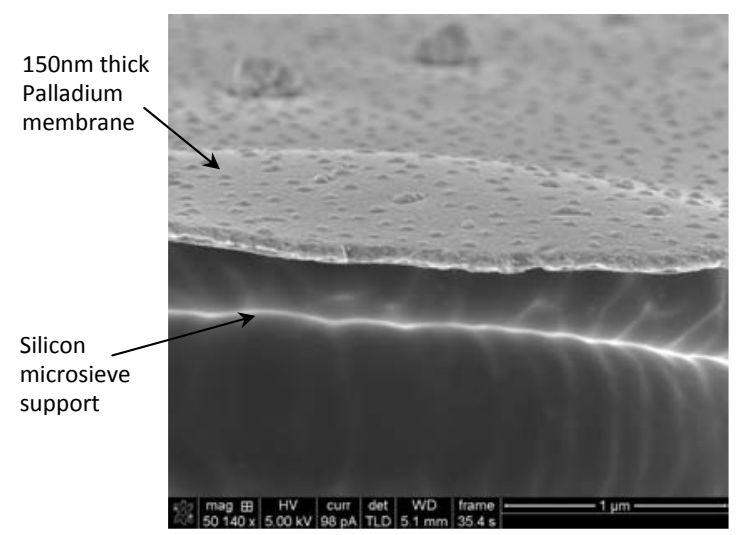

(a)

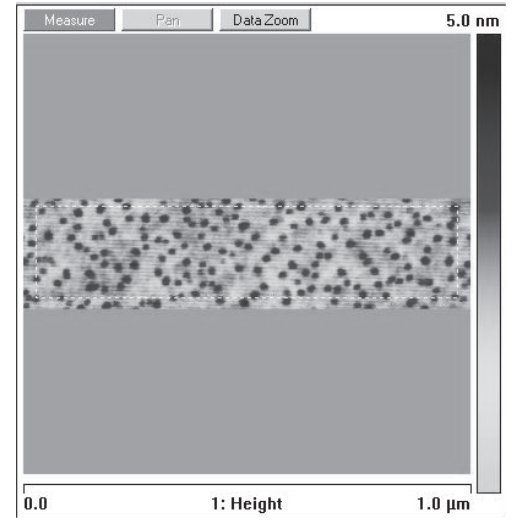

(b) 


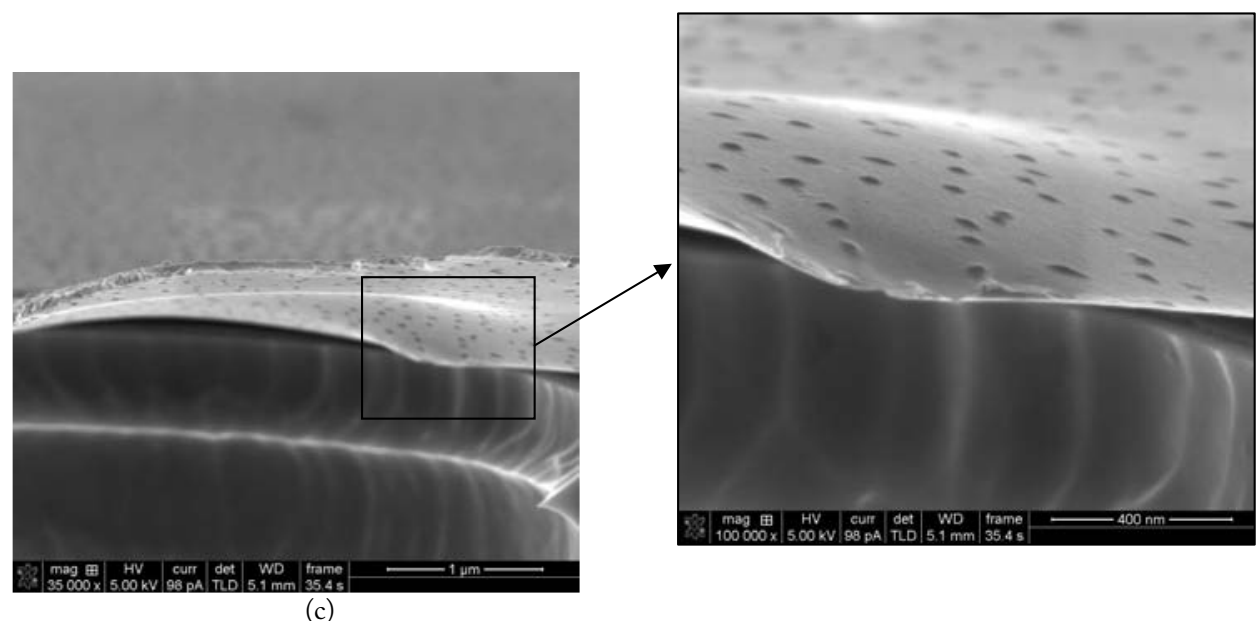

Figure 3.9: a) HRSEM photo of the nano-bumps pattern on top of the palladium membrane b) AFM scan of the nano-bumps pattern on top of the silicon dioxide membrane c) HRSEM photos of the nano-dents pattern under the $150 \mathrm{~nm}$ thin palladium membrane

4) The wet etching step to release the palladium membrane is a crucial one due to the difference in etch rates of the underlying titanium and silicon dioxide. For instance, in a $5 \% \mathrm{HF}$ solution, oxide etches at the rate of $\sim 23 \mathrm{~nm} / \mathrm{min}$ while titanium has a high etch rate of $\sim 1100 \mathrm{~nm} / \mathrm{min}$ [27]. This means that after the removal of the oxide, the HF would attack the titanium adhesion layer rapidly in all directions, which could result in a peel off of the whole palladium layer from the microsieve support. To avoid this scenario, a set of etch experiments was performed to determine the exact etch time required for releasing the palladium membrane (see table 3.2). In these experiments, $1 \% \mathrm{HF}$ is employed to have a better control on the etch speed. The HRSEM photographs depicted in the table 3.2 are focusing inside a microhole at the interface of the palladium membrane and the silicon support, between which the silicon dioxide and titanium layers are sandwiched. It can be clearly seen from the experimental results that the optimum etching time for the proper release of the palladium membrane is 19 minutes. If the etch time is a few minutes lesser, the oxide layer still remains and thus blocks the palladium. When the etch time exceeds 19 minutes, then there is a danger of palladium peel off due to over-etching of the titanium adhesion layer. Another common choice for the adhesion layer is chromium, which can be separately removed in a chromium-etchant after etching the oxide in 
HF. However, chromium has the limitation that it could diffusive into palladium during permeation experiments conducted at high temperatures.

Table 3.2: Etch experiments using $1 \% \mathrm{HF}$ to determine etch time for palladium membrane release

\begin{tabular}{|c|c|c|c|}
\hline $\begin{array}{l}\text { Exp. } \\
\text { No. }\end{array}$ & $\begin{array}{l}\text { Etch } \\
\text { Time }\end{array}$ & $\begin{array}{l}\text { HRSEM image of the palladium membrane and the } \\
\text { silicon support interface (with } \mathrm{SiO}_{2} \text { and } \mathrm{Ti} \text { in between) }\end{array}$ & Remarks \\
\hline 1 & $16 \mathrm{~min}$ & 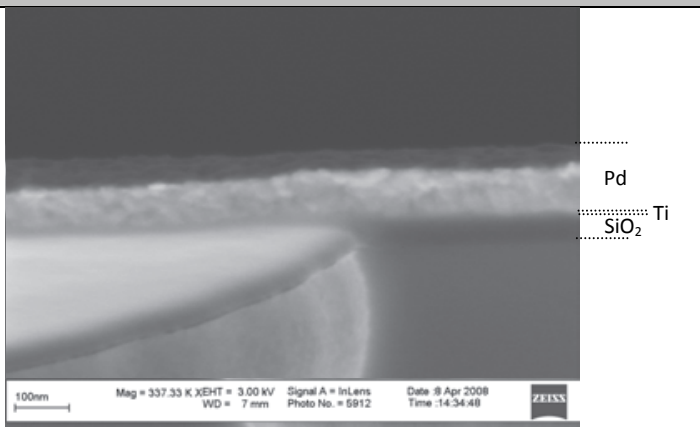 & $\begin{array}{l}\text { The palladium is not } \\
\text { released since the } \\
\text { oxide and titanium } \\
\text { has not been } \\
\text { completely removed. }\end{array}$ \\
\hline 2 & $19 \mathrm{~min}$ & 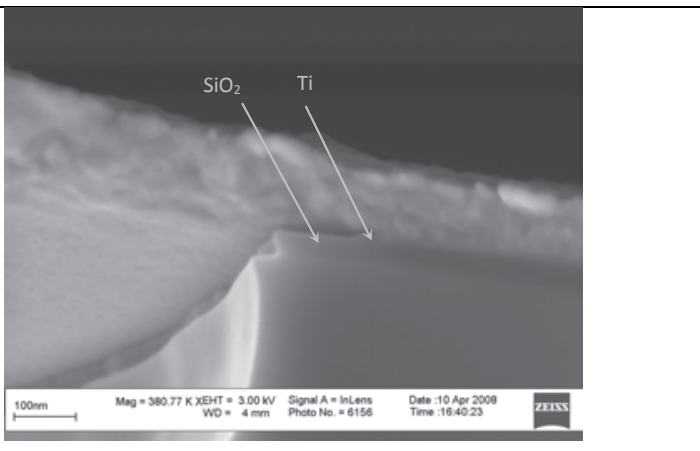 & $\begin{array}{l}\text { Here the palladium is } \\
\text { critically released. } \\
\text { The receding edges } \\
\text { of silicon dioxide and } \\
\text { titanium are } \\
\text { observed. }\end{array}$ \\
\hline 3 & $22 \mathrm{~min}$ & 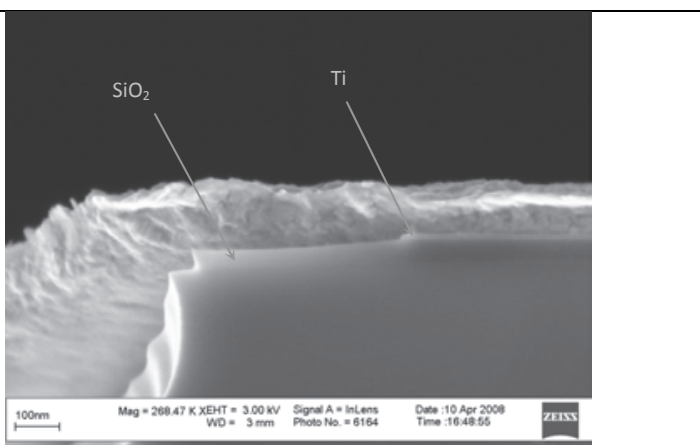 & $\begin{array}{l}\text { Here also the } \\
\text { palladium membrane } \\
\text { is released, but the } \\
\text { titanium adhesion } \\
\text { layer is over-etched. } \\
\text { This could peel off } \\
\text { the palladium } \\
\text { membrane. }\end{array}$ \\
\hline
\end{tabular}




\subsection{Palladium electrode membrane characterization}

After the morphological characterizations, the lateral electronic conductivity of the $1 \mu \mathrm{m}$ thick palladium layer is measured using a 4-probe measurement device. The sample showed a resistance of $0.11 \Omega$ from centre to edge ( $\sim 9 \mathrm{~mm}$ distance), which could become significant when the membrane is used as a fuel cell electrode. Although a thin membrane electrode would have high hydrogen diffusion through it, this could be an inefficient electrode for the fuel cell (if the current is collected laterally at the edge of the membrane). To avoid this problem the supporting GDS could be fabricated with highly doped silicon connected to the bottom of the palladium layer, which could thus enable normal current collection from the electrode. This possibility is not investigated in this current work.

Next, the palladium membranes are studied with respect to their gas permeation behaviour. Apart from detecting defects (e.g. pinholes) in the membrane, one of the main objectives of the permeation tests is to quantify the hydrogen flux through the membrane at different operating pressures and temperatures. Moreover, under these operating conditions, the grain deformation and embrittlement of the palladium membrane due to $\alpha-\beta$ phase transition is investigated.

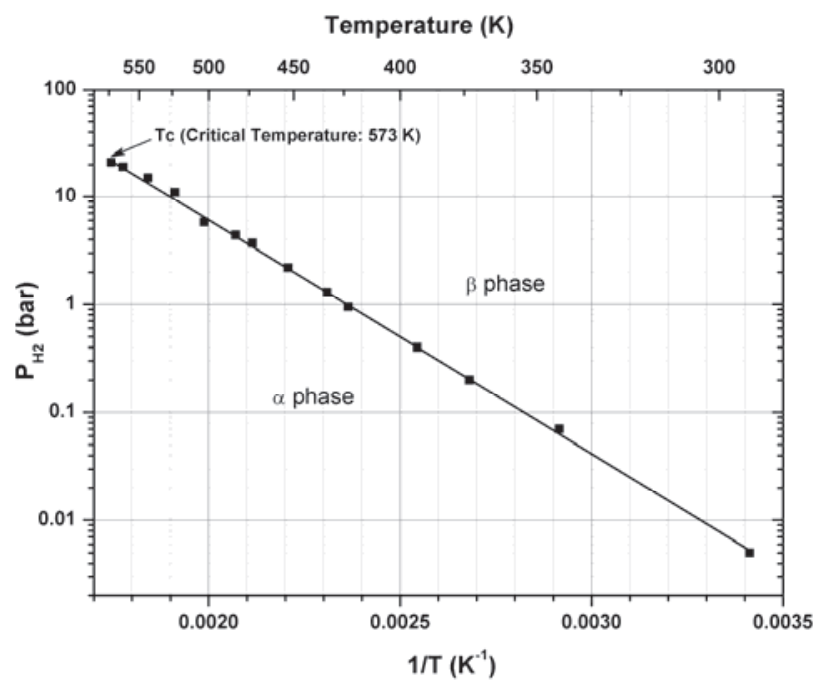

Figure 3.10: Palladium-Hydrogen phase, based on pressure and temperature showing $\alpha$ to $\beta$ transition $[7,28]$ 
As explained before, usually palladium membranes are operated at higher temperatures, i.e. $573 \mathrm{~K}-773 \mathrm{~K}$ [16-22]. Such a temperature of operation has two main advantages: at higher the temperatures the hydrogen flux is higher and secondly the durability of palladium is no longer an issue due to the lack of hydrogen embrittlement. At lower temperatures $(<573 \mathrm{~K})$ pure palladium in the presence of hydrogen is known to have the problem of grain deformation and embrittlement due to phase transition of the palladium-hydrides formed. This transition depends on the concentration of hydrogen in the palladium lattice at a given temperature [7, 28, 29]. Figure 3.10 depicts the pressure-temperature phase diagram indicating the palladium phase transition from hydrogen-poor $\alpha$ phase to hydrogen-rich $\beta$ phase and vice versa. Above the critical temperature $T_{c}(\sim 573 \mathrm{~K})$, the phases of palladium hydride cannot be differentiated. A thorough knowledge of the palladium-hydrogen system is essential to fabricate and use the palladium membranes as dense electrodes in the $\mu$ SAFC. Thus, the aspect of phase transition is kept in mind while planning the gas permeation experiments.

Since the palladium samples are sputtered at room temperature, their grain size could change during permeation tests at elevated temperatures. Such a crystal modification can influence the hydrogen flux through them during the experiments and that would lead us to incorrect conclusions. To avoid this, the samples are preannealed in nitrogen atmosphere at $523 \mathrm{~K}$ for 20 hours.

\subsubsection{Gas permeation set-up}

The gas permeation set-up used for the palladium membrane characterization is shown in figure 3.11 and 3.12. The palladium characterization is performed in a cocurrent flow configuration by flowing hydrogen gas (also mixtures) on the feed side and a sweep on the permeate side. On the feed side, two mass flow controllers are used to make gas mixtures, while on the permeate side only one mass flow controller is used for the sweep gas flow. The gas pressure is regulated by changing either the mass flow rate and/or by adjusting the needle valve. The total mass flow rate applied on each side of the membrane for all experiments was $20 \mathrm{sccm}$ or $\mathrm{ml} / \mathrm{min}$ (STP). There are pressure sensors placed on permeate side and feed side to register the respective gas pressures above atmospheric pressure. Since the permeate side is always maintained at 
atmospheric pressure during our experiments, the readout of the pressure sensor here is not used. The set-up consists of an oven to heat the membrane sample. The oven is coupled with a temperature controller and two thermocouples are placed inside the oven. One thermocouple records the temperature inside the oven and the other is placed inside the sample holder. During the experiment, the membrane temperature is assumed to be the same as that of the sample holder. The permeated hydrogen during the experiments is swept by flowing nitrogen on the permeate side and taken to a micro gas chromatograph (GC). Since the carrier gas of the GC is selected to be the same as the membrane sweep gas, it will not be detected by the GC. The GC measures the detected gas quantity as volume percentage, which is then later recalculated to permeated flux (see appendix B). For detecting leak through the membrane during permeation, hydrogen is mixed with helium. All gases used in the experiments are of detector 5.0 quality.

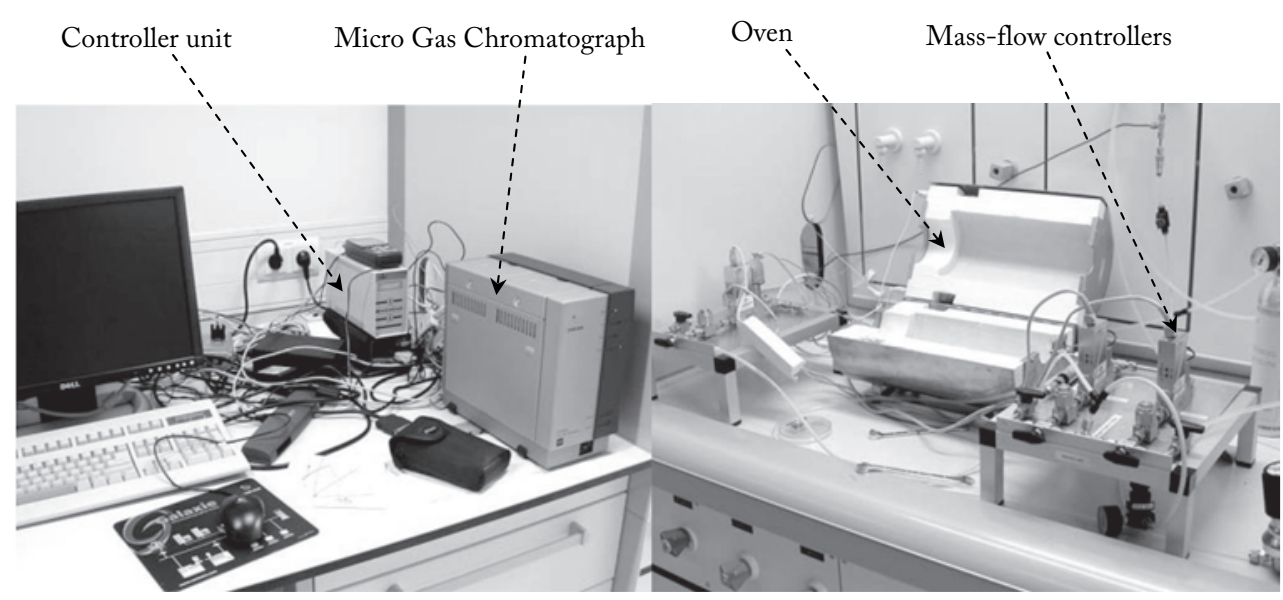

Figure 3.11: The gas permeation set-up used for palladium membrane characterization

Figure 3.12 shows a detailed schematic diagram of the permeation set-up, whose main equipment specifications are given below.

1) Mass flow controller

Type: $\quad$ EL-Flow ${ }^{\circledR}$ Select, F-201CV, Bronkhorst High-Tec B.V.

Range: $\quad 0.16-20 \mathrm{sccm}$ or $\mathrm{mln} / \mathrm{min}$ (norm milliliter per minute)

Error margin: $\pm 0.5 \%$ on readout and $\pm 0.1 \%$ on full scale 
2) Pressure sensor

Range: $\quad 0$ - 5 bar (above atm)

Type: $\quad$ Sensortech B.V.

Error margin: $\pm 0.5 \%$ full scale

3) Temperature controller: CAL 9400 controller (Error margin: $\pm 0.25 \%$ or $\pm 1^{\circ} \mathrm{C}$ )

4) Temperature sensor: Thermocouple type $K$

Range: $\quad-200^{\circ} \mathrm{C}$ to $1200^{\circ} \mathrm{C}$;

Error margin: $\pm 1.5^{\circ} \mathrm{C}$ between $-40{ }^{\circ} \mathrm{C}$ and $375^{\circ} \mathrm{C}$

5) Gas Chromatograph (GC)

Type: $\quad$ VARIAN CP-4900 (Micro GC)

Detector: Thermal conductivity detector (TCD); GC column: $5 \AA ̊$ molecular sieve

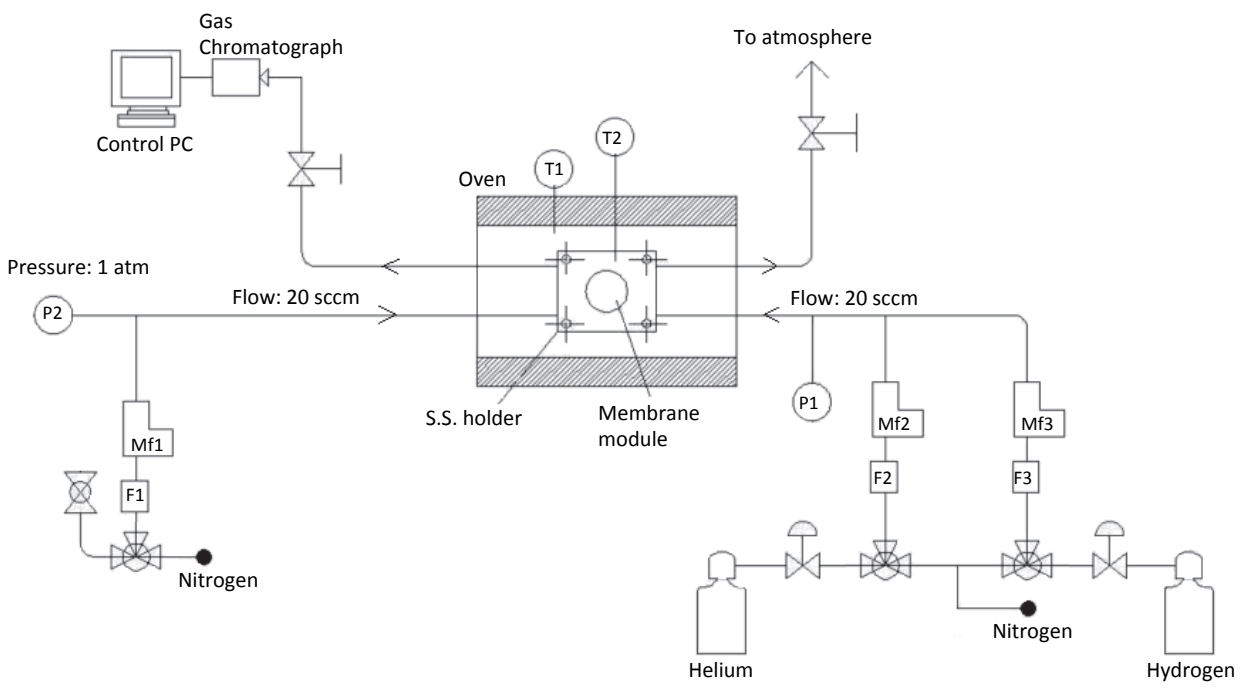

\begin{tabular}{|c|c|c|c|}
\hline Min & $\begin{array}{l}\text { Mass Flow } \\
\text { Controller }\end{array}$ & F1 F2 & Air Trap Filter \\
\hline & Gas Cylinder & (P1) P2) & Pressure Sensors \\
\hline$\bowtie$ & Needle Valve & 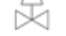 & Pressure Regulator \\
\hline 18 & 3-Way Valve & (11) & Oven Temperature \\
\hline$-\infty$ & 2-Way Valve & (12) & $\begin{array}{l}\text { Membrane Holder } \\
\text { Temperature }\end{array}$ \\
\hline
\end{tabular}

Figure 3.12: A schematic diagram of the gas permeation set-up 
All the aforementioned sensors and controllers are coupled to the PC via communication channels and controlled via a customized LabView software program.

The palladium membrane sample is placed in a custom-made stainless steel (S.S.) holder (see figure 3.13). As seen from the figure both the upper and lower parts of the S.S. holder have two drilled holes of $\varnothing 3 \mathrm{~mm}$ for the inlet and the outlet of the gasses.
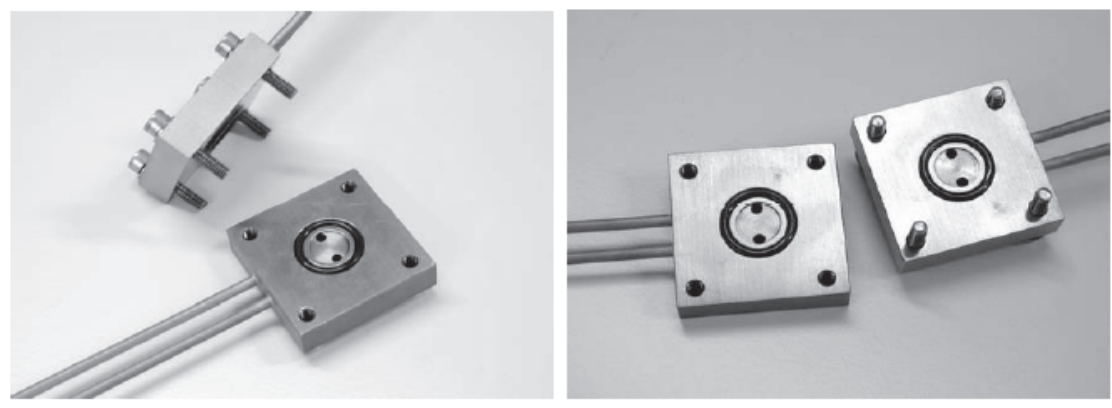

(a)
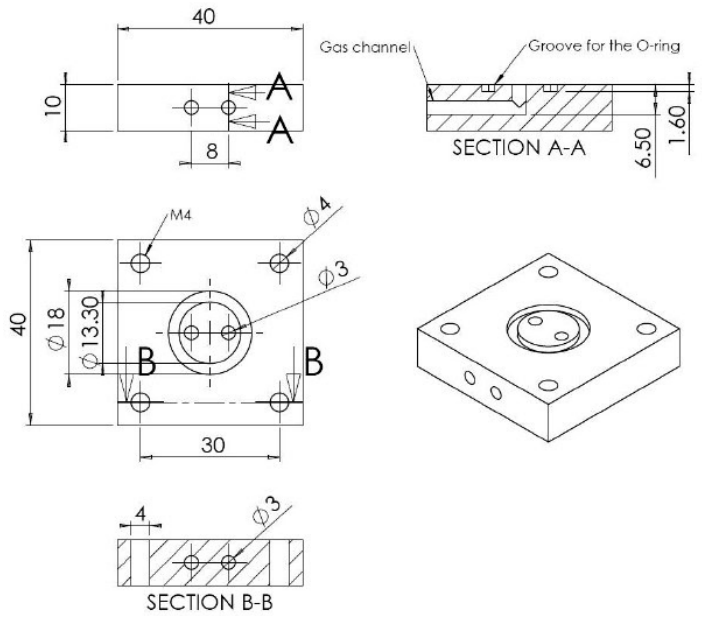

All dimensions in $\mathrm{mm}$

(b)

Figure 3.13: a) Picture of the S.S. holder used for clamping the membrane b) Schematic diagram of the holder 
Around these holes, a groove $(2.35 \mathrm{~mm}$ wide and $1.6 \mathrm{~mm}$ deep $)$ is made in order to fit the sealing O-rings. Depending on the temperature of operation, two different types of $\mathrm{O}$-rings are used for sealing the membrane sample within the holder. Viton ${ }^{\circledR}$ O-rings are used for operational temperatures up to $190{ }^{\circ} \mathrm{C}$ and for higher temperatures (upto $\sim 310^{\circ} \mathrm{C}$ ) $\mathrm{Kalrez}^{\circledR} \mathrm{O}$-rings are employed.

Figure 3.14 shows a cross-sectional illustration of the membrane sample assembled inside the holder, flowing gas in a co-current flow configuration. The microsieve GDS side of the membrane is chosen as the permeate side, since this would be the situation in case of the final membrane-electrode-assembly (MEA) of the $\mu$ SAFC having two such supported palladium electrode membranes sandwiching the electrolyte (as shown in the chapter 2, figure 2.2).

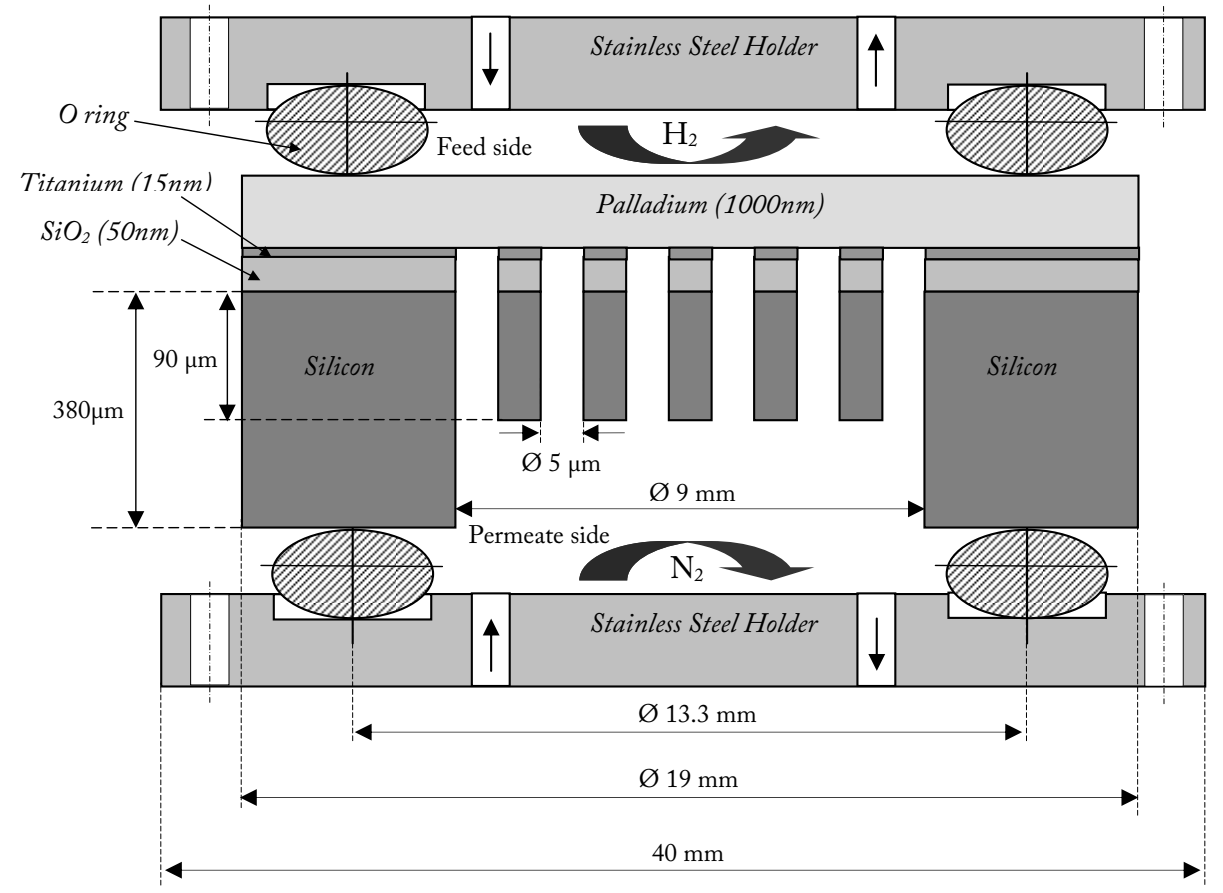

Figure 3.14: The cross sectional illustration of the membrane sample assembled inside the holder. The diagram is not as per proportional scale. 


\section{Calibrating the gas chromatograph}

Before starting to use the set-up the gas chromatograph is calibrated. A calibration gas with a well defined composition (see table 3.3) is used for this purpose. The calibration gas is flown at $20 \mathrm{sccm}$ into the GC from which the GC detects the individual gases and records the peaks. In a GC, the position of the peak in the chromatogram indicates the type of gas and the area under the peak gives the concentration of that particular gas in the total gas mixture supplied to the GC. Calibration of the GC is done to relate the peak-position to the respective gases and the peak-area to their corresponding concentration in volume \%. Since nitrogen is used as the GC carrier gas it cannot be calibrated. All other gases are calibrated to the exact volume percentage by performing multiple GC recordings using the calibration gas.

Table 3.3: Composition of the calibration gas used

\begin{tabular}{|c|l|}
\hline \% by Volume & Name of the gas \\
\hline $80 \%$ & Nitrogen \\
\hline $8 \%$ & Argon \\
\hline $5 \%$ & Helium \\
\hline $5 \%$ & Carbon dioxide \\
\hline $1 \%$ & Hydrogen \\
\hline $1 \%$ & Oxygen \\
\hline
\end{tabular}

Hydrogen, which is the main gas for our permeation tests, is calibrated more vigorously by supplying a customized composition of hydrogen via dilution with nitrogen. The following procedure was followed for hydrogen calibration. One mass flow controller is set to $20 \mathrm{sccm}$ nitrogen and combined with hydrogen at various quantities (up to $20 \mathrm{sccm}$ ) from another mass flow controller. This simulates our actual permeation experiment scenario wherein hydrogen permeating from the feed side of the membrane to the permeate side is swept away to the GC by a constant $20 \mathrm{sccm}$ nitrogen sweep gas flow. Figure 3.15 shows the GC calibration curve for hydrogen relating the area under the chromatogram peak to the volume percentage of hydrogen in the sweep gas. Each of the points on the calibration curve is an average of three consecutive measurements. The $\mathrm{H}_{2}$ calibration line ranging from $1-50 \%$ is linear 
with $\mathrm{R}^{2}=0.9994$ (regression coefficient) and linear equation $\mathrm{y}=247.0647 \mathrm{x}$, where $\mathrm{y}$ and $\mathrm{x}$ are peak area and volume $\%$, respectively. It is noted that such a calibration could have an error of up to $\pm 1.2 \%$ based on the error in the mass flow controllers.

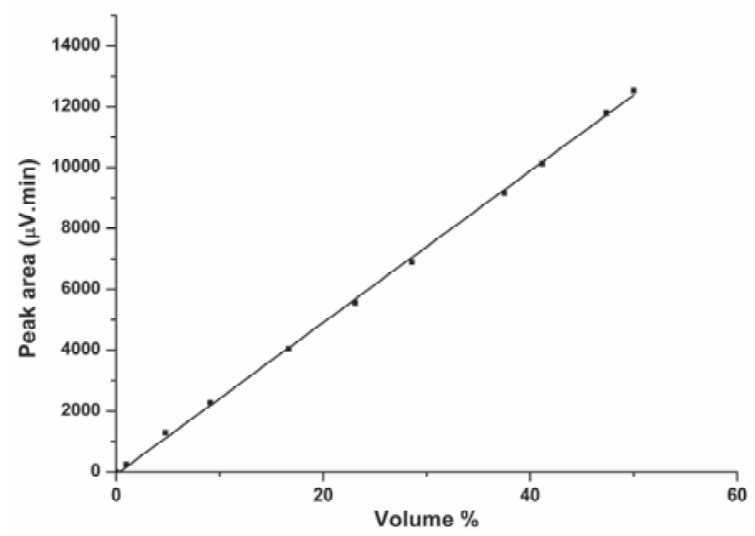

Figure 3.15: Hydrogen calibration curve for the microGC

\section{$\underline{\text { Set-up flushing time test }}$}

After checking the leak tightness of the permeation set-up, the flushing and stabilization times for gas mixtures is verified. A flushing time test is intended to find out how long it takes for a new gas mixture to give a stable GC reading. After the setup is completely flushed with $\mathrm{N}_{2}$ (i.e. no peak detected on the chromatogram), the gas is switched to the calibration gas. About $95 \%$ of the calibration gas concentration is detected by the GC in 6 minutes. After a total of 10 minutes the values stay stable. The gas is switched back to $\mathrm{N}_{2}$ to check the time needed to flush the set-up. Almost all gases are flushed off in 9 minutes. Considering this result, before performing any GC measurement, a flow stabilization time of 15 minutes is chosen for any flow variations done during the experiments. This waiting time ensures that the set-up is flushed completely with the new flow configuration. Of course, the assumption here is that the gas concentration has been uniformly distributed inside the set-up. 


\subsubsection{Experiments and Discussion}

From the first batch of fabricated samples, six of them could be successfully characterised, namely samples S3, S5, S7, S9, S10 and S11. The other samples were damaged either during fabrication or during loading/unloading in the sample holder. Additionally, a second batch was fabricated from which samples S14 and S15 were used for the permeation experiments.

As a standard procedure, after loading each of the samples, leak tests are performed using helium and argon to confirm whether the sample is defect free. Argon leak test is done only when a helium leak through the membrane is detected by the GC. During leak tests, either pure helium or argon is flushed at $20 \mathrm{sccm}$ under a feed pressure of 2.2 bar and a permeate side pressure of 1 bar of $\mathrm{N}_{2}$ sweep gas.

Described in the following section are the permeation experiments with hydrogen. The experiments are divided into 5 different sets. The experimental set 1 aims at understanding the dependence of hydrogen flux through the membrane on the hydrogen feed pressure. Experimental set 2 consists of permeation tests done by continuously varying the operational temperature. Apart from giving us an idea about the temperature dependence of the hydrogen flux, this set also paints a qualitative picture about the $\alpha-\beta$ palladium hydride phase transition happening in the polycrystalline membrane. Studied using experimental set 3 is the influence of external mass transfer on the overall permeation process. Set 4 consists of a continuously run experiment aiming to investigate the operational stability and durability of the palladium membrane. Finally, to compare our results with the theoretical model and to determine the temperature dependent rate limiting steps in the permeation process through our membrane, an experimental set 5 is performed.

\subsubsection{Experiment set 1: hydrogen permeability dependence on pressure and temperature}

The first experiment set is performed (using sample S3), to measure the hydrogen flux through the membrane by varying hydrogen partial pressures (or concentrations) in the feed gas stream. This experiment is repeated for different temperatures: $373 \mathrm{~K}$, $398 \mathrm{~K}, 423 \mathrm{~K}, 453 \mathrm{~K}$ and $503 \mathrm{~K}$. The objective of the experiment is to understand how 
the permeation through the membrane depends on the partial pressure of hydrogen at the feed side and on the temperature.

The experiments are performed using the following procedure. Since there is a chance of phase transition occurring for palladium at lower temperatures, the experiments are started at a higher temperature. After stabilizing the temperature at $503 \mathrm{~K}$ for $15 \mathrm{mins}$, the concentration of hydrogen on the feed side is gradually increased (see table 3.4) while recording the permeated hydrogen flux using the GC. The dilution of hydrogen is done with helium. The total gas pressure on the feed side is always maintained at 2.2 bar, which is adjusted by regulating the needle valve. Subsequently, the feed gas is completely switched to helium before cooling down. After the operating temperature reaches $453 \mathrm{~K}$, hydrogen is again introduced in the feed stream at various concentrations. After every change in gas composition, a stabilization period of 15 mins is observed before starting GC measurements. Once the permeated flux is recorded, the hydrogen in the feed stream is nullified and the temperature is further reduced. Likewise, the hydrogen fluxes at all the aforelisted temperatures are measured for various hydrogen concentrations on the feed side. The variation in permeated hydrogen flux values for changing hydrogen feed pressure is plotted in figure 3.16 .

Table 3.4: Hydrogen composition variation in the feed gas stream (gas1+gas2) during the experiments performed at several temperatures. The total feed pressure is $2.2 \pm 0.025$ bar.

\begin{tabular}{|c|c|c|c|}
\hline $\mathbf{H}_{2}$ conc. [\%] & $\mathbf{P}_{\mathrm{H} 2 \text {,feed }}[\mathrm{bar}]$ & $\mathbf{H}_{2}$ flow $[\mathrm{sccm}]$ & He flow [sccm] \\
\hline 10 & 0.22 & 2 & 18 \\
\hline 25 & 0.55 & 5 & 15 \\
\hline 50 & 1.10 & 10 & 10 \\
\hline 75 & 1.65 & 15 & 5 \\
\hline 90 & 1.98 & 18 & 2 \\
\hline
\end{tabular}




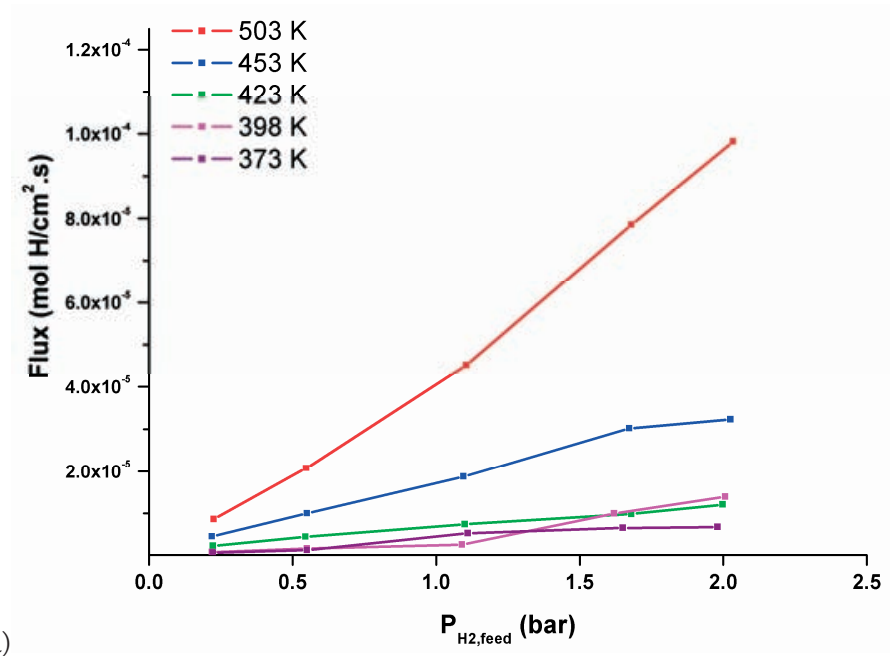

a)

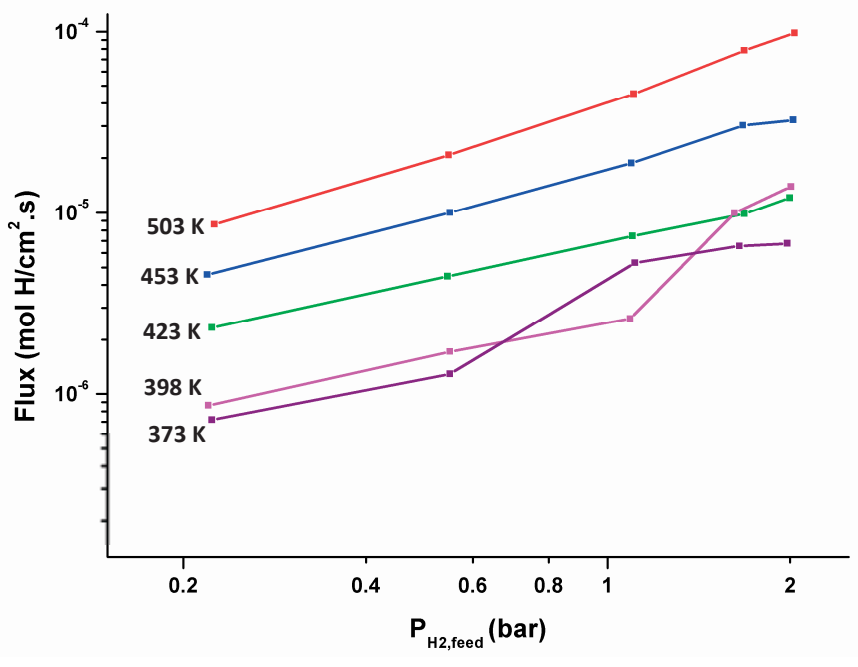

Figure 3.16: Permeation measurements using sample S3 - Flux vs. Hydrogen partial pressure at different temperatures: a) linear scale b) logarithmic scale. The flux measurement has an error $< \pm 2 \%$. The pressure measurement has an error of $\pm 25 \mathrm{mbar}$ and the error in temperature reading is $\pm 2.5 \mathrm{~K}$.

As seen in figure 3.16, the permeated $\mathrm{H}_{2}$ flux at any temperature is always increasing when $\mathrm{H}_{2}$ partial pressure on the feed side is increased. The hydrogen flux line at each temperature shows the same behavior except at $398 \mathrm{~K}$ and $373 \mathrm{~K}$. At 398 $\mathrm{K}$ the permeated hydrogen flux increased suddenly above 1 bar $\mathrm{H}_{2}$ partial pressure. This indicates probably that a $\alpha-\beta$ transition happened. This is because $\beta$ phase has a 
higher $\mathrm{H}_{2}$ permeability due to the larger atom spacing in the metal lattice which causes an increase in its hydrogen solubility and diffusivity [28, 30]. A similar behaviour is shown by the hydrogen flux line at temperature $373 \mathrm{~K}$, but this time at a lower partial pressure (around 0.6 bar). Frieske [29] and Sieverts [31] have described that in palladium, $\alpha-\beta$ transition occurs below $573 \mathrm{~K}$ and is a function of $\mathrm{H}_{2}$ partial pressure and temperature. The lower the temperature, the lower is the hydrogen partial pressure required for the $\alpha-\beta$ transition to occur (see figure 3.10). Although the permeate flux seems to increase after phase transition, the $\beta$ phase growth destructs the membrane itself by creating dislocations and pinholes [32]. The sudden increase in flux observed in our experiments is contributed by the intrinsic properties of the $\beta$ phase and probably also by extra $\mathrm{H}_{2}$ leaking through the pinholes. To confirm the phase transition and to verify the creation of pinholes in the membrane, a helium leak test is performed at the end of the experiments. Helium increased from $0.004 \mathrm{sccm}$ in the permeate stream before the experiments, to $0.056 \mathrm{sccm}$ at the end of the experiments. This confirms that $\alpha-\beta$ transition has occurred, and the related grain deformation has created pinholes in the palladium membrane.

Although an insight on the permeation characteristic of the membrane is obtained from figure 3.16, the information is overlapping with the phase transition of the palladium grains. To understand the influence of phase transition separately, a different kind of experiment is performed.

\subsubsection{Experiment set 2: $\alpha$ - $\beta$ phase transition of palladium}

In this experimental set, the partial pressure of hydrogen in the feed stream is held at a fixed value and the temperature is varied to see its influence on the hydrogen permeate flux. The measurement is repeated at different partial pressures of hydrogen in the feed gas stream: $0.2 \mathrm{bar}, 0.4 \mathrm{bar}, 0.6 \mathrm{bar}$ and 0.8 bar. Compared to experiment set 1 , this set of experiments enables us to monitor the phase transition more closely and to represent the results on an Arrhenius plot. The objective of experimental set 2 is to detect the exact phase transition temperature for every partial pressure of hydrogen used. Since sample S3 has been "destroyed", due to phase transition after the experimental set 1 , a new sample S9 is chosen for this experiment. 
After heating the membrane sample to $523 \mathrm{~K}$ under nitrogen atmosphere, hydrogen is introduced as the feed gas at $10 \%$ concentration. The dilution of hydrogen is done by mixing with helium. The total gas pressure on the feed side is maintained at 2.0 bar. After stabilization for 15 mins, when permeation starts to be recorded by the GC, the sample is cooled with a ramp of $1 \mathrm{~K} / \mathrm{min}$ to a temperature of $348 \mathrm{~K}$. The cooling down process is continuously accompanied by flux measurements being recorded by the GC every 2 mins. After the membrane is cooled down, it is again heated back to $523 \mathrm{~K}$ with a ramp of $1 \mathrm{~K} / \mathrm{min}$ accompanied by $\mathrm{GC}$ measurements. Such a measurement aids us to observe the difference in hydrogen flux through palladium during a cooling and heating cycle caused by the phase transition. If there is no phase transition from $\alpha$ to $\beta$ during the cooling cycle, then the hydrogen flux measured during the heating cycle must be the same as in the cooling cycle. In case of the palladium phase transiting from $\alpha$ to $\beta$ during cooling, the subsequent heating cycle would show a higher hydrogen flux, owing to the higher hydrogen solubility and diffusivity in the $\beta$ phase $[28,30]$ and maybe due to extra hydrogen flux because of leakage. This experiment is done for various hydrogen concentrations incrementing from $10 \%$ up to $40 \%$ (i.e. 0.2 bar to 0.8 bar $\mathrm{H}_{2}$ partial pressure), whose results are plotted in figure 3.17 .

In figure 3.17 , it can be seen that as the palladium membrane is cooled down it undergoes a phase change at specific temperatures depending on the concentration of hydrogen in the feed gas. If we follow the flux measurement curve for $20 \%$ hydrogen (in fig.3.17b) it can be seen that during cooling, the flux after decreasing till $365 \mathrm{~K}$ suddenly rises during phase transition. The sudden increment in the flux happens (as explained before) because of the higher solubility and diffusivity of hydrogen in the $\beta$ phase. Elkina [33] and Li [34] did similar work which show a similar behavior of the cooling down curve during $\alpha-\beta$ transition. Ideally, it could be expected that the flux has an increment offset after the phase transition, but this is not the case and the flux is observed to follow a different downward slope. This can be explained by considering the possible transition of the permeation process from diffusion-limited regime of $\alpha$ phase to a desorption-limited regime of the $\beta$ phase. This could happen due to the sudden decrease in the activation energy for hydrogen diffusion through palladium in the $\beta$ phase. As the membrane is heated back again towards $523 \mathrm{~K}$, it slowly transits 
back from the $\beta$ phase desorption-limited regime to the $\beta$ phase diffusion-limited regime, where its flux rises to a new level. This rise also has a contribution from leak through grain-boundaries (or pinholes) indicated by rise in the helium flux through the membrane.
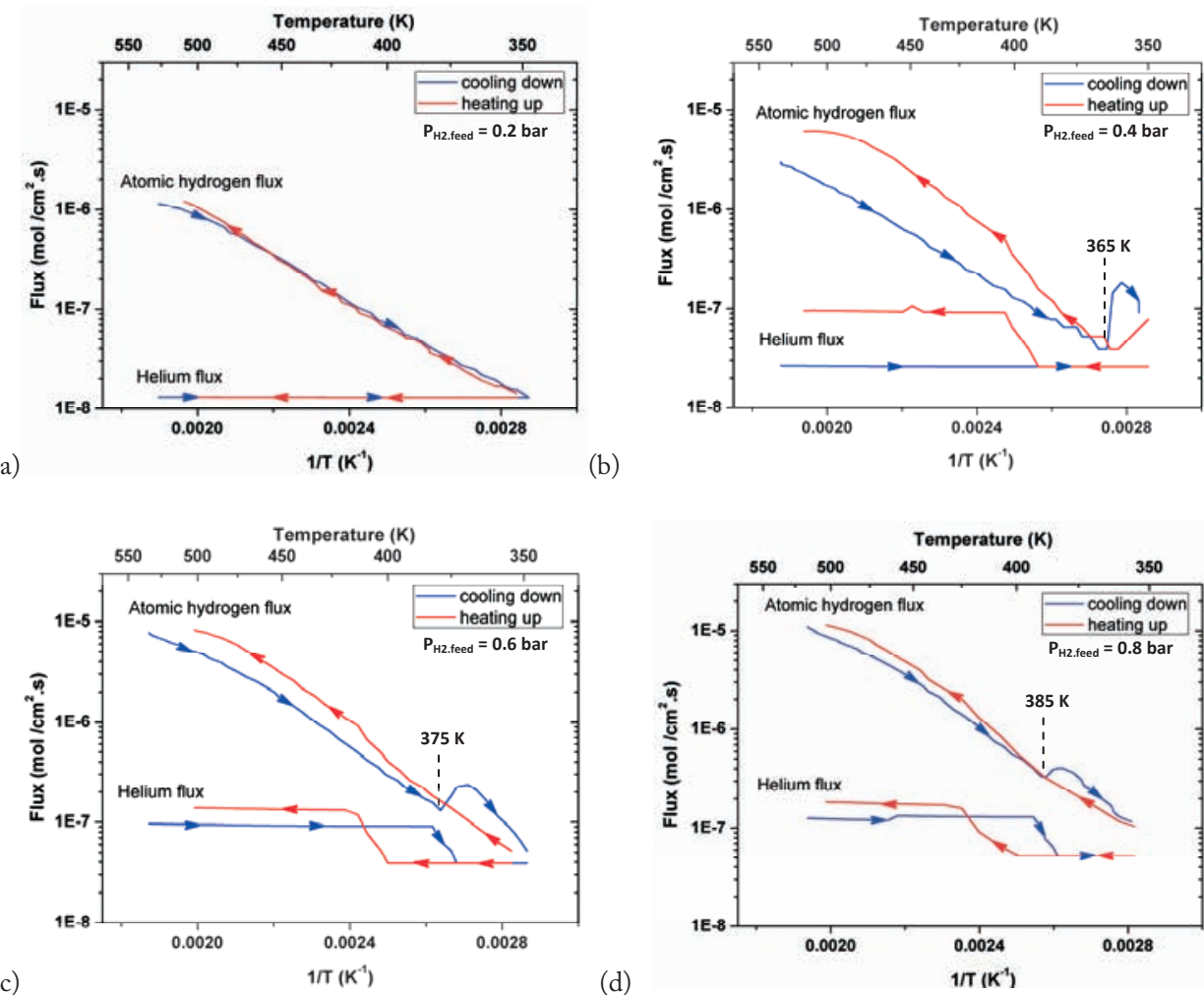

Figure 3.17: Hydrogen flux measured using sample S9 by temperature cycling at partial pressures of a) 0.2 bar $\left(10 \% \mathrm{H}_{2}\right.$ in $\left.\mathrm{He}\right)$ b) $0.4 \operatorname{bar}\left(20 \% \mathrm{H}_{2}\right.$ in $\left.\mathrm{He}\right)$ c) $0.6 \operatorname{bar}\left(30 \% \mathrm{H}_{2}\right.$ in $\left.\mathrm{He}\right)$ and d) 0.8 bar $\left(40 \% \mathrm{H}_{2}\right.$ in $\left.\mathrm{He}\right)$.

While heating up back to $523 \mathrm{~K}$, at the beginning the flux increases and then tends to decrease close to the maximum temperature. This is most likely due to the fact that the gas mass transfer losses start to become significant at high temperature (as will be discussed later in this section), thus introducing a new rate limiting step. Next, when the membrane is cooled with a $30 \%$ concentration of hydrogen in the feed gas stream the phase transition peak is seen at a higher temperature (around $375 \mathrm{~K}$ ) (see fig.3.17c). The membrane follows a similar behaviour pattern also for $40 \%$ hydrogen 
concentration (fig.3.17d). From the graphs, it can be observed that the phase transition temperature $\left(T_{c}\right)$ for every concentration of hydrogen used is having an offset of $\sim 30 \mathrm{~K}$ as compared to palladium-hydrogen system shown in figure 3.10, the reason for this will be explained further on. This offset is the reason why the $10 \%$ hydrogen concentration graph (fig.3.17a) shows no phase transition peak in the tested temperature range $(523 \mathrm{~K}-348 \mathrm{~K})$, although according to figure 3.10 the phase should have transited around $373 \mathrm{~K}$.

One can clearly see in the graphs of figures $3.17 \mathrm{c}$ and $3.17 \mathrm{~d}$ that while cooling down, the leak of helium drops at the phase transition point probably because of sudden expansion of the grains (due to hydrogen filling), which squeezes the pinholes at the boundaries. This causes a higher selectivity for hydrogen. Such lattice expansion based selectivity enhancement has been observed by other researchers studying grain growth effects of polycrystalline palladium membranes [35]. While heating back the palladium sample, the helium leak jumps up again (probably due to grain contractions caused by escaping hydrogen). This could indicate that probably also hydrogen starts to leak though the pinholes/grain boundaries. Figure 3.18 shows a comparison of all the cooling curves in the presence of various concentrations of hydrogen. It can be observed here that all the phase-transition peaks are sequentially positioned in the temperature scale depending on the hydrogen concentration. After phase transition, all the curves seem to follow a common line (almost independent of hydrogen pressure), which could indicate desorption limitation with high surface coverage of adsorbed hydrogen on the permeate side of the membrane. At higher hydrogen feed pressures, the elevated diffusive flux through the membrane causes it to meet this possible desorption limitation sooner. Indicated in figure 3.18 is the position of the postulated desorption-limited flux line, which seems to have a lower activation energy (indicated by a smaller slope) than what is predicted by Ward and Dao model [13]. It is to be noted that the desorption-limited flux line is still hypothetic and more experiments with fresh samples are required to confirm the actual position of the desorptionlimited line. 


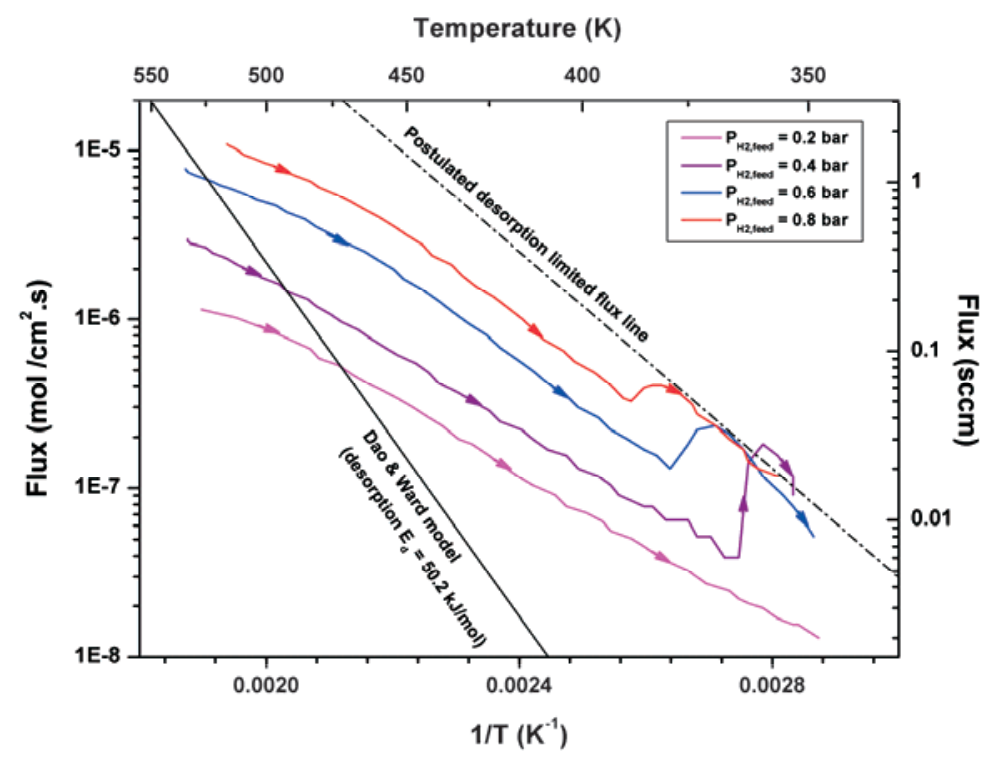

Figure 3.18: Hydrogen permeation through sample S9 - Comparison of graphs shown in fig.3.17. The flux measurement has an error $< \pm 2 \%$. The pressure measurement has an error of \pm 25 mbar and the error in temperature reading is $\pm 2.5 \mathrm{~K}$. For our samples, $1 \mathrm{sccm}=6.5 \times 10^{-6} \mathrm{~mol} \mathrm{H} / \mathrm{cm}^{2} \mathrm{~s}$ (appendix B).

The hydrogen permeation result of sample S9, although qualitatively good, seems to have a lower hydrogen flux as compared to sample S3. The reason for this could be probably that the palladium is not yet properly released after the oxide and titanium etching steps.

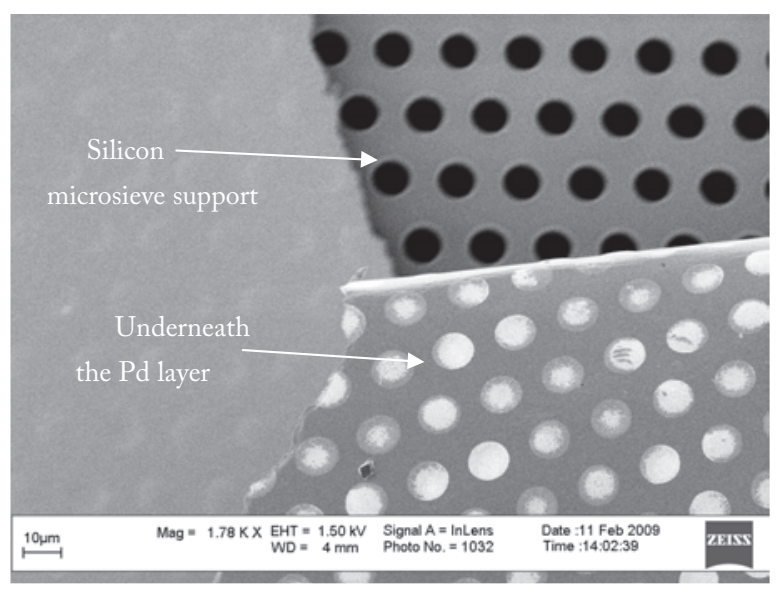

(a) 


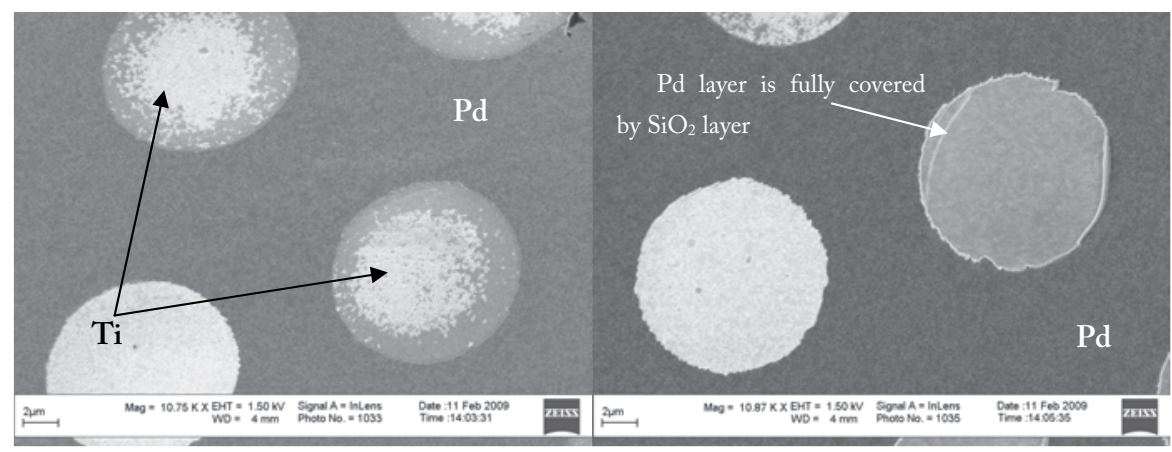

(b)

(c)

Figure 3.19: HRSEM measurement (from top) (a) Pd layer peeled off purposely. (b) \& (c) are zoom in of (a)

This is verified by high-resolution SEM photographs (taken from a sample of the same batch) shown in figure 3.19, where indeed a very thin layer of silicon dioxide can be seen, blocking the palladium over the micropore. After re-etching the sample in 1 $\% \mathrm{HF}$ for 4 mins, the hydrogen permeation is checked again. This time the permeation values increased considerably, although not exactly to the same level as that of sample S3. Etching longer in 1\% HF may help, but this could be critical since an over-etch of titanium could lead to peeling off of the palladium membranes from the supporting microsieve due to low adhesion.

In figure 3.20, the temperatures at which the $\mathrm{H}_{2}$ fluxes suddenly increased while cooling down (i.e. $\alpha-\beta$ phase transiton temperatures) are plotted against the respective $\mathrm{H}_{2}$ partial pressures and compared with the $\mathrm{Pd}-\mathrm{H}$ phase diagram (shown in figure 3.10) as well as to other literature data $[33,34]$. The experimental $\alpha-\beta$ transiton temperatures almost fit to the data depicted in the $\mathrm{Pd}-\mathrm{H}$ phase diagram, but for a $\sim 30$ $\mathrm{K}$ shift in the phase transition point for our membrane. Elkina and Meldon [33] reported that their $\alpha-\beta$ transiton temperatures for $25 \mu \mathrm{m}$ thick foil with different values for $\mathrm{P}_{1}$ and $\mathrm{P}_{2}=1 \mathrm{~atm}$ agreed with the $\mathrm{Pd}-\mathrm{H}$ phase diagram, whereas $\mathrm{Li}$ et. al. [34] found that with $\mathrm{P}_{\text {feed(H2) }}=2$ bar and 3 bar, the $\alpha-\beta$ transiton temperature for a $2 \mu \mathrm{m}$ thick Pd membrane - without applying sweep gas on the permeate side - began at 417 $\mathrm{K}$ and $443 \mathrm{~K}$ respectively, which is $20 \mathrm{~K}$ lower than in $\mathrm{Pd}-\mathrm{H}$ phase diagram. 


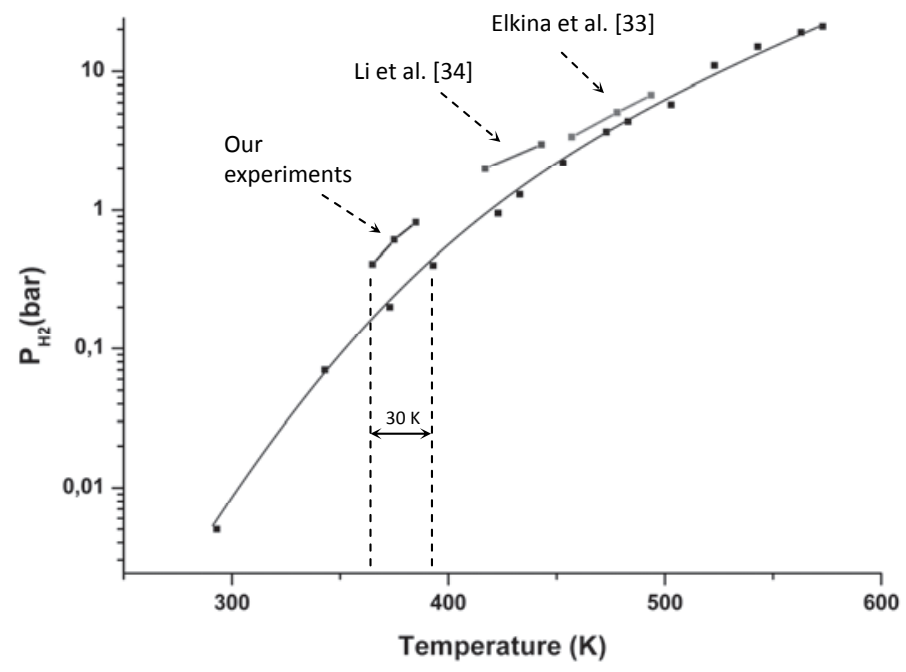

Figure 3.20: $\mathrm{Pd}-\mathrm{H}$ phase diagram (from figure 3.10) compared with $\alpha-\beta$ transition temperatures at various $\mathrm{H}_{2}$ partial pressures used in our experimental and literature

To check whether this $30 \mathrm{~K}$ temperature difference is caused due to the cooling ramp rate $(1 \mathrm{~K} / \mathrm{min})$ being too high for the phase transition to happen, an experiment using $20 \% \mathrm{H}_{2}$ is repeated with two different cooling ramps for sample $\mathrm{S} 9$, the results of which are plotted in figure 3.21. As seen from the figure, also for different cooling ramp rates the occurrence of the phase transition is observed at about $363 \mathrm{~K}$.

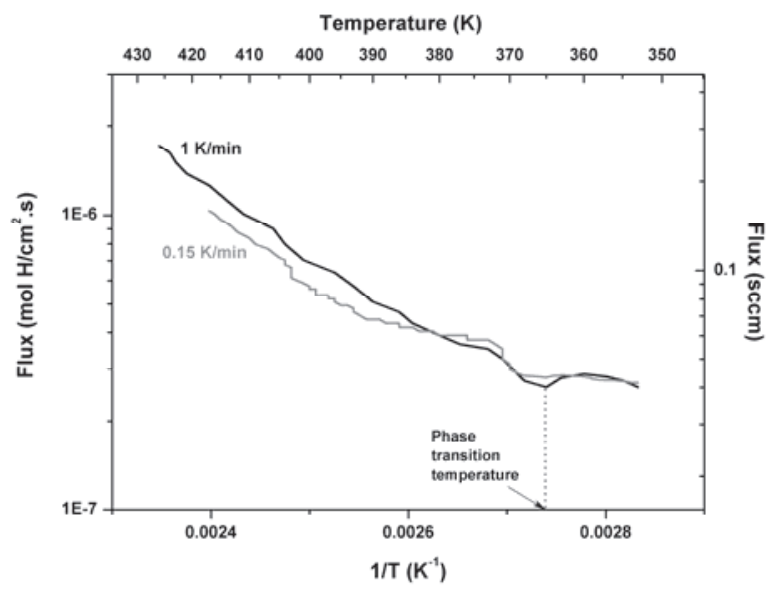

Figure 3.21: Comparison between hydrogen permeation through sample S9 at two different cooling ramp rates. 
$\mathrm{Li}$ et. al. [34] in their paper reported that the deviation of $\alpha-\beta$ transiton temperature of $\sim 20 \mathrm{~K}$ in their experiments may be caused by the nanoscale size of $\mathrm{Pd}$ crystals: $\alpha-\beta$ transiton may have been suppressed due to the nanometer crystal size of Pd membrane [36, 37]. It has been reported that nanocrystalline materials have unique structures, for example, a high density of dislocation inside the grains and at the grain boundaries, many grain/twin boundaries and a single twinned f.c.c. configuration [38, 39], which is probably the reason for the improved resistance against $\alpha-\beta \mathrm{Pd}-\mathrm{H}$ phase transition. This might also be the reason why our $\alpha-$ $\beta$ transiton temperatures deviate around $30 \mathrm{~K}$ from $\mathrm{Pd}-\mathrm{H}$ phase diagram. High resolution SEM picture of our annealed palladium membrane before the permeation experiment (shown in figure 3.22) gives a size of $\mathrm{Pd}$ crystals in the range of $100 \pm 25$ $\mathrm{nm}$.

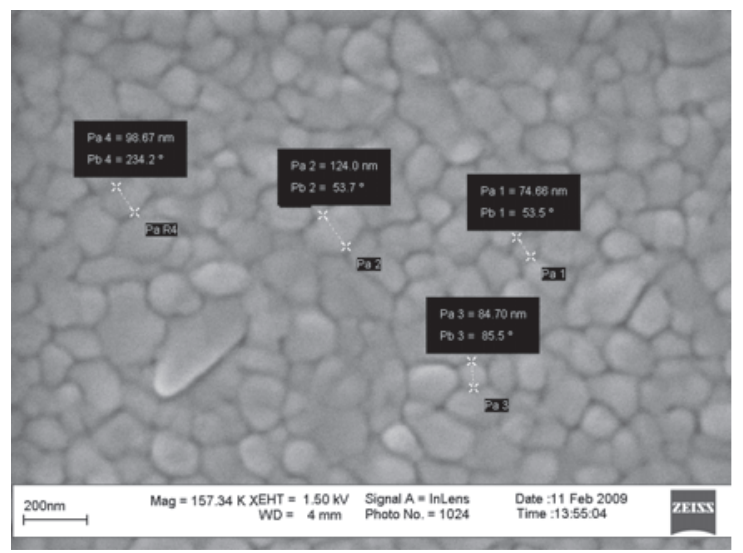

Figure 3.22: HRSEM measurement on top of annealed palladium membrane before permeation experiment

Another reason why the $\alpha-\beta$ transition temperature in our case is lower than the expected value could be that the palladium membrane has a hydrogen concentration gradient across its thickness, due to a linear decrease in the hydrogen concentration from the feed side to the permeate side (if the hydrogen permeation process is diffusion-limited). This concentration gradient will also induce a gradient in the amount of palladium hydride formed. Thus, the $\alpha-\beta$ phase transition would also happen with a gradient depending on the hydrogen concentration at that part of the membrane. Assuming that the gas mass transfer losses on both sides of the membrane 
are negligible, and if the hydrogen concentration on the palladium surface is assumed to be $20 \%$ and $0 \%$ on the feed and permeate sides respectively, the resulting mean concentration of hydrogen inside the palladium membrane would be $10 \%$. With such a lowered concentration, the phase transition temperature almost matches to the value shown in figure 3.10 .

\subsubsection{Experiment set 3: Influence of external mass transfer}

With external mass transfer the transfer or transportation of hydrogen molecules from the gas stream to the palladium membrane surface (or vice versa) is implied. Ward and Dao in their paper described the influence of external mass transfer to hydrogen flux permeation behavior [13]. According to them, the thinner the membrane (having thickness in few micrometers or less) the larger the influence of external mass transfer on the overall permeation process will be. For our membrane thickness of $1 \mu \mathrm{m}$, it is necessary to understand the effects of external mass transfer. The objective of this experiment set is to study the influence of gas mass transfer on the feed side of the membrane in shifting the permeation process from a diffusionlimited behavior at high temperatures. The $\mathrm{H}_{2}$ partial pressure in the feed gas stream is increased by increasing the hydrogen concentration in the gas mixture (hydrogen+helium), while the feed pressure is held constant. The hydrogen flux is measured at temperatures of $503 \mathrm{~K}, 473 \mathrm{~K}$, and $443 \mathrm{~K}$, the results of which are plotted in figure 3.23. The sample used for this experiment is a new sample (S5). When the permeation process is diffusion-limited, the flux should show a square-root dependence on hydrogen partial pressure, thus obeying the Sieverts' law.

Table 3.5: Experimental table: varying $\mathrm{H}_{2}$ concentration at constant feed pressure

\begin{tabular}{|c|c|c|c|}
\hline $\mathbf{H}_{2}$ conc. (\%) & He conc. (\%) & $\mathbf{P}_{\text {feed }}($ bar) & $\mathbf{P}_{\mathrm{H} 2 \text {,feed }}$ (bar) \\
\hline 20 & 80 & 1.5 & 0.3 \\
\hline 40 & 60 & 1.5 & 0.6 \\
\hline 60 & 40 & 1.5 & 0.9 \\
\hline 80 & 20 & 1.5 & 1.2 \\
\hline 100 & 0 & 1.5 & 1.5 \\
\hline
\end{tabular}




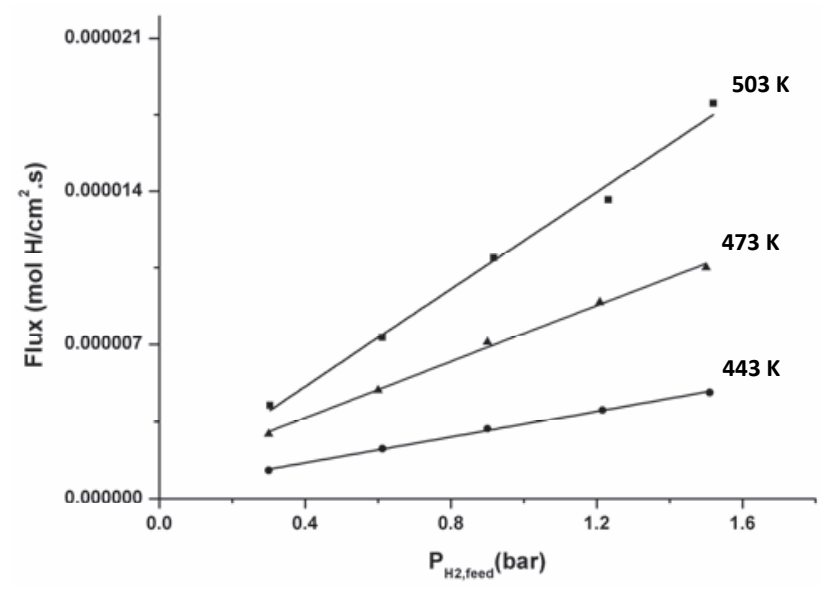

a)

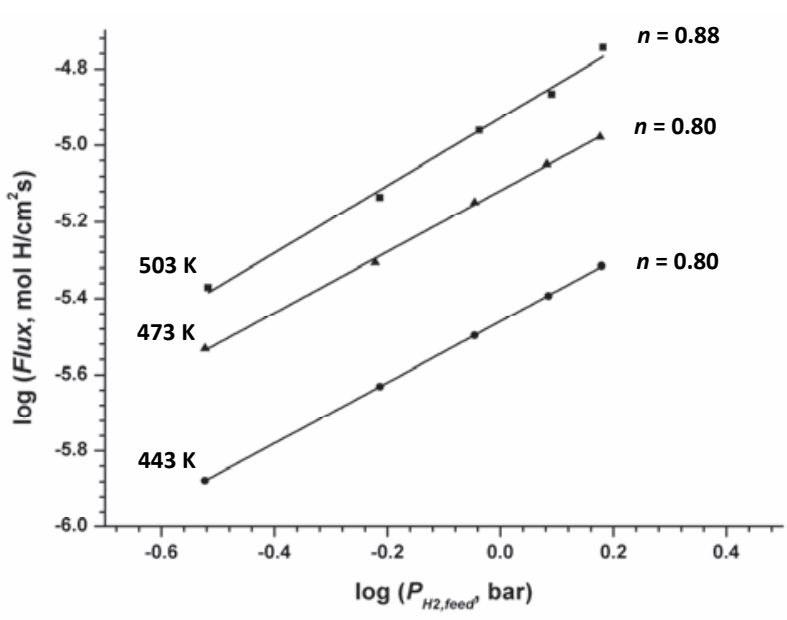

Figure 3.23: The pressure dependence of hydrogen flux through sample $\mathrm{S} 5$, measured at different temperatures: a) Flux vs. $\mathrm{P}_{\mathrm{H} 2 \text {,feed }}$ b) $\log ($ Flux $)$ vs. $\log \left(\mathrm{P}_{\mathrm{H} 2 \text {,feed }}\right)$. The pressure exponent $n$-values (i.e. slope of the fit lines) are also indicated. The flux measurement has an error $< \pm 2 \%$. The pressure measurement has an error of $\pm 25 \mathrm{mbar}$ and the error in temperature reading is $\pm 2.5 \mathrm{~K}$.

As expected from the theory, the measured flux (shown in figure 3.23) increases with increasing hydrogen feed pressure and temperature. From figure $3.23 \mathrm{~b}$ is can be seen that at $443 \mathrm{~K}$ and $473 \mathrm{~K}$, the hydrogen flux seems to be proportional to $\mathrm{P}^{(n=0.80)}$. If the process is purely diffusion-limited, the pressure exponent $n$ should have been 0.5 , indicating dependence on atomic hydrogen diffusion. A $n$-value in between 0.5 and 1 
indicates a combined influence of two or more limitations. Mass transfer limitation creeps in at higher temperatures, where the flux through the membrane is high, making it harder for the external mass transfer on the feed side to keep up with. Such a depletion of hydrogen drives the process to a mass transfer-limited regime, which can be seen from the rise in the $n$-value to 0.88 at $503 \mathrm{~K}$. The $n$-value of 0.80 at lower temperatures could probably be a combined effect of diffusion and desorption limitations.

Like the feed side of the membrane, mass transfer problems on the permeate side can also affect the overall permeation process. For the theoretical model shown in section 3.2, the partial pressure of hydrogen on the permeate side was taken to be almost zero (assuming a vacuum). For our experiments we use a sweep gas on the permeate side and, moreover, the supporting GDS will cause the hydrogen partial pressure on the desorbing palladium surface to be higher than in the sweep gas stream (figure 3.24).

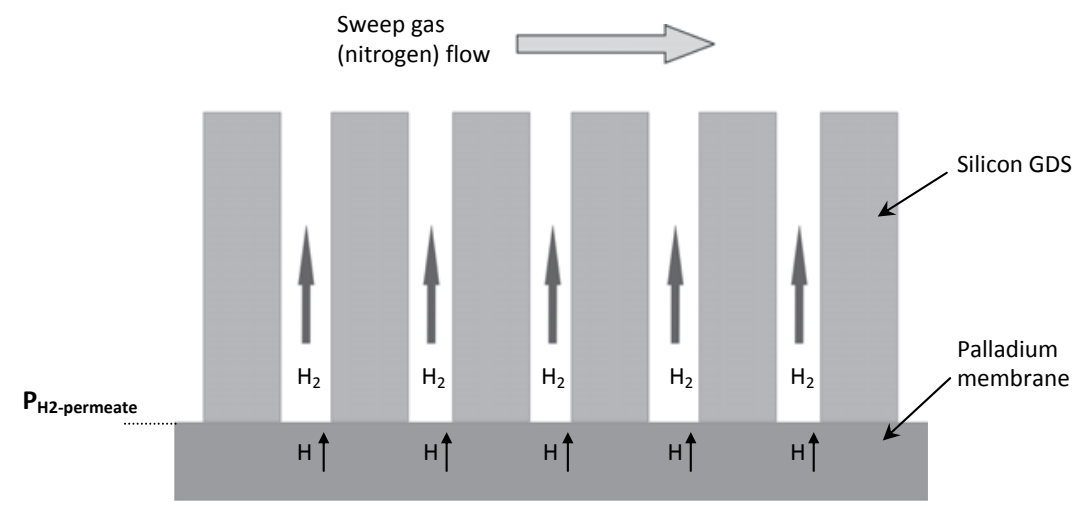

Figure 3.24: Cross-sectional illustration of the permeate side of the GDS supported palladium membrane

Assuming that the sweep gas flow effectively removes hydrogen molecules, still a

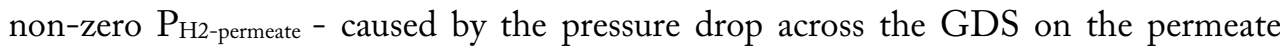
side - can reduce the effective driving force for hydrogen diffusion through the membrane. So, to determine the influence of the GDS support, the pressure drop across it is calculated using the flow-pressure drop relation (2.2) shown in chapter 2. Even for the highest recorded permeation rate of $16 \mathrm{sccm}$ (at $493 \mathrm{~K}$ and $5.5 \mathrm{bar}$ 
hydrogen feed pressure), the pressure drop across the GDS is $<10 \mathrm{~Pa}$, which is negligibly low. This means that the influence of the GDS support on the overall permeation process through the membrane is not significant.

\subsubsection{Experiment set 4: Stability and durability test}

In the case of membranes used in an application, their stability and durability become important issues. By performing a continuous permeation experiment, we can verify at least to a certain extend how stable the membranes behave as function of operational time. The experiment is carried out at a $\mathrm{H}_{2}$ partial pressure of 0.2 bar (10 $\% \mathrm{H}_{2}$ in the feed stream) so that palladium hydride phase transition is avoided.

An operation temperature around $415 \mathrm{~K}$ is chosen for the experiment, such that the palladium membrane can later be used as a hydrogen diffusive electrode (HDE) in the proposed solid acid fuel cell, which works around this temperature. A new sample (S7) is used for this experiment. The temperature is continuously recorded to see the response of hydrogen flux to slight temperature fluctuations. The hydrogen flux was stable around $2.6 \times 10^{-7} \mathrm{~mol} \mathrm{H} / \mathrm{cm}^{2} . \mathrm{s}$ for 24 hours as shown in Figure 3.25a. The temperature slightly fluctuated between $412 \mathrm{~K}$ and $415 \mathrm{~K}$. Figure $3.25 \mathrm{~b}$ (which is a zoomed view of figure $3.25 \mathrm{a}$ ) shows that the hydrogen flux responds quite fast to any temperature change.

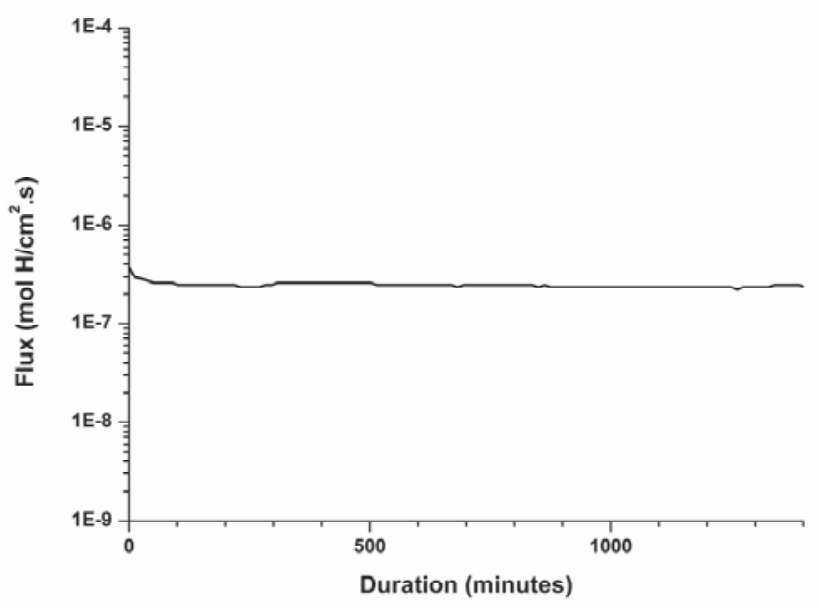

(a) 


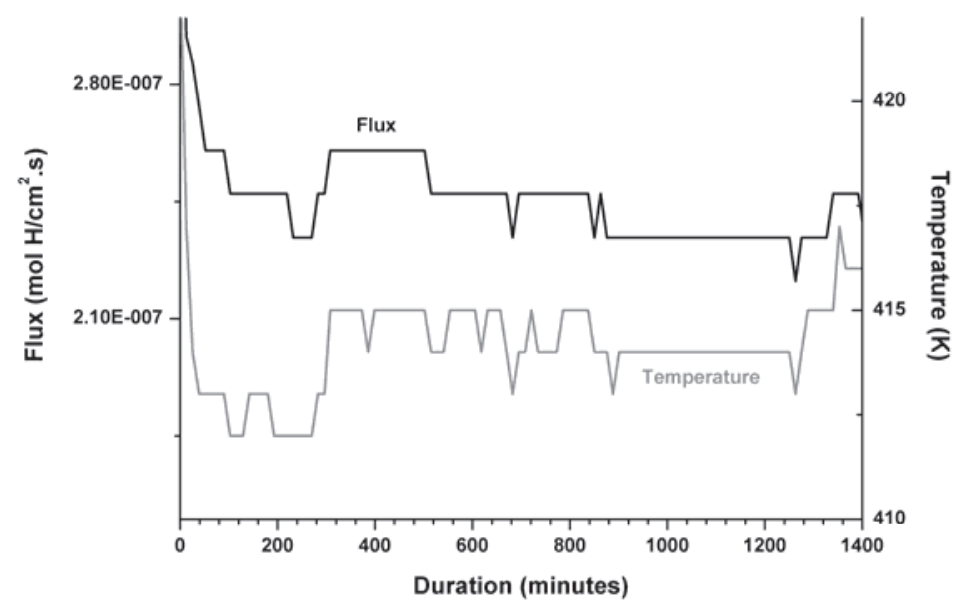

(b)

Figure 3.25. a) The hydrogen flux measured for about 24 hours measured using sample S7 b) The response of hydrogen flux to the temperature change for $24 \mathrm{~h}$

\subsubsection{Experiment set 5: Rate limiting step determination and comparison with theory}

The rate limiting step determination is one of the important methods to optimize any permeation process. Ward and Dao [13] proposed a model of hydrogen permeation behavior in palladium membranes (as explained in section 3.2). We use this model as a reference to determine the rate limitation in our membrane over the temperature range $323 \mathrm{~K}-523 \mathrm{~K}$. The experiments are performed by measuring the permeated hydrogen flux for varying membrane temperatures. The experimental procedure is as follows. After loading a new membrane sample (S10) and performing a leak test (helium leak $=0.002 \mathrm{sccm}$ ), the oven is heated up to $523 \mathrm{~K}$ under nitrogen atmosphere. Once a stable temperature is attained, hydrogen gas (100 \% concentration) is introduced on the feed side with a flow rate of $20 \mathrm{sccm}$ and at a feed pressure of 1.5 bar. After a stabilization time of 15 minutes, sequential flux readings (every 2 minutes) are recorded with the GC during which the oven is cooled down at a rate of $1 \mathrm{~K} / \mathrm{min}$ to $323 \mathrm{~K}$. Figure 3.26 shows the Arrhenius plot of hydrogen flux against temperature. 


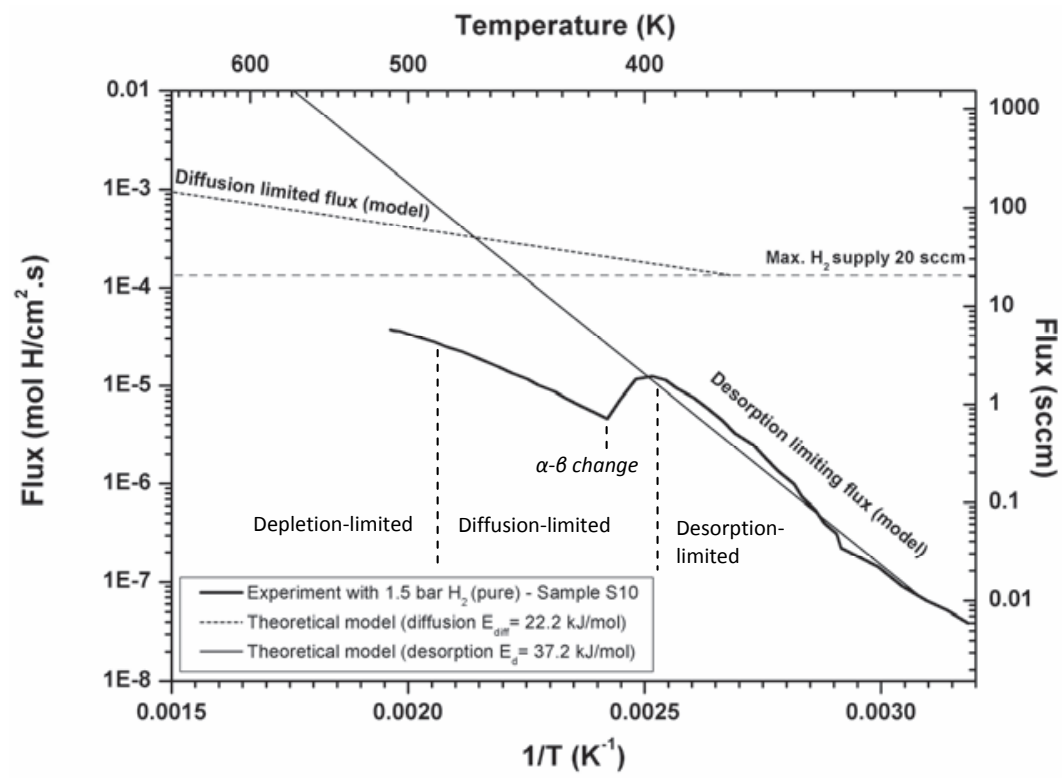

Figure 3.26: Comparison of hydrogen permeation through sample S10 vs. Ward \& Dao model showing lines of diffusion and desorption limited fluxes. The flux measurement has an error $< \pm 2 \%$. The pressure measurement has an error of $\pm 25 \mathrm{mbar}$ and the error in temperature reading is $\pm 2.5 \mathrm{~K}$. For our samples, $1 \mathrm{sccm}=6.5 \times 10^{-6}$ $\mathrm{mol} \mathrm{H} / \mathrm{cm}^{2} \mathrm{~s}$ (see appendix B).

Many interesting observations can be made from the figure 3.26. At high temperatures, the permeation process seems to be limited by mass transfer or in other words, due to inadequate supply of hydrogen on the feed side. This is evident from the curvature of the flux line at temperatures close to $523 \mathrm{~K}$ due to hydrogen depletion. When the sample is cooled, the process tends possibly towards a diffusion limited regime and then further down the phase transition occurs (indicated by the sudden rise in the permeate flux), where the palladium hydrides inside the membrane transit from $\alpha$-phase to $\beta$-phase. The fact that the effect of phase transition can be observed on the flux indicates that the membrane has been operating in the diffusion limited regime. After this sudden increase in flux due to higher permeability of $\beta$-phase $[27,30]$, the process encounters desorption limitation. More evidence is shown later in this section, to support this conclusion. The theoretical estimates for desorption and diffusion fluxes are also plotted in the figure 3.26 for comparison with the experimental results. 
The experimental desorption flux seems to follow the model when the theoretical activation energy for desorption is chosen as $37.2 \mathrm{~kJ} / \mathrm{mol}$. This activation energy is quite less as compared to $50.2 \mathrm{~kJ} / \mathrm{mol}$ assumed by Ward and Dao [13]. According to their model, the permeation process for $1 \mu \mathrm{m}$ thick palladium membrane should be desorption limited below $600 \mathrm{~K}$. This may not be true in our case since the measured flux appears to be diffusion limited from $523 \mathrm{~K}-400 \mathrm{~K}$. This could be due to the superior surface reaction kinetics of sputter deposited palladium membranes, as compared to the conventionally produced membranes.

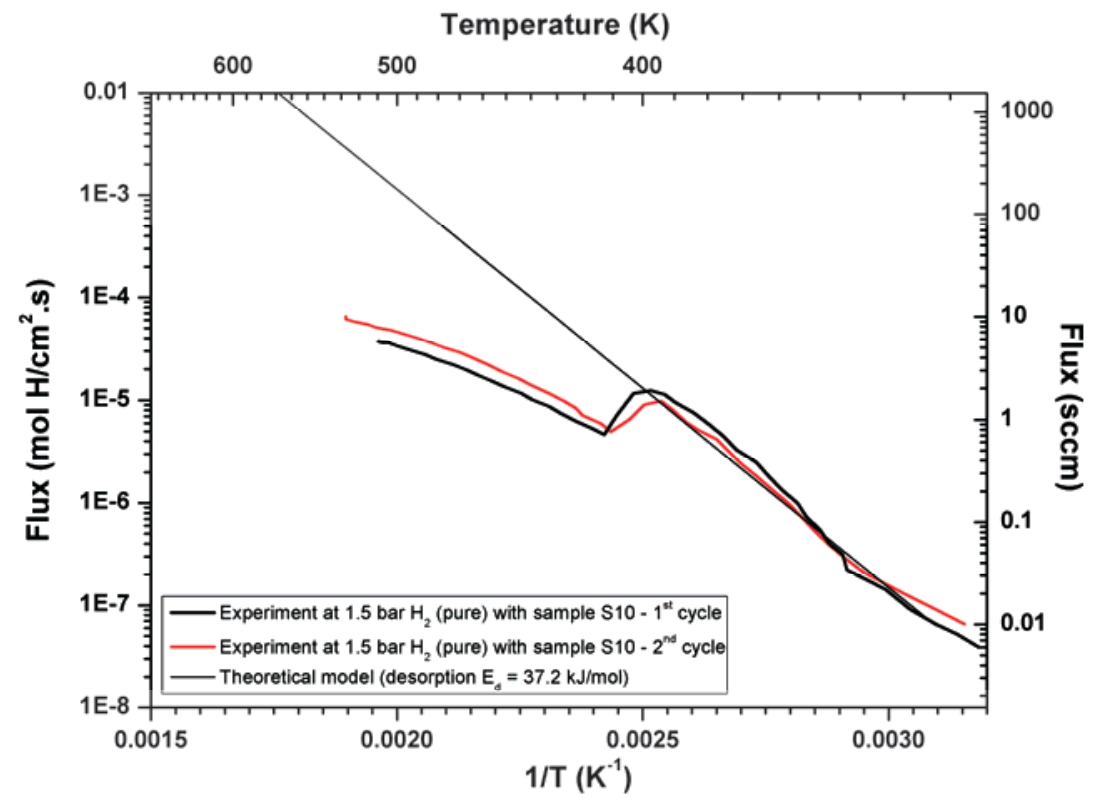

Figure 3.27: Comparison between the first and second cycles of the hydrogen permeation process through sample S10. The flux measurement has an error $< \pm 2 \%$. The pressure measurement has an error of $\pm 25 \mathrm{mbar}$ and the error in temperature reading is $\pm 2.5 \mathrm{~K}$. For our samples, $1 \mathrm{sccm}=6.5 \times 10^{-6} \mathrm{~mol} \mathrm{H} / \mathrm{cm}^{2} \mathrm{~s}$ (appendix B).

The activation energy for diffusion seems to be higher than the theoretical value of $22.2 \mathrm{~kJ} / \mathrm{mol}$ and thus the diffusion limited flux through our membrane appears to be much less than the theoretical estimate based on Fick's law. One of the reasons for the lower diffusive flux could be due to the nanocrystalline structure of the sputter deposited palladium having an increased number of grain boundaries causing higher 
resistance to bulk diffusion of the hydrogen atoms [35]. Another reason might be that at temperatures below $573 \mathrm{~K}$, until the phase transits, the activation energy for diffusion could be governed by $\alpha$-phase, whereas the theoretical model considers no $\alpha$ or $\beta$ phases.

The result depicted in figure 3.26 is confirmed by a second cycle of heating and cooling with the same sample S10, the results of which are plotted in figure 3.27. As seen from the figure, the flux measured during the second cycle follows the first measurement in a similar pattern. After the first cycle the helium leak was measured to be $0.012 \mathrm{sccm}$, which then rose to $0.028 \mathrm{sccm}$ after the second cycle.

\section{Effect of varying the hydrogen feed pressure}

To understand the effect of changing the hydrogen partial pressure on the feed side, another permeation experiment is performed at $\mathrm{P}_{\mathrm{H} 2 \text {,feed }}=5.5$ bar using a new sample S11 (helium leak $=0.001 \mathrm{sccm}$ ). The result is compared with that of sample S10 and plotted in figure 3.28. At $\mathrm{P}_{\mathrm{H} 2 \text {,feed }}=5.5 \mathrm{bar}$, the membrane shows a higher diffusive flux than at $\mathrm{P}_{\mathrm{H} 2 \text {,feed }}=1.5 \mathrm{bar}$, due to the larger hydrogen partial pressure difference across the membrane. An interesting aspect to be seen from figure 3.28 is that the slope of the diffusion limited flux for both the samples is almost identical. After the phase transition, $\mathrm{a}_{\mathrm{H} 2}{ }^{(\mathrm{n}=0)}$ dependence of flux indicates a desorption limitation due to high surface coverage of hydrogen atoms on the permeate surface of the palladium membrane. The slope and position of desorption limited flux lines for both samples are the same, though they encounter this line at different temperatures. During cooling down with $\mathrm{P}_{\mathrm{H} 2 \text {,feed }}=5.5$ bar, the phase transition point for the palladium sample (S11) is shifted to a higher temperature because of an increased hydrogen concentration in the palladium bulk, which in accordance with the $\mathrm{Pd}-\mathrm{H}$ phase diagram (shown in figure 3.10). At higher temperatures both the samples begin to encounter mass transfer limitation (i.e. hydrogen depletion), although there is some unclear fluctuation observed in the measurements for sample S11 at these temperatures. An upgrade of the current permeation set-up with a mass-flow controller of $500 \mathrm{sccm}$ is necessary to overcome the depletion limitation and to understand the diffusion limited flux much better. 


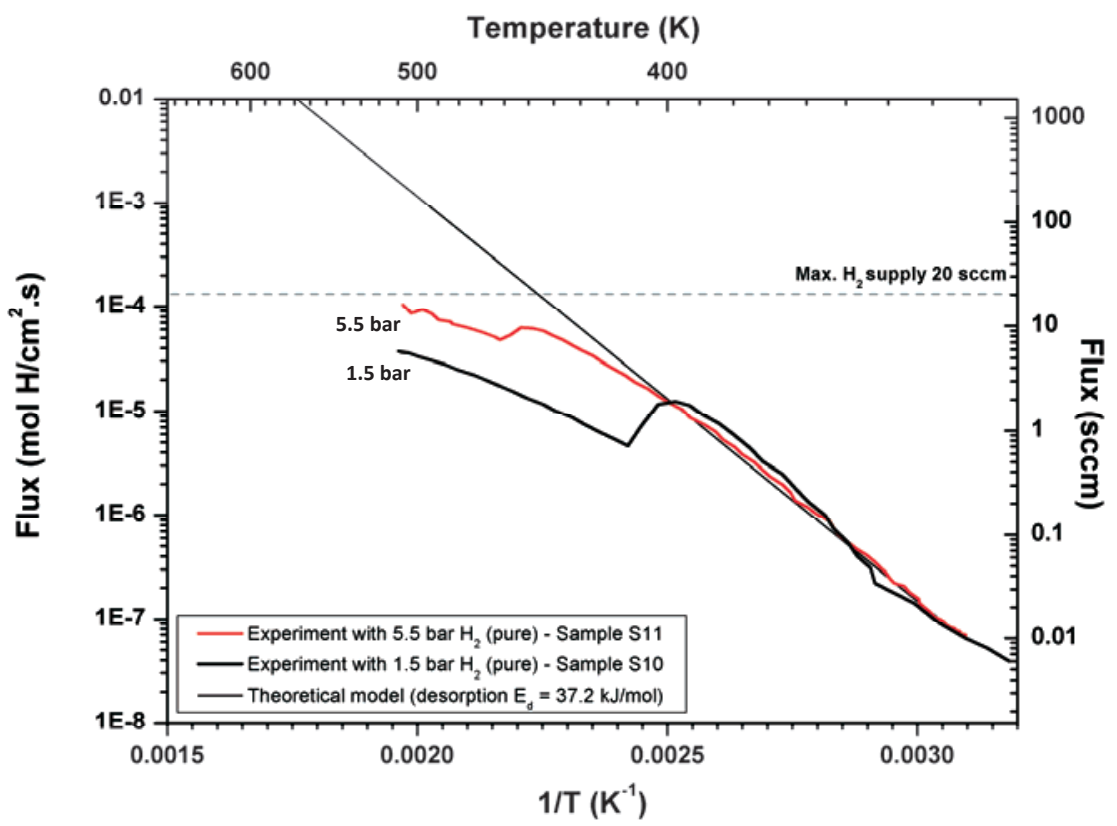

Figure 3.28: Comparison between permeation rates when different hydrogen pressures are used on the feed side. The flux measurement has an error $< \pm 2 \%$. The pressure measurement has an error of $\pm 25 \mathrm{mbar}$ and the error in temperature reading is $\pm 2.5 \mathrm{~K}$. For our samples, $1 \mathrm{sccm}=6.5 \times 10^{-6} \mathrm{~mol} \mathrm{H} / \mathrm{cm}^{2} \mathrm{~s}$ (appendix B).

\section{Effect of hydrogen mixture}

To compare the effect of flowing hydrogen mixtures instead of pure hydrogen in the feed stream, the following experiments are performed. Two new palladium samples S14 and S15 (from a new batch) are used for this purpose. The helium leak measured for both the samples is around $0.001 \mathrm{sccm}$. During the hydrogen permeation experiments, for both samples, a gas flow rate of $20 \mathrm{sccm}$ and a hydrogen partial pressure of $1.5 \mathrm{bar}$ is used on the feed side. While sample S15 is tested with pure hydrogen gas on the feed side, for sample $\mathrm{S} 14$ a mixed feed gas comprising of $50 \% \mathrm{H}_{2}$ and $50 \% \mathrm{He}$ is employed. During the experiments, the temperature regulation is done in a similar fashion as mentioned in the case of sample S10. Plotted in figure 3.29 are the experimental results. The experiment with mixed hydrogen flow shows a larger mass transport limitation at higher temperatures than the pure hydrogen experiment. This is evident from the lower flux through sample S14 as compared to sample S15 
above $450 \mathrm{~K}$. Both the samples experience phase transition around the same temperature and as the temperature is further lowered they both follow same desorption limited flux line.

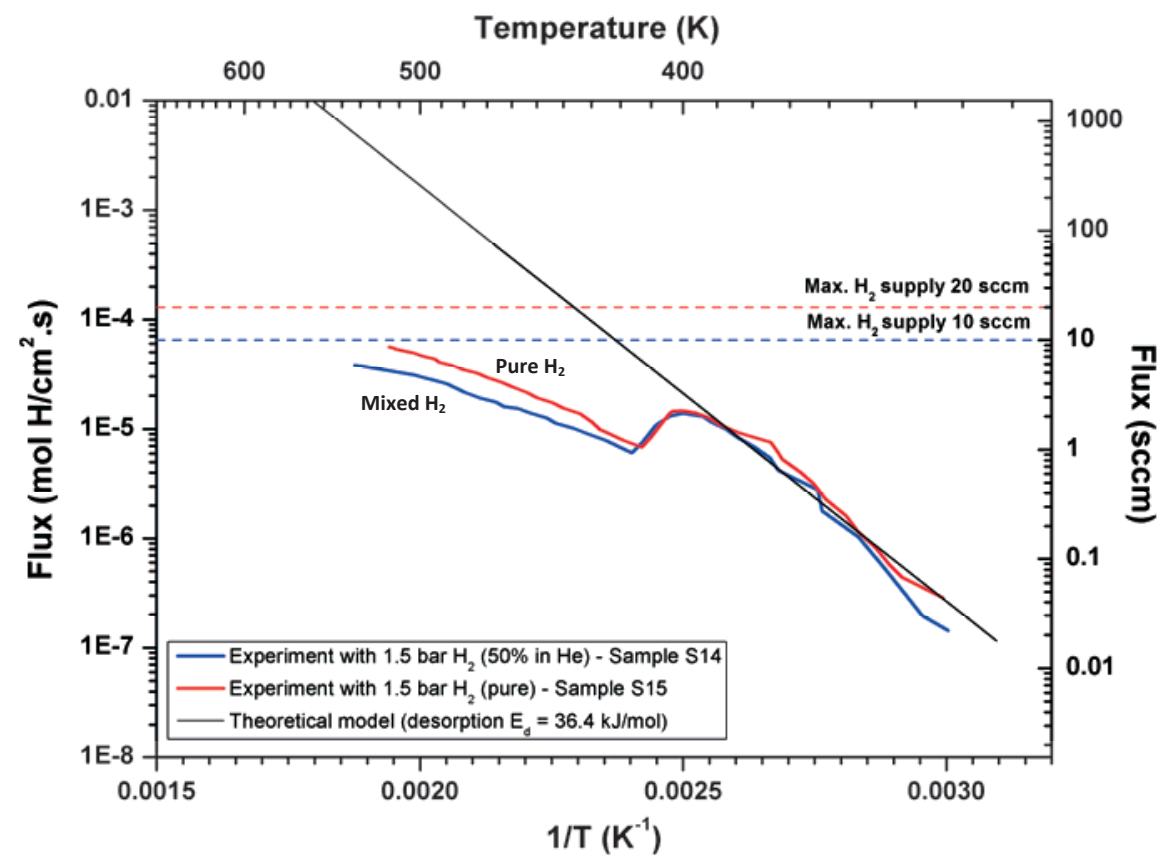

Figure 3.29: Comparison between pure and mixed hydrogen flow. The flux measurement has an error $< \pm 2 \%$. The pressure measurement has an error of $\pm 25 \mathrm{mbar}$ and the error in temperature reading is $\pm 2.5 \mathrm{~K}$. For our samples, $1 \mathrm{sccm}=6.5 \times 10^{-6} \mathrm{~mol} \mathrm{H} / \mathrm{cm}^{2} \mathrm{~s}$ (appendix B).

\subsection{Conclusions}

Described in this chapter is a new methodology to make micromachined palladium thin-film membranes. A thin-film transfer technique via bond-micromachining has been shown as a successful method to fabricate defect free micron and sub-micron thick membranes. Using this method, a $1 \mu \mathrm{m}$ thick dense palladium membrane supported on a perforated silicon gas diffusive support (GDS) has been fabricated to be used as the hydrogen diffusive electrode (HDE) for the proposed $\mu$ SAFC. 
The hydrogen permeation experiments have given us insights on the dependency of the hydrogen flux through the sputter deposited palladium membrane on the temperature and the hydrogen partial pressure (or concentration). Our $1 \mu \mathrm{m}$ thick palladium membrane shows a very good selectivity $(>1500)$ for hydrogen with respect to helium. Unlike what was expected from Ward \& Dao model, our membranes have a much higher flux in the experimental temperature range of $323 \mathrm{~K}-523 \mathrm{~K}$. At $423 \mathrm{~K}$ (the optimal $\mu \mathrm{SAFC}$ operating temperature) and 1.5 bar hydrogen pressure on the feed side, the palladium membranes show a flux within the range $6.3 \times 10^{-6}$ to $8.82 \mathrm{x}$ $10^{-6} \mathrm{~mol} \mathrm{H} / \mathrm{cm}^{2} . \mathrm{s}$, which is approximately $0.61-0.85 \mathrm{~A} / \mathrm{cm}^{2}$ of equivalent current density. Moreover, at $423 \mathrm{~K}$, for hydrogen pressure of $1.5 \mathrm{bar}$, our membrane seems to still operate in the diffusion-limited regime due to its lower activation energy for desorption $(37.2 \mathrm{~kJ} / \mathrm{mol})$, even when using nitrogen as the permeate side sweep gas. This could be due to the superior surface kinetics on a sputtered metal surface. The activation energy for desorption could be further (drastically) lowered when oxygen (or air) is introduced on the permeate side, as would be the case for a fuel cell membrane electrode assembly (MEA). The diffusive flux through the membrane can be enhanced by reducing the thickness of the palladium.

The study conducted to investigate $\alpha-\beta$ phase transition has enabled us to predict the occurrence and phase change of the palladium hydrides in our membranes. This helps us to suppress the phase transition via optimal settings for temperature and pressure in case of palladium being used as a hydrogen diffusive electrode (HDE) for the fuel cell, which thus increases its stability and durability. According to our observation, the maximum allowed hydrogen pressure on the anode side for the $\mu \mathrm{SAFC}$ operating at a temperature of $423 \mathrm{~K}$ (i.e. $150{ }^{\circ} \mathrm{C}$ ) is $\sim 1.5$ bar. Beyond this pressure the palladium would embrittle due to phase transition. When the operational temperature of the fuel cell is less during its start-up or shut-down, the hydrogen has to be automatically removed from the feed stream so as to elude $\alpha-\beta$ phase transition. 


\section{Acknowledgements}

I would like thank Eko Gito Prabowo for his contributions on palladium characterization. My special thanks to Prof. Han Gardeniers of the Mesoscale Chemical Systems group at the University of Twente for providing the GasChromatograph set-up in his lab. Thanks also goes to Bronkhorst High-Tech B.V., the Netherlands for supplying me the mass-flow controllers for the permeation set-up.

\section{References}

[1] Y.-G. Chun, C.-S. Kim, D.-H. Peck, D.-R. Shin, Journal of Power Sources, 1998, 71, pp. 174178

[2] J.W. Phair and R. Donelson, Industrial and Engineering Chemistry Research, 2006, 45 (16), pp. 5657-5674

[3] S. Uemiya, N. Sato, H. Ando, Y. Kude, T. Matsuda and E. Kikuchi, Journal of Membrane Science, 1991, 56, pp. 303.

[4] X.L. Pan, G.X. Xiong, S.S. Sheng, N. Stroh and H. Brunner, Chemical Communications, 2001, p 2536.

[5] J. Tong, H. Suda, K. Haraya, Y. Matsumura, Journal of Membrane Science, 2005, 260, pp. 1018

[6] D. A. Boysen, Superprotonic Solid Acids: Structure, Properties, and Applications, PhD Thesis, California Institute of Technology, Pasadena, California, 2004

[7] F. A. Lewis, International Journal of Hydrogen Energy, 1995, 20 (7), pp. 587-592

[8] F. Roa, J.D. Way, R.L. McCormick and S.N. Paglieri, Chemical Engineering Journal, 2003, 93, pp. 11-22

[9] S. Tosti, L. Bettinali and V. Violante, International Journal of Hydrogen Energy, 2000, 25, pp. 319-325

[10] N.W. Ockwig and T.M. Nenoff, Chemical Reviews, 2007, 107 (10), pp. 4078-4110

[11] M.A. Pick and K. Sonnenberg, Journal of Nuclear Materials, 1985, 131 (2-3), pp. 208-220

[12] I. Ali-Khan, K.J. Dietz, F.G. Waelbroeck and P. Wienhold, Journal of Nuclear Materials, 1978, 76-77 (C), pp. 337-343

[13] T.L. Ward and T.Dao, Journal of Membrane Science, 1999, 153, pp. 211-231

[14] E. Salomons, Journal of Physics: Condensed Matter, 1990, 2 (4), art. no. 006, pp. 845-855

[15] G.L. Holleck, Journal of Physical Chemistry, 1970, 74 (3), pp. 503-511 
[16] H.D.Tong, F.C. Gielens, J.G.E. Gardeniers, H.V. Jansen, J.W. Berenschot, M.J. De Boer, C.J.M. van Rijn, and M.C. Elwenspoek, Journal of Microelectromechanical Systems, 2005, 14(1), pp. 113-124

[17] J.P. Collins and J.D. Way, Industrial and Engineering Chemistry Research, 1993, 32 (12), pp. 3006-3013

[18] E. Kikuchi and S. Uemiya, Gas Separation and Purification, 1991, 5(4), pp. 261-266

[19] P.P. Mardilovich, Y. She, Y.H. Ma and M.-H. Rei, AIChE Journal, 1998, 44(2)

[20] S. Yan, H. Maeda, K. Kusakabe and S. Morooka, Industrial \& Engineering Chemistry Research, 1994, 33 (3), pp. 616-622

[21] G. Xomeritakis and Y.-S. Lin, Journal of Membrane Science, 1996, 120 (2), pp. 261-272

[22] G. Xomeritakis and Y.-S. Lin, AIChE Journal, 1998, 44(1), pp. 174-183

[23] R. Stengl, T. Tan and U. Goesele, Japanese Journal of Applied Physics, 1989, 28(10), pp. 17351741

[24] R.B. Marcus and T. T. Sheng, Journal of Electrochemical Society, 1982, 129, pp. 1278

[25] R.B. Marcus, T.S. Ravi and T. Gmitter, Applied Physics Letters, 1990, 56 (3)

[26] R. Koch, Journal of Physics: Condensed Matter, 1994, 6, pp.9519-9550

[27] K.R. Williams, K. Gupta and M. Wasilik, Journal of Microelectromechanical Systems, 2003, 12(6), pp. 761-778

[28] G. Alefeld and J. Völkl (Eds.), Hydrogen in metals II: application-oriented properties, SpringerVerlag, 1978.

[29] H. Frieske and E. Wicke, Ber.Bunsenges. Physik. Chem., 1973, 77, pp. 50

[30] J. Shu, B.P.A. Grandjean, A.V. Neste and S. Kaliaguine, Caanadian Journal of Chemical Engineering, 1991, 69, pp. 1036

[31] H. Brüning and A. Sieverts, Z. Phys. C/rem. A, 1933, 163, pp. 409

[32] HSIEH, H.P. Inorganic membranes for separation and reaction. Membrane sciences and technology series 3, Elsevier, 1996.

[33] I.B. Elkina and J.H. Meldon, Desalination, 2002, 147, pp. 445-448

[34] H. Li, H. Xu and W. Li, Journal of Membrane Science, 2008, 324, pp. $44-49$

[35] B. A. Mccool and Y. S. Lin, Journal of Materials Science, 2001, 36, pp.3221 - 3227

[36] M.W. Lee, R.J. Wolf and J.R. Ray, Journal of Alloys and Compounds, 1995, 231(1-2), pp. 343346

[37] M.W. Lee, R.J. Wolf and J.R. Ray, Physical Review Letters, 1994, 73(4), pp. 557-560

[38] D. Halley, Y. Samson, A. Marty, C. Beigné and B.Gilles, Surface Science, 2001, 481(1-3), pp. 25-32

[39] M.J. Yacamán,M.M. Almazo and J.A. Ascencio., Journal of Molecular Catalysis A: Chemical, 2001, 173(1-2), pp. 61-74 



\section{The Membrane Electrode Assembly}

After having developed dense palladium electrodes supported on a gas diffusive silicon microsieve support, in this chapter details about the solid acid electrolyte and its properties will be given. A brief description about the protonic activity characterization of the electrolyte is followed by results of a solid acid penny fuel cell test. Subsequently, explanations of the solid acid thin-film coating process and experimental trials done to integrate the palladium electrodes with the electrolyte to form the Membrane Electrode Assembly (MEA) of the fuel cell are given. 


\subsection{Introduction}

The membrane-electrode-assembly or MEA is considered to be the heart of a fuel cell. The MEA consists of two electrodes between which an electrolyte is sandwiched. As seen from chapter 1 , our micro solid-acid fuel cell ( $\mu$ SAFC) has a novel kind of MEA unlike the conventional fuel cells. The novelty is that it is comprised of dense palladium electrodes (shown in chapter 1, figure 1.4b) instead of the conventionally used porous carbon based electrodes (chapter 1, figure. 1.4a). As explained in chapter 3 , the intrinsic property of palladium to selectively diffuse hydrogen through it encourages its usage as a Hydrogen Diffusive Electrode (HDE) in the fuel cell. The idea of using dense HDEs is based on the properties of the solid acid electrolyte. The solid acid salts are well known to be soluble in liquid water, which makes it essential that they are properly sealed within the MEA. If the electrolyte layer is sandwiched between porous electrodes, then there is a high chance that water vapor or humid air can come in contact with the electrolyte and that water condenses or absorbs into the electrolyte. The usage of dense HDEs not only avoids water from external sources to enter the MEA, but also prevents the water formed by the oxygen reduction reaction (ORR) at the cathode, from contacting the electrolyte. Normally, in a conventional PEM fuel cell having porous carbon electrodes with catalysts particles (e.g. platinum) at the electrode-electrolyte interface, the electrochemical reactions occur at so-called "triple-phase boundaries" or, in other words, gas-electrocatalyst-electrolyte junctions (see figure 4.1) located at the electrode-electrolyte interfaces [1]. In our $\mu \mathrm{SAFC}$ with HDEs, the conventional triple-phase boundaries do not exist and the ORR is shifted from the electrode-electrolyte interface to the electrode-gas interfaces. Such a shift implies that the water from the ORR would be formed outside the MEA, and can never have a chance to contact the electrolyte that is protected by the dense palladium electrodes. Apart from protection against water, there are several other advantages of a dense-electrode MEA, as described below.

1) Oxygen doesn't need to diffuse to the cathode-electrolyte interface. It can simply react with the hydrogen diffusing out of the dense cathode surface. This can play a crucial role in minimizing the mass transfer losses of the ORR at the cathode. The reactions on the cathode side can be considered to be much simpler than in the case of a conventional MEA, and thus better understanding and optimization is possible. 
2) Reaction product water doesn't need to diffuse out through the cathode. This is again a very important advantage, since in conventional MEAs with porous gas diffusive electrodes (GDE), the simultaneous diffusion of oxygen into and water out of the cathode-electrolyte interface amounts to considerable losses. Moreover, the GDE water clogging issue is avoided in the dense MEA configuration.

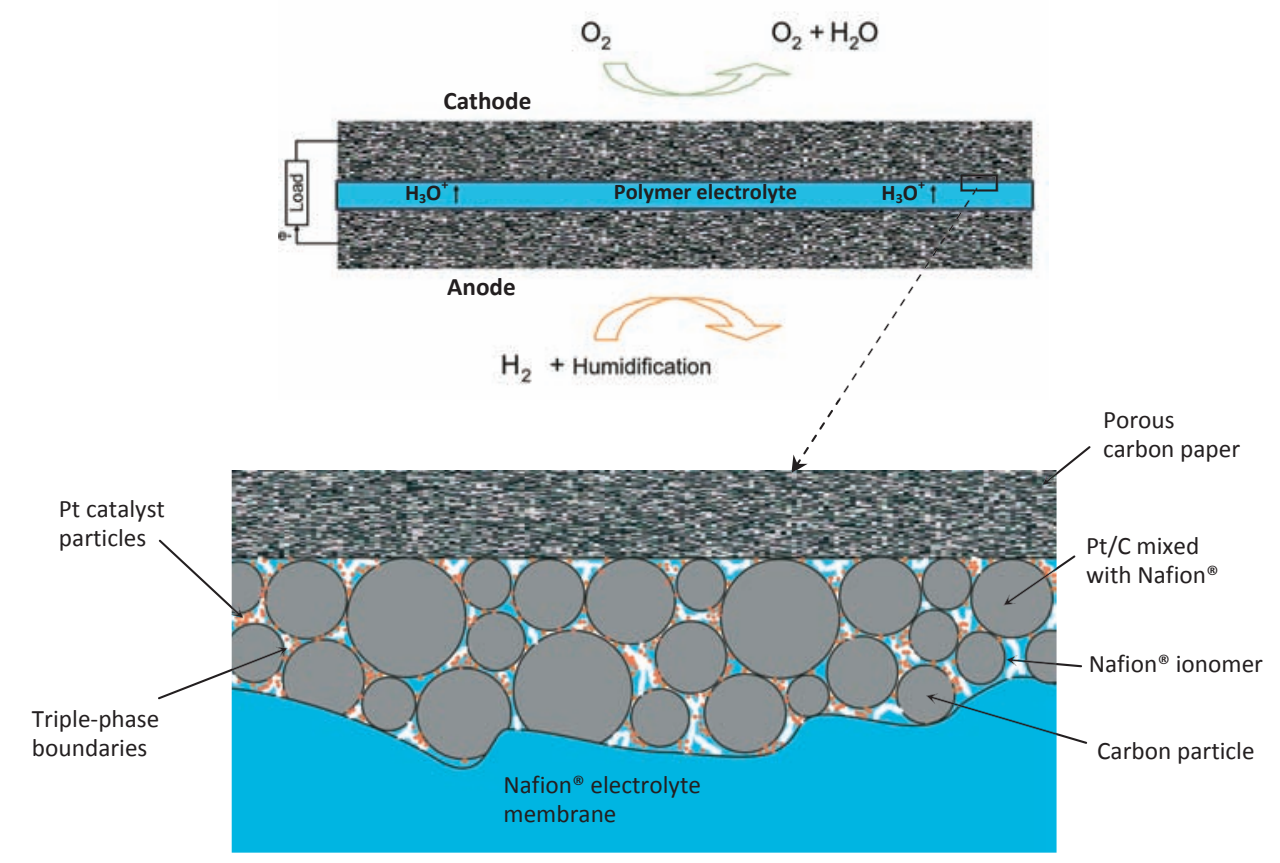

Figure 4.1: The triple-phase boundary formed by the electrocatalyst particles, the ionomer and the gas phase at the interface of a porous GDE and Nafion ${ }^{\circledR}$ electrolyte in the MEA of a PEMFC.

The driving force for any fuel cell is the Gibbs' free energy change $(\Delta G)$ of the spontaneous exothermic water formation reaction (as shown below).

$$
\mathrm{H}_{2}+\frac{1}{2} \mathrm{O}_{2} \rightarrow \mathrm{H}_{2} \mathrm{O}+\text { Energy }
$$

Gibbs' free energy change for any reaction can be expressed as,

$$
\Delta G=\Delta G^{\circ}(T)+R T \ln Q
$$


where, $\Delta G^{\circ}(T)$ is the standard Gibbs' free energy change of the reaction and is defined as the difference in standard molar Gibbs' energies of the products and reactants in their standard states at the reaction temperature, $R$ is the gas constant, $T$ is the temperature of the reaction and $Q$ is the reaction quotient defined as the ratio of the partial pressures of the products and reactants. In the case of reaction (4.1),

$$
Q=p H_{2} O /\left(p H_{2} \cdot p O_{2}^{0.5}\right)
$$

The reaction quotient is usually made dimensionless by expressing the partial pressures of the products and reactants with reference to a unit pressure. The $\Delta G^{\circ}(T)$ term is calculated from the change in enthalpy and change in entropy of the reactants while forming the products. If the reaction (4.1) results in water vapor, as would be the case in the proposed $\mu \mathrm{SAFC}$ (working at temperatures $>140{ }^{\circ} \mathrm{C}$ ), then $\Delta G^{\circ}=-242$ $\mathrm{kJ} / \mathrm{mol}+T^{*} 0.0458 \mathrm{~kJ} / \mathrm{mol} . \mathrm{K}$ for all reaction components in vapor phase [2].

The cell voltage, $\Delta E$ generated can be derived from equation 4.2 by expressing Gibbs' free energy change in terms of electrical work expressed as $\Delta G=-n F \Delta E$, where $n$ is the number of moles of electrons transferred and $F$ is the Faraday's constant. The result is the Nernst equation shown below,

$$
\Delta E=\Delta E^{\circ}(T)-\frac{R T}{n F} \ln Q
$$

where, $\Delta E^{\circ}(T)$ is the Nernst voltage or the cell voltage under standard conditions. At $298 \mathrm{~K}$, when the product of reaction (4.1) is $\mathrm{H}_{2} \mathrm{O}(l)$, the values of $\Delta E^{\circ}(T)$ is around 1.23 V. At higher temperatures of operation, when the product of the reaction (4.1) is $\mathrm{H}_{2} \mathrm{O}(\mathrm{g})$, then $\Delta E^{\circ}(T)$ reduces to about $1.18 \mathrm{~V}$ due to reduction in reaction enthalpy. The maximum achievable cell voltage, $\Delta E$ for our proposed $\mu$ SAFC shall be this Nernst voltage of $1.18 \mathrm{~V}$.

Looking in a more abstract manner, our MEA with dense HDEs can be seen as a hydrogen concentration-cell, which works based on the concentration difference between anode and cathode, where hydrogen is being supplied to the anode side and is removed from the cathode side. In such a concentration-cell, the role of oxygen is that 
of a hydrogen getter, that helps to maintain a high partial pressure difference between the anode and the cathode. From this perspective, the cell voltage can also be expressed in terms of the hydrogen partial pressure difference between the anode and the cathode,

$$
\Delta E=\frac{R T}{n F} \ln Q_{1}
$$

where, $Q_{1}=p H_{2, \text { anode }} / p H_{2, \text { cattode, }}$ and the terms $p H_{2, \text { anode }}$ and $p H_{2, \text { catbode }}$ are the partial pressures of hydrogen on the anode (or high concentration) side and the cathode (or low concentration) side. For a solid acid fuel cell operating at $150{ }^{\circ} \mathrm{C}$ to produce 1.18 $\mathrm{V}, Q_{1}$ needs to be in the order of $\sim 10^{28}$. This means that an extremely efficient hydrogen removal from the cathode is required. In other words, the efficacy with which oxygen reacts with hydrogen, the ORR rate, would determine the result.

In practice, it is almost impossible to attain the theoretical voltage of the fuel cell as there are many losses that need to be taken into account [3]. In the open-circuit condition when no current is drawn from the fuel cell, two kinds of voltage losses can occur.

- Due to hydrogen fuel permeation/crossover through the electrolyte membrane.

- In fuel cells using platinum catalyst, the oxidation of platinum at the cathode leads to a drop in the cell voltage.

Both of these losses together is usually referred to as mixed losses.

When a current is drawn from the fuel cell, the cell voltage again lowers due to various other losses as listed below,

- Activation Losses: due to poor chemical reaction kinetics at the electrodes

- Ohmic Losses: indicate the drop in cell voltage due to the internal resistance of the cell against charge flow

- Mass Transportation Losses: mainly caused by the depletion of gas molecules at the anode and cathode, due to slow replenishment 
By taking these losses into account, the net cell voltage during the operation of the fuel cell can be written as,

$$
\Delta E_{\text {cell }}=\Delta E-E_{\text {mixed }}-\eta_{\text {act }}-\eta_{i R}-\eta_{\text {diff }}
$$

where, $\Delta E_{\text {cell }}$ is the measured cell voltage, $E_{\text {mixed }}$ is the loss in voltage due to leaks across the electrolyte, $\eta_{a c t}$ is the activation overpotential due to slow electrode reactions; $\eta_{i R}$ is the loss due to ohmic resistances in the cell; and $\eta_{\text {diff }}$ is the loss due to mass diffusion or transportion limitations.

The key performance measure of a fuel cell is the voltage output as a function of electrical current drawn, or the polarization curve [4]. The schematic of a typical polarization curve indicating the various voltage losses is depicted in figure 4.2.

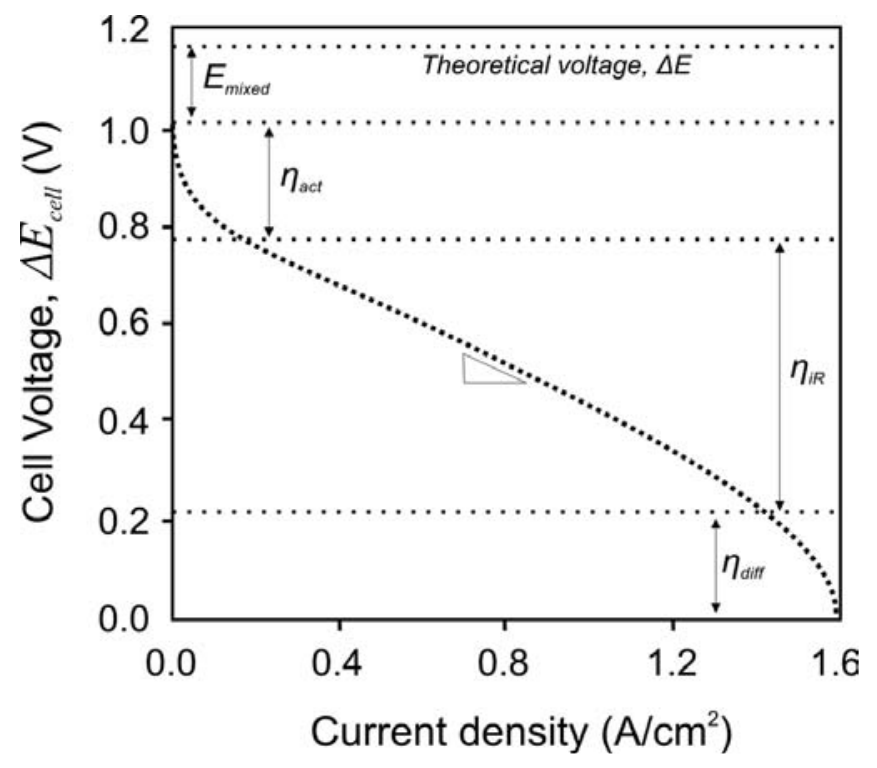

Figure 4.2: The schematic of typical polarization curve of a fuel cell

Before investigating the fabrication of the dense electrode MEA of the $\mu$ SAFC, a brief introduction on the solid-acid electrolyte is provided in the following section. 


\subsection{The Electrolyte: Solid Acid}

Solid acids are solid materials having acidic properties (i.e. proton donors). Solid acids are compounds such as cesium hydrogen sulfate $\left(\mathrm{CsHSO}_{4}\right)$, whose chemistry and properties lie between those of a normal acid (such as $\mathrm{H}_{2} \mathrm{SO}_{4}$ ) and a normal salt (such as $\mathrm{Cs}_{2} \mathrm{SO}_{4}$ ) [5]. They possess unique properties arising from the incorporation of "mobile" protons into their crystalline structure: e.g. ${ }^{1 / 2} \mathrm{Cs}_{2} \mathrm{SO}_{4}+1 / 2 \mathrm{H}_{2} \mathrm{SO}_{4} \rightarrow$ $\mathrm{CsHSO}_{4}$. The structure of solid acids comprises hydrogen-bonded tetrahedral oxyanions (like $\mathrm{SO}_{4}, \mathrm{SeO}_{4}$ or $\mathrm{PO}_{4}$ ) charge balanced by a host lattice of cations (like $\mathrm{Li}$, $\mathrm{Na}, \mathrm{K}, \mathrm{NH}_{4}, \mathrm{Rb}, \mathrm{Cs}$ etc.) [6]. The unique property of solid acid which interests this project is its superprotonic conductivity. Around room temperature, solid acids exhibit protonic conductivity in the order of $10^{-6}$ to $10^{-9} \Omega^{-1} \mathrm{~cm}^{-1}$. This conductivity is due to local defects in the structure and subsequent protonic hopping [7]. However, when they are heated, generally they undergo a solid-solid phase transformation at a specific temperature (depending on the solid acid type), leading to an increase in superprotonic conductivity by at least three orders of magnitude. Most solid acids with superprotonic phase transitions have monoclinic symmetry in their room temperature phase [6]. Above the phase transition temperature, the symmetry of the compounds increases and to accommodate the higher symmetry, the oxygens become disordered. The partial occupancy of the oxygen sites gives a nearly liquid-like nature to the protons as the previously static hydrogen bonded system becomes highly dynamic [8,9]. In this dynamic system, the $\mathrm{XO}_{4}$ groups liberate with intertetrahedra-hopping of the proton. The fast reorientation of the tetrahedra in conjunction with proton translations leads to the jump in conductivity across the phase transition and the "superprotonic conduction". Superprotonic solid acids, such as $\mathrm{CsHSO}_{4}$, conduct protons via a Grotthus mechanism [5]. This mechanism is a cooperative process involving both a molecular (dipole) reorientation and proton-displacement.

Haile et. al. [10] reported the successful usage of $\mathrm{CsHSO}_{4}$ as a stable operating fuel cell electrolyte that needs no humidification due to its anhydrous proton conduction mechanism. Its operational temperature $>141{ }^{\circ} \mathrm{C}$ (which is its superprotonic phase transition temperature [11]), contributes to improved electrode kinetics of the fuel cell and tolerance against catalyst poisoning. The problem with solid acids based on sulphates and selenates is that they gradually decompose in a hydrogen atmosphere. 
There is a different class - phosphate based solid acids - like cesium dihydrogen phosphate $\left(\mathrm{CsH}_{2} \mathrm{PO}_{4}\right)$ that stays stable when in contact with hydrogen and show good performance [12,13]. But this class of solid acids needs significant humidification (ca. $0.3 \mathrm{~atm}$ ) to avoid dehydration of the salt. It is noted here that unlike the polymer electrolyte, the humidification for the solid acid is intended for suppressing dehydration and is not required for the proton transport mechanism itself. A variation of the $\mathrm{CsH}_{2} \mathrm{PO}_{4}$, cesium dihydrogen phosphite $\left(\mathrm{CsH}\left(\mathrm{PO}_{3} \mathrm{H}\right)\right)$ with an asymmetric anion, has been shown to have a high protonic conductivity $\left(4.6 \cdot 10^{-3} \Omega^{-1} \mathrm{~cm}^{-1}\right)$, as well as to be stable under hydrogen atmosphere [14]. This has inspired the investigation of the usage of phosphite based solid acids for the electrolyte of our proposed $\mu$ SAFC.

\subsubsection{Solid acid preparation and characterization}

The experiments on electrolyte preparation and characterization were mainly carried out by co-researchers W. Zhou and A.S. Bondarenko of the $\mu$ SAFC project team. Powders of the $\mathrm{MH}\left(\mathrm{PO}_{3} \mathrm{H}\right)$ phosphites $\left(\mathrm{M}=\mathrm{Li}^{+}, \mathrm{Rb}^{+}, \mathrm{Na}^{+}, \mathrm{Cs}^{+}, \mathrm{K}^{+}\right.$and $\left.\mathrm{NH}_{4}^{+}\right)$were prepared by slow evaporation of aqueous solutions of carbonates (or hydroxides) of the corresponding metals in phosphorous acid (99\%, Aldrich) in mole ratio $\mathrm{M}_{2} \mathrm{H}_{3} \mathrm{PO}_{3}$ of 1:1. All powders were dried in an oven in air at $\sim 105{ }^{\circ} \mathrm{C}$ during $20 \mathrm{~h}$ prior to experiments. Chemicals used for powder syntheses included potassium hydroxide (Merck, $99.5 \%$ ), sodium hydroxide (Merck, $99.5 \%$ ), lithium carbonate (99\%, SigmaAldrich), rubidium carbonate (99.8\%, Alfa Aesar), cesium carbonate (99.9\%, Aldrich), and ammonium hydrogen carbonate (Alfa Aesar).

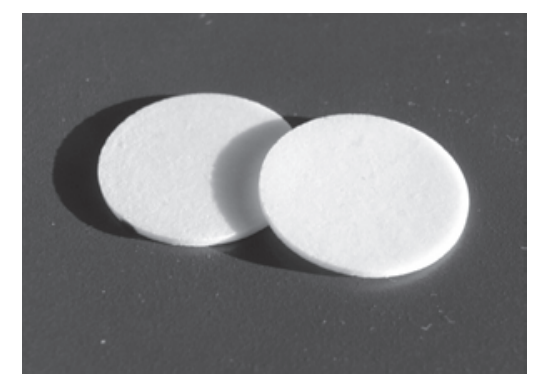

Figure 4.3: Photos of compressed solid acid discs (Ø $10 \mathrm{~mm}, 1 \mathrm{~mm}$ thick) 
Subsequently, the phosphite powders were isostatically pressed into discs of $1 \mathrm{~mm}$ thickness and $10 \mathrm{~mm}$ diameter at 4000 bar (see figure 4.3).

To understand the proton conductivity of these salts, conductivity measurements were carried out using electrochemical impedance spectroscopy for which the solid acid discs shown in figure 4.3 were sputter-coated with $100 \mathrm{~nm}$ platinum electrodes on both sides. For impedance measurements a PGstat20 Autolab Potentiostat (ECOChemie) with integrated frequency response analyser under flowing $(45 \mathrm{ml} / \mathrm{min})$ dry nitrogen was employed. An excitation voltage with an amplitude of $10 \mathrm{mV}$ was used to ensure that measurements were performed in the linear regime. No bias voltage was applied. The temperature of measurement was increased/decreased stepwise with heating/cooling rates of $0.8 \mathrm{Kmin}^{-1}$. Measurements were performed below the superprotonic phase transition $\left(\mathrm{T}_{\mathrm{s}}\right)$ over the frequency range $0.5 \mathrm{MHz}$ to $100 \mathrm{~Hz}$, and from $50 \mathrm{kHz}$ to 100 or $10 \mathrm{~Hz}$ above $\mathrm{T}_{\mathrm{s}}$ [15]. Figure 4.4 shows an Arrhenius plot comparing the proton conductivities of various $\mathrm{MH}\left(\mathrm{PO}_{3} \mathrm{H}\right)$ phosphite salts. The data give clear evidence that all the monoclinic phases of $\mathrm{MH}\left(\mathrm{PO}_{3} \mathrm{H}\right)$ with $\mathrm{M}$ being $\mathrm{Cs}^{+}$, $\mathrm{Na}^{+}, \mathrm{K}^{+}, \mathrm{Rb}^{+}$and $\mathrm{NH}_{4}^{+}$exhibit superprotonic behaviour upon heating. In contrast to the monoclinic dihydrogen phosphites, orthorhombic $\mathrm{LiH}\left(\mathrm{PO}_{3} \mathrm{H}\right)$ does not exhibit superprotonic behaviour and its conductivity remains below $10^{-8} \Omega^{-1} \mathrm{~cm}^{-1}$ at all temperatures before thermal decomposition. Among the high conductivity salts, $\mathrm{NH}_{4} \mathrm{H}\left(\mathrm{PO}_{3} \mathrm{H}\right)$ and $\mathrm{RbH}\left(\mathrm{PO}_{3} \mathrm{H}\right)$ are not stable after the superprotonic transition since they start to melt around their transition temperatures. Only $\mathrm{KH}\left(\mathrm{PO}_{3} \mathrm{H}\right)$ and $\mathrm{CsH}\left(\mathrm{PO}_{3} \mathrm{H}\right)$ show stability after the structural phase transformation. Upon heating, the conductivity of $\mathrm{KH}\left(\mathrm{PO}_{3} \mathrm{H}\right)$ rises from $1.4 \cdot 10^{-7} \Omega^{-1} \mathrm{~cm}^{-1}$ at $80{ }^{\circ} \mathrm{C}$ to $3.8 \cdot 10^{-3}$ $\Omega^{-1} \mathrm{~cm}^{-1}$ at $135^{\circ} \mathrm{C}$ (just above its superprotonic transition temperature of $132{ }^{\circ} \mathrm{C}$ ). The proton conductivity reaches values of $4.2 \cdot 10^{-3} \Omega^{-1} \mathrm{~cm}^{-1}$ at $140{ }^{\circ} \mathrm{C}$. Although, their conductivities are in the same order of magnitude, the higher cost of manufacturing $\mathrm{Cs} \mathrm{H}\left(\mathrm{PO}_{3} \mathrm{H}\right)$ forced us to go for its potassium counterpart as our electrolyte choice (keeping in mind commercialization aspects). The magnitude of protonic conductivity of $\mathrm{KH}\left(\mathrm{PO}_{3} \mathrm{H}\right)$ is comparable with that of well known $\mathrm{CsHSO}_{4}$, which exhibits a superprotonic transition at a temperature of about $141{ }^{\circ} \mathrm{C}[16,17]$. As mentioned earlier, the latter has the disadvantage that it is unstable in hydrogen atmospheres. 


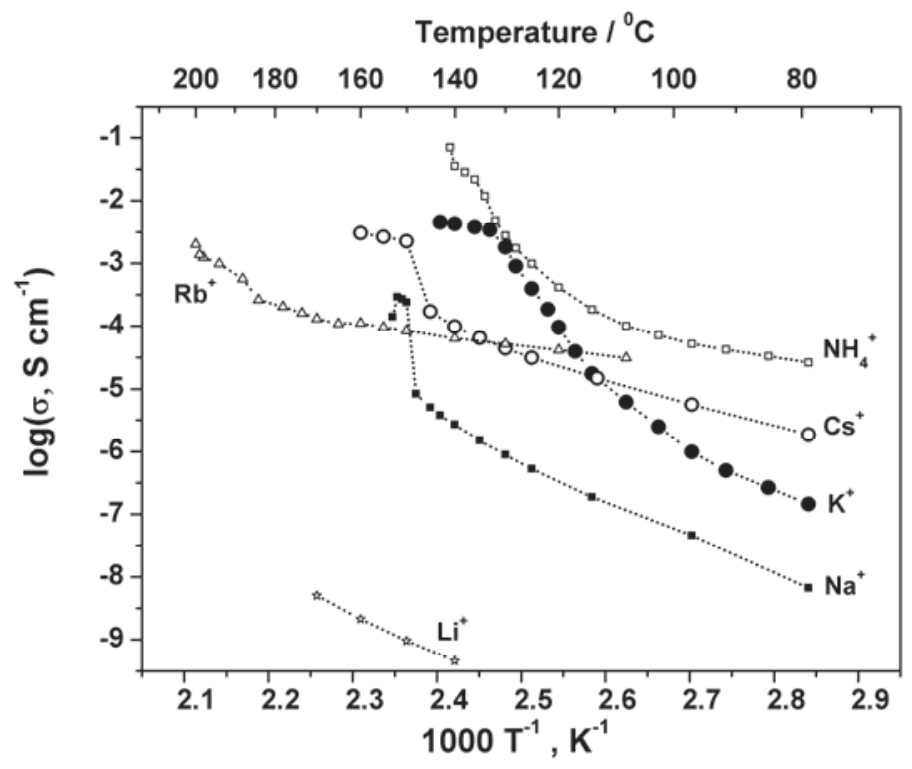

Figure 4.4: Arrhenius plot of the proton conductivity for various $\mathrm{MH}\left(\mathrm{PO}_{3} \mathrm{H}\right)$ salts. Measurements were performed in a dry $\mathrm{N}_{2}$ atmosphere.

Figure 4.5 shows the confirmation of the superprotonic phase transition phenomenon, verified using differential thermal analysis (DTA) done with a TGDTA system (Setaram SETSYS 16/18) under flowing nitrogen (45 ml/min) [18]. An endothermic peak can be observed at $\sim 132{ }^{\circ} \mathrm{C}$ and is associated with the superprotonic phase transition point recorded in the conductivity measurements.

To check the stability and durability of superprotonic conduction, a long duration test was performed under dry nitrogen atmosphere, as well as under humidified air. Figure 4.6 shows that the superprotonic conductivity of pure $\mathrm{KH}\left(\mathrm{PO}_{3} \mathrm{H}\right)$ in dry nitrogen gradually decreases with time due to slow dehydration [18]. A water partial pressure as low as $~ 0.02 \mathrm{~atm}$, however, turns out to be sufficient to suppress this slow dehydration. A point to be clearly understood here is that the need for humidification of the $\mathrm{KH}\left(\mathrm{PO}_{3} \mathrm{H}\right)$ is only to avoid its dehydration and not for its superprotonic conduction through the electrolyte. Since the solid acid electrolyte would be completely sealed in between two dense palladium electrodes (in the proposed $\mu \mathrm{SAFC}$ ), the chance of moisture escaping the salt is low. In this way, electrolyte 
dehydration could probably be suppressed. However, further investigations are required to verify this.

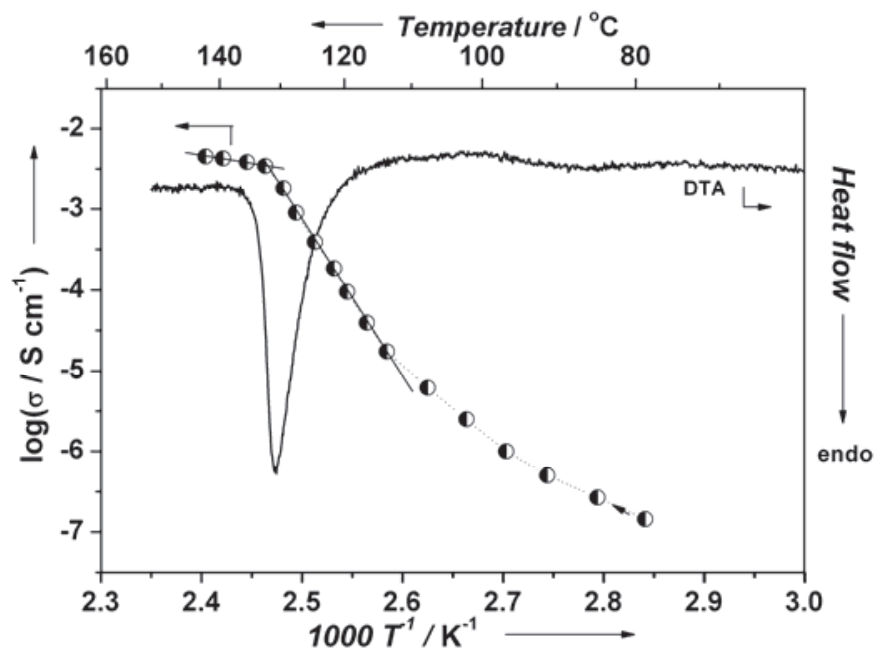

Figure 4.5: Dependence of proton conductivity of pure $\mathrm{KH}\left(\mathrm{PO}_{3} \mathrm{H}\right)$ on temperature, overlapped with the differential thermal analysis (DTA) measurements. Heating scan done under dry N2 atmosphere.

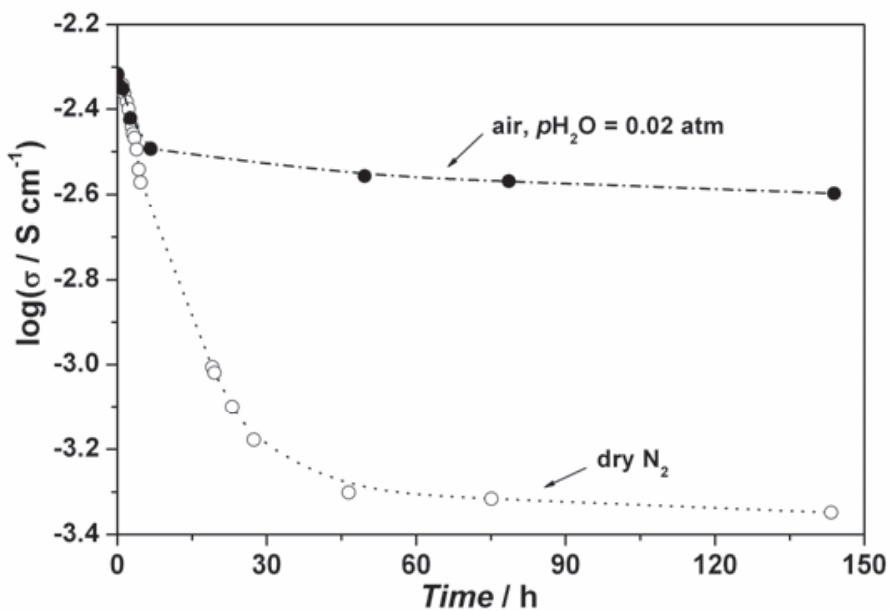

Figure 4.6: Time dependence of the superprotonic conductivity of pure $\mathrm{KH}\left(\mathrm{PO}_{3} \mathrm{H}\right)$ at $140{ }^{\circ} \mathrm{C}$ in different atmospheres. 


\subsection{Fuel cell MEA fabrication}

Before getting on with the task of micromachining the dense HDE based MEA, to get an initial idea about the voltage and current supply capabilities of a $\mathrm{KH}\left(\mathrm{PO}_{3} \mathrm{H}\right)$ based MEA, a test is performed on a small manually-pressed penny fuel cell. Such a penny fuel cell test helps to understand the functioning of the electrolyte layer when tested in a conventional type fuel cell configuration.

\subsubsection{Penny fuel cell}

For the penny fuel cell experiment, a solid-acid disc electrolyte with porous carbon paper based electrodes is used. A compressed solid acid disc of $\sim 0.5 \mathrm{~mm}$ thickness and $\varnothing 20 \mathrm{~mm}$ is assembled within a MEA by pressing two catalyst coated carbon GDEs on both sides. The carbon paper (commercially available Toray Carbon Paper TGP$\mathrm{H}-090)$ of $0.28 \mathrm{~mm}$ thickness and $78 \%$ porosity is pre-processed prior to the assembly in the following manner. After cutting the carbon paper in the appropriate size (12 $\mathrm{mm}$ in diameter), it is impregnated with a PTFE (60\% wt\% from Aldrich, diluted to $20 \%$ ) suspension to make it hydrophobic, so that the water-clogging problem in avoided. After impregnation and sintering at $340{ }^{\circ} \mathrm{C}$ for 30 mins, the final weight ratio of PTFE inside the carbon paper is around $50 \%$. Subsequently, $\mathrm{KH}\left(\mathrm{PO}_{3} \mathrm{H}\right)$ particles, carbon supported platinum catalyst particles $(\mathrm{Pt} / \mathrm{C})$, and $\mathrm{PTFE}$ are mixed in a ratio of 3:1:1 (by weight) and brushed onto the carbon paper to form the catalytic layer (catalyst loading: $1 \mathrm{mg} / \mathrm{cm}^{2}$ ).

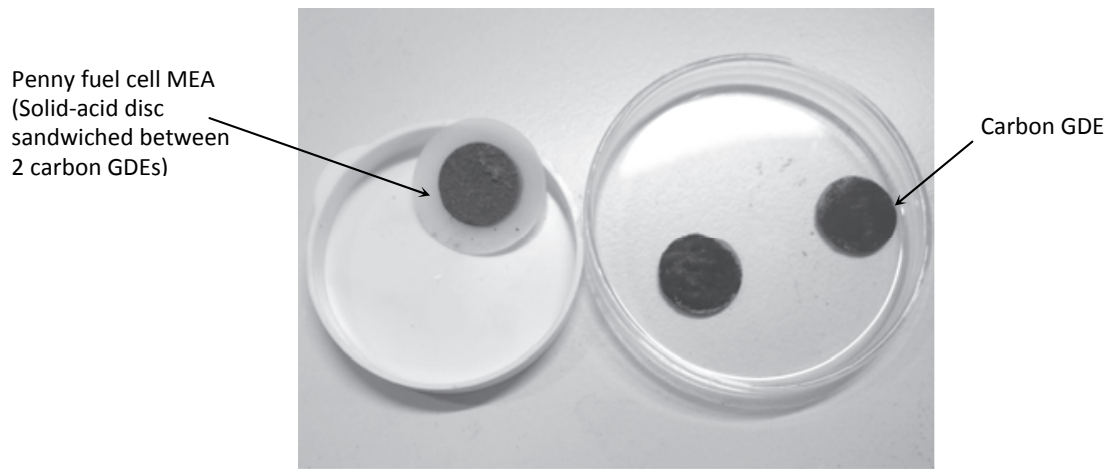

(a) 


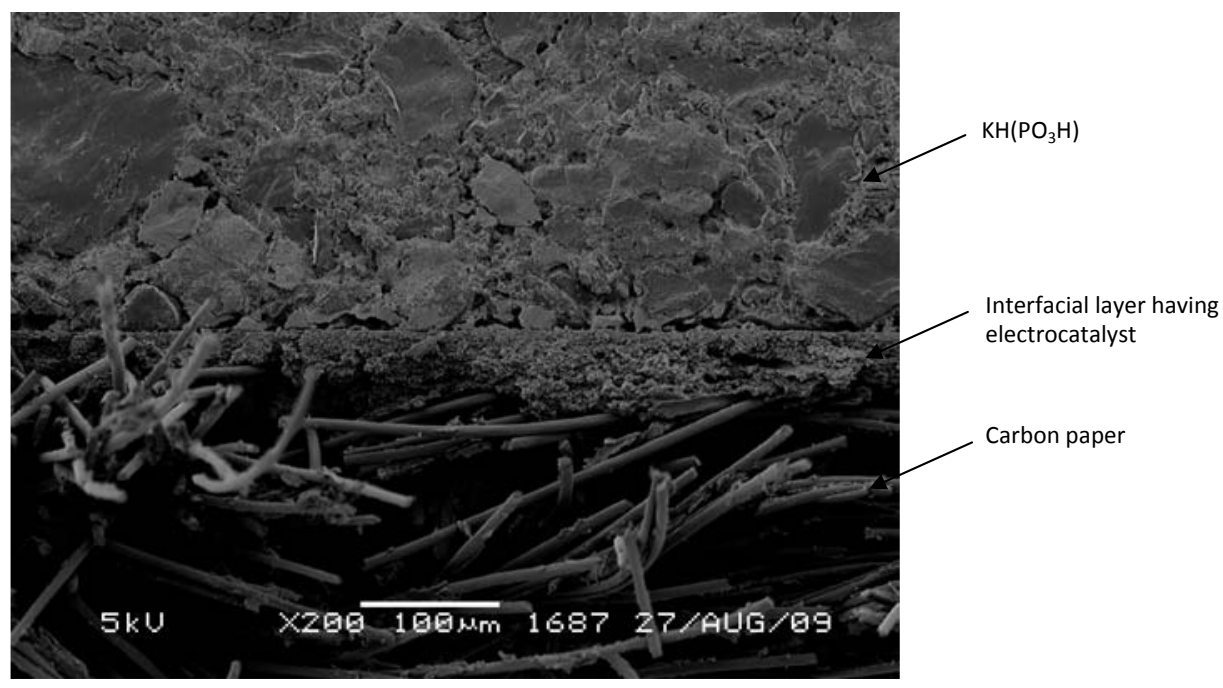

(b)

Figure 4.7: a) MEA of the $\mathrm{KH}\left(\mathrm{PO}_{3} \mathrm{H}\right)$ electrolyte based penny fuel cell b) SEM photo of the MEA crosssection showing the interface of electrolyte and the electrode

The final step involves the heat treatment of the carbon paper with the catalyst layer at $200{ }^{\circ} \mathrm{C}$ for 30 minutes to form the GDE, which is then to be assembled in the fuel cell MEA (see figure $4.7 \mathrm{a}$ ) by pressing. Shown in figure $4.7 \mathrm{~b}$ is a SEM picture of the cross-section of the MEA revealing the interface of the electrolyte and the electrode.

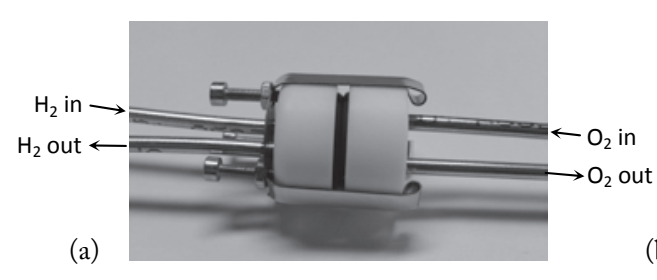

(b)

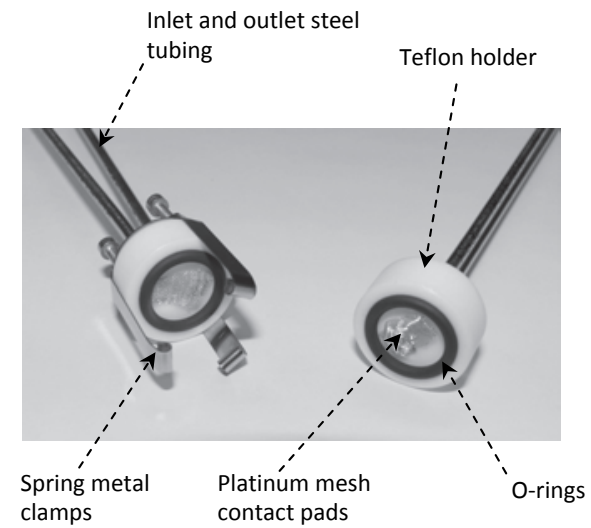

Figure 4.8: Fuel cell MEA holder a) assembled b) the holder parts 
In order to mount into a fuel cell experimental setup the MEA discs were assembled within an in-house fabricated holder (see figure 4.8). The holder is made of two parts, both having gas inlet and outlet streams in each of them. For sealing the MEA disc, Viton ${ }^{\circledR}$ O-rings are located inside the holder. For electrical contact, platinum mesh pads are used inside both holder parts. After loading the MEA disc, sealing is accomplished by tightening screws against a spring load.

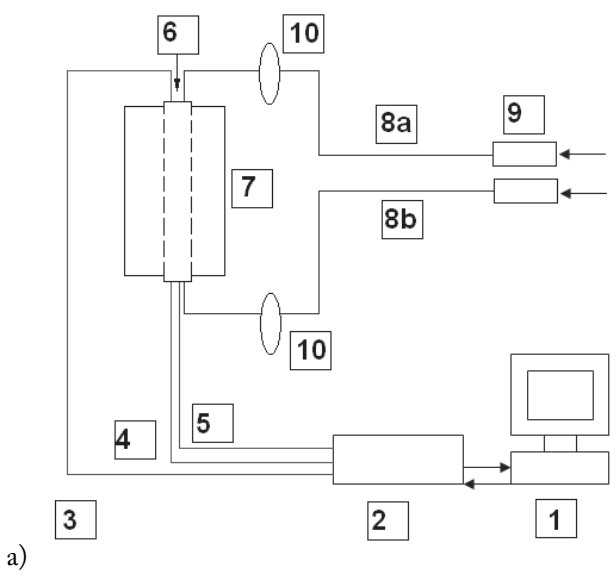

1. Computer

2. Potentiostat (PGStat20 with FRA2, Autolab)

b)

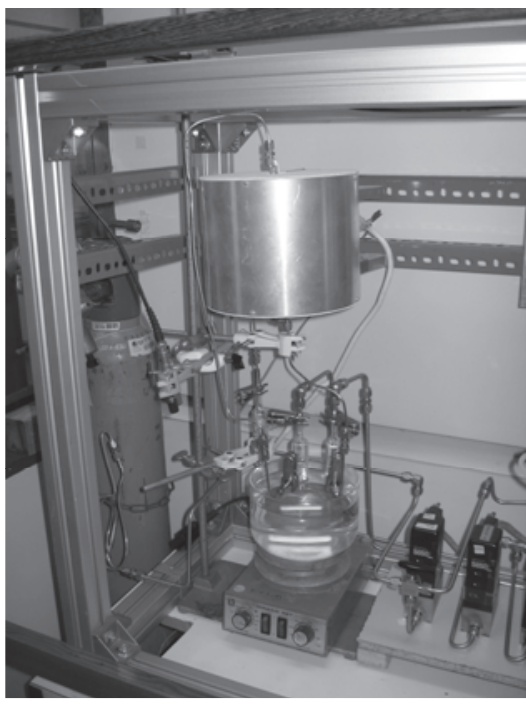

3. Working electrode (wiring, $\mathrm{Pt}$ )

4. Counter electrode (wiring, $\mathrm{Pt}$ )

5. Reference electrode (wiring, $\mathrm{Pt}$ )

6. Fuel cell

7. Oven with temperature controller

8. Gas supply tubes a) Air b) $\mathrm{H}_{2}$

9. Mass flow controllers

10. Bubbling humidifiers

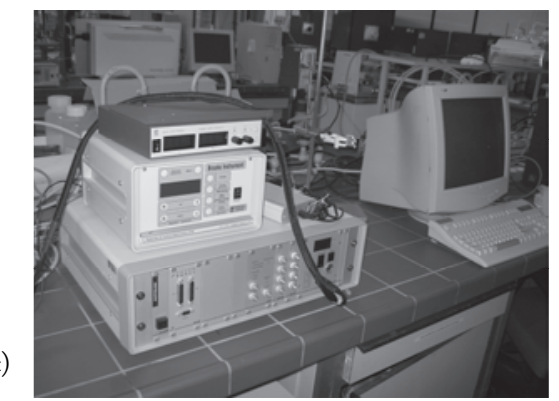

Figure 4.9: Experimental set-up for the penny fuel cell test

Figure 4.9 shows the experimental set-up used for this penny fuel cell test. It consists of a temperature regulated vertical oven within which the fuel cell MEA is loaded. Humidified fuel and air streams are supplied (at $40 \mathrm{mln} / \mathrm{min}$ and $1 \mathrm{~atm}$ 
pressure) on either sides of the MEA via water bubblers. A humidification of $3 \%$ on supply pressure is applied. For safety reasons the maximum hydrogen concentration in the fuel stream was restricted to $5 \%$. Measurement of the cell voltage and current are done using a Potentiostat (PGStat20 with FRA2, Autolab). One of the typical plots showing the performance of a fuel cell is the polarization curve. For the penny fuel cell the polarization plot is shown in figure 4.10. The penny fuel cell records an open circuit voltage $(\mathrm{OCV})$ of $0.65 \mathrm{~V}$. When a current of $0.5 \mathrm{~mA} / \mathrm{cm}^{2}$ is drawn, the voltage drops to $0.3 \mathrm{~V}$, thus leading to a power density of $0.15 \mathrm{~mW} / \mathrm{cm}^{2}$. The maximum power density increased by about 3-4 times when $30 \%$ humidification on supply pressure is applied. From figure 4.6 it was already clear that to suppress the electrolyte dehydration, a water partial pressure of $\sim 0.02 \mathrm{~atm}$ is sufficient. Thus the increment in power density with higher humidification indicates probably an enhanced proton exchange at the GDE-electrolyte interface, where the catalyst particles are dispersed. As mentioned in the previous section, with a dense electrode fuel cell the dehydration of the solid acid and the electrode-electrolyte interfaces can probably be minimized, since water has less chance to evaporate.

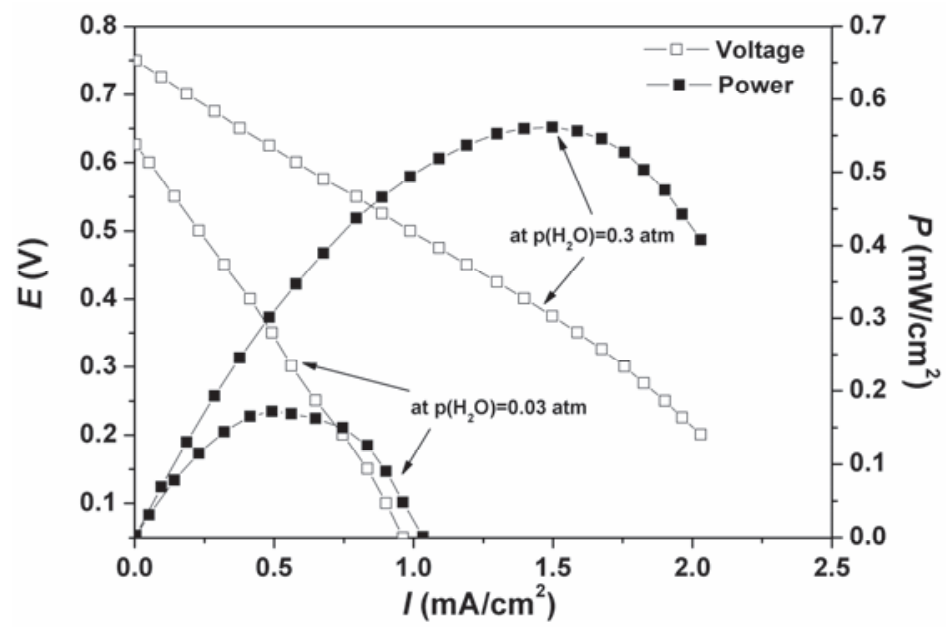

Figure 4.10: Penny fuel cell performance at $140{ }^{\circ} \mathrm{C} ; \mathrm{p}\left(\mathrm{H}_{2}\right)=0.05 \mathrm{~atm}, \mathrm{p}\left(\mathrm{O}_{2}\right)=0.21 \mathrm{~atm}$. Nitrogen is used to dilute hydrogen on the anode side and the cathode side is supplied with air. Both sides of the MEA are maintained at $1 \mathrm{~atm}$ pressure. 
It is also noted that at higher humidification, there is an enhancement in the OCV of the fuel cell. As explained earlier in this chapter, the OCV tends to get closer to the theoretical Nernst potential when the amount of leak through the fuel cell electrolyte is reduced. As the humidification is increased, the hygroscopic solid acid electrolyte absorbs more water, leading to grain swelling and more stiction between the electrolyte grains, which could cause a reduction in the intergranular gas leakage thus an increment in the fuel cell OCV.

To verify the influence of humidification on the proton exchange at the GDEelectrolyte interface, as well as on the proton conduction through the electrolyte bulk, plots of impedance spectra of the fuel cell MEA are made (see figure 4.11).

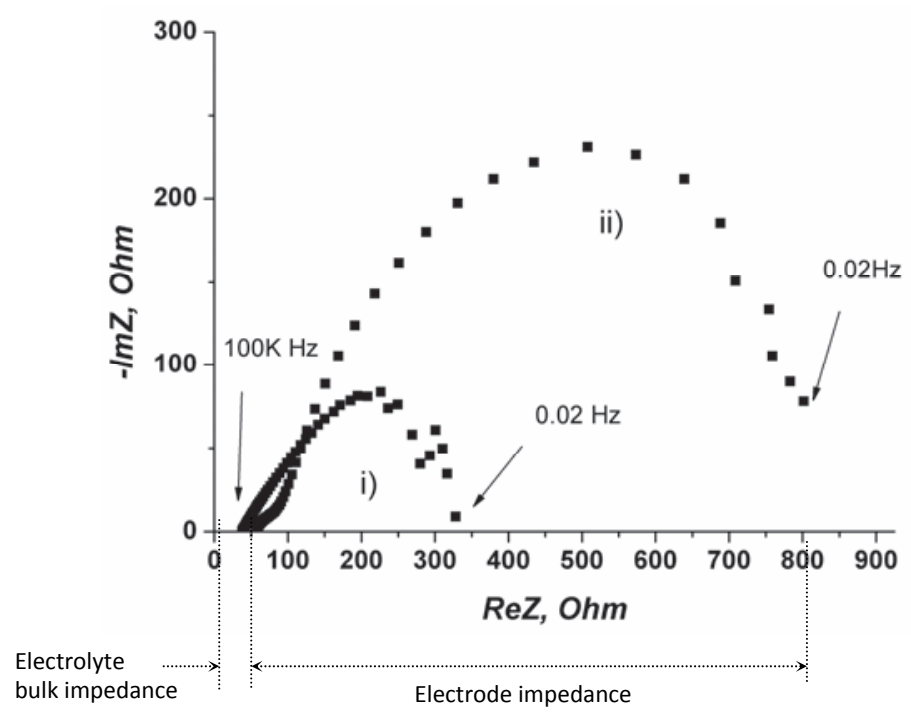

Figure 4.11: $\mathrm{MEA}$ impedance measured at $\mathrm{OCV}$ at $140{ }^{\circ} \mathrm{C} ; \mathrm{p}\left(\mathrm{H}_{2}\right)=0.05$ atm $\mathrm{p}\left(\mathrm{O}_{2}\right)=0.21$ atm i) $\mathrm{p}\left(\mathrm{H}_{2} \mathrm{O}\right)=$ $0.30 \mathrm{~atm}$ and ii) $\mathrm{p}\left(\mathrm{H}_{2} \mathrm{O}\right)=0.03 \mathrm{~atm}$.

The impedance spectra indeed show larger electrode impedance than electrolyte impedance. A ten times increase in the partial pressure of water vapor caused a considerable reduction in the electrode impedance, while the electrolyte impedance did not change much. 
Studies were also done to verify the influence of temperature on the MEA impedance. Figure 4.12 shows the impedance spectra recorded at different temperatures. A higher temperature tremendously lowers the electrode impedance and also the bulk impedance of the electrolyte. The reduction in the electrode impedance could be due to improved reaction kinetics at the GDE-electrolyte interface, which leads to an enhanced interfacial proton exchange. The reduction in electrolyte impedance is due to enhanced proton conductivity through the electrolyte bulk at higher temperatures.

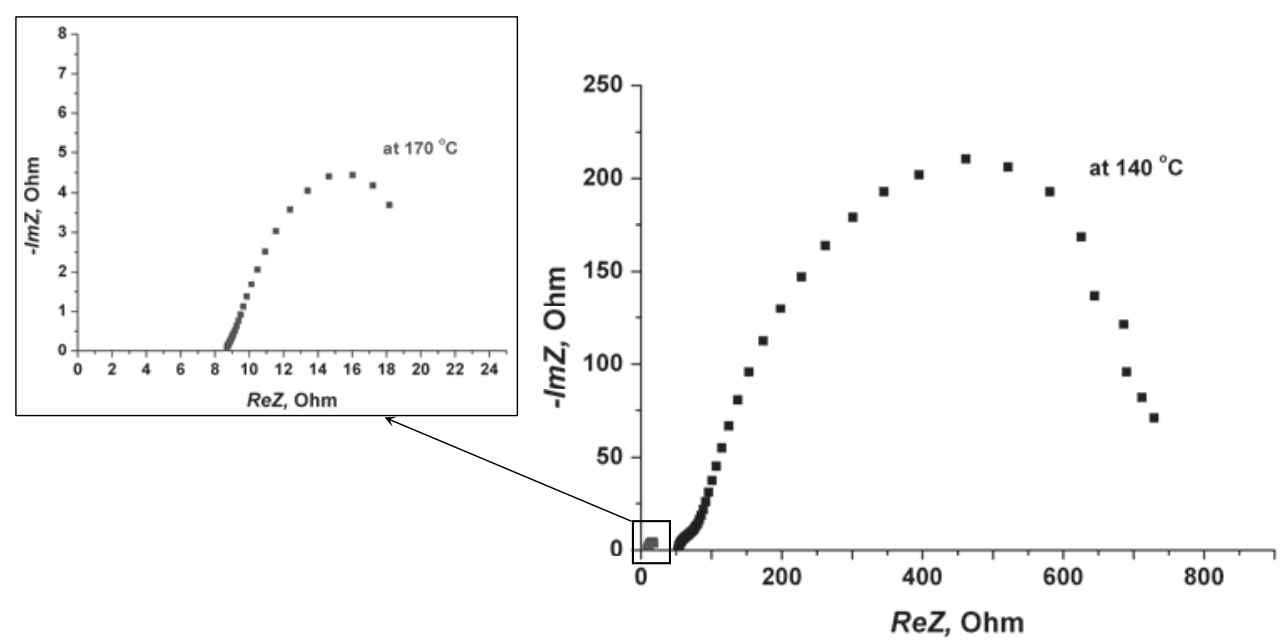

Figure 4.12: MEA impedance measured at $\mathrm{OCV}$ with different temperatures at $\mathrm{p}\left(\mathrm{H}_{2} \mathrm{O}\right)=0.03$ atm. The zoomed inset shows the reduced impedance at higher temperature $\left(170{ }^{\circ} \mathrm{C}\right)$.

A polarization plots were made to verify the influence of temperature on the performance of the fuel cell MEA, and are shown in figure 4.13. As expected, at a higher temperature the performance of the fuel cell improved. Also observed at higher temperature is a drop in the fuel cell OCV. As explained for figure 4.10, this voltage drop could be related to the porosity of the electrolyte. As the temperature is increased, the solid acid electrolyte starts to dehydrate, leading to less stiction between the grains, which causes an increase in the intergranular gas leakage and thus the voltage loss. 


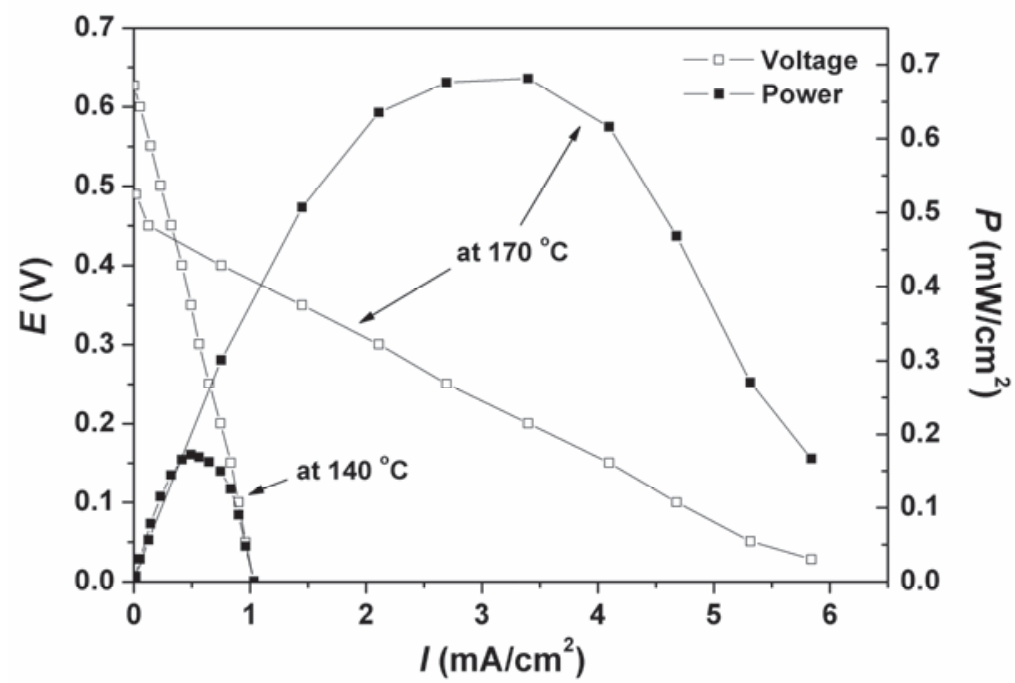

Figure 4.13: Penny fuel cell performance at $170{ }^{\circ} \mathrm{C}$ compared with that of at $140{ }^{\circ} \mathrm{C} ; \mathrm{p}\left(\mathrm{H}_{2}\right)=0.05 \mathrm{~atm}, \mathrm{p}\left(\mathrm{O}_{2}\right)=$ $0.21 \mathrm{~atm}$. Nitrogen is used to dilute hydrogen on the anode side and the cathode side is supplied with air. Both sides of the MEA are maintained at $1 \mathrm{~atm}$ pressure and a humidification of $0.03 \mathrm{~atm}$ is applied.

The penny fuel cell test has given us a brief insight into the MEA based on $\mathrm{KH}\left(\mathrm{PO}_{3} \mathrm{H}\right)$ electrolyte, although the performance still has to be optimized. The electrode impedance can be further lowered through the enhancement of electrode reaction kinetics by tuning the catalyst particle size, dispersion and loading. In order to reduce the electrolyte impedance, the thickness of the electrolyte has to be reduced to several micrometers. The following section explains the method used to obtain a thinfilm of $\mathrm{KH}\left(\mathrm{PO}_{3} \mathrm{H}\right)$.

\subsubsection{Thin-film electrolytic layer}

There are various film-coating methods like dip-coating, spin-coating, spraying, blade-casting etc., which can be used to make a solid acid thin-film. Dip-coating is chosen in our experiments due to equipment availability at the Inorganic Membranes group. Test substrates for the dip-coating process were prepared by sputter depositing a $300 \mathrm{~nm}$ palladium layer on a polished silicon wafer, by using $15 \mathrm{~nm}$ titanium adhesion layer. The dip-coating was carried out using a special apparatus shown in figure 4.14. The dip-coater works with a rotary arm mechanism, in which the sample 
to be coated is attached to the end of the arm and then slowly swiped over a solution to be dip-coated. Such a set-up ensures that only the sample surface to be coated will come in contact with the solution.

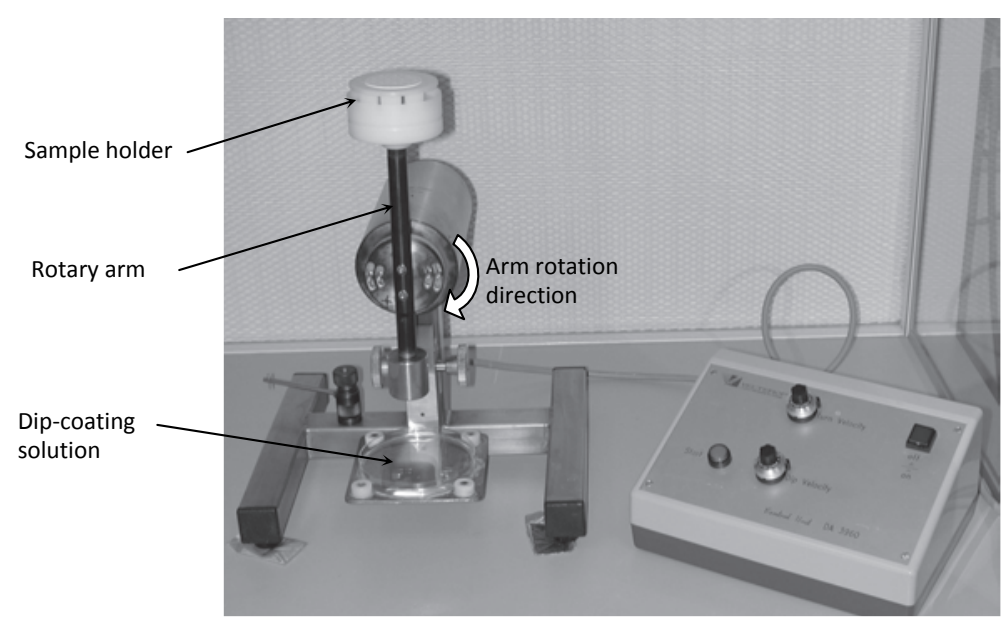

Figure 4.14: Dip-coating apparatus

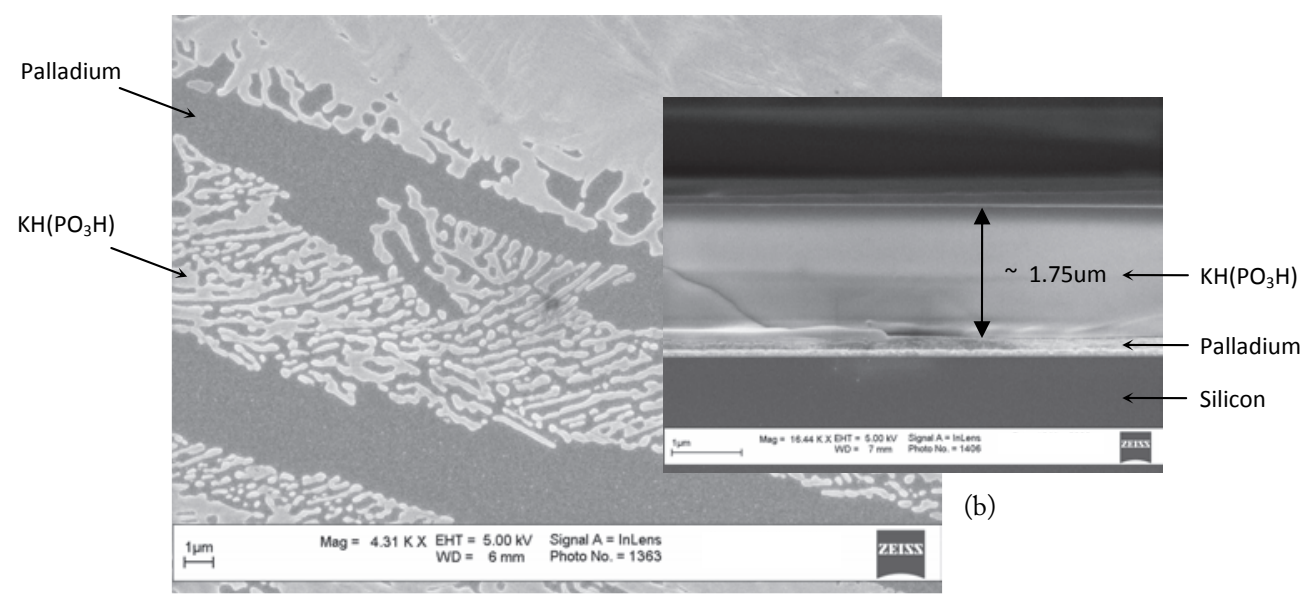

(a)

Figure 4.15: SEM photograph of the results of dip-coating potassium dihydrogen phosphite on a palladium substrate a) top view of the non-continuous layer b) cross-sectional views showing the salt layer atop the palladium at a random location. 
The contact time between the sample and the solution can be varied by regulating the arm rotation speed. The effective speed in which the solution is swiped against the sample surface is set to $10 \mathrm{~mm} / \mathrm{s}$ in our experiments. An aqueous solution of $\mathrm{KH}\left(\mathrm{PO}_{3} \mathrm{H}\right)$ (20 $\mathrm{wt} \%$ in water) is used to perform the dip-coating (at room temperature). Subsequently, the samples were dried in an oven at $40{ }^{\circ} \mathrm{C}$ for 20 hours. Figure 4.15 shows the thin-film salt layer on top of the palladium. Observed from figure 4.15 is the non-uniformly coated layer and the randomly crystallizing nature of the solid acid salt. The non-uniform coating could be due to the surface tension of the solution. The irregular crystallization is due to the uncontrolled crystal nucleation and growth during the drying process. Such random crystallization can be controlled by impregnating some fine inorganic particles inside the salt solution. The inert inorganic particles would act as nuclei for crystal formation. A lot of such nuclei dispersed in the solid acid solution cause simultaneous nucleation of small salt crystals, thus resulting in a homogenous polycrystalline layer. The impregnation of nanoparticles will also reduce the surface tension of the aqueous solution [19], thereby resulting in a more uniformly coated salt layer. Moreover, suspended silica particles can modify the solution viscosity and rheological properties [20], which is helpful in a continuous layer formation. For the subsequent dip-coating experiments, silica nanoparticles (fumed silica, Aldrich, approx. size of $14 \mathrm{~nm}$ ) were added into the aqueous solution of solid acid resulting in a mixture $\mathrm{KH}\left(\mathrm{PO}_{3} \mathrm{H}\right) / \mathrm{SiO}_{2} / \mathrm{H}_{2} \mathrm{O}$ in the proportion 4:1:20 (by weight) respectively.

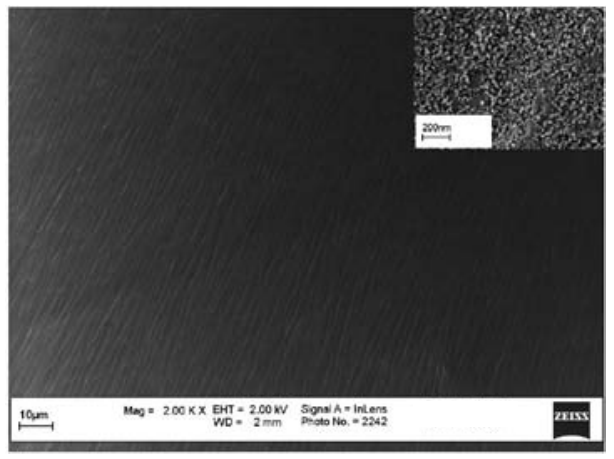

(a)

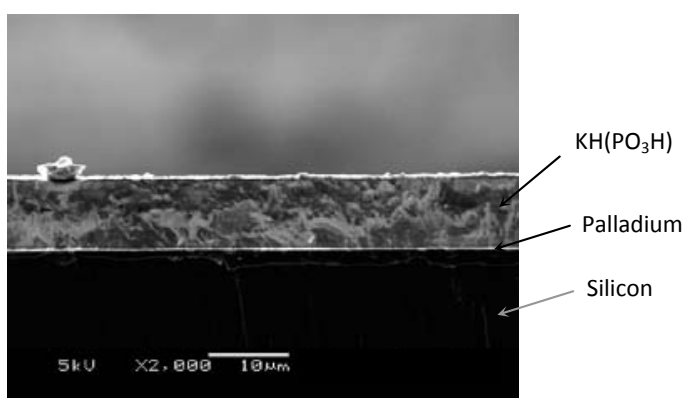

(b)

Figure 4.16: SEM image of the dip coated thin-film $(10 \mu \mathrm{m})$ composite $\mathrm{KH}\left(\mathrm{PO}_{3} \mathrm{H}\right) / \mathrm{SiO}_{2}(80 / 20 \mathrm{wt} \%)$. a) top view b) cross-sectional view. 
Figure 4.16 shows the SEM pictures of a sample dip-coated with the new solution. The surface is much improved, with a better control over random crystallization. The cross-section shows a seemingly dense and uniform layer of $10 \mu \mathrm{m}$ thickness.

The proton conductivity of this $10 \mu \mathrm{m}$ thick solid acid composite layer is measured and plotted in figure 4.17. The thin-film also shows a superprotonic transition similar to that of the compressed solid acid pellets, although the transition point is not sharply marked. The superprotonic conductivity of the thin-film is observed to be slightly less than that of pure compressed pellets, which could be due to the effect of impregnated silica particles [18]. At lower temperatures the conductivity of the thin-film composite seems to be better than the pure salt, the reason for which is not clear.

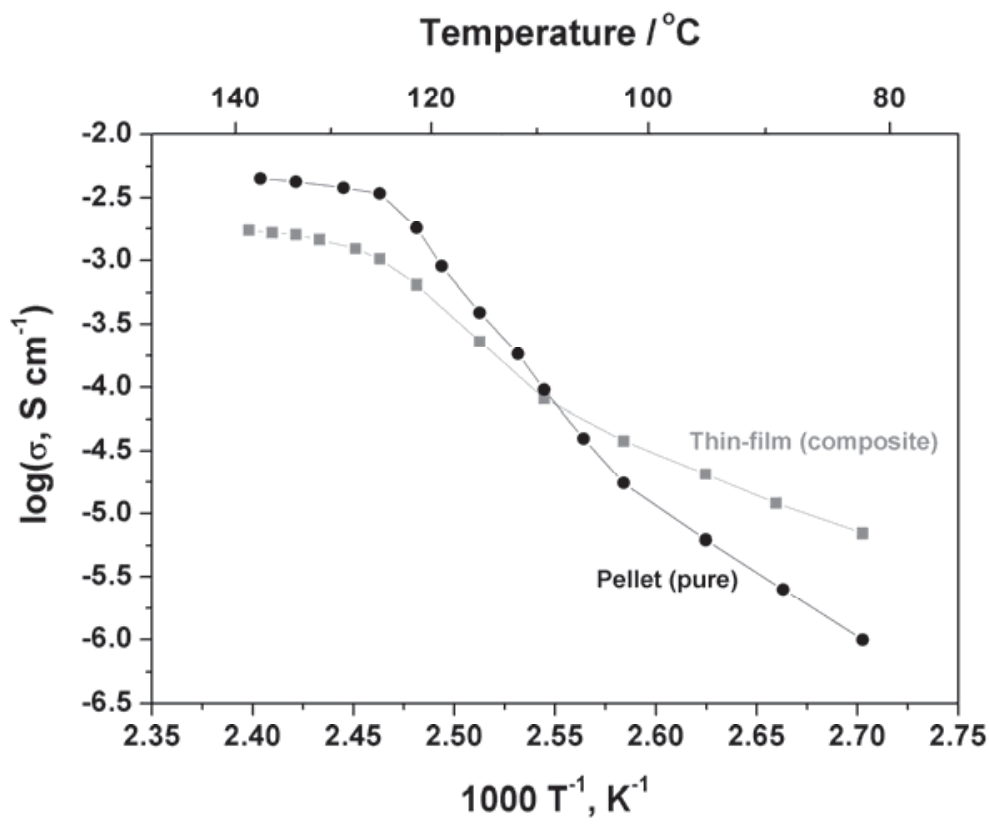

Figure 4.17: Comparison of proton conductivities of $10 \mu \mathrm{m}$ thin-film composite $\mathrm{KH}\left(\mathrm{PO}_{3} \mathrm{H}\right) / \mathrm{SiO}_{2}(80 / 20 \mathrm{wt} \%)$ layer and a $0.5 \mathrm{~mm}$ thick compressed solid acid (pure) pellets.

Based on data from figure 4.17 , the area specific conductivity $\sigma_{\mathrm{AS}}\left[\mathrm{S} / \mathrm{cm}^{2}\right]$ of the 10 $\mu \mathrm{m}$ thin-film seems to be around an order of magnitude higher than that of the 0.5 mm thick compressed pellets. 


\subsubsection{Thin-film MEA}

With the above shown results of the thin-film solid acid, the next step is to assemble the electrodes with the electrolyte to form the MEA. Two different configurations were tried for the MEA formation.

\section{Configuration 1: Deposited second electrode}

In this configuration, first a microsieve supported dense palladium electrode (described in chapter 3 ) is coated with a $\sim 40 \mu \mathrm{m}$ thick solid acid film using the dipcoating technique. Subsequently, after drying, a second palladium thin-film electrode is deposited over it. Figure 4.18 shows the illustration of MEA configuration-1. The trials with such an assembly method failed due to the non-dense electrolyte film. Although in figure $4.16 \mathrm{~b}$ the electrolyte layer seems to be visually dense, during the sputter deposition of the second palladium electrode, the atoms of palladium penetrated through the solid acid layer, thereby causing short-circuit in the MEA.

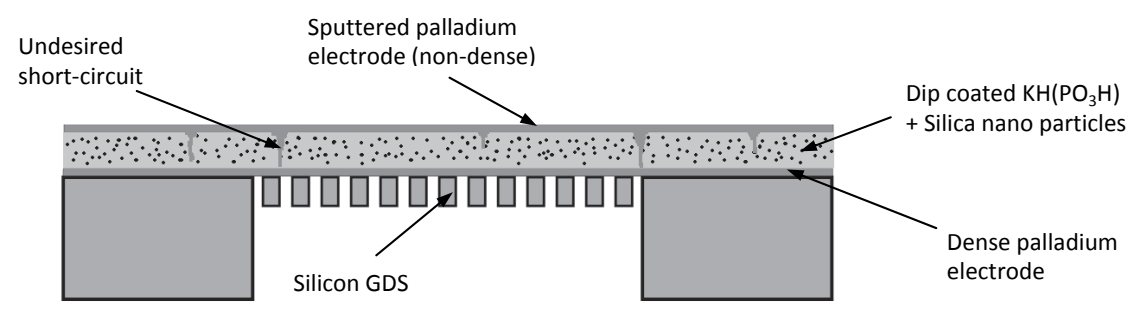

Figure 4.18: MEA configuration-1. Also depicted are the undesired short-circuits caused due to palladium passing through the porous electrolyte layer.

More optimization is required for the dip-coating and drying process to ensure a completely dense thin-film solid acid layer. The drying process needs to be performed in a humidity controlled cabinet, which helps in having more control over the solid acid crystallization process, rendering a denser layer. Increasing the content of the silica nanoparticles could increase layer quality, but would lead to a drop in its proton conductivity [18]. Other thin-film coating techniques such as spin-coating, bladecasting could probably serve as an alternative to the dip-coating process. However, the 
short-circuit problem faced in configuration-1 can be tackled in a different way, as will be shown in the following section.

\section{Configuration 2: Two microsieve supported electrodes}

In this configuration, two microsieve supported palladium electrodes are coated with a solid acid film of $\sim 20 \mu \mathrm{m}$. After drying, the two electrodes are contacted on the electrolyte side (as shown in figure 4.19) and annealed at $190{ }^{\circ} \mathrm{C}$ for about 5 mins. This temperature is chosen since it was experimentally found to be the melting and reflowing temperature of $\mathrm{KH}\left(\mathrm{PO}_{3} \mathrm{H}\right)$. Figure 4.20 shows differential thermal analysis (DTA) and thermo gravimetry (TG) measurements of $\mathrm{KH}\left(\mathrm{PO}_{3} \mathrm{H}\right)$ performed under nitrogen atmosphere. It is clear from these measurements that dehydration and melting start to occur around $190{ }^{\circ} \mathrm{C}$ and decomposition of $\mathrm{KH}\left(\mathrm{PO}_{3} \mathrm{H}\right)$ happens at a much higher temperature $\left(\sim 300{ }^{\circ} \mathrm{C}\right)$. Subsequent conductivity measurements of the salt after melting and re-solidification also indicated no change in its superprotonic conductivity (as seen in figure 4.21).

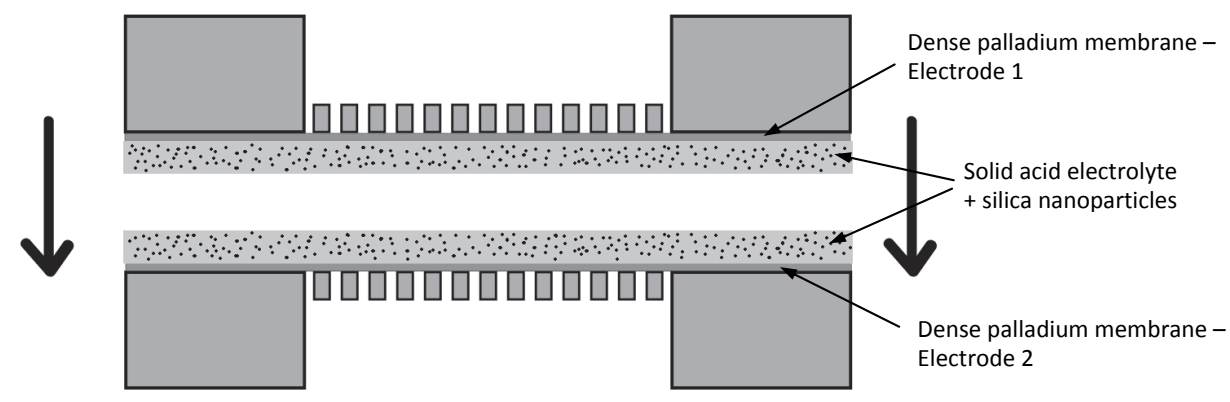

Figure 4.19: MEA configuration-2

Although the electrolyte did not denature, another unexpected problem occurred during the MEA assembly. During heating, as the temperature got closer to $190{ }^{\circ} \mathrm{C}$, the electrolyte started to degas and released bubbles, thus leading to failure of the assembly. This issue needs further investigation to understand the source of the bubbles and methods to suppress its formation. Material analysis has to be carried out to determine the properties of the electrolyte after it has completely degassed when annealed for a long time at $190{ }^{\circ} \mathrm{C}$. Since its possible to completely melt $\mathrm{KH}\left(\mathrm{PO}_{3} \mathrm{H}\right)$ 
and handle it like a liquid, methods like injecting the molten electrolyte between two electrodes could be an alternative option to be studied.

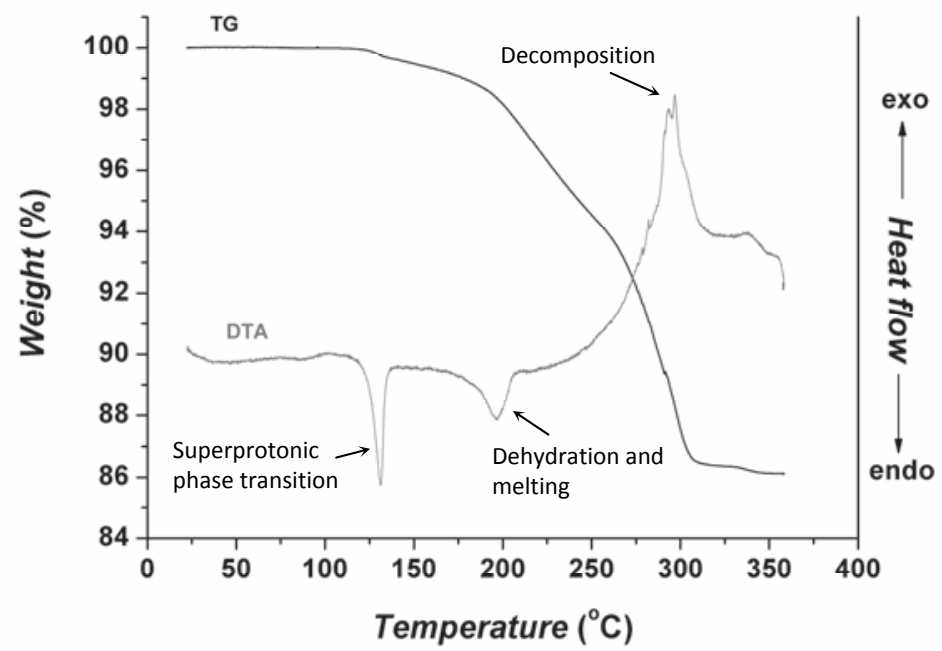

Figure 4.20: Differential Thermal Analysis and Thermal Gravimetry data of the pure $\mathrm{KH}\left(\mathrm{PO}_{3} \mathrm{H}\right)$ electrolyte.

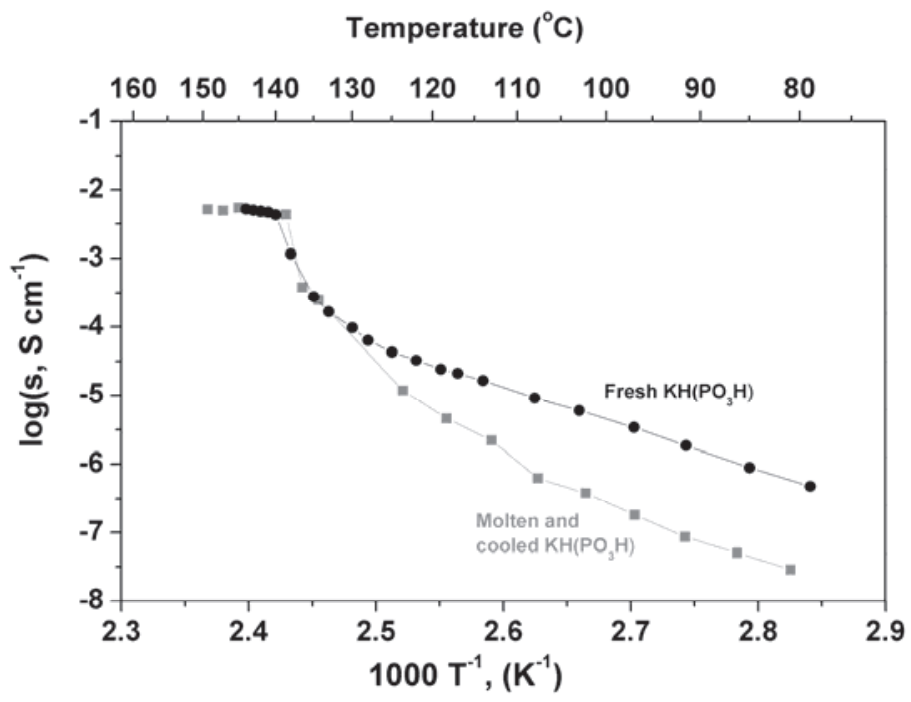

Figure 4.21: Comparison between the protonic conductivities of $\mathrm{KH}\left(\mathrm{PO}_{3} \mathrm{H}\right)$ pellets before and after the short annealing (5 mins) at $190{ }^{\circ} \mathrm{C}$. 


\subsection{Conclusions}

A relatively new kind of solid acid, potassium dihydrogen phosphite - $\mathrm{KH}\left(\mathrm{PO}_{3} \mathrm{H}\right)$, has been investigated as a potential electrolyte for the $\mu \mathrm{SAFC}$. This solid acid type was found to have a proton conductivity of $3.8 \cdot 10^{-3} \Omega^{-1} \mathrm{~cm}^{-1}$ at $135{ }^{\circ} \mathrm{C}$ just above the superprotonic transition temperature of $132{ }^{\circ} \mathrm{C}$. Phosphite solid acids are stable in hydrogen atmospheres unlike their sulphate and selenate counterparts. And when compared to phosphates, the humidification required for phosphites to prevent dehydrative weight loss was found to be much less.

To get an initial understanding of the solid acid fuel cell, experiments have been performed with a penny fuel cell consisting of a compressed electrolyte disc $(\sim 0.5 \mathrm{~mm}$ thick) with catalyst coated carbon electrodes on both sides. The measured OCV for the penny fuel cell is about $0.65 \mathrm{~V}$. When a current of $0.5 \mathrm{~mA} / \mathrm{cm}^{2}$ is drawn, the voltage drops to $0.3 \mathrm{~V}$, thus leading to a power density of $0.15 \mathrm{~mW} / \mathrm{cm}^{2}$. The maximum power density increased by about 3-4 times when the humidification was enhanced from $3 \%$ to $30 \%$ of the supply pressure, which shows that the dehydration of the electrolyte and its interfaces with the electrode could be significant. This observed performance of the penny fuel cell is very low as compared to a power density of $0.4 \mathrm{~W} / \mathrm{cm}^{2}$ at $0.4 \mathrm{~V}$ for solid acid fuel cells reported in literature [21]. This poor performance could be mainly due to bad electrode kinetics. The number of triple phase boundaries at the electrode-electrolyte interface has to be enhanced by increasing the platinum loading and by modifying the electrode-electrolyte assembly technique.

Dip-coating has been tested to be a suitable technique to make thin-films of the $\mathrm{KH}\left(\mathrm{PO}_{3} \mathrm{H}\right)$. Attempts were made to fabricate thin-films of the electrolyte down to 10 $\mu \mathrm{m}$ thickness. Impregnation with inorganic particles ( $14 \mathrm{~nm}$ size) helps to suppress random crystallization of the solid acid during drying, which was found to be a problem for pure salts. Thin-film solid acid composite layers exhibited a lower proton conductivity than that of $0.5 \mathrm{~mm}$ thick compressed solid acid pellets, which could be an effect of impregnated silica particles.

Two different assembly configurations have been tried to make a thin-film MEA. Both the configurations could not be successfully fabricated due to various problems of the electrolyte layer as discussed in section 4.3.3. The thin-film electrolyte layer needs further optimization before it can be integrated within the MEA. A detailed 
description of the $\mathrm{KH}\left(\mathrm{PO}_{3} \mathrm{H}\right)$ electrolyte, its thin-film coating processes and the final $\mu$ SAFC MEA integration will be provided in a second thesis by co-researcher Weihua Zhou.

\section{Acknowledgements}

I would like thank teammates Weihua Zhou and Alexander S. Bondarenko of the Inorganic Membranes group, for their contributions relating to the work on the solid acid electrolyte. My special thanks to Dr. Henny Bouwmeester for useful discussions and guidance on this subject.

\section{References}

[1] S. Gottesfeld and T. Zawodzinski, Advances in Electrochemical Science and Engineering; R. C. Alkire, H. Gerischer, D. M. Kolb and C. W. Tobias (Eds.); Wiley-VCH: Weinheim, New York, 1997; Vol. 5.

[2] D.D. Wagman, W.H. Evans, V.B. Parker, R.H. Schumm, I. Halow, S.M. Bailey, K.L. Churney, R.L. Nutall, Journal of Physical Chemistry,1982, 11 (suppl. 2).

[3] S.M. Haile, Acta Materialia, 2003, 51, pp.5981-6000

[4] D.R. Crow, Principles and applications of electrochemistry, 3rd ed. London: Chapman \& Hall, 1988

[5] D. A. Boysen, Superprotonic Solid Acids: Structure, Properties, and Applications, PhD Thesis, California Institute of Technology, Pasadena, California, 2004

[6] C. R. I. Chisholm, Superprotonic Phase Transitions in Solid Acids: Parameters affecting the presence and stability of superprotonic transitions in the $M H n X O 4$ family of compounds $(X=S, S e, P$, $A s ; M=L i, N a, K, N H 4, R b, C s), \mathrm{PhD}$ Thesis, California Institute of Technology, Pasadena, California, 2002

[7] A. I. Baranov, L.A. Shuvalov and N.M. Shchagina, JETP Letters, 1982, 36, pp.459-462

[8] R. Blinc, J. Dolinsek, G. Lahajnar, I. Zupancic, L.A. Shuvalov, and A.I. Baranov, Physica Status Solidi B, 1984, 123, pp.83-87

[9] B. V. Shchepetil'nikov, A.I. Baranov, L.A. Shuvalov and V.A. Dolbinina, Soviet Physics- Solid State, 1990, 32, pp.142-147 
Chapter 4: The Membrane Electrode Assembly

[10] S. M. Haile, D. A. Boysen, C. R. I. Chisholm and R. B. Merle, Nature, 2001, 410 (19), pp.910-913

[11] M. Komukae, T. Osaka, Y. Makita, K. Itoh and E. Nakamura, Journal of the Physical Society of Japan, 1981, 50, pp.3187-3188

[12] D.A. Boysen, T. Uda, C.R.I. Chisholm, S.M. Haile, Science, 2004, 303, pp.68-70

[13] T. Uda and S. M. Haile, Electrochemical and Solid-State Letters, 2005, 8 (5), A245-A246

[14] C.R.I. Chisholm, R.B. Merle, D.A. Boysen, S.M. Haile, Chemistry of Materials, 2002, 14, p.3889

[15] W. Zhou, A.S. Bondarenko, B.A. Boukamp, H.J.M. Bouwmeester, Solid State Ionics, 2008, 179, pp.380-384

[16] V.G. Ponomareva and G.V. Lavrova, Solid State Ionics 2001, 145, p.197

[17] E. Ortiz, R.A. Vargas, B.E. Mellander, Journal of Physics: Condensed Matter, 2006, 18, p. 9561

[18] A.S. Bondarenko, W. Zhou, H.J.M. Bouwmeester, Journal of Power Sources, 2009, doi:10.1016/j.jpowsour.2009.06.001

[19] S. Vafaei, A. Purkayastha, A. Jain, G. Ramanath and T. Borca-Tasciuc, Nanotechnology, 2009, 20, 185702

[20] K. Yokoyama, Y. Koike, A. Masuda, M. Kawaguchi, Japanese Journal of Applied Physics, 2007, 46 (1), pp.328-332

[21] T. Uda and S. M. Haile, Electrochemical and Solid-State Letters, 2005, 8 (5), A245-A246 



\section{Membrane Packaging}

In this chapter a novel packaging cum interfacing technique for microfluidic devices is reported. This new method employs standard glass tubes as substrates onto which microfluidic components are fabricated. The tubular-substrate directly translates into a package and an interface, leading to 'plug-n-play' devices. The external handling forces on the microfluidic system are redirected towards the tube thus improving device robustness. This packaging enables such a $M E M S$-on-tube assembly to be encapsulated within standard Swagelok $k^{\oplus}$ connectors. Such a packaging technique can be used for the independent characterizations of the individual components of a membrane electrode assembly (MEA) of a fuel cell.

Most of the contents of this chapter have been published in Lab Chip, 2009, 9, pp. 1966-1969. The novel method for membrane packaging and interfacing is filed as a European patent: EP08007746.4, April 2008. 


\subsection{Introduction}

Microfluidics is a tremendously growing field with applications in gasseparation, filtration, microreactors, Lab-On-a-Chip (LOC) systems etc. [1,2,3,4]. One of the main challenges faced by such systems is to have hermetic packaging and interfacing to the external world. A reliable package must consist of a robust support and a suitable interface to the equipment where it would be implemented. Providing leak-proof connections to such microfluidic chips is non-trivial. Usually, interconnections to such microchips are made via mechanical clamping or by gluing $[5,6]$. In order to attain hermetic sealing, mechanical clamps exert forces on the delicate microchips, which could lead to breakage. Glued connections, on the other hand, could block channels and/or capillaries and moreover cannot withstand harsh thermal and chemical environments. Presented in this chapter is a convenient solution: "MEMS-on-tube assembly" to hermetically package microsystems using tubularsubstrates, which at the same time solves the interfacing issue. By using the MEMSon-tube assembly technique, it is possible to assemble microfluidic devices onto glass tube supports and to encapsulate them within Swagelok ${ }^{\varpi}$ connectors. The tube acts as a support for the relatively smaller and fragile microfluidic device, while also being a functional part of the system. Micro Electro Mechanical Systems (MEMS) or Micro System Technology (MST) has been mostly based on a two-dimensional fabrication methodology involving processes being carried out on planar silicon or glass substrates. Extending microsystems in the third dimension could open a new perspective for the MEMS community and form a base for the next-generation micro/nano systems [7]. With 3D-micromachining, the design, fabrication, packaging and interfacing constraints of planar microsystems can disappear. In this chapter, we show a new micromachining method employing three-dimensional tubular substrates. The substrates used here are commercially available Duran ${ }^{\oplus}$ or Pyrex ${ }^{\oplus}$ glass tubes. Micromachining devices on such substrates lead directly to a package that is interfacable to standard pipe connectors. This technique has been successfully employed for the independent characterization of the gas diffusive support (GDS) of the electrode (as shown in chapter 2 and 7), before assembly into the membrane electrode assembly (MEA) of the solid acid fuel cell. 
The outline of this chapter is as follows. An explanation of the fabrication process for attaining the MEMS-on-tube assembly package is followed with the description of its novelty. Subsequently, few applications examples like membrane based sensor/actuator, fluid filter, gas separator, and a check valve are depicted, which shows its ease of usability. Next, the characterization results for the quality and robustness of this package cum interface are presented. Finally, the advantages and limitations of this new technique are discussed.

\subsection{Fabrication technique}

The basic fabrication scheme involves: Preparation of the micro(fluidics) component $\rightarrow$ Preparation of the tubular substrate $\rightarrow$ Assembly of the micro(fluidics) component onto the tubular substrate $\rightarrow$ Continuing micromachining of the tube assembled MEMS (if required) $\rightarrow$ Direct mounting of the MEMS-on-tube assembly within the Swagelok $\rightarrow$ Test and usage of the microsystem. Based on this fabrication scheme, there is a class of various tube assembled devices possible like thin-film membranes, particle-filter, gas-separators, and micro-valves, which are discussed later in this section. However, first the main novelties of the MEMS-on-tube concept are discussed.

\subsubsection{MEMS-on-tube: main concept}

The basic idea of MEMS-on-tube assembly is, as the name says, the assembly of small micromachined components onto relatively large tubular-substrates instead of the usual vice versa practice, where small tube(s) are connected to larger planar microchips. The selection of the package first and adjusting the microsystem to fit to it increases modularity [8]. This assembly can be mounted onto various equipments by a double-Swagelok ${ }^{\circledast}$ technique (see figure 5.1), which secures the device within the connector.

The integration of the tubular glass substrate with the microsystem can be done at various stages of the fabrication process depending on the intended application. The glass tubes are integrated to the wafer using a fusion bonding technique [9], previously reported from our group. After placing the glass tubes on the wafer in an oven, they are heated up to $800{ }^{\circ} \mathrm{C}$, where the glass begins to soften. Since the viscosity of the glass is lowered at this high temperature, it starts to reflow thereby covering the glass- 
silicon interface by capillarity. Given enough time for glass to flow at the elevated temperature, homogenous coverage of the bonding region is obtained. When the oven is cooled down, glass solidifies to form a stable bond [10]. Homogeneity of the bond across the mating surfaces of the glass tube and silicon is crucial for the hermeticity. For this reason the preparation of the glass tube prior to bonding plays an important role. After dicing the tubes to appropriate lengths, they are polished to optical grade.

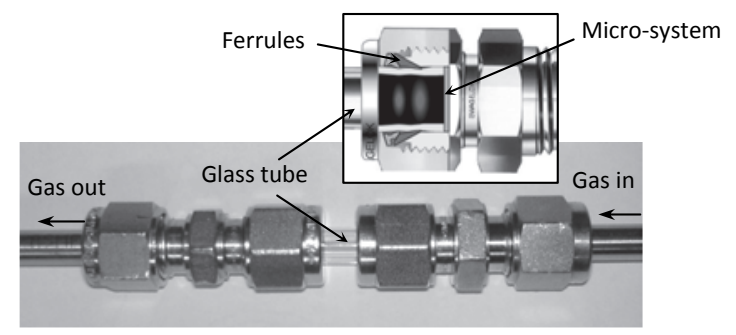

Figure 5.1. The double-Swagelok ${ }^{\circledR}$ connection technique for tube-assembled MEMS devices. Cut-sectional representation showing the MEMS device on one end of the glass tube.

It was suggested by Fazal [9] that multiple glass tubes can be bonded to a microfluidic chip to act as fluidic interconnects. The problem of a chip with multiple non-concentric tube connections is that they could fail at their interface due to external handling loads (torsional and bending forces) while tightening connectors like Swagelok ${ }^{\oplus}$. In our approach, this issue is solved by confining the microsystem within the glass tube's circumference. By this means the external handling forces on the microfluidic system are redirected from the microsystem and the bond-interface towards the glass tube. It is also possible to provide multiple inlet and outlet connections to a microsystem using our technique, as would be illustrated later in this chapter.

\subsubsection{MEMS-on-tube: micro-membranes}

For many applications in the field of acoustics or pressure sensing [11], a free hanging thin membrane is useful. Such a micromachined membrane can be easily supported and interfaced using the MEMS-on-tube approach as explained below. The fabrication process (see figure 5.2a) involves batch-bonding (figure 5.3) of the glass 
tubes to a wafer having a uniformly deposited thin-film material; in this case a $1 \mu \mathrm{m}$ thick LPCVD silicon nitride layer. Subsequently, the silicon wafer is dissolved in $\mathrm{KOH}$ solution, which results in the release of the membrane, free-hanging on the glass tubes. The tubes are easily separated from each other by cleaving them from the thin silicon nitride membrane between them. Shown in figure $5.2 \mathrm{~b}$ is the $1 \mu \mathrm{m}$ thick free-hanging silicon nitride membrane packaged onto a glass tube of $1.5 \mathrm{~mm}$ wallthickness and $3 \mathrm{~mm}$ inner-diameter.

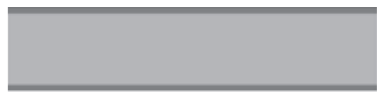

i) LPCVD growth of $1 \mu \mathrm{m} \mathrm{Si}_{3} \mathrm{~N}_{4}$ on silicon wafer

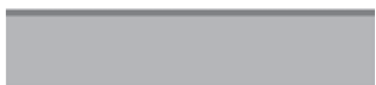

ii) Plasma etching of the $\mathrm{Si}_{3} \mathrm{~N}_{4}$ layer on one side

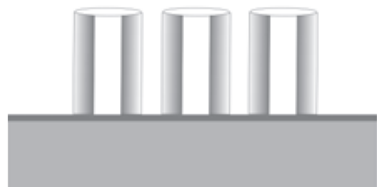

iii) Fusion bonding of Duran ${ }^{\oplus}$ glass tubes at $800{ }^{\circ} \mathrm{C}$

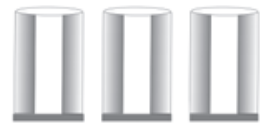

iv) Releasing the tube-assembled membranes by $\mathrm{KOH}$ etching of the silicon wafer

(a)

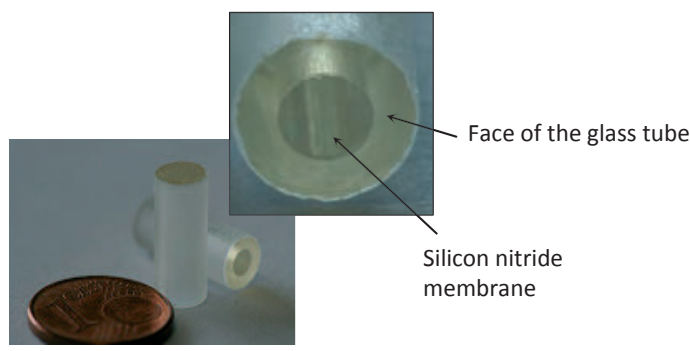

(b)

Figure 5.2. a) Fabrication process for making free-hanging silicon nitride membrane assembled on a glass tube b) $1 \mu \mathrm{m}$ thick silicon nitride membrane packaged on a glass tube of $\varnothing 3 \mathrm{~mm}$ internal diameter 
Hermetically packaged, free-hanging thin-film membranes like these can be further processed to make pressure sensors or membrane actuators. Alternatively, by drilling a hole in the center of the membrane (and with additional processing), it could be used for fluid flow sensing or fluid temperature sensing applications. If the hole at the center of the membrane is drilled extremely small with Focussed Ion Beam (FIB) technique, it could also suit applications like bio-molecule isolation or single-cell characterization, which can be of high interest to Lab-on-a-Chip researchers.

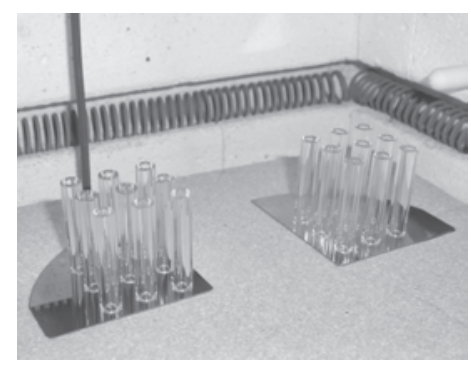

Figure 5.3. Fusion bonding of a batch of glass tubes of $30 \mathrm{~mm}$ length onto silicon wafer

The glass tubes used here can be of any desired diameters (depending on the availability of Swagelok ${ }^{\circledast}$ connector sizes) and wall thicknesses, which are defined based upon the desired strength of the membrane. Choosing tubes with smaller internal diameters can increase the membrane strength as well as reduce the tube deadvolume substantially. Borosilicate glass tubes with inner diameter down to $90 \mu \mathrm{m}$ are commercially available [12].

Like dense membranes, it is also possible to assemble perforated membranes (like the gas diffusive support shown in chapter 2) on a glass tube. Described in figure 5.4a is the fabrication process for making a tube assembled particle filter. After photolithography of a hexagonally packed pattern of $\varnothing 5 \mu \mathrm{m}$ microholes on a silicon wafer, they are plasma etched $90 \mu \mathrm{m}$ deep (see figure 5.4a(ii)). After stripping of the mask and proper cleaning, the wafer is oxidized to grow an etch stop layer (see figure 5.4a(iii)). Next, the entire wafer is plasma back-etched till the stop-layer is exposed, which is then stripped in hydrofluoric acid, thus resulting in a perforated silicon membrane sieve (figure 5.4a(iv)). Subsequently, as shown in figure $5.4 \mathrm{a}(\mathrm{v})$, glass tubes of desired size are fusion bonded as a batch onto the wafer and each of the tubes are just cleaved out of the wafer aided by the orderly microholes pattern. Seen in figure 
5.4b is a $90 \mu \mathrm{m}$ thick silicon particle filter with $\varnothing 5 \mu \mathrm{m}$ pores and $18 \%$ porosity, assembled on a glass tube.

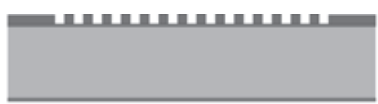

i) Photolithography of the $\varnothing 5 \mu \mathrm{m}$ microsieve mask pattern

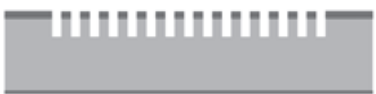

ii) DRIE Etching $\varnothing 5 \mu \mathrm{m}$ holes $90 \mu \mathrm{m}$ into silicon wafer

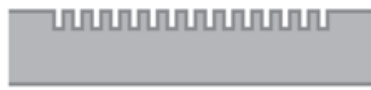

iii) Oxidation of the wafer to grow $\mathrm{SiO}_{2}$ stop-layer

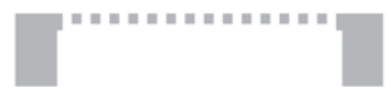

iv) Wafer back-etching and stripping of the stop-layer in $\mathrm{HF}$

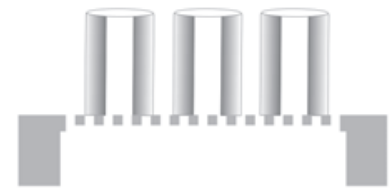

v) Fusion bonding of Duran ${ }^{\circ}$ glass tubes on the sieve at $800^{\circ} \mathrm{C}$

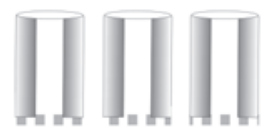

vi) Breaking away of the tube-bonded particle filters

(a)

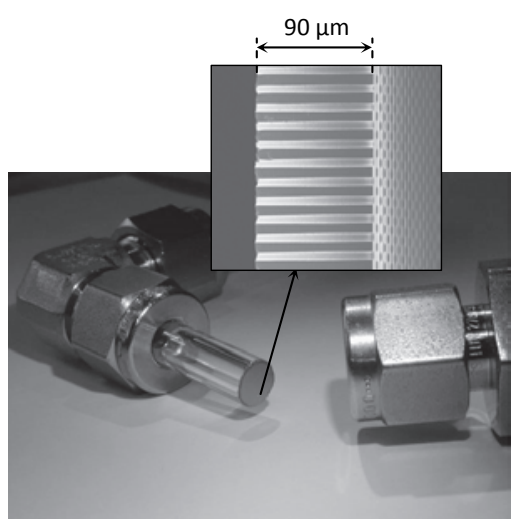

(b) 


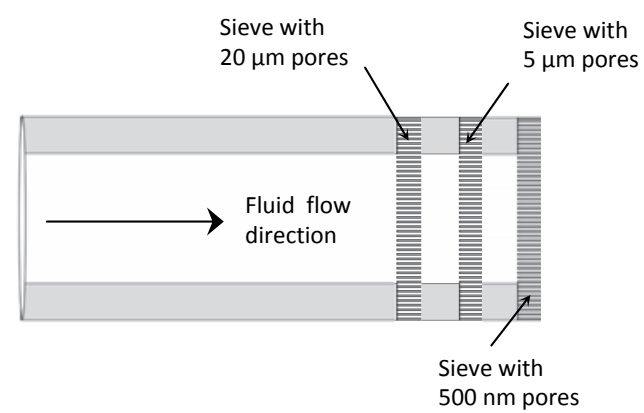

(c)

Figure 5.4. a) Fabrication process flow for making a glass tube assembled particle filter membrane b) Picture of a silicon microsieve particle filter (with $\varnothing 5 \mu \mathrm{m}$ pores) on a glass tube within a double-Swagelok ${ }^{\varpi}$ ) Illustration of a multi-stage particle filter with sieves with different pore-sizes bonded in a series.

\subsubsection{MEMS-on-tube: gas separators}

For gas separation and reaction applications, ultra-thin membranes are desired because thinner membranes have lower transport resistance during permeation. Inorganic membranes of silicon dioxide and palladium have been successfully used for selective gas permeation applications for many years [13,14]. Conventionally, these membranes are prepared on randomly porous alumina support, which is less reproducible and more prone to defects. Using micromachining techniques it is possible to create defect free, low flow resistance ultra-thin membranes [1,15]. By incorporating the MEMS-on-tube assembly technique, such delicate membranes can be easily packaged. Thin membranes have to be supported by a porous membrane like the silicon microsieve (described in figure 5.4a) for mechanical strength. These supported ultra-thin membranes can either be flat or corrugated. Figure 5.5 shows a $150 \mathrm{~nm}$ thick tube-assembled palladium membrane (for hydrogen separation) supported on a silicon-microsieve. The process of nano-membrane fabrication involves thin-film transfer technique which has been previously described by the authors [16]. After the thin-film transfer of the oxide membrane onto the microsieve, the latter is assembled on a glass tube. Subsequently, a $150 \mathrm{~nm}$ thick palladium layer is deposited on it and released by etching the oxide layer underneath. If the palladium layer is 
deposited prior to the tube bonding step, then there is a high possibility that the metal changes its grain properties during high temperature bonding.

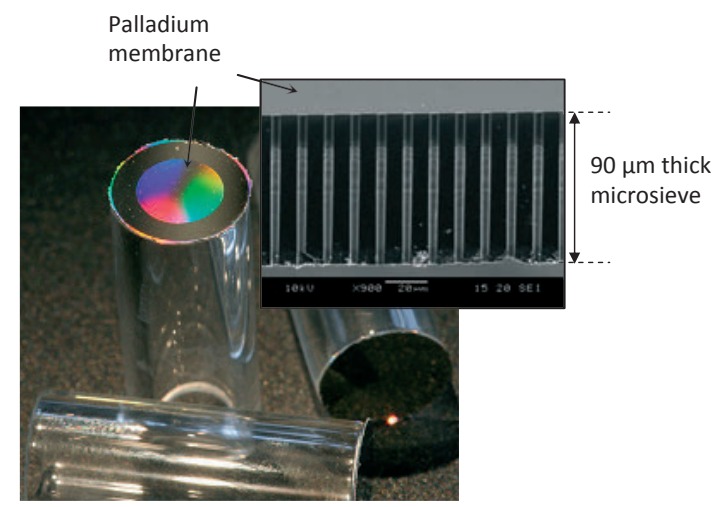

Figure 5.5. A $150 \mathrm{~nm}$ thick supported flat palladium membrane assembled on $\varnothing 8 \mathrm{~mm}$ inner diameter glass tube. SEM picture shows the cross-section of the membrane stack.

Corrugated gas permeation membranes have the advantage of having large surface area which results in a higher permeate flux. An example of a corrugated silica membrane of $50 \mathrm{~nm}$ thickness supported on a silicon microsieve (assembled on a glass tube) can be seen in figure 5.6b. These are fabricated directly on a silicon microsieve support using a similar process flow as in figure $5.4 \mathrm{a}$, but with the difference that instead of removing the oxide etch stop-layer, it is retained during tube bonding and cleavage (see figure 5.6a).

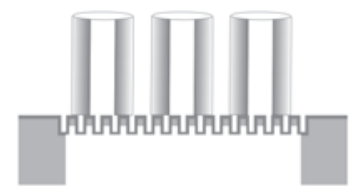

iv) Back-etching till the oxide etch stop-layer and fusion bonding of glass tubes

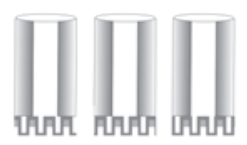

v) Breaking away of the tube-bonded corrugated membrane

(a) 


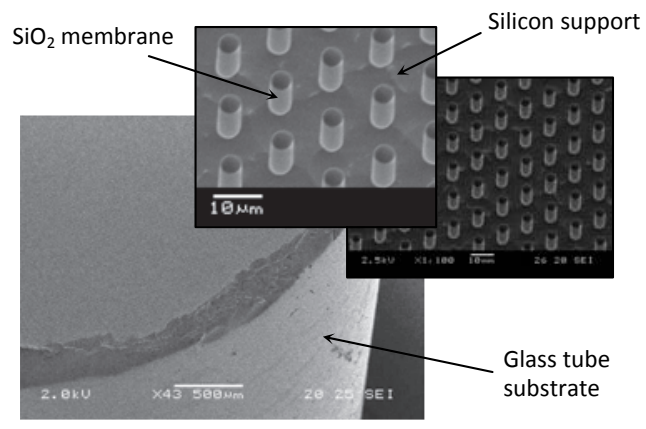

(b)

Figure 5.6. a) The process steps (iv) and (v) as a modification of the scheme in figure 5.4a. b) SEM picture of a microsieve supported corrugated $\mathrm{SiO}_{2}$ membrane on a tube of $3 \mathrm{~mm}$ internal diameter.

\subsubsection{MEMS-on-tube: micro-valves}

The microsystem can also be integrated with the tube after the former is completely fabricated. Shown in figure 5.7 is a microfabricated boss-valve [17] packaged onto a glass tube of $\varnothing 2 \mathrm{~mm}$ internal diameter. The boss-valves were processed separately on a silicon wafer and were diced apart as chips. Such valves can be used as check valve or a pressure release valve in a fluidic system. Thus, MEMS-on-tube assembly also suits post-process interfacing which is at par with the usual packaging requirements.

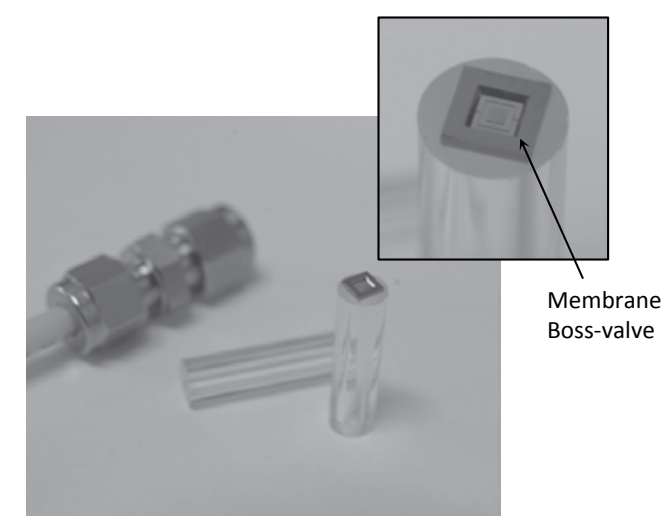

Fig. 5.7. View of the micromachined boss-valve assembled on a $2 \mathrm{~mm}$ internal diameter glass tube. 


\subsection{Characterization and Results}

The glass tube assemblies were tested for leak using a helium gas flow set-up (figure 5.8) consisting of a gas chromatograph (Varian CP- 4900 Micro-GC). All the leak tests were performed at different temperatures ranging from $30{ }^{\circ} \mathrm{C}$ until $200{ }^{\circ} \mathrm{C}$. The silicon nitride membrane shown in figure $5.2 \mathrm{~b}$ was tested for helium leak at $0.1 \mathrm{bar}$ transmembrane pressure. The silicon microsieve supported corrugated silica membrane shown in figure 5.6b being stronger, was tested for leak under 5 bar helium transmembrane pressure.

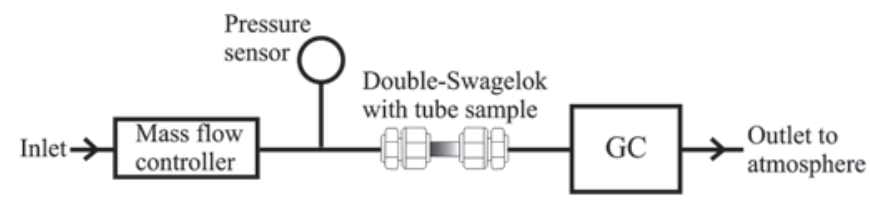

Figure 5.8. Helium leak test-setup

During high pressure tests ( $>3$ bar), for safety, the surface of the tube was slightly roughened to avoid its slipping off the ferrule grip. No helium leak was detected by the gas chromatograph for any of the membrane samples, confirming that the bondinterface (figure 5.9) is hermetically sealed.

Apart from hermeticity, bond-strength is another parameter which defines the quality of the fusion-bond. The bond-strength was tested using a water pressurizer equipment, on which the tube-bonded membrane was connected using a Swagelok ${ }^{\oplus}$ and the water was pressurized from inside the tube. Bond-strength tests done by Fazal [9] with glass tubes of $3 \mathrm{~mm}$ internal diameter and $1.5 \mathrm{~mm}$ wall thickness bonded to a plain silicon wafer of $525 \mu \mathrm{m}$ thickness revealed a burst strength of 65 bar.

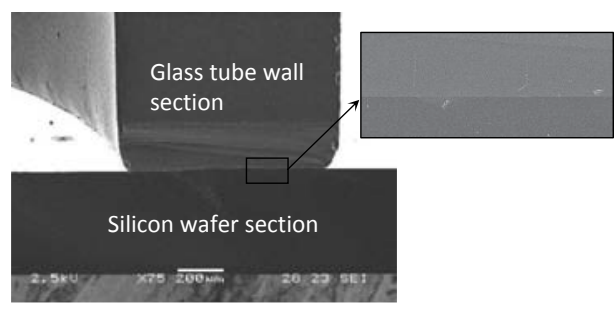

Figure 5.9. SEM picture of the longitudinal cross-section of a silicon wafer bonded glass tube showing the interface. The inset is showing the zoomed view of the interface. 
However, perforated membranes like the microsieve will break at a lower pressure. Tests revealed a burst strength of 7 bar for the microsieve of $90 \mu \mathrm{m}$ thickness with 18 $\%$ porosity. During Fazal's test, the glass tube cracked and not the thick unprocessed silicon wafer. In our case, the silicon membrane (being thin and processed) ruptured during the test. However, in both cases the bond was intact, thus proving its robustness.

To check the conformity of the measurement with the theory, the radial stress in the membrane at its bonded circumference (where it is the maximum) was determined. Since the deflection of the membrane is at least an order of magnitude smaller than its thickness and the membrane radius being 17 times larger than its thickness, the theoretical estimations are based on thin plate theory [18]. The load to stress relationship for a dense circular membrane with clamped edges is given by the following equation.

$$
\sigma_{r(\max )}=\frac{3}{4} \frac{q a^{2}}{h^{2}}
$$

Where, $\sigma_{\mathrm{r}(\max )}\left[\mathrm{N} / \mathrm{m}^{2}\right]$ is the maximum radial stress at the membrane edge, $q[\mathrm{~Pa}]$ is the uniform load over the membrane, $b[\mathrm{~m}]$ is the membrane thickness and $a[\mathrm{~m}]$ is its radius. For a perforated membrane, the load bearing strength is reduced by its void fraction (i.e. porosity), as approximated by Van Rijn [19]. For a load of 7 bar, the maximum radial stress in the microsieve is calculated as $0.19 \mathrm{GPa}$. This value is in the same order of magnitude as $0.47 \mathrm{GPa}$, which is the yield strength of processed silicon wafer (in millimeter scale) as measured by Namazu [20]. The reason for the difference in the stress values of the microsieve membrane could be due to various factors including etching induced defects in the membrane and thermally induced stresses.

The boss-valve, after assembly on the tube (shown in figure 5.7), was tested within a fluidic circuit as a check valve, opening at a pressure of 40 mbar. Such valves can also be used as safety pressure relief valves. One can also think of fabricating flowmeters in such a method. 


\subsection{Discussion}

The glass tube is tightened inside the Swagelok ${ }^{\circledast}$ connector using teflon ferrules instead of the usual stainless steel ferrules, which could break the glass. Due to the usage of teflon ferrules, the temperature of device operation is limited to $\sim 220{ }^{\circ} \mathrm{C}$ although the MEMS-on-tube assemblies can withstand higher temperatures of operation (depending on the microsystem and glass tube materials). For higher operational temperatures (up to $450^{\circ} \mathrm{C}$ ) the use of graphite-ferrules is an option.

There are various microsystems, which require multiple connections to act as inlet and outlet. Using MEMS-on-tube assembly it is also possible to assemble multiple tubes to a microsystem, by maintaining the concentricity of the connections so that it can be mounted within Swageloks ${ }^{\circledR}$. This is achieved by a tube-in-a-tube assembly as shown in figure 5.10, where an example of a microreactor with inlet and outlet connections can be seen. In such a cross-flow configuration, the reactants can flow in through the internal tube and after reacting inside the micro-reactor, the products can flow out through the outer tube. Optionally, for a micro-membrane reactor, the permeating products could be collected separately.

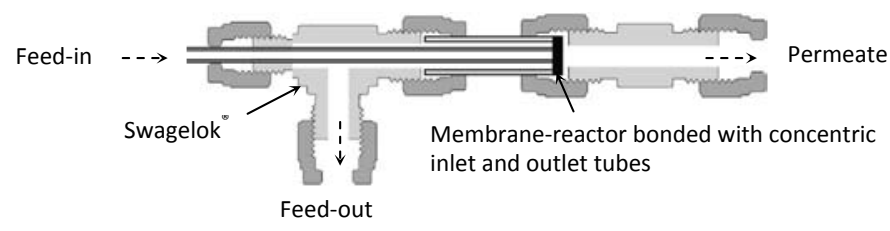

Figure 5.10. Cross-sectional illustration of a tube-in-a-tube assembly enabling multiple fluidic connections to a MEMS device, while still being enclosable within double-Swagelok ${ }^{\circ}$.

Another advantage of using MEMS-on-tube assemblies is that one can customize the shape, configuration and functionality of the glass support. Instead of multiple concentric tubes, even glass tubes with multiple bores can be used, which then later can be directed to split connections for feed and exhaust fluids. Depending on the requirements of the applications, glass tubes can be configured to function as a fluid reservoir/buffer, channel, pre-conditioner, reaction-chamber etc. It is also possible to stack MEMS components within a tube to serve some specific functionality. One such application is a micro-thruster shown in figure 5.11 with a valve and actuator system 
within a tube [21]. This combination of advantages of micromachining and glassmachining widens the versatility of this technique.

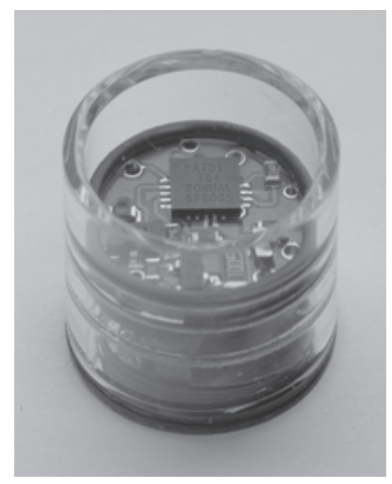

Figure 5.11. $13 \mathrm{~mm}$ glass tube with thruster components and control electronics inside

For using the double-Swagelok ${ }^{\oplus}$ technique, the glass tube must have a minimum length of 25-30 mm, which ensures the proper connectability of two Swagelok couplings on either end of the tube. Longer tubes are better in this respect, but they have the limitation that during fusion bonding process, they could bend or curve (as shown in figure $5.12 \mathrm{~b}$ ) due to thermal gradients and the pull of gravity.

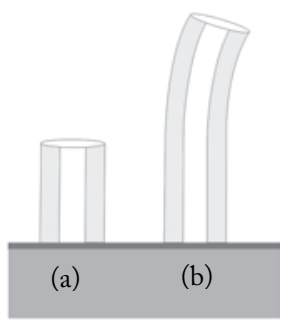

Figure 5.12. Illustration of tube cross-sections a) straightly bond short tube b) long bend tube.

Mechanical bonding supports could help for straight bonding of high aspect ratio tubes. The support should be made of a material which does not bond to the glass. In our experiments, we have used alumina supports of different forms as seen in figure 5.13. 


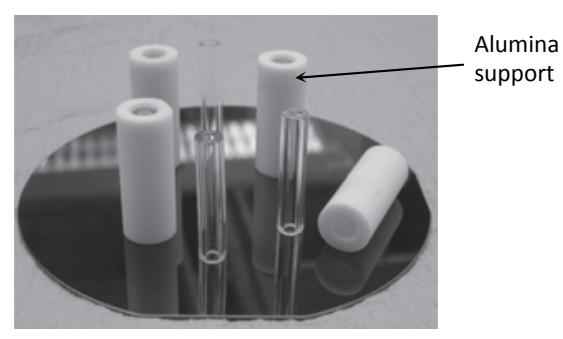

(a)

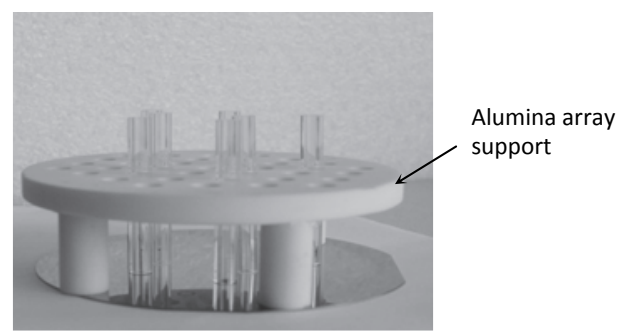

(b)

Figure 5.13. Providing mechanical supports for straight bonding of glass tubes a) cylindrical alumina supports for individual tube b) alumina array support for batch-bonding of tubes.

For certain MEMS materials, the fusion bond temperature of $800{ }^{\circ} \mathrm{C}$ can be too high. For such cases it is also possible to lower the bonding temperature and increase the bonding-time instead. Extremely smooth glass tube surfaces could be helpful in this regard. Another option is to use tubes made of low-melting point glass, which will soften at a lower temperature. However, while using different glass tube materials, there should not be a large difference in their thermal expansion coefficients as compared to silicon or silicon based materials.

\subsection{Conclusions}

A new methodology for hermetic packaging cum interfacing of microfluidic devices has been demonstrated. Instead of the usual 2D micromachining approach, a 3D perspective is adopted, which uses tubular glass substrates. While in conventional packaging, the MEMS is first developed and finally packaged, a 'turn-around' approach has been adopted here by starting from the package or integrating it with the 
microsystem during the fabrication process itself. A double-Swagelok ${ }^{\circledast}$ technique has been shown here, which enables the $M E M S$-on-tube assembly to be easily mounted onto various equipments. Swagelok ${ }^{\bowtie}$ connectors which are normally used for fluidic interconnections can now contain a smart microsystem within them. This novel technique enables the easy implementation of microfluidic devices for applications like air-sterilizaion, emulsification, fluid-filtration, gas permeation, microreactors, cellsamplers etc. In this project, this method of micro packaging has been successfully employed to characterize the strength and permeability of the gas diffusive supports (GDS) for the electrodes of the solid acid fuel cell. Overall, the MEMS-on-tube assembly acts as a versatile platform for microfluidic devices, paving way to Lab-On-aTube systems.

\section{References}

[1] H. D. Tong, F. C. Gielens, J. G. E. Gardeniers, H. V. Jansen, J. W. Berenschot, M. J. de Boer, J. H. de Boer, C. J. M. van Rijn, and M. C. Elwenspoek., Journal of Microelectromechanical Systems, 2005, 14 (1), pp. 113-124

[2] C. J. M. van Rijn, W. Nijdam, S. Kuiper, G. J. Veldhuis, H. van Wolferen and M. Elwenspoek, Journal of Micromechanics and Microengineering, 1999, 9, pp. 170-172

[3] S. V. Karnik, M. K. Hatalis and M. V. Kothare, Journal of Microelectromechanical Systems, 2003, 12 (1), pp. 93-100

[4] B. H. Weigl, R. L. Bardell, C. R. Cabrera, Advanced Drug Delivery Reviews, 2003, 55, pp. 349-377

[5] B. L. Gray, D. Jaeggi, N. J. Mourlas, B. P. van Drieenhuizen, K. R. Williams, N. I. Maluf, G. T. A. Kovacs, Sensors Actuators A, 1999, 77, pp. 57-65

[6] T. J. You, S. Lee, W. Fang and Y. C. Tai, Conf. Proc. MEMS, 2000, pp. 624-7

[7] C. Li, P. M. Wu, J. Han and C. H. Ahn, Biomedical Microderices, 2008, 10, pp. 671-679

[8] Patent pending, Eurpean Patent Application no. EP-A-08007746.4, 2008

[9] I. Fazal, E. Berenschot, R. de Boer, H. Jansen and M. Elwenspoek, Conf. Proc. Transducers, 2005, pp. 936-939

[10] B. Mogulkoc, H. Jansen, M. ter Brake and M. Elwenspoek, Conf. Proc. Micro Mechanics Europe, 2008, pp. 283-86 
[11] W. P. Eaton and J. H. Smith, Smart Material Structures 1997, 6, pp. 530-539

[12] Nippon Electric Glass Co. Ltd., Japan, http://www.neg.co.jp

[13] S. Uemiya, T. Matsuda and E. Kikuchi, Journal of Membrane Science, 1991, 56, pp. 315-325

[14] R. J. R. Uhlhorn, M. H. B. J. Huis In't Veld, K. Keizer, A. J. Burggraaf, Journal of Material Science Letters 1989, 8, pp. 1135-1138

[15] Y. Li, N. G. Pinto, H. T. Henderson, S. Hwang, P. Nguyen, Material Science and Engineering B, 1995, 32, pp. 63-68

[16] S. Unnikrishnan, H. Jansen, E. Berenschot and M. Elwenspoek, Journal of Micromechanics and Microengineering , 2008, 18 (6), 064005

[17] E. Oosterbroek, Modeling, Design and Realization of Microfluidic Components, PhD Thesis, University of Twente, 1999, ISBN 90-36513464

[18] S. Timoshenko and S. Woinowsky-Krieger, in Theory of Plates and Shells, McGraw-Hill publication, $2^{\text {nd }}$ Edition, 1959 , pp. 55-56

[19] C. J. M. van Rijn, M. van der Wekken, W. Nijdam, and M. C. Elwenspoek, Journal of Microelectromechanical Systems, 1997, 6 (1), pp. 48-54

[20] T. Namazu, Y. Isono, and T. Tanaka, Journal of Microelectromechanical Systems, 2000, 9(4), pp. 450-459

[21] M. Louwerse, H. Jansen and M. Elwenspoek, Conf. Proc. Micro Mechanics Europe, 2008, pp. 17-20 



\section{The Nanosieve}

The fabrication and gas flow characterization of an ultra-thin inorganic nanosieve structured by interference lithography and a bond-micromachining approach is reported. Such a membrane could be used as a nanoporous gas diffusive support (GDS) for supporting ultra-thin palladium electrodes. The nanosieve exhibits transition gas flow behavior around atmospheric pressure and ambient temperature. The small lip-thickness $(45 \mathrm{~nm})$ of the nanopores with respect to their diameter $(120 \mathrm{~nm})$ helps in understanding pure transition flow by minimizing interactions between molecule and inner pore wall. Due to absence of these collisions, the transition flux is the superimposition of viscous and molecular fluxes without the need for higher order slip correction. The nanosieve shows flow selectivity of 3.1 between helium and argon at 20 mbar. 


\subsection{Introduction}

Inorganic nanoporous membranes have been an intensively studied topic for the past few years with wide applications in filtration and separation sectors [1,2]. The usual kind of inorganic nanoporous membranes are randomly porous structures having many tortuous as well as dead-end pores and with broad pore size distribution. A new class of these membranes - the nanosieves - has lately gained considerable attention with their uniform array of non-tortuous cylindrical pores, having superior advantages like narrow poresize distribution and high flux [3,4,5,6,7]. Nanosieves can be classified into one-dimensional (1D) and two-dimensional (2D) morphologies as shown in figure 6.1. While a $1 \mathrm{D}$ nanosieve is defined here as a membrane with pore diameters of around or below hundred nanometers, a $2 \mathrm{D}$ nanosieve has additionally its thickness equal to or less than the size of its nanopores. There have been a few reports in the literature about 1D nanosieve fabrication and flow characterization [3-5]. Their main disadvantage is that due to the high aspect ratio of their pores the transfer pressure drop is quite high. In order to reduce the flow resistance without hardly affecting the selectivity between species to be separated, the nanosieve needs to be thinned down, thus converting it to a $2 \mathrm{D}$ nanosieve.

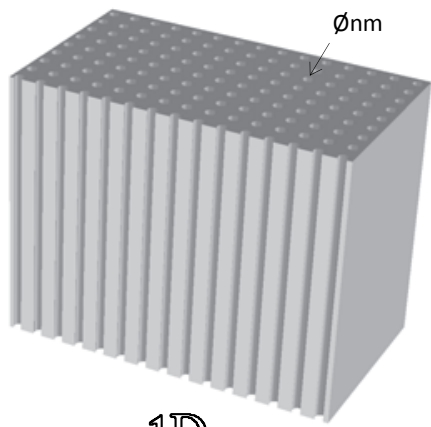

(a)

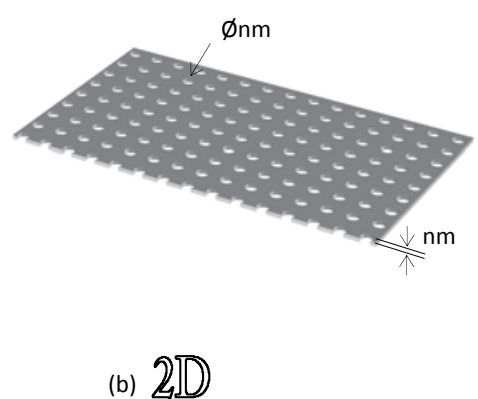

(b)

Figure 6.1: Cross sectional models of a) one-dimensional nanosieve with poresize in nanometers

b) two-dimensional nanosieve with poresize and thickness in nanometers

Although there is some literature available on the fabrication of the fragile $2 \mathrm{D}$ nanosieves for fluid filtration and separation applications [6,7], there have not been 
much research efforts in the direction of understanding their gas flow behavior, especially in the transition regime.

In this chapter, we report the fabrication of an ultra-thin inorganic $2 \mathrm{D}$ nanosieve membrane and its characterization with respect to transition flow. The ultra-thin supported nanosieve is realized by wafer-scale interference lithography and a bondmicromachining technique, and is of $45 \mathrm{~nm}$ thickness with clearly defined circular pores of $\varnothing 120 \mathrm{~nm}$. Such a nanosieve can be employed as a nano gas diffusive layer (nano-GDS) for the $\mu$ SAFC, when extremely thin palladium electrodes are used. The characteristics of the nanosieve are determined by measuring the flux and selectivity of different gas species at varying mean and differential pressures. The experimental investigations are supported by theoretical formulations derived and adapted from the early works including that of Graham [8], Sampson [9], Knudsen [10], Dushmann [11] and Clausing [12]. The small lip-thickness of its nanopores enables us to understand the pure transition flow through the $2 \mathrm{D}$ nanosieve by minimal wall interaction effects [13]. In this work we show that with an extremely thin membrane with a well defined uniform pore structure, the transition flux is the linear addition of the viscous and molecular fluxes without using any fitting parameters. The outline of this paper is as follows. After explaining the fabrication process for the nanosieve membrane, its assembly onto a robust microsieve support is described. Next, the theoretical model and important parameters to estimate the flow through the microsieve supported nanosieve are explained. Finally, discussions on the comparison of estimated flow rates with the measured values are presented.

\subsection{Fabrication technique}

Being a strong and inert inorganic material, silicon nitride is chosen as the material for the nanosieve in this study. Laser Interference Lithography (LIL) [14] is used as the technique to create the nanoscale holes or pores pattern on the silicon nitride layer. This technique uses the interference of two coherent laser beams producing standing waves, to record a pattern in a photosensitive material. The interference of the laser beams is achieved by reflecting a part of the incoming laser beam using a Lloyd's mirror setup (figure 6.2). 


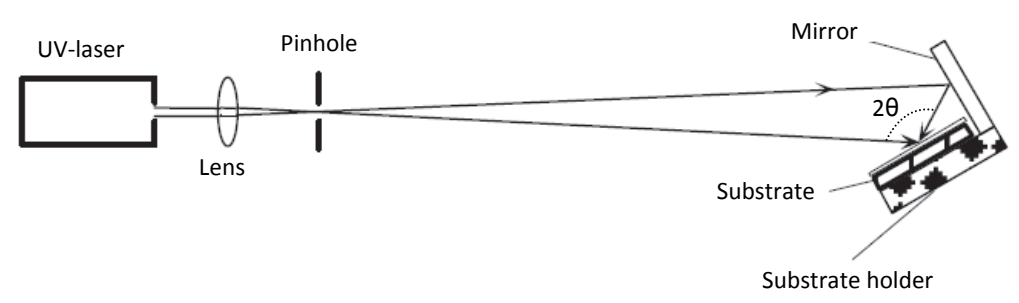

Figure 6.2: Lloyd's mirror configuration for Interference Lithography

The grating period of the interference pattern can be theoretically determined using the formula,

$$
\Lambda=\frac{\lambda_{w}}{2 \sin \theta}
$$

With grating period $\Lambda[\mathrm{m}]$, wavelength $\lambda_{w}[\mathrm{~m}]$ of the laser and half the angle between the interfering laser beams $\theta\left[^{\circ}\right]$. The laser source used here is frequency quadrupled Nd-YAG Continuous-Wave laser operating in the deep-UV regime with wavelength of $266 \mathrm{~nm}$. By adjusting half-angle $\theta$, it is possible to adjust the line-width, periodicity and the area of exposure. For independently varying the line-width, the exposure dose $\left[\mathrm{J} / \mathrm{cm}^{2}\right]$ can be tuned; usually the line width is tuned to be half of the grating period. To convert the line pattern into a dots pattern, a double exposure is done by rotating the wafer $90^{\circ}$ between exposures. Depending on the type of photoresist used (positive or negative) the dots can become posts or holes subsequent to pattern development in developer solution. LIL has been shown to be a suitable technique to create sieve patterns by prior researches in our group $[15,16]$. In this work, this technique is extended to make large area thin-film pore patterns and transform them into a supported ultra-thin $2 \mathrm{D}$ nanosieve membrane to study its gas flow behavior.

The fabrication process (illustrated in figure 6.3) starts with the LPCVD deposition of a $45 \mathrm{~nm}$ thick silicon nitride layer on a thermally oxidized silicon carrier wafer. This wafer is then spin-coated with a $20 \mathrm{~nm}$ thick bottom anti-reflection coating: BARC layer (DUV 46, Brewer Science Inc.) followed by a $130 \mathrm{~nm}$ thick positive photoresist (PEK 500, Sumitomo Chemical Co. Ltd.). 


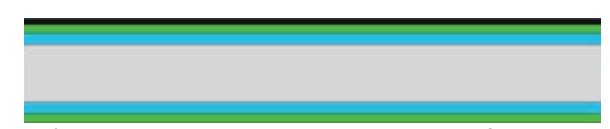

a) $21 \mathrm{~nm}$ thick BARC spinning on a wafer with $80 \mathrm{~nm}$ $\mathrm{SiO}_{2}$ and $50 \mathrm{~nm} \mathrm{Si}{ }_{3} \mathrm{~N}_{4}$

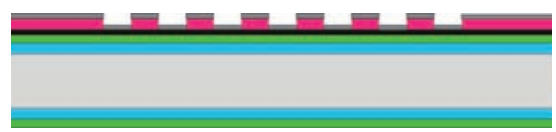

c) $20 \mathrm{~nm}$ thick aluminum evaporation

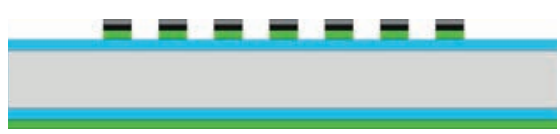

e) Plasma etching BARC and $\mathrm{Si}_{3} \mathrm{~N}_{4}$

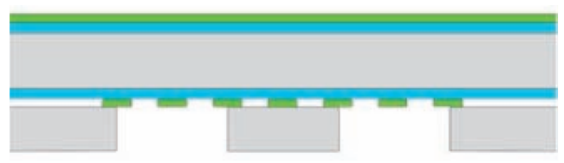

g) Fusion bonding of the wafer to a microsieve

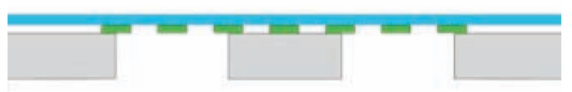

i) Wafer through plasma etching

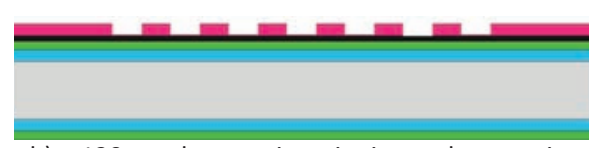

b) $130 \mathrm{~nm}$ photo resist spinning and patterning using LIL

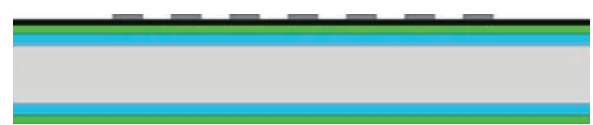

d) Lift-off process in acetone

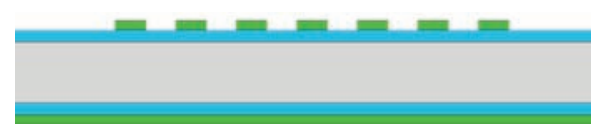

f) Stripping the aluminum and BARC layer

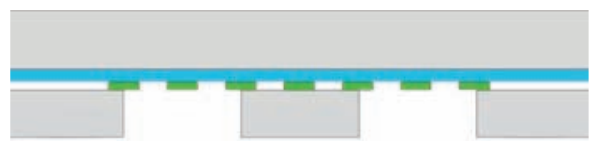

h) Plasma etching of the $\mathrm{SiO}_{2}$ and $\mathrm{Si}_{3} \mathrm{~N}_{4}$ layers

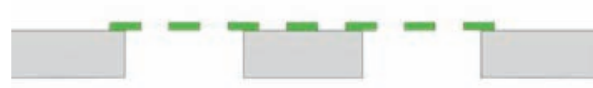

j) Stripping oxide stop-layer in hydrofluoric acid

Figure 6.3: Fabrication process flow for the nanosieve

Using LIL, double exposure of the photoresist at a half-angle of $30^{\circ}$ and exposure dose of $1.1 \mathrm{~mJ} / \mathrm{cm}^{2}$ are done to generate a square array of posts after development (see figure 6.4). The pattern reversal is done by a lift-off process in which after depositing a $20 \mathrm{~nm}$ layer of aluminium, the posts pattern is inverted to pores pattern by dissolving the photoresist in acetone. An evaporation process is chosen so that aluminium is directionally deposited over the posts pattern resulting in a shadowing effect which benefits the lift-off procedure. The pattern is then transferred into the underlying BARC and silicon nitride layers via plasma etching, stopping selectively on the $80 \mathrm{~nm}$ thick silicon oxide layer underneath (figure 6.5). 


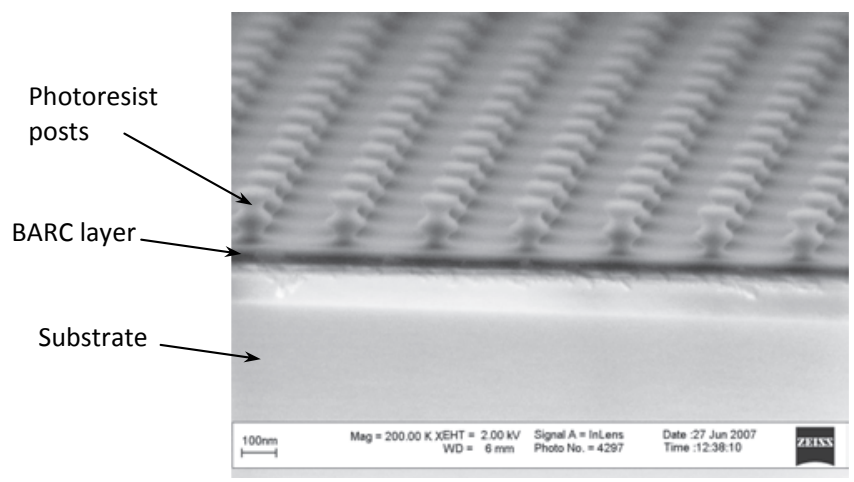

Figure 6.4: Square array of nanoposts of positive photoresist formed after development of the double exposed resist layer.
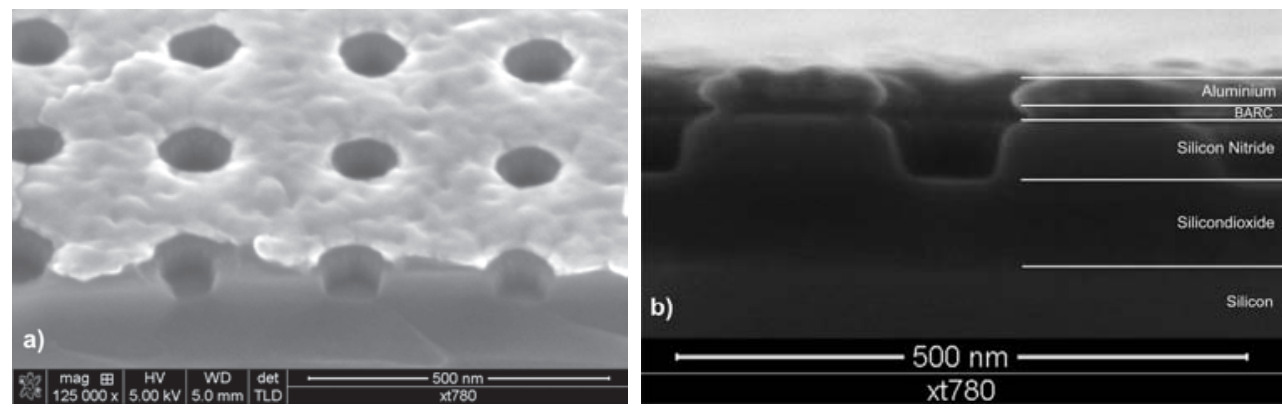

Figure 6.5: a) High Resolution SEM photograph showing the nanoholes etched into the silicon nitride layer with the aluminium mask still on top b) Cross-section of a nanohole in the silicon nitride layer, depicting also the various layers.

The BARC layer is etched with a low power $(5 \mathrm{~W})$ oxygen plasma under $20 \mathrm{sccm}$ $\mathrm{O}_{2}$ flow and 10 mTorr chamber pressure. Whereas, the silicon nitride layer is directionally etched using a $25 \mathrm{~W}$ mixed gas plasma of trifluoro-methane $\left(\mathrm{CHF}_{3}\right)$ and oxygen flown at $20 \mathrm{sccm}$ and $5 \mathrm{sccm}$ respectively, under $10 \mathrm{~m}$ Torr chamber pressure. After the creation of the pattern, the next step is to release it by a bondmicromachining approach involving a thin-film transfer technique as explained below. After stripping of the aluminium mask and the BARC layer, the nano-patterned carrier wafer is thoroughly cleaned and fusion bonded to a wafer having a silicon microsieve structure (similar to the one shown in chapter 2). This microsieve wafer acts as a robust supporting structure to the nanosieve membrane after it is released by 
etching away the carrier wafer [17]. The silicon microsieve with well defined straight pores of $\varnothing 6 \mu \mathrm{m}$ (figure 6.6) is created by a Deep Reactive Ion Etching (DRIE) process using a time multiplexed Bosch recipe (explained in chapter 2), where sulphurhexafluoride $\left(\mathrm{SF}_{6}\right)$ and trifluoro-methane $\left(\mathrm{CHF}_{3}\right)$ are used as the etching gas and passivating gas respectively [18]. The silicon oxide acts as a stop-layer also during the carrier wafer etching step, thereby protecting the silicon nitride nanosieve from damage.

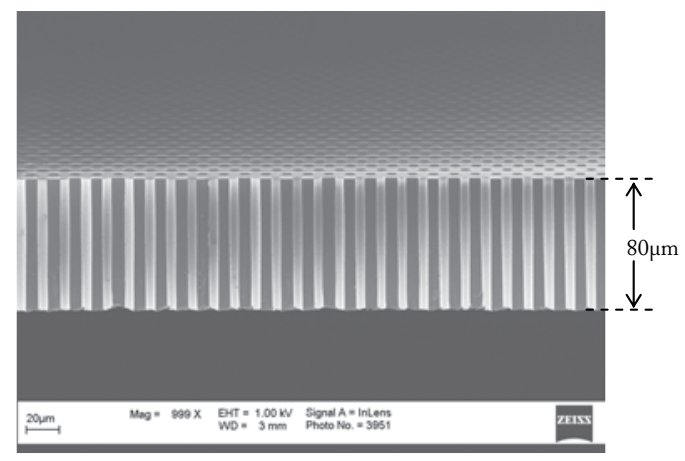

Figure 6.6: Cross-section of the plasma etched microsieve support showing the straight and parallel micropores of $\varnothing 6 \mu \mathrm{m}$.

Subsequently, this protecting oxide is selectively removed in $1 \% \mathrm{HF}$ solution to finally release the 2D nanosieve. Figure 6.7 shows the SEM images of the nanosieve suspended on a micropore of the support. Across the wafer, the LIL pattern exhibits poresize non-uniformity due to the Gaussian intensity profile of the laser beam. This intensity variation was found to cause a $10 \%$ standard deviation in the feature sizes measured within an area of $50 \mathrm{~mm} \times 50 \mathrm{~mm}$ at the middle of the wafer. The nanopores for the samples chosen for our experiments are of $120 \pm 10 \mathrm{~nm}$ in diameter, resulting in a porosity of $\sim 18 \%$. Together with the microsieve, which has a porosity of $18 \%$, the final void fraction of the total sieve (nanosieve supported on microsieve) is about $3.2 \%$. 

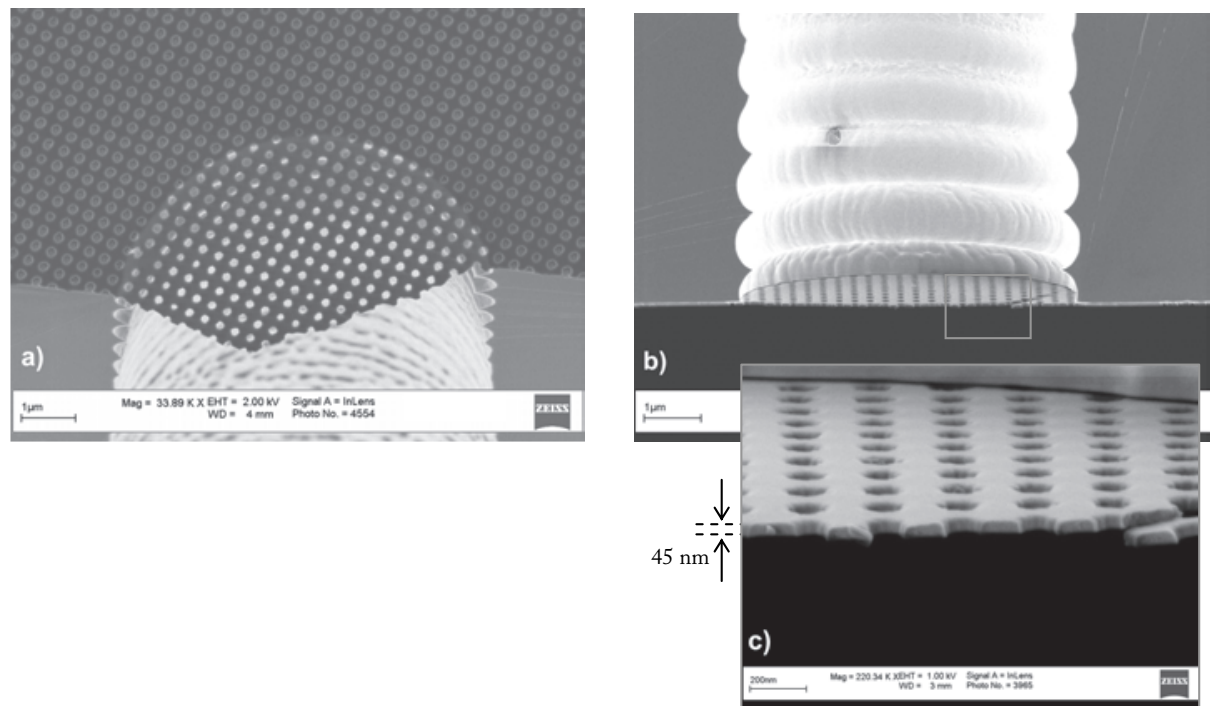

Figure 6.7: The released nanosieve membrane bonded on the microsieve support etched using DRIE process. a) view from the top of the nanosieve membrane b) view from inside a microhole c) zoomed view of the freehanging nanosieve

After the removal of the silicon dioxide, in some samples the problem of peeling or detachment of the silicon nitride sieve from the microsieve support was observed (figure 6.8).

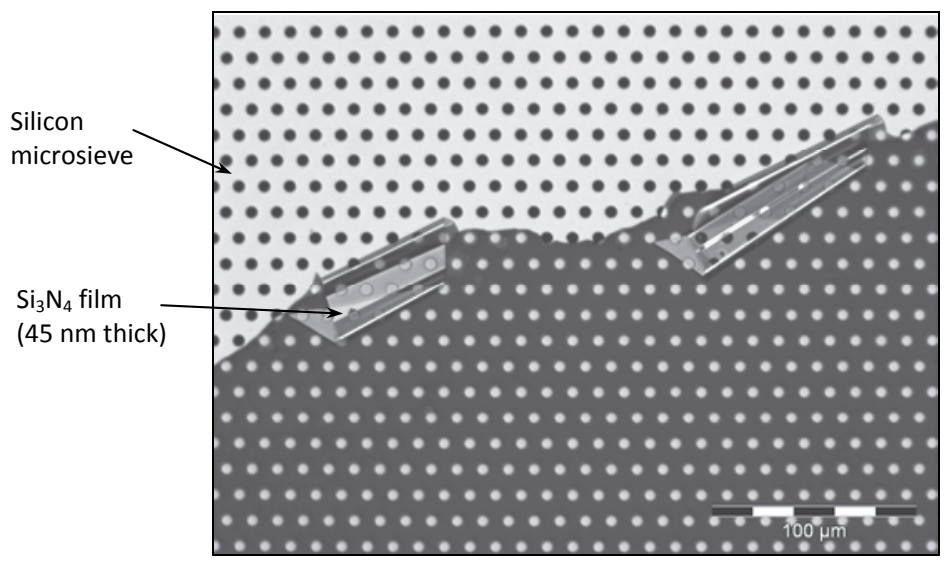

Figure 6.8: Microscope photo revealing peeling of the silicon nitride nanosieve film from the surface of the microsieve support. 
The reason for this peeling off was concluded to be the combined effect of high internal stress in the film and poor interfacial bond strength. The source of this randomly occurring film adhesion problem is attributed to encapsulated water inside the nanopores due to improper drying of the wafer prior to fusion bonding (figure 6.3, step g). To eliminate this problem, extra care was taken to properly dry the nanosieve by employing dry nitrogen while drying.

In order to test gas flow behaviour through it, the total sieve is fusion bonded at 800 ${ }^{\circ} \mathrm{C}$ onto $6 \mathrm{~mm}$ long Duran ${ }^{\circledR}$ glass tubes of $\varnothing 3 \mathrm{~mm}$ inner diameter (see figure 6.9), which can be sealed within standard Swagelok ${ }^{\circledR}$ connectors [19]. A detailed explanation regarding this membrane packaging has been given in chapter 5 .

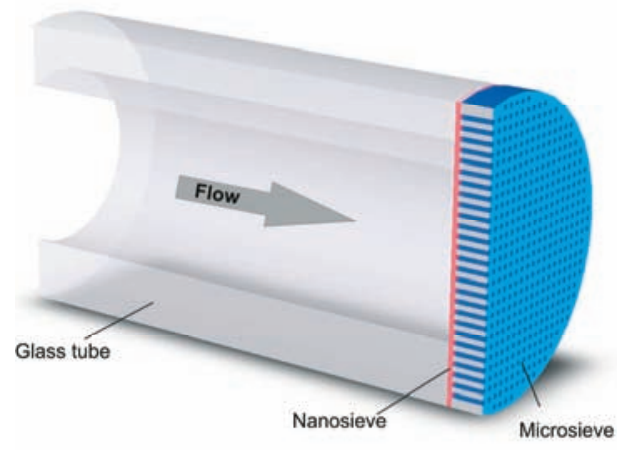

Figure 6.9: Cross-sectional illustration of the microsieve supported nanosieve fusion bonded on a glass tube.

\subsection{Flow characterization}

Gases behave as a continuum with viscous effects dominating when the size of the pore through which it flows is significantly larger than the mean-free-path of the gas (i.e. $d » \lambda$ ). As the pore diameter is reduced to a size much smaller than the mean-freepath of the gas (i.e. $d$ « $\lambda$ ), it starts to act molecular, i.e. as a collection of molecules moving independently through largely empty space. When the pore diameter is in the same order of magnitude as the mean-free-path of the gas (i.e. $d \approx \lambda$ ), the flow behavior is termed to be in transition between viscous and molecular flows, which is the case for the pores of the $2 \mathrm{D}$ nanosieve around atmospheric pressure. Initial efforts to quantify transition flow were made by Knudsen [10] by means of studying flow 
through capillaries. His studies led to the dimensionless number known as Knudsen number: $K_{n}=\lambda / d$. Based on the Knudsen number, the flow behavior of gases can be categorized into viscous $\left(K_{n}<0.01\right)$, transition $\left(0.01<K_{n}<1\right)$ and molecular $\left(K_{n}>1\right)$ flow regimes [11]. Although Knudsen had tried to approximate the transition flow through capillaries as superimposition of viscous and molecular fluxes, he had to include correction terms to account for wall interaction effects. Moreover, intermolecular collisions will limit the molecular transport drastically when the length of the capillary is well above the mean-free-path of the gas. These effects become less significant and the flux superimposition technique could work when the length of the capillary is reduced below the mean-free-path of the gas, as proven by Lund and Berman [20] while doing experiments with tubes of different aspect ratios. Later on, Eickmann and Werner [21] showed the applicability of the superimposition technique for approximating flow through porous membranes. However, due to the ambiguously defined pore size and shape of their considerably thick membranes, morphology dependent correction factors had to be used as fitting parameters. In this work we show that when the membranes are made extremely thin and with well defined pores, the transition flux is indeed the linear addition of the viscous and molecular fluxes, without the need of any fitting parameters.

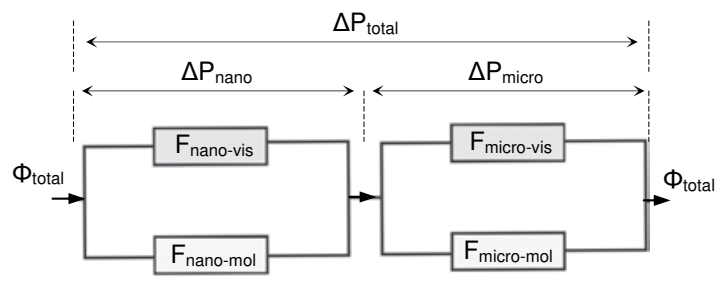

Figure 6.10: Equivalent circuit model for the mass flows through the microsieve and nanosieve. $\Delta \mathrm{P}, \Phi$ and $\mathrm{F}$ stand for pressure-drop, mass-flow and flow-conductance respectively.

For easy understanding of the flow through the total sieve, an equivalent circuit model is developed using electrical analogy as shown in figure 6.10. The equivalent circuit model is based on the following equations,

$$
\Delta P_{\text {total }}=\Delta P_{\text {micro }}+\Delta P_{\text {nano }}
$$




$$
\Phi_{\text {total }}=\Phi_{\text {micro }}=\Phi_{\text {nano }}
$$

where, $\Delta P$ and $\Phi$ stand for pressure-drop $[\mathrm{Pa}]$ and mass-flow $[\mathrm{mol} / \mathrm{s}]$ respectively. The subscripts micro and nano relate the aforementioned parameters respectively to the microsieve and nanosieve. Equation 6.2 is valid only in the case of fluxes being expressed as mass flows (for example in unit $\mathrm{sccm}$, i.e. $\mathrm{cm}^{3} / \mathrm{min}$ at STP) due to the conservation of mass for the gas while passing the membrane. Following the attempts of Knudsen [10], we quantify the theoretical transition flux as a linear addition of the viscous and molecular fluxes.

$$
\begin{aligned}
& \Phi_{\text {micro }}=\Delta P_{\text {micro }}\left(F_{\text {micro-vis }}+F_{\text {micro-mol }}\right) \\
& \Phi_{\text {nano }}=\Delta P_{\text {nano }}\left(F_{\text {nano-vis }}+F_{\text {nano-mol }}\right)
\end{aligned}
$$

where, $F$ represents the flow-conductance $[\mathrm{mol} / \mathrm{s} . \mathrm{Pa}]$ through the sieves and the subscripts vis and mol indicate viscous and molecular flows respectively corresponding to the microsieve and nanosieve. The physical background of this superimposition is that the total flux is the summation of the collective drift of the gas molecules (i.e. viscous flux) and a flow due to statistical imbalance of the thermal molecular motion (i.e. molecular flux) caused by a applied pressure difference across the sieves. The flowconductance for both sieves in the molecular flow regime is as follows $[8,10,11,12,22]$,

$$
\begin{aligned}
& F_{\text {micro-mol }}=\frac{A \kappa_{\text {micro }}}{\sqrt{2 \pi M R T}}\left(1+\frac{3 t_{\text {micro }}}{8 r_{\text {micro }}}\right)^{-1} \\
& F_{\text {nano-mol }}=\frac{A \kappa}{\sqrt{2 \pi M R T}}\left(1+\frac{t_{\text {nano }}}{2 r_{\text {nano }}}\right)^{-1}
\end{aligned}
$$

where, $M$ is the molar mass $[\mathrm{kg} / \mathrm{mol}]$ of the gas used, $R$ is the universal gas constant $[\mathrm{J} / \mathrm{mol} . \mathrm{K}], T$ is the ambient temperature $[\mathrm{K}], A$ is area of the free-hanging sieve bonded on the glass tube $\left[\mathrm{m}^{2}\right], \kappa$ is the net porosity of the total sieve (which is a product of porosity of the nanosieve $\kappa_{\text {nano }}$ and the porosity of the microsieve $\left.\kappa_{\text {micro }}\right), r_{\text {micro }}$ 
and $r_{\text {nano }}$ are the radii $[\mathrm{m}]$ of the micropore and nanopore respectively, $t_{\text {micro }}$ and $t_{\text {nano }}$ are the respective thicknesses $[\mathrm{m}]$ of the microsieve and nanosieve. The terms $(1+3 t / 8 r)$ and $(1+t / 2 r)$ are the Clausing factors of the microsieve with long pores and nanosieve with short pores respectively. The flow-conductance for the viscous regime can be written as $[9,23,24]$,

$$
\begin{aligned}
& F_{\text {micro-vis }}=\frac{A \kappa_{\text {micro }} r_{\text {micro }} P_{\text {micro }}}{3 \eta R T \pi}\left(1+\frac{8 t_{\text {micro }}}{3 \pi r_{\text {micro }}}\right)^{-1}\left(1-f\left(\kappa_{\text {micro }}\right)\right)^{-1} \\
& F_{\text {nano-vis }}=\frac{A \kappa r_{\text {nano }} P_{\text {nano }}}{3 \eta R T \pi}\left(1+\frac{8 t_{\text {nano }}}{3 \pi r_{\text {nano }}}\right)^{-1}\left(1-f\left(\kappa_{\text {nano }}\right)\right)^{-1}
\end{aligned}
$$

here, $P_{\text {micro }}$ and $P_{\text {nano }}$ are the respective arithmetic mean pressures $[\mathrm{Pa}]$ in the microsieve and nanosieve and $\eta$ is the viscosity [Pa.s] of the gas used. The term $(1+8 t / 3 \pi r)$ describes the frictional losses experienced by the gas due to interaction with the pore surface and $(1-f(\kappa))$ quantifies the influence of flow through the neighbouring pores on the flow through a single pore.

\begin{tabular}{|c|c|}
\hline Parameters & Values \\
\hline Ambient temperature, $T$ & $296 K$ \\
\hline Active area of total sieve, $A$ & $7.548 E-6 m^{2}$ \\
\hline Porosity of the microsieve, $\boldsymbol{K}_{\text {miro }}$ & $18.1 \%$ \\
\hline Porosity of the nanosieve, $K_{\text {nano }}$ & $17.3 \%$ \\
\hline Radius of the micropore, $r_{\text {mirro }}$ & $3 E-6 m$ \\
\hline Radius of the nanopore, $r_{\text {nano }}$ & $62.5 E-9 m$ \\
\hline Thickness of the microsieve, $t_{\text {micro }}$ & $80 E-6 \mathrm{~m}$ \\
\hline Thickness of the nanosieve, $t_{\text {nano }}$ & $45 E-9 m$ \\
\hline Correction microsieve $\left(1-f\left(\kappa_{\text {miroo }}\right)\right)$ & 0.9726 \\
\hline Correction nanosieve $\left(1-f\left(\kappa_{\text {nano }}\right)\right)$ & 0.9743 \\
\hline \multirow{5}{*}{ Viscosity, at $296 K$} & Hydrogen: $8.86 E-06$ Pa.s \\
\hline & Helium: 1.97E-05 Pa.s \\
\hline & Nitrogen: 1.78E-05 Pa.s \\
\hline & Air: $1.84 E-05$ Pa.s \\
\hline & Argon: 2.26E-05 Pa.s \\
\hline \multirow{5}{*}{ Molecular mass, $M$} & Hydrogen: $0.00202 \mathrm{~kg} / \mathrm{mol}$ \\
\hline & Helium: $0.004003 \mathrm{~kg} / \mathrm{mol}$ \\
\hline & Nitrogen: $0.02801 \mathrm{~kg} / \mathrm{mol}$ \\
\hline & Air: $0.02897 \mathrm{~kg} / \mathrm{mol}$ \\
\hline & Argon: $0.03995 \mathrm{~kg} / \mathrm{mol}$ \\
\hline
\end{tabular}

Table 6.1: Parametric values used for calculating flow-conductances 
In order to account for compressibility effects of gas flow, the Sampson's viscous orifice flow expression [9] is modified using the ideal gas law. By substituting the flow-conductances in the equations 6.3 and 6.4, the mass flows through the sieves are determined. The parameter values used in the calculations are listed in table 6.1. The mass flows are converted from $[\mathrm{mol} / \mathrm{s}]$ to $[\mathrm{sccm}]\left(1 \mathrm{~mol} / \mathrm{s} \approx 1.344 \cdot 10^{6} \mathrm{sccm}\right)$.

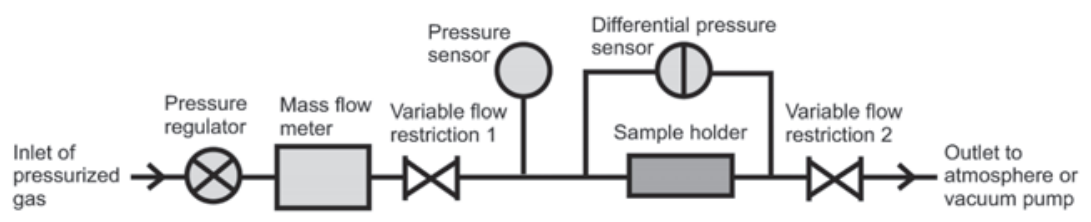

Figure 6.11: Schematic representation of the gas flow set-up

The schematic of the gas flow set-up used for characterisation is illustrated in figure 6.11. Initial experiments are performed by flowing air at $296 \mathrm{~K}$, at varying mean pressures (from above-atmospheric down to sub-atmospheric pressures of $\sim 0.02 \mathrm{bar}$ ) and at a fixed differential pressure across the total sieve. For measurement at aboveatmospheric pressures, after setting the inlet pressure at the desired value and fully opening the flow restriction 1 , the flow restriction 2 is adjusted till the desired pressure drop is shown by the differential pressure sensor. Any change in the inlet pressure is corrected again with the pressure regulator. For sub-atmospheric measurements, the inlet pressure is set to 1 bar and the flow restriction 2 is left fully open. Then, the pressure drop across the sieve is tuned solely using flow restriction 1 . The outlet of the set-up is connected to a vacuum pump in the latter case unlike the former case where it is open to the atmosphere. The sensors used in the gas flow setup have the following error margins: The differential pressure sensor (Sensortechnics $\mathrm{GmbH}$ ) has an error margin of $0.2 \%$ on full scale 0.344 bar. The pressure sensor (Sensortechnics $\mathrm{GmbH}$ ) has an error margin of $0.5 \%$ on full scale 5 bar and registers the pressure above $1 \mathrm{~atm}$. The mass flow through the nanosieve is registered by a mass flow meter (Bronkhorst High-Tech b.v.) having an error margin of $0.5 \%$ on readout and $0.1 \%$ on full scale $240 \mathrm{sccm}$ or $\mathrm{mln} / \mathrm{min}$. 


\subsection{Results and Discussion}

Plotted in figure 6.12a are the measurement points and theoretical curves of air flows through the sieve, which shows a good match between the model and experiments. An average pore size of $\varnothing 125 \mathrm{~nm}$ is assumed for the theoretical calculations, which is within the size measurement error limits. At higher mean pressures, a linear increasing trend can be observed in the measured flow, which is an effect of the viscous flow behaviour. At atmospheric pressure and 100 mbar transmembrane pressure, the air flux through the tube bonded sieve is $7.56 \mathrm{~L} / \mathrm{hr}$ (i.e. 121 sccm), which resembles $10.7 \cdot 10^{6} \mathrm{~L} / \mathrm{hr}^{2} \mathrm{~m}^{2}$.bar.

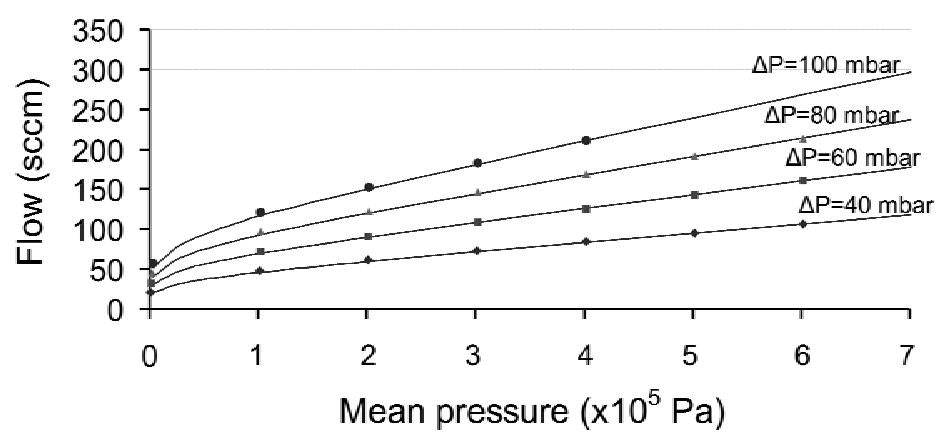

(a)

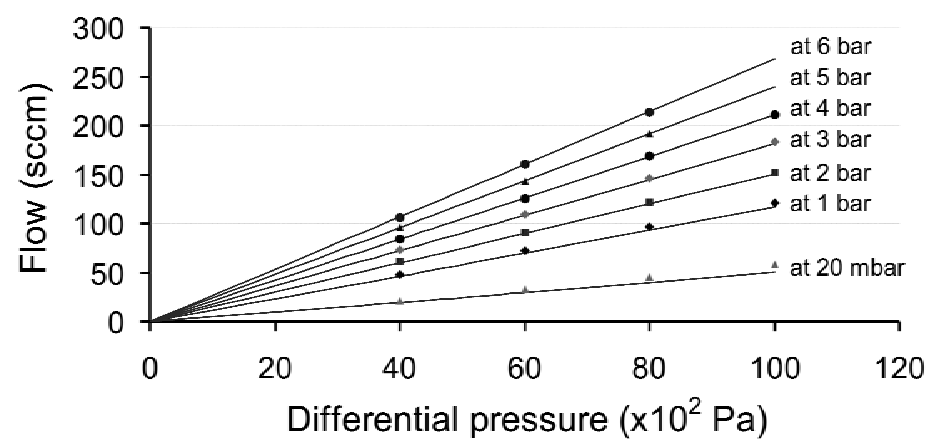

(b)

Figure 6.12. Air fluxes through the nanosieve a) for varying mean pressures recorded at different differential pressures. b) for varying differential pressures recorded at different mean pressures. The solid lines represent the theoretical estimate for the flows. The flow measurement errors range from $\pm 1 \%$ for low flows to $\pm 0.6 \%$ for high flows. The pressure measurement error lies within a margin of $\pm 2 \%$ for around atmospheric pressure and gets smaller for higher pressures. The error in the differential pressure is negligibly small. 
At sub-atmospheric pressures, the flow lines are not linear, because at low mean pressures - dictated by the free molecular flux - the Clausing loss of the microsieve becomes significant. As estimated, the flow at lower mean pressures is not reaching zero, but a value equal to the molecular flux through the sieve. The measurements can be viewed differently by plotting the total mass flow against varying differential pressures across the sieve as shown in figure $6.12 \mathrm{~b}$. The linearity of these curves prove that the kinetic losses of the sieve are negligible.

Since the total flow has a considerable contribution from the molecular flow, the nanosieve should show some selectivity between gas molecules based on the difference in their molecular mobilities. The maximum selectivity between two gases in the molecular flow regime is the square-root of the ratio of their molecular masses [8]. Shown in figure 6.13 are results of experiments performed with gases of different molecular weights, which reveals a definite mass-based selectivity (for large $K_{n}$ values). The selectivities are determined with pure gas flow experiments. It can be observed in this graph that helium starts to enter the molecular regime at a higher pressure than the others. This is because of its longer mean-free-path compared to the other gases at the same pressure. The flows of nitrogen and air are overlapping due to their similar molecular weights. Furthermore argon, the heaviest of the lot has the lowest flux.

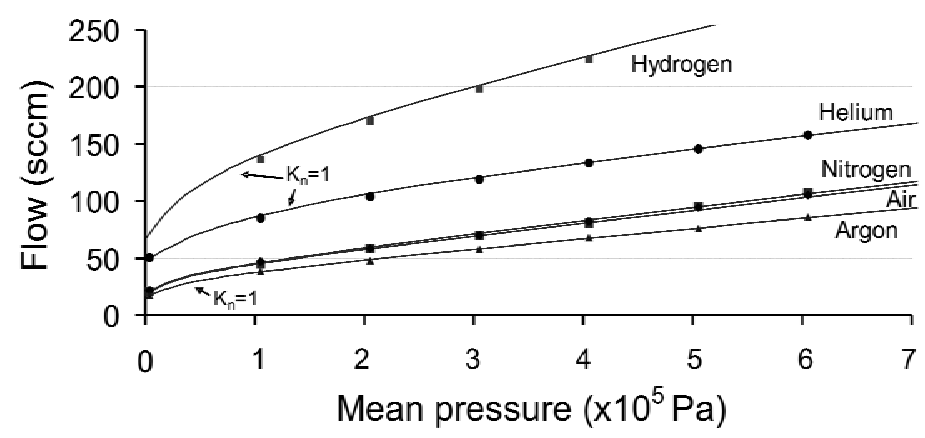

Figure 6.13. Fluxes of different gases at varying mean pressures measured at a fixed differential pressure of 40 mbar. The solid lines represent the theoretical estimate for the flows.

The He/Ar selectivity is 3.1 at 20 mbar mean pressure, which is quite in accordance with the theory. The selectivity could be made even better by eliminating the viscous 
effects of the flow by further reducing the poresizes. With LIL technology, it is possible to achieve nano-patterns down to around $60 \mathrm{~nm}$ in dimension [16]. Or alternatively, the poresize of the current nanosieves can be reduced by depositing an extra silicon nitride layer on it using chemical vapour deposition technique [7]. The selectivity could also be improved by placing multiple sieves in a cross-flow configuration. A selectivity of 2.32 is observed around 1 bar mean pressure due to the difference in viscosity of gases. This viscosity based selectivity seen at higher pressures would vanish when mixed gas experiments are performed.

The strength of the total sieve bonded on the glass tube of $\varnothing 3 \mathrm{~mm}$ inner diameter was found to be at least 5 bars of trans-membrane pressure, measured to the limit of our pressure sensors. The sieve assembled onto the glass tube was tested for mechanical integrity up to $700{ }^{\circ} \mathrm{C}$.

Another interesting observation from figure 6.13 is that the nanosieve is selective to hydrogen, with a selectivity of 2.9 against nitrogen/air at 1 bar pressure. This makes its application as a gas diffusive support (GDS) for the $\mu \mathrm{SAFC}$ even more interesting.

\subsection{Conclusions}

To summarize, a nanosieve with $45 \mathrm{~nm}$ thickness and $120 \mathrm{~nm}$ pore diameter has been fabricated using nanomachining techniques. The ultra-thin nanosieve is supported onto a robust microsieve having $\varnothing 6 \mu \mathrm{m}$ pores and $80 \mu \mathrm{m}$ thickness via a bond-micromachining technique. Such a sieve can serve as a nano-GDS when very thin palladium membranes are used in the $\mu \mathrm{SAFC}$. The composite sieve structure has been characterized for understanding the flow behaviour of different gases at varying mean pressures and trans-membrane pressures. A mass flow based model has been developed using electrical analogy to determine the total flux through the composite sieve. The transition flow regime has been the focus of the study, where the flux through the $2 \mathrm{D}$ nanosieve is shown to be a linear addition of viscous and molecular fluxes, without using any fitting parameters. The extremely small lip-thickness of the nanopores enabled the quantification of pure transition flow by minimizing the pore wall interaction effects of the gas molecules. A major contribution to the net flux from molecular flow was observed for the nanosieve at atmospheric pressure. The nanosieve 
clearly demonstrates a molecular mass based selectivity between different gas species. Due to the geometrically regular nanopore pattern and small thickness, the $2 \mathrm{D}$ nanosieve can deliver higher fluxes at low pressure drops, which makes it attractive for various applications including particle filtration, air-sterilisation or gas separation.

\section{Acknowledgements}

I would like thank Floris Falke for his contributions to this work.

\section{References}

[1] T. Tsuru, Separation and Purification Revierws, 2001, 30, p.191

[2] R. M. De Vos and H. Verweij, Science, 1998, 279, p.1710

[3] J. K. Holt, H. G. Park, Y. Wang, M. Stadermann, A. B. Artyukhin, C. P. Grigoropoulos, A. Noy and O. Bakajin, Science, 2006, 312, p.1034

[4] A. Thormann, N. Teuscher, M. Pfannmoeller, U. Rothe and A. Heilmann, Small, 2007, 3 p.1032

[5] S. Gruener and P. Huber, Physical Review Letters, 2008, 100, 064502

[6] S. Kuiper, C. J. M. Van Rijn, W. Nijdam and M. Elwenspoek, Journal of Membrane Science, 1998, 150, p.1

[7] H. D. Tong, H. V. Jansen, V. J. Gadgil, C. G. Bostan, E. Berenschot, C. J. M. Van Rijn and M. Elwenspoek, Nano letters, 2004, 4, p.283

[8] T. Graham, Phil. Trans. of the Royal Society of London, 1846, 136, p.573

[9] R. A. Sampson, Philos. Trans. of the Royal Society of London A, 1891, 182, p.449

[10] M. Knudsen, Journal of Membrane Science, 1995, 100, p.23 (English translation of Ann. der Physik, 1909, 28, p.75)

[11] S. Dushmann and J. M. Lafferty, Scientific Foundations of Vacuum Technique, Second Ed., 1962 (New York: John Wiley \& Sons)

[12] P. Clausing, Journal of Vacuum Science and Technology, 1971, 8, p.636 (English translation of Ann. der Physik, 1932, 12, p.961)

[13] E. B. Arkilic, K. Breuer and M. A. Schmidt, Journal of Fluid Mechanics, 2001, 437, p.29

[14] E. Kapon and A. Katzir, Journal of Applied Physics, 1982, 53, p.1387

[15] C. J. M. Van Rijn, G. J. Veldhuis and S. Kuiper, Nanotechnology, 1998, 9, p.343 
[16] S. Kuiper, H. Van Wolferen, C. J. M. Van Rijn, W. Nijdam, G. Krijnen and M. Elwenspoek, Journal of Micromechanics and Microengineering, 2001, 11, p.33

[17] S. Unnikrishnan, H. Jansen, E. Berenschot, M. Elwenspoek, Journal of Micromechanics and Microengineering, 2008, 18, 064005

[18] H. Jansen, M. De Boer, S. Unnikrishnan, M. Louwerse and M. Elwenspoek, Journal of Micromechanics and Microengineering, 2009, 19, 033001

[19] S. Unnikrishnan, H. Jansen, E. Berenschot, B. Mogulkoc and M. Elwenspoek, IEEE Proc. MEMS, 2009, p.324

[20] L. M. Lund and A. S. Berman, Journal of Applied Physics, 1966, 37, p.2489, p.2496

[21] U. Eickmann and U. Werner, German Chemical Engineering, 1985, 8, p.186

[22] E. Kennard, Kinetic Theory of Gases, 1938 (New York: McGraw-Hill)

[23] Z. Dagan, S. Weinbaum and R. Pfeffer, Chemical Engineering Science, 1983, 38, p.583

[24] K. Tio and S. S. Sadhal, Applied Scientific Research, 1994, 52, p.1 


\section{Conclusions and Future scope}

In this final chapter, the main conclusions of the $\mu S A F C$ research are drawn based on the important results described in the previous chapters. After summarizing the experiences gained in micromachining the gas diffusive support, dense palladium electrode and solid acid thin-film, this chapter highlights the further challenges involved for realizing a successful membrane electrode assembly (MEA) of the fuel cell. Conclusions are also drawn from the characterization results of each of the MEA components and discussions are made on possible improvements of their performances. Towards the end of this chapter, future scope of the $\mu S A F C$ research is described. 


\subsection{Conclusions: What has been done until now?}

The overall aim of the project is to fabricate a micromachined solid acid fuel cell ( $\mu$ SAFC), which has a membrane electrode assembly (MEA) consisting of a thin-film solid acid electrolyte encapsulated within two dense thin-film palladium electrode membranes. The goal of this thesis work has been to investigate microfabrication techniques to realize free-hanging dense palladium membranes and to understand their suitability as hydrogen diffusive electrodes (HDEs) for the micromachined solid acid fuel cell ( $\mu \mathrm{SAFC})$. The following conclusions are drawn from the research.

A new methodology to make micromachined palladium thin-film membranes: thinfilm transfer technique via bond-micromachining, has been shown as a successful method to fabricate defect free micron and sub-micron thick membranes. Using this method, a $1 \mu \mathrm{m}$ thick dense palladium membrane supported on a perforated silicon gas diffusive support (GDS) has been fabricated as the fuel cell electrode. The supporting GDS is a silicon microsieve having straight cylindrical pores, which show low pressure drop as well as good strength. A customized recipe based on deep reactive ion etching has been developed to anisotropically etch the micropores. Two of such sieve supported HDEs could be used to sandwich the electrolyte in between them to form the Membrane Electrode Assembly (MEA) of the $\mu$ SAFC.

The hydrogen flux through the palladium membrane has been measured for different temperatures and hydrogen feed pressures. In contrast to what was expected from the theoretical model, our $1 \mu \mathrm{m}$ thick palladium membranes have a much higher flux in the experimental temperature range of $323 \mathrm{~K}-523 \mathrm{~K}$. At $423 \mathrm{~K}$ (the optimal $\mu \mathrm{SAFC}$ operating temperature) and 1.5 bar hydrogen pressure on the feed side, the palladium membranes show a flux within the range $6.3 \times 10^{-6}$ to $8.8 \times 10^{-6} \mathrm{~mol}$ $\mathrm{H} / \mathrm{cm}^{2}$.s, which is approximately $0.6-0.8 \mathrm{~A} / \mathrm{cm}^{2}$ of equivalent current density. Our palladium membranes show a very good selectivity (> 1500) for hydrogen with respect to helium. At $423 \mathrm{~K}$, for the hydrogen feed pressure of $1.5 \mathrm{bar}$, the $1 \mu \mathrm{m}$ thick membrane seems to still operate in the diffusion-limited regime. The diffusive flux through the membrane can be further enhanced by reducing the thickness of the palladium. Very thin palladium membranes need to be supported by a nanoporous GDS like a nanosieve shown in chapter 6. However, it has to be noted that while lowering the thickness to nanometers, the chances of pinhole or defect occurrence is 
high, which will lower the selectivity of the membrane towards hydrogen and can let water molecules contact the water soluble solid acid electrolyte. Another point to be noted is that as the palladium electrode membrane is thinned down its lateral electronic resistance will increase. The $1 \mu \mathrm{m}$ thick membrane sample was measured to have a lateral resistance of $0.11 \Omega$ from centre to edge ( $9 \mathrm{~mm}$ distance), which would be significant when the membrane is used as a fuel cell electrode. To avoid this problem the supporting GDS could be fabricated with highly doped silicon connected to the bottom of the palladium layer, which could thus enable normal current collection from the electrode. This possibility would be investigated in the future.

The study conducted to investigate $\alpha-\beta$ phase transition has enabled us to predict the occurrence and phase change of the palladium hydrides in our membranes. This helps us to suppress the phase transition in palladium, which thus increases its stability and durability when used as a HDE in the fuel cell. According to our observation, the maximum allowed hydrogen pressure on the anode side for the $\mu$ SAFC operating at a temperature of $423 \mathrm{~K}$ (i.e. $150{ }^{\circ} \mathrm{C}$ ) is $\sim 1.5$ bar. Beyond this pressure the palladium would completely embrittle due to phase transition. When the operational temperature of the fuel cell is less during its start-up or shut-down, the hydrogen has to be automatically removed from the feed stream so as to elude $\alpha-\beta$ phase transition.

Trials for making a dense electrode fuel cell MEA has been performed using a relatively new kind of solid acid, potassium dihydrogen phosphite - $\mathrm{KH}\left(\mathrm{PO}_{3} \mathrm{H}\right) . \mathrm{A} \varnothing$ $10 \mathrm{~mm}$ and $1 \mathrm{~mm}$ thick compressed disc of $\mathrm{KH}\left(\mathrm{PO}_{3} \mathrm{H}\right)$ was found to have a proton conductivity of $3.8 \cdot 10^{-3} \Omega^{-1} \mathrm{~cm}^{-1}$ at $135^{\circ} \mathrm{C}$ just above the superprotonic transition temperature of $132{ }^{\circ} \mathrm{C}$. Phosphite solid acids are stable in hydrogen atmospheres unlike their sulphate and selenate counterparts. And when compared to phosphates, the humidification required for phosphites to prevent dehydrative weight loss was found to be much less. Prior to integration with the palladium electrodes, the performance of $\mathrm{KH}\left(\mathrm{PO}_{3} \mathrm{H}\right)$ was tested in a conventional (porous carbon electrodes) MEA of $\varnothing 12 \mathrm{~mm}$. For an electrolyte thickness of $0.5 \mathrm{~mm}$, the measured open circuit voltage was about $0.65 \mathrm{~V}$. When a current of $0.5 \mathrm{~mA} / \mathrm{cm}^{2}$ is drawn, the operational voltage drops to $0.3 \mathrm{~V}$, thus leading to a power density of $0.15 \mathrm{~mW} / \mathrm{cm}^{2}$. The maximum power density increased by about 3-4 times as the humidification was 
enhanced from $3 \%$ to $30 \%$ of the supply pressure, which shows that the dehydration of the electrolyte and its interfaces with the electrode could be significant.

Thin-films of $\mathrm{KH}\left(\mathrm{PO}_{3} \mathrm{H}\right)$ were fabricated down to $10 \mu \mathrm{m}$ thickness using a dipcoating technique. Impregnation of inorganic particles ( 14 nm size) was helpful for suppressing random crystallization of the solid acid while drying, which was found to be a problem when working with pure salts. The thin-film solid acid composite layers exhibited a lower proton conductivity than that of the $0.5 \mathrm{~mm}$ thick compressed solid acid pellets, which could be an effect of impregnated silica particles. Though the fabrication and characterization of the thin-film palladium electrode and the solid acid electrolyte was successful, the final integration of both is still a challenge due to certain problems with the electrolyte layer, which needs further investigation.

\subsection{Future scope: What more needs to be done to achieve the final goal?}

To achieve the final goal of a microfabricated fuel cell, the first and foremost task is to solve the problems of integration of the thin-film electrolyte with the palladium electrodes. The two configurations of electrodes-electrolyte assembly discussed in chapter 4 needs further study to become successful. The success of the first assembly configuration depends on how dense the electrolyte layer can be coated. The density of the thin-film electrolyte can be improved by increasing its silica composition, which would increase the poly-crystallinity of the film. However, this could reduce the proton conductivity of the film, thus needs proper study [1]. The other method to improve film density is to perform the drying in a humidity controlled atmosphere. The second assembly configuration for the MEA involved melting of the electrolyte (at $190{ }^{\circ} \mathrm{C}$ ) and faced the bottleneck of bubble formation in the electrolyte. These bubbles might be that of moisture escaping the electrolyte, but no conclusions can be drawn before a detailed investigation of the material properties of $\mathrm{KH}\left(\mathrm{PO}_{3} \mathrm{H}\right)$ before and after the bubbling.

Only after the integration is successful, the feasibility of a dense electrode $\mu \mathrm{SAFC}$ can be tested. Recent PEMFCs are able to deliver high power densities, an example being $0.4 \mathrm{~W} / \mathrm{cm}^{2}$ at a current density of $0.8 \mathrm{~A} / \mathrm{cm}^{2}$ [2]. It has also been shown that with fuel cells based on solid acid electrolyte, it is possible to obtain such high power 
densities at comparable current densities [3]. The current or flux of hydrogen atoms (thus equivalent amount of protons) permeated through our $1 \mu \mathrm{m}$ thick palladium electrode membrane at $423 \mathrm{~K}$ and 1.5 bar hydrogen feed pressure, seems to be in the same order of magnitude. This gives an indication that when every other component in the $\mu \mathrm{SAFC}$ functions efficiently, the palladium could probably become rate limiting. It is possible to increase the hydrogen diffusive flux through palladium by thinning down the membrane to $200 \mathrm{~nm}$, provided we don't run into hydrogen desorption issues. Anyway, it is too premature to conclude what the rate limiting aspect of our fuel cell would be, since according to our present understanding of the electrolyte $\mathrm{KH}\left(\mathrm{PO}_{3} \mathrm{H}\right)$, its ohmic and interfacial charge transfer losses could pose a larger rate limitation in the final $\mu \mathrm{SAFC}$. An increase in the operational temperature ( $>423 \mathrm{~K}$ ) will be also beneficial to improve the $\mu$ SAFC's performance, but the stability of $\mathrm{KH}\left(\mathrm{PO}_{3} \mathrm{H}\right)$ at these higher temperatures needs further study. Although the proton conduction mechanism exhibited by $\mathrm{KH}\left(\mathrm{PO}_{3} \mathrm{H}\right)$ is anhydrous, its dehydration was observed to hinder the performance. This is because the presence of water molecules at the interface of the electrode and electrolyte facilitates charge transfer. When the electrolyte is operated at higher temperatures, it dehydrates causing the interfacial charge transfer to decline. Probably, when $\mathrm{KH}\left(\mathrm{PO}_{3} \mathrm{H}\right)$ is sealed in between two dense palladium electrodes, the chances of moisture escaping the electrolyte might become less, thereby reducing or eluding the dehydration issue.

Currently, the $1 \mu \mathrm{m}$ thick membrane is observed to be operating in a diffusionlimited regime. The flux could be further increased by thinning down the membrane, which would shift the process to a desorption limitation. This problem could be probably tackled by dispersing platinum catalyst nano-particles ( $5 \mathrm{~nm}$ size) by controlled sputtering on the permeate side of the palladium membrane. Such a catalyst would be definitely needed to have an efficient Oxygen Reduction Reaction when the palladium membrane would be subsequently employed as the cathode of the proposed $\mu$ SAFC. Platinum is a well known catalyst that can dissociate oxygen molecules easily and enhance their reaction with hydrogen to form water.

Given the current state of our research, it would take much more efforts to realize a functional $\mu \mathrm{SAFC}$ proving the concept of a dense electrode MEA. Integration of the palladium electrodes and the thin-film electrolyte layer is the first task to be tackled. 
The subsequent task would be to optimize its performance to match the level of a PEMFC. After making it technically feasible, it also has to be made commercially viable so as to compete with PEMFC in the market. Rather than large scale applications $\mu \mathrm{SAFC}$ can serve as micro power sources for smaller applications, an example being an embedded power supply in a circuit board.

\section{References}

[1] A.S. Bondarenko, W. Zhou, H.J.M. Bouwmeester, Journal of Power Sources, 2009, doi:10.1016/j.jpowsour.2009.06.001

[2] C. Tori, M. Baleztena, C. Peralta, R. Calzada, E. Jorge, D. Barsellini, G. Garaventta, A. Visintin and W.E. Triac, International Journal of Hydrogen Energy, 2008, 33 (13), pp. 3588 3591

[3] T. Uda and S. M. Haile, Electrochemical and Solid-State Letters, 2005, 8 (5), A245-A246 


\section{Appendix A}

\section{Fabrication process for the microsieve supported palladium membrane}

\section{A.1 Microsieve wafer processing}

\begin{tabular}{|c|c|c|c|}
\hline Step & Process & & Comment \\
\hline 1 & $\begin{array}{l}\text { Substrate selection - } \\
\text { Silicon }<110>\text { DSP } \\
(\# \text { subs002) }\end{array}$ & $\begin{array}{l}\text { CR112B / Wafer Storage Cupboard } \\
\text { Supplier: } \\
\text { Orientation: }<110> \\
\text { Diameter: } 100 \mathrm{~mm} \\
\text { Thickness: } 380 \mu \mathrm{m}+/-25 \mu \mathrm{m} \\
\text { Polished: Double side } \\
\text { Resistivity: } 5-10 \Omega \mathrm{cm} \\
\text { Type: p }\end{array}$ & $\begin{array}{l}\text { DSP Si }<110>\text { is only } \\
\sim 380 \mu \mathrm{m} \text { thick, which makes } \\
\text { it easier to etch through the } \\
\text { wafer }\end{array}$ \\
\hline 2 & $\begin{array}{l}\text { Cleaning Standard } \\
(\# \text { clean003) }\end{array}$ & $\begin{array}{l}\text { CR112B / Wet-Bench 3-2 } \\
\mathrm{HNO}_{3}(100 \%) \text { Selectipur: MERCK } 100453 \\
\mathrm{HNO}_{3}(69 \%) \text { VLSI: MERCK } 116445 \\
\text { - Beaker 1: fumic } \mathrm{HNO}_{3}(100 \%), 5 \mathrm{~min} \\
\text { - Beaker 2: fumic } \mathrm{HNO}_{3}(100 \%), 5 \mathrm{~min} \\
\text { - Quick Dump Rinse }<0.1 \mu \mathrm{S} \\
\text { - Beaker 3: boiling }\left(95^{\circ} \mathrm{C}\right) \mathrm{HNO}_{3}(69 \%), 10 \mathrm{~min} \\
\text { - Quick Dump Rinse }<0.1 \mu \mathrm{S} \\
\text { - Spin drying }\end{array}$ & \\
\hline 3 & $\begin{array}{l}\text { Dry Oxidation } \\
\text { (DOX) of silicon at } \\
1100^{\circ} \mathrm{C} \\
(\# \text { depo032) })\end{array}$ & $\begin{array}{l}\text { CR112B / Furnace A2 } \\
\text { Only for dedicated processing (CMOS) } \\
\text { Standby temperature: } 700^{\circ} \mathrm{C} \\
\text { - Program: DOX1100 } \\
\text { - See Calbration curve on MIS page } \\
\text { - Temp.: } 1100^{\circ} \mathrm{C} \\
\text { - Time: } 2 \text { hrs } 5 \text { mins } \\
\text { - Gas: } \mathrm{O}_{2}\end{array}$ & $\begin{array}{l}200 \mathrm{~nm} \text { thick. } \\
\text { This layer is to later on } \\
\text { protect the Silicon surface } \\
\text { from fluorocarbon, } \\
\text { resputtering. This also helps } \\
\text { to avoid nano-ridges at the } \\
\text { edge of every micropore, } \\
\text { while oxidation in step } 13 .\end{array}$ \\
\hline 4 & $\begin{array}{l}\text { Lithography - } \\
\text { Coating Olin907-17 } \\
(\# \text { lith005) }\end{array}$ & $\begin{array}{l}\text { CR112B / Suss Micro Tech Spinner (Delta 20) } \\
\text { Hotplate } 95^{\circ} \mathrm{C} \\
\text { Olin } 907-17 \\
\text { - Spinning acceleration: } 4000 \mathrm{rpm} / \mathrm{s}\end{array}$ & $\begin{array}{l}\text { This masking layer is for } \\
\text { both the following dry } \\
\text { etching and wet etching } \\
\text { steps. }\end{array}$ \\
\hline
\end{tabular}




\begin{tabular}{|c|c|c|c|c|c|}
\hline & & \multicolumn{3}{|c|}{$\begin{array}{l}\text { - Spinning speed: } 4000 \mathrm{rpm} \\
\text { - Spinning time: } 20 \mathrm{~s} \\
\text { - Prebake }\left(95^{\circ} \mathrm{C}\right): 60 \mathrm{~s}\end{array}$} & \\
\hline 5 & $\begin{array}{l}\text { Lithography - } \\
\text { Alignment \& } \\
\text { Exposure Olin 907- } \\
17(\mathrm{EV}) \\
\text { (\#lith021) }\end{array}$ & \multicolumn{3}{|c|}{$\begin{array}{l}\text { CR117B / EVG } 20 \\
\text { Electronic Vision Group } 20 \\
\text { • Hg lamp: } 12 \mathrm{~mW} / \mathrm{cm}^{2} \\
\text { - Exposure Time: } 4 \mathrm{sec}\end{array}$} & Mask pattern: Microsieve \\
\hline 6 & $\begin{array}{l}\text { Lithography - } \\
\text { Development Olin } \\
\text { Resist } \\
\text { (\#lith011) }\end{array}$ & \multicolumn{3}{|c|}{$\begin{array}{l}\text { CR112B / Wet-Bench } 11 \\
\text { Developer: OPD4262 } \\
\text { Hotplate } 120^{\circ} \mathrm{C}(\mathrm{CR} 112 \mathrm{~B} \text { or CR117B) } \\
\text { - After Exposure Bake }\left(120^{\circ} \mathrm{C}\right): 60 \mathrm{sec} \\
\text { Development: } \\
\text { - Time: } 30 \text { sec in Beaker } 1 \\
\text { - Time: } 15-30 \text { sec in Beaker } 2 \\
\text { - Quick Dump Rinse }<0.1 \mu \mathrm{S} \\
\text { - Spin drying }\end{array}$} & \\
\hline 7 & $\begin{array}{l}\text { Lithography - } \\
\text { Postbake standard } \\
\text { (\#lith009) }\end{array}$ & \multicolumn{3}{|c|}{$\begin{array}{l}\text { CR112B / Hotplate } 120^{\circ} \mathrm{C} \\
\text { - Time: } 30 \mathrm{~min}\end{array}$} & $\begin{array}{l}\text { To withstand the } \\
\text { subsequent wet etching step. }\end{array}$ \\
\hline 8 & $\begin{array}{l}\text { Ozone anneal of } \\
\text { Olin } 908 \text { (to } \\
\text { improve wetting) }\end{array}$ & \multicolumn{3}{|c|}{$\begin{array}{l}\text { CR116B-1 / UV PRS-100 } \\
\text { - time: } 120 \mathrm{sec}\end{array}$} & $\begin{array}{l}\text { To improve wetting during } \\
\text { etching of oxide layers }\end{array}$ \\
\hline 9 & $\begin{array}{l}\text { Etching BHF (1:7) } \\
\mathrm{SiO}_{2} \\
(\# \text { etch024) }\end{array}$ & \multicolumn{3}{|c|}{$\begin{array}{l}\text { CR112B / Wet-Bench 3-3 } \\
\mathrm{NH}_{4} \mathrm{~F} / \mathrm{HF}(1: 7) \text { VLSI: MERCK } 101171.2500 \\
\text { - Quick Dump Rinse }<0.1 \mu \mathrm{S} \\
\text { - Spin drying } \\
\text { Etchrate thermal } \mathrm{SiO}_{2}=60-80 \mathrm{~nm} / \mathrm{min}\end{array}$} & $\begin{array}{l}\text { This is for patterning the } \\
\text { oxide layer underneath. } \\
\text { Time: } 3.5 \text { mins (including a } \\
0.5 \text { min over etch). }\end{array}$ \\
\hline 10 & $\begin{array}{l}\text { Plasma etching of } \\
\text { Silicon } \\
\text { B-CHF3 }\end{array}$ & $\begin{array}{l}\text { CR125c/A } \\
\text { Parameters } \\
\text { Gas } \\
\text { Flow sccm } \\
\text { Time sec } \\
\text { Priority }\end{array}$ & $\begin{array}{l}\text { Etch } \\
\text { SF6 } \\
400 \\
4 \\
2\end{array}$ & $\begin{array}{l}\text { Deposition } \\
\text { CHF3 } \\
200 \\
0.5 \\
1\end{array}$ & $\begin{array}{l}\text { For } 15 \text { mins - resulting in } \\
\text { 95um deep micropores in } \\
\text { Silicon. }\end{array}$ \\
\hline
\end{tabular}


Appendix A

\begin{tabular}{|c|c|c|c|c|c|}
\hline & & $\begin{array}{l}\text { APC \% } \\
\text { ICP Watt } \\
\text { CCP Watt }[L F] \\
\text { Pulsed (LF) ms. } \\
\text { He mBar } \\
\text { SH mm } \\
\text { Electrode } \\
\text { temp. }{ }^{\circ} \text {. }\end{array}$ & $\begin{array}{l}15 \\
2500 \\
20 \\
20 \text { on/80off } \\
10 \\
110 \\
-120\end{array}$ & $\begin{array}{l}15 \\
2500 \\
20 \\
20 \mathrm{on} / 80 \text { off } \\
10 \\
110 \\
-120\end{array}$ & \\
\hline 11 & $\begin{array}{l}\text { Stripping of Olin } \\
\text { PR by oxygen } \\
\text { plasma } \\
\text { Tepla } 300 \text { (\#lith042) }\end{array}$ & \multicolumn{3}{|c|}{$\begin{array}{l}\text { CR125A / Tepla } 300 \\
\text { Barrel Etcher (2.45 GHz) } \\
\text { Ultra clean system only (no metals except Al) } \\
\text { - See list with recipes in CR } \\
\text { - } \mathrm{O}_{2} \text { flow: } 200 \mathrm{sccm}(50 \%) \\
\text { - Power: up to } 1000 \mathrm{~W} \\
\text { - Pressure: } 1 \text { mbar } \\
\text { - Time: see recipes on the wall }\end{array}$} & $15 \mathrm{mins}$ \\
\hline 12 & $\begin{array}{l}\text { Stripping of Olin } \\
\text { PR - standard } \\
\text { (\#lith016) }\end{array}$ & \multicolumn{3}{|c|}{$\begin{array}{l}\text { CR112B / Wet-Bench 3-2 } \\
\mathrm{HNO}_{3}(100 \%) \text { Selectipur: MERCK } 100453 \\
\text { - Time: 30min } \\
\text { - Quick Dump Rinse }<0.1 \mu \mathrm{S} \\
\text { - Spin drying } \\
\text { - Visual microscopic inspection }\end{array}$} & $15 \mathrm{mins}$ \\
\hline 13 & $\begin{array}{l}\text { Cleaning Standard } \\
(\# \text { clean003) }\end{array}$ & \multicolumn{3}{|c|}{$\begin{array}{l}\text { CR112B / Wet-Bench 3-2 } \\
\mathrm{HNO}_{3}(100 \%) \text { Selectipur: MERCK } 100453 \\
\mathrm{HNO}_{3}(69 \%) \text { VLSI: MERCK } 116445 \\
\text { - Beaker 1: fumic } \mathrm{HNO}_{3}(100 \%), 5 \mathrm{~min} \\
\text { - Beaker 2: fumic } \mathrm{HNO}_{3}(100 \%), 5 \mathrm{~min} \\
\text { - Quick Dump Rinse }<0.1 \mu \mathrm{S} \\
\text { - Beaker 3: boiling }\left(95^{\circ} \mathrm{C}\right) \mathrm{HNO}_{3}(69 \%), 10 \mathrm{~min} \\
\text { - Quick Dump Rinse }<0.1 \mu \mathrm{S} \\
\text { - Spin drying }\end{array}$} & \\
\hline 14 & $\begin{array}{l}\text { Dry Oxidation } \\
(\mathrm{DOX}) \text { at } 1100^{\circ} \mathrm{C} \text { of } \\
\text { Silicon } \\
\text { (\#depo026) }\end{array}$ & \multicolumn{3}{|c|}{$\begin{array}{l}\text { CR112B / Furnace B3 } \\
\text { Standby temperature: } 1100^{\circ} \mathrm{C} \\
\text { - Program: OX1100 } \\
\text { - Temp.: } 1100^{\circ} \mathrm{C} \\
\text { - Gas: } \mathrm{O}_{2} \\
\text { - Flow: } 41 / \mathrm{min}\end{array}$} & $\begin{array}{l}10 \text { mins. This is for burning } \\
\text { the Fluorocarbon residues } \\
\text { from Plasma etched } \\
\text { micropores. And also to } \\
\text { form a etch stop oxide layer } \\
\text { of } 50 \mathrm{~nm} \text { inside the pores. }\end{array}$ \\
\hline 15 & Blue dicing foil & \multicolumn{3}{|c|}{ Sticking the foil on the micropores side and folding } & For protecting the oxide on \\
\hline
\end{tabular}




\begin{tabular}{|c|c|c|c|}
\hline & masking & it slightly onto the etchable side. & $\begin{array}{l}\text { the micropores side of the } \\
\text { wafer during BHF etch }\end{array}$ \\
\hline 16 & $\begin{array}{l}\text { Etching BHF (1:7) } \\
\mathrm{SiO}_{2} \\
(\# \text { etch024) }\end{array}$ & $\begin{array}{l}\text { CR112B / Wet-Bench 3-3 } \\
\mathrm{NH}_{4} \mathrm{~F} / \mathrm{HF}(1: 7) \text { VLSI: MERCK } 101171.2500 \\
\text { - Quick Dump Rinse }<0.1 \mu \mathrm{S} \\
\text { - Spin drying } \\
\text { Etchrate thermal } \mathrm{SiO}_{2}=60-80 \mathrm{~nm} / \mathrm{min} \\
\text { Etchrate PECVD } \mathrm{SiO}_{2}=125 / \mathrm{nm} / \mathrm{min} \\
\text { Etchrate TEOS } \mathrm{SiO}_{2}=180 / \mathrm{nm} / \mathrm{min}\end{array}$ & $\begin{array}{l}3.5 \text { mins to remove the } \\
200 \mathrm{~nm} \text { oxide on the back of } \\
\text { the wafer completely. The } \\
\text { wet stripping of oxide is } \\
\text { necessary so as to proceed } \\
\text { directly with the dry etching } \\
\text { of Silicon wafer. }\end{array}$ \\
\hline 17 & $\begin{array}{l}\text { Cleaning, Removing } \\
\text { the blue foil and } \\
\text { Cleaning }\end{array}$ & $\begin{array}{l}\text { CR112B / Wet-Bench 3-2 } \\
\text { - Quick Dump Rinse }<0.1 \mu \mathrm{S} \\
\text { - Spin drying }\end{array}$ & $\begin{array}{l}\text { Quick dump rinse needs to } \\
\text { be done both before and } \\
\text { after removing the blue foil } \\
\text { (manually), with the } \\
\text { intention of removing any } \\
\text { HF residues from the wafer } \\
\text { surface. }\end{array}$ \\
\hline 18 & $\begin{array}{l}\text { Lithography - } \\
\text { Coating Olin908-35 } \\
\text { (\#lith006) }\end{array}$ & $\begin{array}{l}\text { CR112B / Suss Micro Tech Spinner (Delta 20) } \\
\text { Hotplate } 95^{\circ} \mathrm{C} \\
\text { Olin } 908-35 \\
\text { - Spinning acceleration: } 4000 \mathrm{rpm} / \mathrm{s} \\
\text { - Spinning speed: } 4000 \mathrm{rpm} \\
\text { - Spinning time: } 20 \mathrm{~s} \\
\text { - Prebake }\left(95^{\circ} \mathrm{C}\right): 120 \mathrm{~s}\end{array}$ & Coating on the back side \\
\hline 19 & $\begin{array}{l}\text { Lithography - } \\
\text { Alignment \& } \\
\text { Exposure Olin 908- } \\
35 \text { (EV) } \\
\text { (\#lith022) }\end{array}$ & $\begin{array}{l}\text { CR117B / EVG } 20 \\
\text { Electronic Vision Group } 20 \text { Mask Aligner } \\
\text { - Hg lamp: } 12 \mathrm{~mW} / \mathrm{cm}^{2} \\
\text { - Exposure Time: } 9 \mathrm{sec}\end{array}$ & $\begin{array}{l}\text { Mask pattern: Back etching } \\
\text { mask }\end{array}$ \\
\hline 20 & $\begin{array}{l}\text { Lithography - } \\
\text { Development Olin } \\
\text { Resist } \\
\text { (\#lith011) }\end{array}$ & $\begin{array}{l}\text { CR112B / Wet-Bench } 11 \\
\text { Developer: OPD4262 } \\
\text { Hotplate } 120^{\circ} \mathrm{C}(\mathrm{CR} 112 \mathrm{~B} \text { or CR117B) } \\
\text { - After Exposure Bake }\left(120^{\circ} \mathrm{C}\right): 60 \mathrm{sec} \\
\text { Development: } \\
\text { - Time: } 30 \text { sec in Beaker } 1 \\
\text { - Time: } 15-30 \text { sec in Beaker } 2 \\
\text { - Quick Dump Rinse }<0.1 \mu \mathrm{S} \\
\text { - Spin drying }\end{array}$ & \\
\hline 21 & Lithography - & CR112B / Hotplate $120^{\circ} \mathrm{C}$ & \\
\hline
\end{tabular}


Appendix A

\begin{tabular}{|c|c|c|c|c|}
\hline & $\begin{array}{l}\text { Postbake standard } \\
\text { (\#lith009) }\end{array}$ & \multicolumn{2}{|l|}{ - Time: 30min } & \\
\hline \multirow[t]{13}{*}{22} & \multirow[t]{13}{*}{$\begin{array}{l}\text { Plasma etching of } \\
\text { Silicon (C-FAST) } \\
\text { (\#etch063) }\end{array}$} & \multicolumn{2}{|c|}{$\begin{array}{l}\text { CR 125c/Adixen AMS } 100 \mathrm{SE} \\
\text { Applications: Wafer back etch with high selectivity } \\
\text { for oxide layers }\end{array}$} & \multirow{13}{*}{$\begin{array}{l}\text { Continue etching till the } \\
\text { oxidized holes are visible } \\
\text { from back side. } \\
\text { Etchtime: } 26 \text { mins for } \mathrm{Si} \\
<110>\text { wafer. For } 50 \mathrm{~nm} \\
\text { tubes, its better to etch only } \\
25.5 \text { mins ( } 25+0.5) \text {. } \\
\text { For better uniformity while } \\
\text { etching, a OSP Silicon } \\
<100>\text { sacrificial ring wafer } \\
\text { of inner hole diameter } \\
\varnothing 8 \mathrm{~cm} \text { is placed and } \\
\text { positioned over the wafer } \\
\text { (using Fomblin oil in } \\
\text { between for temporary } \\
\text { adhesion). }\end{array}$} \\
\hline & & Parameters & Value & \\
\hline & & $\mathrm{SF}_{6}[\mathrm{sccm}]$ & 400 & \\
\hline & & $\mathrm{O}_{2}[\mathrm{sscm}]$ & 0 & \\
\hline & & $\begin{array}{l}\text { He-backside cooling } \\
\text { [mbar] }\end{array}$ & 10 & \\
\hline & & ICP [watt] & 2500 & \\
\hline & & Vdc [Volts] & 0 & \\
\hline & & $\mathrm{p}[\mathrm{Pa}]$ & 12 & \\
\hline & & APC position $\%$ & 15 & \\
\hline & & Electrode temperature $\left[{ }^{\circ} \mathrm{C}\right]$ & 10 & \\
\hline & & Substrate height $[\mathrm{mm}]$ & 110 & \\
\hline & & $\begin{array}{l}\text { Etch rate Olin } 907 \\
{[\mu \mathrm{m} / \mathrm{min}]}\end{array}$ & Low & \\
\hline & & $\begin{array}{l}\text { Etch rate -Silicon } \\
(\mu \mathrm{m} / \mathrm{min})\end{array}$ & $\sim 11.5$ & \\
\hline 23 & $\begin{array}{l}\text { IPA cleaning of } \\
\text { Fomblin oil }\end{array}$ & $\begin{array}{l}\text { CR112B / Wet-Bench 3-2 } \\
\text { Clean the residues of the For } \\
\text { Isopropanol }\end{array}$ & mblin oil with & \\
\hline 24 & $\begin{array}{l}\text { Stripping of Olin } \\
\text { PR by oxygen } \\
\text { plasma } \\
\text { Tepla } 300 \text { (\#lith042) }\end{array}$ & $\begin{array}{l}\text { CR125A / Tepla } 300 \\
\text { Barrel Etcher }(2.45 \mathrm{GHz}) \\
\text { Ultra clean system only (no r } \\
\text { - See list with recipes in CR } \\
\text { - } \mathrm{O}_{2} \text { flow: } 200 \mathrm{sccm}(50 \%) \\
\text { - Power: up to } 1000 \mathrm{~W} \\
\text { - Pressure: } 1 \text { mbar } \\
\text { - Time: see recipes on the w }\end{array}$ & $\begin{array}{l}\text { netals except Al) } \\
\text { all }\end{array}$ & $\begin{array}{l}\text { stripping the resist for } \\
15 \mathrm{~min}\end{array}$ \\
\hline 25 & $\begin{array}{l}\text { Stripping of Olin } \\
\text { PR - standard } \\
\text { (\#lith016) }\end{array}$ & $\begin{array}{l}\text { CR112B / Wet-Bench 3-2 } \\
\mathrm{HNO}_{3}(100 \%) \text { Selectipur: } \\
\text { - Time: } 30 \mathrm{~min} \\
\text { - Quick Dump Rinse }<0.1 \mu \mathrm{S}\end{array}$ & IERCK 100453 & $15 \mathrm{mins}$ \\
\hline
\end{tabular}




\begin{tabular}{|c|c|c|c|}
\hline & & $\begin{array}{l}\text { - Spin drying } \\
\text { - Visual microscopic inspection }\end{array}$ & \\
\hline 26 & $\begin{array}{l}\text { Cleaning Standard } \\
\text { (\#clean003) }\end{array}$ & $\begin{array}{l}\text { CR112B / Wet-Bench 3-2 } \\
\mathrm{HNO}_{3}(100 \%) \text { Selectipur: MERCK } 100453 \\
\mathrm{HNO}_{3}(69 \%) \text { VLSI: MERCK } 116445 \\
\text { - Beaker 1: fumic } \mathrm{HNO}_{3}(100 \%), 5 \mathrm{~min} \\
\text { - Beaker 2: fumic } \mathrm{HNO}_{3}(100 \%), 5 \mathrm{~min} \\
\text { - Quick Dump Rinse }<0.1 \mu \mathrm{S} \\
\text { - Beaker 3: boiling }\left(95^{\circ} \mathrm{C}\right) \mathrm{HNO}_{3}(69 \%), 10 \mathrm{~min} \\
\text { - Quick Dump Rinse }<0.1 \mu \mathrm{S} \\
\text { - Spin drying }\end{array}$ & $\begin{array}{l}\text { It is better to replace the } \\
\text { Quick dump rinsing step } \\
\text { with 3-beaker mild rinsing } \\
\text { and the spin drying step } \\
\text { with IPA drying, since the } \\
\text { membranes could be fragile. }\end{array}$ \\
\hline 27 & $\begin{array}{l}\text { Etching HF (50\%) } \\
\text { LPCVD SiN or } \\
\text { Thermal oxide } \\
\text { (\#etch029) }\end{array}$ & $\begin{array}{l}\text { CR112B / Wet-Bench 3-3 } \\
\mathrm{HF}(50 \%) \text { VLSI: MERCK } 100373.2500 \\
\text { - Quick Dump Rinse }<0.1 \mu \mathrm{S} \\
\text { - Spin drying } \\
\text { Etchrate } \mathrm{SiRN}=5 \mathrm{~nm} / \mathrm{min} \\
\text { Etchrate } \mathrm{SiO}_{2}=1 \mu \mathrm{m} / \mathrm{min}\end{array}$ & $\begin{array}{l}2 \mathrm{mins} \\
\text { to strip the oxide } \\
\text { completely, including the } \\
50 \mathrm{~nm} \text { oxide tubes and the } \\
\text { surface protective } 200 \mathrm{~nm} \\
\text { oxide. }\end{array}$ \\
\hline
\end{tabular}

\section{A.2 Thin-film transfer and palladium processing}

\begin{tabular}{|c|c|c|c|}
\hline Step & Process & & Comment \\
\hline 1 & $\begin{array}{l}\text { Substrate selection - } \\
\text { Silicon <110> DSP } \\
(\# \text { subs002) }\end{array}$ & $\begin{array}{l}\text { CR112B / Wafer Storage Cupboard } \\
\text { Supplier: } \\
\text { Orientation: }<110> \\
\text { Diameter: } 100 \mathrm{~mm} \\
\text { Thickness: } 380 \mu \mathrm{m}+/-25 \mu \mathrm{m} \\
\text { Polished: Double side } \\
\text { Resistivity: } 5-10 \Omega \mathrm{cm} \\
\text { Type: p }\end{array}$ & $\begin{array}{l}\mathrm{Si}<110>\text { is } \sim 380 \mu \mathrm{m} \\
\text { thick, which makes it } \\
\text { easier to etch through } \\
\text { the wafer }\end{array}$ \\
\hline 2 & $\begin{array}{l}\text { Cleaning Standard } \\
(\# \text { clean003) }\end{array}$ & $\begin{array}{l}\text { CR112B / Wet-Bench 3-2 } \\
\mathrm{HNO}_{3}(100 \%) \text { Selectipur: MERCK } 100453 \\
\mathrm{HNO}_{3}(69 \%) \text { VLSI: MERCK } 116445 \\
\text { - Beaker 1: fumic } \mathrm{HNO}_{3}(100 \%), 5 \mathrm{~min} \\
\text { - Beaker 2: fumic } \mathrm{HNO}_{3}(100 \%), 5 \mathrm{~min} \\
\text { - Quick Dump Rinse <0.1 } \mathrm{SS} \\
\text { - Beaker 3: boiling }\left(95^{\circ} \mathrm{C}\right) \mathrm{HNO}_{3}(69 \%), 10 \mathrm{~min}\end{array}$ & \\
\hline
\end{tabular}


Appendix A

\begin{tabular}{|c|c|c|c|}
\hline & & $\begin{array}{l}\text { - Quick Dump Rinse }<0.1 \mu \mathrm{S} \\
\text { - Spin drying }\end{array}$ & \\
\hline 3 & $\begin{array}{l}\text { Dry Oxidation (DOX) } \\
\text { at } 950^{\circ} \mathrm{C} \text { of Silicon } \\
(\# \text { depo032)) }\end{array}$ & $\begin{array}{l}\text { CR112B / Furnace A2 } \\
\text { Only for dedicated processing (CMOS) } \\
\text { Standby temperature: } 700^{\circ} \mathrm{C} \\
\text { - Program: DOX } 950 \\
\text { - See Calbration curve on MIS page } \\
\text { - Temp.: } 950^{\circ} \mathrm{C} \\
\text { - Time: } 1 \mathrm{hr} 30 \text { mins } \\
\text { - Gas: } \mathrm{O}_{2}\end{array}$ & $\begin{array}{l}\text { 50nm thick. } \\
\text { This is the layer which } \\
\text { forms the final oxide } \\
\text { membrane supported } \\
\text { by the Silicon } \\
\text { microsieve }\end{array}$ \\
\hline \multicolumn{4}{|c|}{ The following steps involve both the thin-film wafer and the microsieve wafer } \\
\hline 4 & $\begin{array}{l}\text { Cleaning Standard } \\
\text { (\#clean003) }\end{array}$ & $\begin{array}{l}\text { CR112B / Wet-Bench 3-2 } \\
\mathrm{HNO}_{3}(100 \%) \text { Selectipur: MERCK } 100453 \\
\mathrm{HNO}_{3}(69 \%) \text { VLSI: MERCK } 116445 \\
\text { - Beaker 1: fumic } \mathrm{HNO}_{3}(100 \%), 5 \mathrm{~min} \\
\text { - Beaker 2: fumic } \mathrm{HNO}_{3}(100 \%), 5 \mathrm{~min} \\
\text { - Quick Dump Rinse }<0.1 \mu \mathrm{S} \\
\text { - Beaker 3: boiling }\left(95^{\circ} \mathrm{C}\right) \mathrm{HNO}_{3}(69 \%), 10 \mathrm{~min} \\
\text { - Quick Dump Rinse }<0.1 \mu \mathrm{S} \\
\text { - Spin drying }\end{array}$ & $\begin{array}{l}\text { Clean both the thin- } \\
\text { film and microsieve } \\
\text { wafers. }\end{array}$ \\
\hline 5 & $\begin{array}{l}\text { Cleaning "Piranha" } \\
\left(\mathrm{H}_{2} \mathrm{SO}_{4} / \mathrm{H}_{2} \mathrm{O}_{2}\right) \\
\text { (\#clean } 008)\end{array}$ & $\begin{array}{l}\text { CR112B / Wet-Bench 3-1 } \\
\mathrm{H}_{2} \mathrm{SO}_{4}(96 \%) \text { VLSI: MERCK } 100709.2500 \\
\mathrm{H}_{2} \mathrm{O}_{2}(31 \%) \text { VLSI: MERCK } 108552.2500 \\
\text { Only use the dedicated wafer carriers and glass rod! } \\
\mathrm{H}_{2} \mathrm{SO}_{4}: \mathrm{H}_{2} \mathrm{O}_{2}(3: 1) \text { vol\% } \\
\text { - add } \mathrm{H}_{2} \mathrm{O}_{2} \text { to } \mathrm{H}_{2} \mathrm{SO}_{4} \\
\text { - exothermic process! } \\
\text { - temperature } 130^{\circ} \mathrm{C} \\
\text { - cleaning time } 15-20 \text { min } \\
\text { - Quick Dump Rinse }<0.1 \mu \mathrm{S} \\
\text { - Spin drying }\end{array}$ & $\begin{array}{l}20 \text { mins } \\
\text { For extra-clean and } \\
\text { hydrophilic surfaces } \\
\text { during fusion bonding }\end{array}$ \\
\hline 6 & $\begin{array}{l}\text { Manually Aligning \& } \\
\text { Prebonding } \\
\text { (\#bond001) }\end{array}$ & $\begin{array}{l}\text { CR112B/Wet Bench } \\
\text { - Contact wafers manually } \\
\text { - Apply light pressure with tweezers } \\
\text { - If necessary use tweezers to press out air-bubbles } \\
\text { - Check prebonding by using IR-setup }\end{array}$ & $\begin{array}{l}\text { Bond the microsieve } \\
\text { wafer to the thin-film } \\
\text { wafer. }\end{array}$ \\
\hline 7 & IR-inspection & -use IR setup to check the pre-bond & Checking for bond \\
\hline
\end{tabular}




\begin{tabular}{|c|c|c|c|c|}
\hline & & \multicolumn{2}{|c|}{$\begin{array}{l}\text {-use tweezers for additional pressure to } \\
\text { promote bonding of not bonded spots }\end{array}$} & $\begin{array}{l}\text { quality and air } \\
\text { bubbles }\end{array}$ \\
\hline 8 & $\begin{array}{l}\text { Anneal of } \mathrm{Si}-\mathrm{Si} \\
\text { bond at } 1100^{\circ} \mathrm{C} \\
\text { (\#anne } 012 \text { ) }\end{array}$ & \multicolumn{2}{|c|}{$\begin{array}{l}\text { CR112B / Furnace B2 } \\
\text { Standby temp.: } 700^{\circ} \mathrm{C} \\
\text { - Program: ANN1100 } \\
\text { - Temp.: } 1100^{\circ} \mathrm{C} \\
\text { - Gas: } \mathrm{N}_{2} \\
\text { - Time } 120 \mathrm{~min} \\
\text { - Ramp: yes }\end{array}$} & 2 hours \\
\hline 9 & $\begin{array}{l}\text { Blue dicing foil } \\
\text { masking }\end{array}$ & \multicolumn{2}{|c|}{$\begin{array}{l}\text { Sticking the foil on the face of the bottom wafer and } \\
\text { folding it slightly onto the top wafer. }\end{array}$} & $\begin{array}{l}\text { For protecting the } \\
\text { oxide inside the } \\
\text { micropores during } \\
\text { BHF etch }\end{array}$ \\
\hline 10 & $\begin{array}{l}\text { Etching } \mathrm{BHF}(1: 7) \\
\mathrm{SiO}_{2} \\
(\# \text { etch024) }\end{array}$ & \multicolumn{2}{|c|}{$\begin{array}{l}\text { CR112B / Wet-Bench 3-3 } \\
\mathrm{NH}_{4} \mathrm{~F} / \mathrm{HF} \text { (1:7) VLSI: MERCK } 101171.2500 \\
\text { - Quick Dump Rinse }<0.1 \mu \mathrm{S} \\
\text { - Spin drying } \\
\text { Etchrate thermal } \mathrm{SiO}_{2}=60-80 \mathrm{~nm} / \mathrm{min}\end{array}$} & $\begin{array}{l}1 \mathrm{~min} \text { to remove the } \\
50 \mathrm{~nm} \text { oxide on non- } \\
\text { bonded side of the } \\
\text { thin-film wafer. The } \\
\text { wet stripping of oxide } \\
\text { is necessary so as to } \\
\text { proceed directly with } \\
\text { the dry etching of } \\
\text { silicon wafer. }\end{array}$ \\
\hline 11 & $\begin{array}{l}\text { Removing the blue foil } \\
\text { and Cleaning Standard } \\
\text { (\#clean003) }\end{array}$ & \multicolumn{2}{|c|}{$\begin{array}{l}\text { CR112B / Wet-Bench 3-2 } \\
\mathrm{HNO}_{3}(100 \%) \text { Selectipur: MERCK } 100453 \\
\mathrm{HNO}_{3}(69 \%) \text { VLSI: MERCK } 116445 \\
\text { - Beaker 1: fumic } \mathrm{HNO}_{3}(100 \%), 5 \mathrm{~min} \\
\text { - Beaker 2: fumic } \mathrm{HNO}_{3}(100 \%), 5 \mathrm{~min} \\
\text { - Quick Dump Rinse }<0.1 \mu \mathrm{S} \\
\text { - Beaker 3: boiling }\left(95^{\circ} \mathrm{C}\right) \mathrm{HNO}_{3}(69 \%), 10 \mathrm{~min} \\
\text { - Quick Dump Rinse }<0.1 \mu \mathrm{S} \\
\text { - Spin drying }\end{array}$} & \\
\hline \multirow[t]{4}{*}{12} & \multirow[t]{4}{*}{$\begin{array}{l}\text { Plasma etching of } \\
\text { Silicon (C-FAST) } \\
\text { (\#etch063) }\end{array}$} & \multicolumn{2}{|c|}{$\begin{array}{l}\text { CR 125c/Adixen AMS } 100 \mathrm{SE} \\
\text { Applications: Wafer back etch with high selectivity for } \\
\text { oxide layers }\end{array}$} & $\begin{array}{l}\text { Etch the thin-film } \\
\text { wafer till the oxide } \\
\text { layer is reached }(C-\end{array}$ \\
\hline & & Parameters & Value & Fast recipe is selective \\
\hline & & $\mathrm{SF}_{6}[\mathrm{sccm}]$ & 400 & $\begin{array}{l}\text { to } \mathrm{SIO}_{2} \text { - least sputter } \\
\text { etch due to } 0 \mathrm{~V} \text { bias). }\end{array}$ \\
\hline & & $\mathrm{O}_{2}[\mathrm{sscm}]$ & 0 & \\
\hline
\end{tabular}




\begin{tabular}{|c|c|c|c|c|}
\hline & & $\begin{array}{l}\text { He-backside cooling } \\
{[\mathrm{mbar}]}\end{array}$ & 10 & $\begin{array}{l}\text { silicon ring needs to be } \\
\text { used for uniform }\end{array}$ \\
\hline & & ICP [watt] & 2500 & |etching. \\
\hline & & Vdc [Volts] & 0 & Etchtime: $45+1 \mathrm{mins}$ \\
\hline & & $\mathrm{p}[\mathrm{Pa}]$ & 12 & \\
\hline & & APC position $\%$ & 15 & \\
\hline & & Electrode temperature $\left[{ }^{\circ} \mathrm{C}\right]$ & 10 & \\
\hline & & Substrate height $[\mathrm{mm}]$ & 110 & \\
\hline & & $\begin{array}{l}\text { Etch rate Olin } 907 \\
{[\mu \mathrm{m} / \mathrm{min}]}\end{array}$ & Low & \\
\hline & & $\begin{array}{l}\text { Etch rate -Silicon } \\
(\mu \mathrm{m} / \mathrm{min})\end{array}$ & $\sim 8.3$ & \\
\hline 13 & $\begin{array}{l}\text { IPA cleaning of } \\
\text { Fomblin oil }\end{array}$ & $\begin{array}{l}\text { CR112B / Wet-Bench 3-2 } \\
\text { Clean the residues of the Fo }\end{array}$ & mblin oil with Isopropanol & \\
\hline 14 & $\begin{array}{l}\text { Cleaning Standard } \\
(\# \text { clean003) }\end{array}$ & $\begin{array}{l}\text { CR112B / Wet-Bench 3-2 } \\
\mathrm{HNO}_{3}(100 \%) \text { Selectipur: } \\
\mathrm{HNO}_{3}(69 \%) \text { VLSI: MERC } \\
\text { - Beaker 1: fumic } \mathrm{HNO}_{3}(10 \\
\text { - Beaker 2: fumic } \mathrm{HNO}_{3}(10 \\
\text { - Quick Dump Rinse }<0.1 \mu \\
\text { - Beaker 3: boiling }\left(95^{\circ} \mathrm{C}\right) \mathrm{H} \\
\text { - Quick Dump Rinse }<0.1 \mu \\
\text { - Spin drying }\end{array}$ & $\begin{array}{l}\text { } \mathrm{AERCK} 100453 \\
\mathrm{CK} 116445 \\
0 \%), 5 \mathrm{~min} \\
0 \% \text { ), } 5 \mathrm{~min} \\
\mathrm{INO}_{3}(69 \%), 10 \mathrm{~min} \\
\mathrm{~S}^{2}\end{array}$ & $\begin{array}{l}\text { It is better to replace } \\
\text { the Quick dump } \\
\text { rinsing step with 3- } \\
\text { beaker mild rinsing } \\
\text { and the spin drying } \\
\text { step with IPA drying, } \\
\text { since the membranes } \\
\text { could be fragile. }\end{array}$ \\
\hline$P a$ & dium deposition a & release & & \\
\hline 15 & $\begin{array}{l}\text { Sputtering of } \mathrm{Ti} \\
\text { (Sputterke) } \\
\text { (\#depo016) }\end{array}$ & $\begin{array}{l}\text { CR106A / Sputterke } \\
\text { Ti Target (new gun) } \\
\text { - Electrode temp.: water coo } \\
\text { - Ar flow: } 80 \mathrm{sccm} \\
\text { - Base pressure: } 1.0 \text { e- } 6 \mathrm{mbar} \\
\text { - Sputter pressure: } 6.6 \mathrm{e}-3 \mathrm{~m} \\
\text { - power: } 200 \mathrm{~W} \\
\text { - Depositionrate }=13 \mathrm{~nm} / \mathrm{m}\end{array}$ & led electrode & $20 \mathrm{~nm}$ adhesion layer \\
\hline 16 & $\begin{array}{l}\text { Sputtering of Pd } \\
\text { (Sputterke) } \\
\text { (\#depo018) }\end{array}$ & $\begin{array}{l}\text { CR106A / Sputterke } \\
\text { Pd Target } \\
\text { • Electrode temp.: water coo }\end{array}$ & led electrode & $1000 \mathrm{~nm}$ \\
\hline
\end{tabular}




\begin{tabular}{|c|c|c|c|}
\hline & & $\begin{array}{l}\text { - Ar flow: } 80 \mathrm{sccm} \\
\text { - Base pressure: } 1.0 \text { e-6mbar } \\
\text { - Sputter pressure: } 6.6 \mathrm{e}-3 \mathrm{mbar} \\
\text { - power: } 200 \mathrm{~W} \\
\text { Depositionrate }=\sim 35 \mathrm{~nm} / \mathrm{min}\end{array}$ & \\
\hline 17 & $\begin{array}{l}\text { Etching HF (1\%) } \\
\text { Native Oxide } \\
\text { (\#tch027) }\end{array}$ & $\begin{array}{l}\text { CR112B / Wet-Bench 3-3 } \\
\text { HF (1\%) VLSI: MERCK } 112629.500 \\
\text { - Etch time: >1min } \\
\text { - Quick Dump Rinse }<0.1 \mu \mathrm{S} \\
\text { - Spin drying } \\
\text { Etchrate: } 4.2 \mathrm{~nm} / \mathrm{min} \text { (plain thermal oxide) }\end{array}$ & $\begin{array}{l}\text { Etchtime } 19 \text { mins. } \\
\text { Also Titanium is } \\
\text { etched simultaneously } \\
\text { (etch rate: > } \\
100 \mathrm{~nm} / \mathrm{min} \text { ) } \\
\text { There is a } \\
\text { concentration gradient } \\
\text { of HF inside the } \\
\text { silicon micropores, } \\
\text { because of which the } \\
\text { etching take more time }\end{array}$ \\
\hline
\end{tabular}




\section{Appendix B}

\section{Permeated hydrogen flux conversion calculations}

In a gas chromatograph (GC), the position of the peak in the chromatogram indicates the type of gas and the area under the peak gives the concentration of that particular gas in the total gas mixture supplied to the GC. Calibration of the GC is done to relate the peak-position to the respective gases and the peak-area to their corresponding concentration in volume \% (refer calibration graph shown chapter 3, figure 3.15). In our case, the GC measures the permeated hydrogen in terms of $\mathrm{H}_{2}$ concentration in the $\mathrm{N}_{2}$ sweep gas (which is flown at a constant $20 \mathrm{sccm}$ on the permeate side of the palladium membrane).

The concentration of permeated $\mathrm{H}_{2}$ [\%] can be related to the $\mathrm{H}_{2}$ flux [sccm or standard $\mathrm{cm}^{3} / \mathrm{min}$ ] as follows,

$$
\text { Permeated } \mathrm{H}_{2} \text { in } \%=\frac{\text { Permeated } \mathrm{H}_{2} \text { in } \mathrm{sccm}}{20 \mathrm{sccm} \mathrm{N}_{2}+\text { Permeated } \mathrm{H}_{2} \text { in } \mathrm{sccm}} \times 100
$$$$
\Rightarrow \quad \text { Permeated } \mathrm{H}_{2} \text { in sccm }=\frac{20 \operatorname{sccm~}_{2} \times\left(\frac{\text { Permeated } \mathrm{H}_{2} \text { in } \%}{100}\right)}{1-\left(\frac{\text { Permeated } \mathrm{H}_{2} \text { in } \%}{100}\right)}
$$

Using the ideal gas law, the permeated $\mathrm{H}_{2}$ flux [ $\mathrm{sccm}$ ] can be converted to molar flux $\left[\mathrm{mol} \mathrm{H}_{2} / \mathrm{s}\right]$ as shown below,

$$
\Phi\left[\mathrm{mol} \mathrm{H}_{2} / \mathrm{s}\right]=\frac{101325[\mathrm{~Pa}] \times\left(\text { Permeated } \mathrm{H}_{2} \text { in sccm } \times \frac{10^{-6}}{60}\right)\left[\mathrm{m}^{3} / \mathrm{s}\right]}{8.3144[\mathrm{~J} / \mathrm{mol} . \mathrm{K}] \times 273.15[\mathrm{~K}]}
$$


After normalizing over the effective area of the palladium membrane (explained later in this section), the total atomic hydrogen flux through the membrane [mol $\left.\mathrm{H} / \mathrm{cm}^{2} \mathrm{~s}\right]$ is expressed as follows,

$$
J\left[\mathrm{~mol} \mathrm{H} / \mathrm{cm}^{2} \mathrm{~s}\right]=\frac{2 \times \Phi\left[\mathrm{mol} \mathrm{H}_{2} / \mathrm{s}\right]}{0.229\left[\mathrm{~cm}^{2}\right]}
$$

For all the graphs plotted in chapter 3, the permeated hydrogen flux in $\mathrm{sccm}$ is converted to $\mathrm{mol} \mathrm{H} / \mathrm{cm}^{2} \mathrm{~s}$ using the relation $1 \mathrm{sccm}=6.5 \times 10^{-6} \mathrm{~mol} \mathrm{H} / \mathrm{cm}^{2} \mathrm{~s}$.

The effective area of palladium was affected by the following aspects.

a) The microsieve support (of diameter $\varnothing 0.9 \mathrm{~cm}$ ) having $\varnothing 5 \mu \mathrm{m}$ pores was designed to have $27 \%$ porosity.

b) During plasma etching, the diameter of the micropores increased by $0.75-0.8$ $\mu \mathrm{m}$, thus increasing the porosity to about $36 \%$.

c) The wafer-back etching process leaves a slight residue of unetched silicon at the inner edges of the $\varnothing 0.9 \mathrm{~cm}$ sample, which reduces its effective diameter by $\sim 0.5 \mathrm{~mm}$.

d) After the release of the palladium membrane by 19 mins etching in $1 \% \mathrm{HF}$ solution, the resultant diameter of the palladium membranes on each micropore became $\sim 6.1 \mu \mathrm{m}$, which enhanced the porosity to around $40 \%$.

Considering all these parameters, the effective area of the palladium membrane exposed to hydrogen was determined to be $0.229 \mathrm{~cm}^{2}$. The counter effects of (c) and (d) on the palladium area coincidently nullify their influence.

There can be a random error in the palladium area caused due to improper release of the membrane in HF. However, determining this error needs further detailed studies. The alternative is to avoid this error by using a different palladium membrane release process having better repeatability. 




\section{Publications \& Patents}

\section{Journal Papers}

- S. Unnikrishnan, H.V. Jansen, J.W. Berenschot and M.C. Elwenspoek, Wafer scale nanomembrane supported on a silicon microsieve using thin-film transfer technology, Journal of Micromechanics and Microengineering 2008, 18 (6), 064005

- S. Unnikrishnan, H. Jansen, E. Berenschot, B. Mogulkoc and M. Elwenspoek, MEMS within a Swagelok ${ }^{\circledR}$ : a new platform for microfluidic devices, Lab Chip, 2009, 9, pp.19661969

- S. Unnikrishnan, H.V. Jansen, F.H. Falke, N.R. Tas, H.A.G.M. Van Wolferen, M.J. De Boer, R.G.P. Sanders and M.C. Elwenspoek (2009), Transition flow through an ultra-thin nanosieve, Nanotechnology 2009, 20, 305304

- H. V. Jansen, M. J. De Boer, S. Unnikrishnan, M. C. Louwerse and M. C. Elwenspeok, Black silicon method X: a review on high speed and selective plasma etching of silicon with profile control: an in-depth comparison between Bosch and cryostat DRIE processes as a roadmap to next generation equipment, Journal of Micromechanics and Microengineering 2009, 19, 033001

- S. Unnikrishnan, H.V. Jansen, E.G. Prabowo, R.G.P. Sanders and M.C. Elwenspoek, Micromachined palladium membranes as hydrogen diffusive electrodes for solid-acid fuel cell application, Journal of Membrane Science or Journal of Power Sources (in preparation)

\section{Conference proceedings}

- S. Unnikrishnan, H.V. Jansen, J.W. Berenschot and M.C. Elwenspoek, Wafer scale nanomembranes supported on a silicon microsieve, Micromechanics Europe 2007, Portugal

- S. Unnikrishnan, H.V. Jansen, J.W. Berenschot, B. Mogulkoc, and M.C. Elwenspoek, Microfluidics within a Swagelok ${ }^{\circledR}$ a MEMS-on-tube assembly, MEMS 2009, Italy 


\section{Patents}

- S. Unnikrishnan, H.V. Jansen, J.W. Berenschot, I. Fazal, M.C. Louwerse, B. Mogulkoc, M.J. De Boer, R.G.P. Sanders, M.C. Elwenspoek; A method for making a glass supported system, such glass supported system, and the use of a glass support therefor; EP08007746.4, Filing date: April 2008 (Patent pending)

- S. Unnikrishnan, J.K. Chinthaginjala, H.V. Jansen, M.C. Elwenspoek, L. Lefferts; Separation unit, method of making such unit, a fuel cell and separation devices comprising such units; EP09075166, Filing date: April 2009 (Patent pending) 


\section{Summary}

This thesis paves the way towards the microfabrication of a solid acid electrolyte based fuel cell ( $\mu \mathrm{SAFC}$ ), which has a membrane electrode assembly (MEA) consisting of a thin-film of water soluble electrolyte encapsulated between two dense palladium electrode membranes. This project work investigates microfabrication techniques to realize the dense palladium membranes and to understand their suitability as hydrogen diffusive electrodes (HDEs) for the $\mu \mathrm{SAFC}$. A thin-film transfer technique has been shown as a successful method to make defect free micron and sub-micron thick palladium membranes. $1 \mu \mathrm{m}$ thick dense palladium membranes supported on perforated silicon gas diffusive supports (GDS) has been fabricated as the fuel cell electrodes. The supporting GDS is a silicon microsieve having straight cylindrical pores, which show low pressure drop as well as good strength. A customized recipe based on deep reactive ion etching has been developed to anisotropically etch the micropores.

At $423 \mathrm{~K}$ and 1.5 bar hydrogen pressure on the feed side, the palladium membranes show a hydrogen permeate flux within the range $6.3 \times 10^{-6}$ to $8.8 \times 10^{-6}$ $\mathrm{mol} \mathrm{H} / \mathrm{cm}^{2}$.s and a good selectivity (> 1500) for hydrogen with respect to helium. The $\alpha-\beta$ phase change (and embrittlement) happening in palladium in the presence of hydrogen at lower temperatures $(<473 \mathrm{~K})$ is thoroughly studied in this work. According to our observation, the maximum allowed hydrogen pressure on the anode side for the $\mu \mathrm{SAFC}$ operating at a temperature of $423 \mathrm{~K}$ (i.e. $150{ }^{\circ} \mathrm{C}$ ) is $\sim 1.5 \mathrm{bar}$.

Pottasium dihydrogen phosphite - $\mathrm{KH}\left(\mathrm{PO}_{3} \mathrm{H}\right)$ has been investigated as the electrolyte for the proposed $\mu \mathrm{SAFC}$. A $\varnothing 10 \mathrm{~mm}$ and $1 \mathrm{~mm}$ thick compressed disc of $\mathrm{KH}\left(\mathrm{PO}_{3} \mathrm{H}\right)$ was found to have a ex-situ proton conductivity of $3.8 \times 10^{-3} \Omega^{-1} \mathrm{~cm}^{-1}$ at $408 \mathrm{~K}$ just above the superprotonic transition temperature. The performance of $\mathrm{KH}\left(\mathrm{PO}_{3} \mathrm{H}\right)$ was also tested in a conventional (porous carbon electrodes) MEA of $\varnothing$ $12 \mathrm{~mm}$. For an electrolyte thickness of $0.5 \mathrm{~mm}$, the measured open circuit voltage was about $0.65 \mathrm{~V}$. When a current of $0.5 \mathrm{~mA} / \mathrm{cm} 2$ is drawn, the operational voltage drops to $0.3 \mathrm{~V}$. Thin-films of $\mathrm{KH}\left(\mathrm{PO}_{3} \mathrm{H}\right)$ were also fabricated down to $10 \mu \mathrm{m}$ thickness using a dip-coating technique. Impregnation of inorganic particles ( 14 nm size) was helpful in suppressing random crystallization of the solid acid while drying. 



\section{Samenvatting}

Dit proefschrift effent de weg naar de micro fabricage van een, op een sterk zuur elektrolyt gebaseerde, brandstofcel ( $\mu$ SAFC). Deze bestaat uit een dunne-film van water oplosbare elektrolyt ingekapseld tussen twee niet poreus palladium elektrode membranen. Dit onderzoekt richt zich op micro fabricage technieken ten behoeve van het realiseren van palladium membranen. Daarnaast, wordt onderzocht of deze membranen geschikt zijn om als waterstof diffusie elektroden (HDEs) te dienen voor de $\mu$ SAFC. Het is aangetoond dat een dunne-film overdracht techniek een succesvolle methode is om defect vrije micrometer en sub-micrometer dikke palladium membranen te maken. Een $1 \mu \mathrm{m}$ dik palladium membraan wordt gebruikt als brandstofcel elektrode. Dit membraan wordt ondersteund door geperforeerd silicium wat functioneert als gas diffusie support (GDS). De ondersteunende GDS is een silicium micro zeef met rechte cilindervormige poriën, gekarakteriseerd door een lage drukval. Een geoptimaliseerd recept is ontwikkeld gebaseerd op diep reactief ionen etsen voor het anisotroop etsen van de micro poriën.

De palladium membranen zijn gekarakteriseerd bij een temperatuur van $423 \mathrm{~K}$ en een waterstofdruk van 1,5 bar aan de voedingszijde. Waterstof dringt door het palladium membraan met een flux tussen $6,3 \times 10^{-6}$ tot $8,8 \times 10^{-6} \mathrm{~mol} \mathrm{H} / \mathrm{cm}^{2}$.s. Het membraan laat een goede selectiviteit (>1500) zien van waterstof ten opzichte van helium. De $\alpha-\beta$ fase verandering (en verbrossing) die plaats vind in palladium, in anwezigheid van waterstof, bij lagere temperaturen $(<473 \mathrm{~K})$ wordt grondig bestudeerd in dit werk. Volgens onze waarneming, is de maximaal toegestane waterstofdruk op de anode zijde van de $\mu \mathrm{SAFC}$ ca. 1,5 bar bij een temperatuur van $423 \mathrm{~K}$ (d.w.z. $150^{\circ} \mathrm{C}$ ).

Pottasium dihydrogen phosphite - $\mathrm{KH}\left(\mathrm{PO}_{3} \mathrm{H}\right)$ is onderzocht om te functioneren als elektrolyt voor de voorgestelde $\mu$ SAFC. Een $\varnothing 10 \mathrm{~mm}$ en $1 \mathrm{~mm}$ dik samengeperste schijf van $\mathrm{KH}\left(\mathrm{PO}_{3} \mathrm{H}\right)$ bleek een ex-situ proton geleiding van $3,8 \times 10^{-3} \Omega^{-1} \mathrm{~cm}^{-1}$ te hebben op een temperatuur van $408 \mathrm{~K}$ net boven de superprotonic overgangstemperatuur. De prestatie van $\mathrm{KH}\left(\mathrm{PO}_{3} \mathrm{H}\right)$ is ook getest in een conventionele brandstofcel met poreuze koolstof elektroden van $\varnothing 12 \mathrm{~mm}$. Voor een elektrolyt dikte van $0,5 \mathrm{~mm}$ is de gemeten spanning bij open stroomkring ongeveer $0,65 \mathrm{~V}$. Wanneer er een stroom van $0,5 \mathrm{~mA} / \mathrm{cm}^{2}$ loopt, zakt de operationele spanning tot $0,3 \mathrm{~V}$. Dunne 
films van $\mathrm{KH}\left(\mathrm{PO}_{3} \mathrm{H}\right)$ met een minimale dikte van $10 \mu \mathrm{m}$ zijn gefabriceerd met behulp van een dip-coating techniek. Impregneren van anorganische deeltjes ( $14 \mathrm{~nm}$ groot) heeft geholpen bij het onderdrukken van het random kristalliseren van het $\mathrm{KH}\left(\mathrm{PO}_{3} \mathrm{H}\right)$ tijdens het drogen. 


\section{Acknowledgements}

The research presented in this thesis is the result of my work conducted at the Transducer Science and Technology group of the $\mathcal{M E S A} \mathcal{A}^{+}$Institute of $\mathcal{N a n o t e c h n o l o g y}$ at the University of Twente. During this time I have been fortunate to be accompanied, encouraged and supported by several people professionally as well as personally, to whom I would like to express my sincere acknowledgements.

At first, I would like to thank my professor, Miko Elwenspoek, to have given me the opportunity to pursue research in his group. His encouragement and confidence in me, especially during stressful times has helped me in completing my thesis.

I hardly have words to express thanks to my unique supersurpriser Henri Jansen. He has been inspiring, guiding, positively criticizing and trying to focus me towards my final goal. Henri, without your help and support both on the professional side and personal side it would have been hard for me to have a successful thesis. I specially enjoyed the regular scientific fights (or meetings) that we used to have for many hours. The initial impression of a crazy scientist that I had about you still prevails, except now I see 'crazy' more positively.

My thanks to all TST/MicMec members the company of whom I have been enjoying for the past years. I owe my special thanks to Erwin, $\mathcal{N}$ iels, Meint, Pino and Henk, with whom I have 6een enjoying personal and scientific discussions frequently. Erwin, your motivation to go for patents instead of papers has been worthwhile and a great learning experience for me. Pino, without your over-sophisticated setups, it would have been a difficult experimental time for me. The students who have been working with me: Guillaume, Floris, Nishant and Gito have contributed a lot towards my project; I am thankful to all of them for that. I would like to thank.Marcus for his friendship and for sharing his philosophical insight. My thanks go also to my roomy Jeroen who has been tolerating and helping me for the past years. I also use to enjoy the occasional relaxing chats with Shahina, Doekle, Natalia, Marcel, Hadi, Berker and former colleagues Chris, Imran and Laura, for which I am thankful. Chris, thanks for your help especially during the last few months. I am grateful to my group secretaries Susan, Judith and Satie, who have been of great support.

My experiments in the MESA $A^{+}$cleanroom would not have been so smooth without the timely support from all the cleanroom staff, for which I would like to thank them. 
Thanks to Weihua and Alexander, my teammates (from IM group) for their cooperation during the fuel cell research. I would like to express my thanks to Gaby Janssen (ECN) and Henny Bouwmeester (IM Group) for constructive discussions and guidance during the execution of my project. My gratitude is also expressed to professor Han Gardeniers (MCS group) to have accommodated me in his lab. I thankfully acknowledge the inputs from my project user committee members and the Dutch technology foundation STW for financially supporting my project.

I would like to thank Bauke Visser from PQZO, who has been constantly helping me to swim past the Dutch bureaucratical currents. My gratitude is extended also to professor Vinod Subramaniam for his personal encouragement at times.

I express my hearty thanks to all my friends who have been making my stay in Holland a pleasant and memorable one. My special thanks to housemates Jitender and Srivatsa who have been my family for the past four years and have supported me always. Also, my thanks to Musthafa-Shahina, Berni-Kamalamma, Pramod-Vishaka, Shaji-Mercy, Babu-Indu, AntonyMeega, Chandu-Meenakshi, Arbind-Selina, Seshan-Jayanthi, Ram-Veda, Vijay-Sangeetha, Ashok, Hrudya, Vidhu, Vinay, Tony, Sekhar, Karina, Ragav, Ganesh, Vishnu, Digvijay, Jigar, Mayur, Dhaval, Parma and all other friends who have been a part of my life in Enschede. I am indebted to my good friend Mal-Guru Stefan, who has played an unforgettable role both in my university and personal lives. Also, I would like to thank Didi, Ro6 and Roald to have extended their friendship to me. Roald, thanks for reading my thesis with a microscope. My special gratitude to my friend Maaike, from whom I have learned a lot about the Dutch culture. I am also grateful to have friends like Hasan, Tanya and Severine, the gatherings with whom have always been memorable.

My heartfelt gratitude to Parameshwarji and family, who have constantly supported and made me feel at home from the first day I came to Europe.

My beloved parents have always supported and encouraged me to achieve newer heights in my career. I am indebted to them and also to my grandparents for what I am today. Same goes for my sister Sindhu whose love and support along with her husband Sreejith has been vital. My very special gratitude to my loving wife Jalaja for being so affectionate, understanding and supportive in my life. 


\section{Biography}

Sandeep Unnikrishnan was born to T.P. Unnikrishnan \& K.P. Santhakumary in Chennai (formerly Madras), India on $22^{\text {nd }}$ March 1979. During his primary schooling, after the birth of his sister Sindhu, his family relocated to Coimbatore (also in Tamil Nadu state) and then to Palghat (in Kerala state), where he completed education till $12^{\text {th }}$ class at Central School Palakkad. Sandeep graduated in the field of Production Engineering from Amrita Institute of Technology and Science at Coimbatore in the year 2000. After gaining work experience for more than two years in India, he left to Germany in September 2002 to pursue post-graduation in the field of Mechatronics at the Aachen University of Applied Sciences, on completion of which he was also rewarded the DAAD prize for 'Outstanding foreign student of the year 2004'. He decided to continue his quest for knowledge by taking up Ph.D. studies in 2005 at the Transducer Science and Technology group of the University of Twente in Enschede, the Netherlands. Sandeep lost his bachelor title when he got married to Jalaja in 2009 and hopes to compensate the loss with a doctor title this same year. 